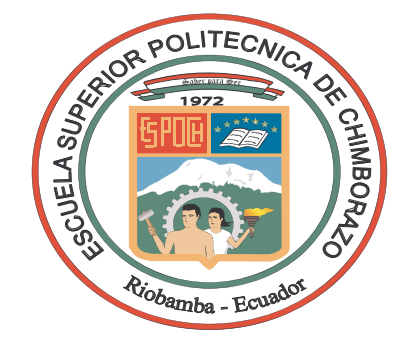

ESCUELA SUPERIOR POLITÉCNICA DE CHIMBORAZO

FACULTAD DE SALUD PÚBLICA

ESCUELA DE EDUCACIÒN PARA SALUD

"PROGRAMA EDUCATIVO PARA PREVENIR LA ZOONOSIS

EN LAS FAMILIAS DE LA COMUNIDAD SAN ROQUE DEL

CANTÓN SUCRE, PARROQUIA CHARAPOTÓ. PROVINCIA DE MANABÍ. 2011"

\title{
TESIS DE GRADO
}

Previo a la obtención del título de:

Licenciada en Promoción y Cuidados de la Salud

Katy Maricela Logroño Noboa

RIOBAMBA-ECUADOR 


\section{CERTIFICACIÓN}

La presente investigación fue revisada y se autoriza su presentación.

Dra. Paulina Robalino V.

DIRECTORA DE TESIS 


\section{CERTIFICADO}

Los miembros de tesis certifican que el trabajo de investigación titulado "PROGRAMA EDUCATIVO PARA PREVENIR LA ZOONOSIS EN LAS FAMILIAS DE LA COMUNIDAD SAN ROQUE DEL CANTÓN SUCRE, PARROQUIA CHARAPOTÓ. PROVINCIA DE MANABÍ 2011"; de responsabilidad de Katy Maricela Logroño Noboa ha sido revisada y se autoriza su publicación.

Dra. Paulina Robalino V.

DIRECTORA DE TESIS

Dr. Ángel Parreño U.

MIEMBRO DE TESIS

Riobamba, 10-10-2011 


\section{AGRADECIMIENTO}

A la Escuela Superior Politécnica de Chimborazo, Facultad de Salud Pública, Escuela de Promoción y Cuidados de la Salud por la formación académica recibida.

A la Dra. Paulina Robalino V. Directora de tesis que con su paciencia, dedicación, y sus conocimientos ha sabido guiarme en el desarrollo de la tesis.

Al Dr. Ángel Parreño U. Miembro de tesis por su comprensión, paciencia y dedicación, enseñanza para realizar correctamente esta investigación.

A la Organización Plan Internacional de la Provincia de Manabí, Capital Portoviejo, que han aportado a la realización de los programas educativos realizados en este, lugar, y han colaborado con su poder de convocatoria a la comunidad.

Al Ing. Fernando Gaón Factor de Desarrollo Comunitario de Plan Internacional quien fue una guía y ayuda en la realización y coordinación de las intervenciones educativas realizadas para cumplir con la planificación y realización de esta investigación. 


\section{DEDICATORIA}

Esta investigación va dedicada primeramente a Dios, por ser quien guía mi camino, y me acompaña siempre en todo lugar guiándome, ayudándome, protegiéndome y dándome salud, vida, memoria, inteligencia y voluntad para cumplir con mis objetivos propuestos. Y a mi madre del cielo María Auxiliadora.

A mi madre querida la Dra. Anita Noboa, que siempre me ha apoyado siendo mi madre, mi amiga y mi compañera quien me ha ayudado y a estado conmigo en las buenas y en las malas, y es mi modelo a seguir por su fortaleza y su espíritu de superación, por ser madre y padre para mi, y nunca faltarme económica ni moralmente. Madre mía hago votos para que hoy de dicha mis logros te colmen y mañana te llenen de orgullo. Ten presente madre querida que la gloria más grande que tengo es ser hijo tuyo y le agradezco a Dios por darme un ángel al que quiero tenerlo toda la vida.

A mis hermanos queridos Germania, Jhony, y Anita, quienes han sido un ejemplo para mi todos profesionales, me han apoyado en todo momento y han estado siempre conmigo en las buenas y malas, y me han enseñado que en la vida existen barreras y que hay que luchar para superarlas y llegar al éxito, que hoy estoy obteniendo.

Al amor de mi vida Guillo, quien siempre ha estado a mi lado, ayudándome en lo que pueda, y motivándome siempre a salir adelante enseñándome que el éxito no se espera, se lo alcanza 


\section{RESUMEN}

Investigación con diseño no experimental, de tipo transversal, para prevenir la zoonosis en familias de la comunidad San Roque del Cantón Sucre, Manabí mediante encuesta aplicada a 40 familias se determinaron las siguientes variables, características socio demográficas, factores de riesgo, conocimientos y prácticas.

Grado de escolaridad de las madres, primaria el $50 \%$, secundaria $29 \%$ y Superior el 12\%; edad fértil de las madres embarazadas el $70 \%$; factores de riesgo, enfermedades prevalentes, toxoplasmosis niños en contacto con el gato el 98\%; Histoplasmosis, estiércol de aves el 61\%; Rabia, mordedura de animales 85\%; Leptospirosis, Mal de Hanta contacto con ratas 40\%, Niguas, por animales de granja $70 \%$.

Se recomienda que en los hogares se aplique una mejor educación sanitaria, teniendo a los animales fuera del alcance de la vivienda, que se pida asesoría técnica sobre el manejo adecuado de animales domésticos y de granja a Ministerios de Salud y Agricultura. 


\section{SUMMARY}

Prevent the zoonosis in the families of San Roque Community, Sucre Canton, Manabí.

This investigation is experimental, and transversal. The survey were applied to 40 families and were determined the following variables, characteristics and sociodemografic, risk factors, knowledge and practices.

School level of mothers, elementary $50 \%$, high school $29 \%$ and university $12 \%$, fertile age of pregnant ,mothers, elementary $50 \%$, high school $29 \%$ and university $12 \%$, fertile age of pregnant mothers $70 \%$; risk factors, illnesses, toxoplasmosis children in contact with cats $98 \%$; Histoplasmosis, manure of birds $61 \%$; Rabia, animals $70 \%$.

We suggest that applying a better sanitary education, having the animals outside home, and ask for help to the Ministery of Heath for a better handle of domestic animals. 


\section{ÍNDICE DE CONTENIDOS}

I. INTRODUCCIÓN 1

II. JUSTIFICACIÓN 4

III. OBJETIVOS
A. General
B. Específicos

IV. MARCO TEÓRICO

V. METODOLOGÍA

A. Localización y temporalización

B. Variables

1. Identificación

2. Definición 37

3. Operacionalización 38

C. Tipo y diseño de la investigación $\quad 50$

D. Grupo de Estudio 50

E. Descripción de procedimientos 51

VI. RESULTADOS

VII. PROGRAMA EDUCATIVO 214

$\begin{array}{ll}\text { VIII. CONCLUSIONES } & 273\end{array}$

IX. RECOMENDACIONES 275

X. RECOMENDACIONES BIBLIOGRÁFICAS 276 
XI. ANEXOS

XII. FOTOS 


\section{ÍNDICE DE TABLAS}

\section{TABLA No 1}

EDAD DE LAS MADRES DE FAMILIA DE LA COMUNIDAD DE SAN ROQUE. PERTENECIENTE AL CANTÓN SUCRE PARROQUIA CHARAPOTÓ. PROVINCIA DE MANABÍ.2011

\section{TABLA No 2}

ESCOLARIDAD DE LAS MADRES DE FAMILIA DE LA COMUNIDAD DE SAN ROQUE. PERTENECIENTE AL CANTÓN SUCRE PARROQUIA CHARAPOTÓ. PROVINCIA DE MANABÍ.2011

\section{TABLA No 3}

EMBARAZADAS DE LA COMUNIDAD DE SAN ROQUE. 56 PERTENECIENTE AL CANTÓN SUCRE PARROQUIA CHARAPOTÓ. PROVINCIA DE MANABÍ.2011

\section{TABLA No 4}

ANIMALES DOMÉSTICOS QUE TIENEN LAS MADRES DE FAMILIA DE LA COMUNIDAD DE SAN ROQUE PERTENECIENTE AL CANTÓN SUCRE PARROQUIA CHARAPOTÓ. PROVINCIA DE MANABÍ. 2011. 
TABLA No 5

UTILIDAD DE ANIMALES DOMÉSTICOS QUE TIENEN LAS MADRES DE FAMILIA DE LA COMUNIDAD DE SAN ROQUE 60 PERTENECIENTE AL CANTÓN SUCRE PARROQUIA CHARAPOTÓ. PROVINCIA DE MANABÍ.2011

\section{TABLA No 6}

PERSONAS DE LA FAMILIA QUE TIENEN CONTACTO DIRECTO CON PERROS EN EL HOGAR EN LA COMUNIDAD DE SAN ROQUE PERTENECIENTE AL CANTÓN SUCRE PARROQUIA CHARAPOTÓ. PROVINCIA DE MANABÍ. 2011

\section{TABLA No 7}

PERSONAS DE LA FAMILIA QUE TIENEN CONTACTO DIRECTO CON GATOS EN EL HOGAR EN LA COMUNIDAD DE SAN ROQUE PERTENECIENTE AL CANTÓN SUCRE PARROQUIA CHARAPOTÓ. PROVINCIA DE MANABÍ. 2011. 
TABLA No 8

HIGIENE DEL LUGAR DONDE COME EL PERRO Y

GATO EN LA COMUNIDAD DE SAN ROQUE

PERTENECIENTE AL CANTÓN SUCRE PARROQUIA

CHARAPOTÓ. PROVINCIA DE MANABÍ. 2011

TABLA No 9

HIGIENE DEL LUGAR DONDE DEFECA EL PERRO EN LA COMUNIDAD DE SAN ROQUE PERTENECIENTE AL

CANTÓN SUCRE. PARROQUIA CHARAPOTÓ. PROVINCIA

DE MANABÍ. 2011

TABLA No 10

HIGIENE DEL LUGAR DONDE DEFECA EL GATO EN LA

COMUNIDAD DE SAN ROQUE PERTENECIENTE AL CANTÓN SUCRE. PARROQUIA CHARAPOTÓ. PROVINCIA DE MANABÍ. 2011 
TABLA No 11

HIGIENE A LOS PERROS DE LAS FAMILIAS DE LA

COMUNIDAD DE SAN ROQUE PERTENECIENTE AL CANTÓN SUCRE PARROQUIA CHARAPOTÓ. PROVINCIA DE MANABÍ. 2011.

TABLA No 12

HIGIENE DEL GATO EN LAS FAMILIAS DE LA COMUNIDAD

DE SAN ROQUE PERTENECIENTE AL CANTÓN SUCRE PARROQUIA CHARAPOTÓ. PROVINCIA DE MANABÍ. 2011.

\section{TABLA No 13}

VACUNACIÓN A LOS PERROS CONTRA LA RABIA EN LA COMUNIDAD DE SAN ROQUE PERTENECIENTE AL CANTÓN SUCRE PARROQUIA CHARAPOTÓ. PROVINCIA DE MANABÍ. 2011.

\section{TABLA No 14}

VACUNACIÓN A LOS GATOS CONTRA LA RABIA EN LA COMUNIDAD DE SAN ROQUE PERTENECIENTE AL 78 CANTÓN SUCRE PARROQUIA CHARAPOTÓ. PROVINCIA DE MANABÍ. 2011. 
TABLA No 15

DESPARACITACIÓN A LOS PERROS EN LA COMUNIDAD DE SAN ROQUE PERTENECIENTE AL CANTÓN SUCRE 80 PARROQUIA CHARAPOTÓ. PROVINCIA DE MANABÍ. 2011.

\section{TABLA No 16}

DESPARACITACIÓN A LOS GATOS EN LA COMUNIDAD DE SAN ROQUE PERTENECIENTE AL CANTÓN SUCRE PARROQUIA CHARAPOTÓ. PROVINCIA DE MANABÍ. 2011.

\section{TABLA No 17}

TENENCIA DE ANIMALES DE GRANJA EN LA COMUNIDAD DE SAN ROQUE PERTENECIENTE AL CANTÓN SUCRE PARROQUIA CHARAPOTÓ.PROVINCIA DE MANABÍ. 2011

\section{TABLA No 18}

TIPOS DE ANIMALES DE GRANJA QUE TIENEN LAS FAMILIAS EN LA COMUNIDAD DE SAN ROQUE PERTENECIENTE AL CANTÓN SUCRE PARROQUIA CHARAPOTÓ.PROVINCIA DE MANABÍ. 2011 
TABLA No 19

BENEFICIOS QUE BRINDAN LOS ANIMALES DE GRANJA

EN LA COMUNIDAD DE SAN ROQUE PERTENECIENTE AL CANTÓN SUCRE PARROQUIA CHARAPOTÓ.PROVINCIA DE MANABÍ. 2011.

\section{TABLA No 20}

PERSONA DE LA FAMILIA ENCARGADA DEL CUIDADO DE ANIMALES DE GRANJA EN LA COMUNIDAD DE SAN ROQUE PERTENECIENTE AL CANTÓN SUCRE PARROQUIA CHARAPOTÓ.PROVINCIA DE MANABÍ.2011.

\section{TABLA No 21}

TENENCIA DE CORRALES PARA GANADO BOVINO EN LA COMUNIDAD DE SAN ROQUE PERTENECIENTE AL CANTÓN SUCRE PARROQUIA CHARAPOTÓ.PROVINCIA DE MANABÍ.2011.

\section{TABLA No 22}

CHANCHERAS PARA PORCINOS EN LA COMUNIDAD DE SAN ROQUE PERTENECIENTE AL CANTÓN SUCRE PARROQUIA CHARAPOTÓ.PROVINCIA DE MANABÍ.2011. 
TABLA No 23

GALPONES PARA AVES EN LA COMUNIDAD DE SAN ROQUE PERTENECIENTE AL CANTÓN SUCRE 98 PARROQUIA CHARAPOTÓ.PROVINCIA DE MANABÍ.2011.

\section{TABLA No 24}

LIMPIEZA DE ESTIÉRCOL DE BOVINOS EN LA 101 COMUNIDAD DE SAN ROQUE PERTENECIENTE AL CANTÓN SUCRE PARROQUIA CHARAPOTÓ.PROVINCIA DE MANABÍ.2011.

\section{TABLA No 25}

FRECUENCIA DE LIMPIEZA DE ESTIÉRCOL DE BOVINOS EN LA COMUNIDAD DE SAN ROQUE PERTENECIENTE AL 104 CANTÓN SUCRE PARROQUIA CHARAPOTÓ.PROVINCIA DE MANABÍ.2011.

\section{TABLA No 26}

LIMPIEZA DE ESTIÉRCOL DE PORCINOS EN LA COMUNIDAD DE SAN ROQUE PERTENECIENTE AL CANTÓN SUCRE PARROQUIA CHARAPOTÓ.PROVINCIA DE MANABÍ.2011. 
TABLA No 27

FRECUENCIA DE LIMPIEZA DE ESTIÉRCOL DE BOVINOS 108 EN LA COMUNIDAD DE SAN ROQUE PERTENECIENTE AL CANTÓN SUCRE PARROQUIA CHARAPOTÓ.PROVINCIA DE MANABÍ.2011.

\section{TABLA No 28}

LIMPIEZA DE ESTIÉRCOL DE AVES EN LA COMUNIDAD DE SAN ROQUE PERTENECIENTE AL CANTÓN SUCRE PARROQUIA CHARAPOTÓ.PROVINCIA DE MANABÍ.2011.

\section{TABLA No 29}

FRECUENCIA DE LIMPIEZA DE ESTIÉRCOL DE AVES EN LA COMUNIDAD DE SAN ROQUE PERTENECIENTE AL CANTÓN SUCRE PARROQUIA CHARAPOTÓ.PROVINCIA DE MANABÍ.2011.

TABLA No 30

VACUNACIÓN A BOVINOS EN LA COMUNIDAD DE SAN ROQUE PERTENECIENTE AL CANTÓN SUCRE PARROQUIA CHARAPOTÓ.PROVINCIA DE MANABI.2011. 
TABLA No 31

VACUNACIÓN A PORCINOS EN LA COMUNIDAD DE SAN ROQUE PERTENECIENTE AL CANTÓN SUCRE 116 PARROQUIA CHARAPOTÓ.PROVINCIA DE MANABÍ.2011.

TABLA No 32

DESPARASITACIÓN A GANADO VACUNO EN LA COMUNIDAD DE SAN ROQUE PERTENECIENTE AL CANTÓN SUCRE PARROQUIA

\section{TABLA No 33}

DESPARASITACIÓN A PORCINOS EN LA COMUNIDAD DE SAN ROQUE PERTENECIENTE AL CANTÓN SUCRE 120 PARROQUIA

\section{TABLA No 34}

AGUA PARA EL CONSUMO EN LA COMUNIDAD DE SAN ROQUE PERTENECIENTE AL CANTÓN SUCRE PARROQUIA

\section{TABLA No 35}

MANEJO DE BASURA EN LA COMUNIDAD DE SAN 124 ROQUE PERTENECIENTE AL CANTÓN SUCRE PARROQUIA CHARAPOTÓ.PROVINCIA DE MANABÍ.2011. 
TABLA No 36

VIVIENDAS EN MAL ESTADO EN LA COMUNIDAD DE SAN 126

ROQUE PERTENECIENTE AL CANTÓN SUCRE PARROQUIA CHARAPOTÓ.PROVINCIA DE MANABÍ.2011.

TABLA No 37

NIÑOS QUE ANDAN DESCALZOS EN LA COMUNIDAD DE 128 SAN ROQUE PERTENECIENTE AL CANTÓN SUCRE PARROQUIA CHARAPOTÓ.PROVINCIA DE MANABÍ.2011.

\section{TABLA No 38}

ADULTOS QUE ANDAN DESCALZOS EN LA COMUNIDAD DE SAN ROQUE PERTENECIENTE AL CANTÓN SUCRE PARROQUIA CHARAPOTÓ.PROVINCIA DE MANABÍ.2011.

\section{TABLA No 39}

PRESENCIA DE ROEDORES (RATAS) EN LA VIVIENDA EN LA COMUNIDAD DE SAN ROQUE PERTENECIENTE AL 132 CANTÓN SUCRE PARROQUIA CHARAPOTÓ.PROVINCIA DE MANABÍ.2011. 
TABLA No 40

NIVEL DE CONOCIMIENTOS SOBRE ZOONOSIS EN LA

COMUNIDAD DE SAN ROQUE PERTENECIENTE AL CANTÓN SUCRE PARROQUIA CHARAPOTÓ.PROVINCIA DE MANABÍ.2011.

\section{TABLA No 41}

NIVEL DE CONOCIMIENTOS SOBRE LA RABIA EN LA COMUNIDAD DE SAN ROQUE PERTENECIENTE AL CANTÓN SUCRE PARROQUIA CHARAPOTÓ.PROVINCIA DE MANABÍ.2011

\section{TABLA No 42}

NIVEL DE CONOCIMIENTOS SOBRE TOXOPLASMOSIS EN LA COMUNIDAD DE SAN ROQUE PERTENECIENTE AL

CANTÓN SUCRE PARROQUIA CHARAPOTÓ.PROVINCIA DE MANABÍ.2011

\section{TABLA No 43}

NIVEL DE CONOCIMIENTOS SOBRE NIGUAS EN LA 140 COMUNIDAD DE SAN ROQUE PERTENECIENTE AL CANTÓN SUCRE PARROQUIA CHARAPOTÓ.PROVINCIA DE MANABÍ.2011 


\section{TABLA No 44}

DE CONOCIMIENTOS SOBRE HISTOPLASMOSIS EN LA 141 COMUNIDAD DE SAN ROQUE PERTENECIENTE AL CANTÓN SUCRE PARROQUIA CHARAPOTÓ.PROVINCIA DE MANABÍ.2011

\section{TABLA No 45}

NIVEL DE CONOCIMIENTOS SOBRE HANTAVIRUS O MAL DE HANTA EN LA COMUNIDAD DE SAN ROQUE 143 PERTENECIENTE AL CANTÓN SUCRE PARROQUIA CHARAPOTÓ.PROVINCIA DE MANABÍ.2011

\section{TABLA No 46}

NIVEL DE CONOCIMIENTOS SOBRE LEPTOSPIROSIS EN LA COMUNIDAD DE SAN ROQUE PERTENECIENTE AL CANTÓN SUCRE PARROQUIA CHARAPOTÓ.PROVINCIA DE MANABÍ.2011

\section{TABLA No 47}

CONOCIMIENTOS SOBRE ZOONOSIS EN LA COMUNIDAD DE SAN ROQUE, PERTENECIENTE AL CANTÓN SUCRE PARROQUIA CHARAPOTÓ. PROVINCIA DE MANABI.2011. 
TABLA No 48

CONOCIMIENTOS DE TRANSMISIÓN DE ZOONOSIS POR

MEDIO DE VECTORES EN LA COMUNIDAD DE SAN ROQUE, PERTENECIENTE AL CANTÓN SUCRE PARROQUIA CHARAPOTÓ. PROVINCIA DE MANABI.2011

TABLA No 49

CONOCIMIENTOS SOBRE CAUSAS DE ZOONOSIS EN LA 153 COMUNIDAD DE SAN ROQUE, PERTENECIENTE AL CANTÓN SUCRE PARROQUIA CHARAPOTÓ. PROVINCIA DE MANABI.2011.

TABLA No 50

CONOCIMIENTOS SOBRE TOXOPLASMOSIS EN LA COMUNIDAD DE SAN ROQUE, PERTENECIENTE AL CANTÓN SUCRE PARROQUIA CHARAPOTÓ.

\section{TABLA No 51}

$\begin{array}{llllll}\text { CONOCIMIENTOS SOBRE } & \text { CAUSAS } & \text { DE } & \text { LA } & 158\end{array}$ TOXOPLASMOSIS EN LA COMUNIDAD DE SAN ROQUE, PERTENECIENTE AL CANTÓN SUCRE PARROQUIA CHARAPOTÓ. PROVINCIA DE MANABI.2011. 
TABLA No 52

CONOCIMIENTOS SOBRE CONSECUENCIAS DE LA 162 TOXOPLASMOSIS EN LA COMUNIDAD DE SAN ROQUE, PERTENECIENTE AL CANTÓN SUCRE PARROQUIA CHARAPOTÓ. PROVINCIA DE MANABI.2011.

\section{TABLA No 53}

CONOCIMIENTOS SOBRE MEDIDAS DE PREVENCIÓN DE LA TOXOPLASMOSIS EN LA COMUNIDAD DE SAN 164 ROQUE, PERTENECIENTE AL CANTÓN SUCRE PARROQUIA CHARAPOTÓ. PROVINCIA DE MANABI.2011.

\section{TABLA NO 54}

LA HISTOPLASMOSIS CONOCIMIENTOS SOBRE HISTOPLASMOSIS EN LA COMUNIDAD DE SAN ROQUE, 167 PERTENECIENTE AL CANTÓN SUCRE PARROQUIA CHARAPOTÓ. PROVINCIA DE MANABI.2011.

\section{TABLA No 55}

CONOCIMIENTOS SOBRE MECANISMO DE TRANSMISIÓN DE HISTOPLASMOSIS EN LA COMUNIDAD DE SAN ROQUE, PERTENECIENTE AL CANTÓN SUCRE PARROQUIA CHARAPOTÓ. PROVINCIA DE MANABI.2011. 
TABLA No 56

CONOCIMIENTOS SOBRE PREVENCIÓN DE 174 HISTOPLASMOSIS EN LA COMUNIDAD DE SAN ROQUE, PERTENECIENTE AL CANTÓN SUCRE PARROQUIA CHARAPOTÓ. PROVINCIA DE MANABI.2011.

\section{TABLA No 57}

CONOCIMIENTOS SOBRE MAL DE HANTA EN LA COMUNIDAD DE SAN ROQUE, PERTENECIENTE AL CANTÓN SUCRE PARROQUIA CHARAPOTÓ. PROVINCIA DE MANABI.2011.

\section{TABLA No 58}

CONOCIMIENTOS SOBRE MECANISMO DE TRANSMISIÓN DEL MAL DE HANTA EN LA COMUNIDAD DE SAN ROQUE, PERTENECIENTE AL CANTÓN SUCRE PARROQUIA CHARAPOTÓ. PROVINCIA DE MANABI.2011.

\section{TABLA No 59}

CONOCIMIENTOS SOBRE CÓMO PREVENIR EL MAL DE HANTA EN LA COMUNIDAD DE SAN ROQUE, PERTENECIENTE AL CANTÓN SUCRE PARROQUIA 182 CHARAPOTÓ. PROVINCIA DE MANABI.2011. 
TABLA No 60

CONOCIMIENTOS SOBRE LEPTOSPIROSIS EN LA 184 COMUNIDAD DE SAN ROQUE, PERTENECIENTE AL CANTÓN SUCRE PARROQUIA CHARAPOTÓ. PROVINCIA DE MANABI.2011.

\section{TABLA No 61}

CONOCIMIENTOS SOBRE MECANISMO DE TRANSMISIÓN DE LA LEPTOSPIROSIS EN LA COMUNIDAD DE SAN 186 ROQUE, PERTENECIENTE AL CANTÓN SUCRE PARROQUIA CHARAPOTÓ. PROVINCIA DE MANABI.2011

\section{TABLA No 62}

CONOCIMIENTOS SOBRE MEDIDAS DE PREVENCIÓN DEL LEPTOSPIROSIS EN LA COMUNIDAD DE SAN 189 ROQUE, PERTENECIENTE AL CANTÓN SUCRE PARROQUIA CHARAPOTÓ. PROVINCIA DE MANABI.2011.

\section{TABLA No 63}

CONOCIMIENTOS SOBRE LA RABIA EN LA COMUNIDAD DE SAN ROQUE, PERTENECIENTE AL CANTÓN SUCRE 191 PARROQUIA CHARAPOTÓ. PROVINCIA DE MANABI.2011. 


\section{TABLA No 64}

CONOCIMIENTOS SOBRE MECANISMO DE TRANSMISIÓN DE LA RABIA EN LA COMUNIDAD DE SAN ROQUE, PERTENECIENTE AL CANTÓN SUCRE PARROQUIA CHARAPOTÓ. PROVINCIA DE MANABI.2011.

\section{TABLA No 65}

CONOCIMIENTOS SOBRE MEDIDAS DE PREVENCIÓN DE LA RABIA EN LA COMUNIDAD DE SAN ROQUE, 196 PERTENECIENTE AL CANTÓN SUCRE PARROQUIA CHARAPOTÓ. PROVINCIA DE MANABI.2011.

\section{TABLA No 66}

CONOCIMIENTOS SOBRE LA TUNGA PENETRANS (NIGUAS) EN LA COMUNIDAD DE SAN ROQUE, 198 PERTENECIENTE AL CANTÓN SUCRE PARROQUIA CHARAPOTÓ. PROVINCIA DE MANABI.2011.

\section{TABLA No 67}

CONOCIMIENTOS SOBRE MECANISMO DE TRANSMISIÓN DE LA TUNGA PENETRANS (NIGUAS) EN LA COMUNIDAD DE SAN ROQUE, PERTENECIENTE AL CANTÓN SUCRE PARROQUIA CHARAPOTÓ. PROVINCIA DE MANABI.2011. 
TABLA No 68

CONOCIMIENTOS SOBRE MEDIDAS DE PREVENCIÓN DE LA TUNGA PENETRANS (NIGUAS) EN LA COMUNIDAD DE SAN ROQUE, PERTENECIENTE AL CANTÓN SUCRE PARROQUIA CHARAPOTÓ. PROVINCIA DE MANABI.2011.

\section{TABLA No 69}

CONOCIMIENTOS SOBRE MEDIDAS DE PREVENCIÓN DE ZOONOSIS EN LA COMUNIDAD DE SAN ROQUE, PERTENECIENTE AL CANTÓN SUCRE PARROQUIA CHARAPOTÓ. PROVINCIA DE MANABI.2011.

\section{TABLA No 70}

CONOCIMIENTOS SOBRE MANEJO DE ESTIÉRCOL DE ANIMALES DE GRANJA EN LA COMUNIDAD DE SAN ROQUE, PERTENECIENTE AL CANTÓN SUCRE PARROQUIA CHARAPOTÓ. PROVINCIA DE MANABI.2011. 


\section{ÍNDICE DE GRÁFICOS}

\section{GRÁFICO No 1}

EDAD DE LAS MADRES DE FAMILIA DE LA COMUNIDAD DE SAN ROQUE. PERTENECIENTE AL CANTÓN SUCRE PARROQUIA CHARAPOTÓ. PROVINCIA DE MANABÍ.2011 GRÁFICO No 2 ESCOLARIDAD DE LAS MADRES DE FAMILIA DE LA COMUNIDAD DE SAN ROQUE. PERTENECIENTE AL CANTÓN SUCRE PARROQUIA CHARAPOTÓ. PROVINCIA DE MANABÍ.2011

GRÁFICO No 3

EMBARAZADAS DE LA COMUNIDAD DE SAN ROQUE. PERTENECIENTE AL CANTÓN SUCRE PARROQUIA CHARAPOTÓ. PROVINCIA DE MANABÍ.2011

\section{GRÁFICO No 4}

ANIMALES DOMÉSTICOS QUE TIENEN LAS MADRES DE FAMILIA DE LA COMUNIDAD DE SAN ROQUE PERTENECIENTE AL CANTÓN SUCRE PARROQUIA CHARAPOTÓ. PROVINCIA DE MANABÍ. 2011. 


\section{GRÁFICO No 5}

UTILIDAD DE ANIMALES DOMÉSTICOS QUE TIENEN LAS MADRES DE FAMILIA DE LA COMUNIDAD DE SAN ROQUE PERTENECIENTE AL CANTÓN SUCRE PARROQUIA CHARAPOTÓ. PROVINCIA DE MANABÍ.2011

GRÁFICO No 6

PERSONAS DE LA FAMILIA QUE TIENEN CONTACTO DIRECTO CON PERROS EN EL HOGAR EN LA COMUNIDAD DE SAN ROQUE PERTENECIENTE AL CANTÓN SUCRE PARROQUIA CHARAPOTÓ. PROVINCIA DE MANABÍ. 2011

GRÁFICO No 7

PERSONAS DE LA FAMILIA QUE TIENEN CONTACTO DIRECTO CON GATOS EN EL HOGAR EN LA COMUNIDAD DE SAN ROQUE PERTENECIENTE AL CANTÓN SUCRE PARROQUIA CHARAPOTÓ. 63 PROVINCIA DE MANABÍ. 2011 


\section{GRÁFICO No 8}

HIGIENE DEL LUGAR DONDE COME EL PERRO Y

GATO EN LA COMUNIDAD DE SAN ROQUE

PERTENECIENTE AL CANTÓN SUCRE PARROQUIA

CHARAPOTÓ. PROVINCIA DE MANABÍ. 2011

\section{GRÁFICO No 9}

HIGIENE DEL LUGAR DONDE DEFECA EL PERRO EN LA COMUNIDAD DE SAN ROQUE PERTENECIENTE AL CANTÓN SUCRE. PARROQUIA CHARAPOTÓ. PROVINCIA DE MANABÍ. 2011

\section{GRÁFICO No 10}

HIGIENE DEL LUGAR DONDE DEFECA EL GATO EN LA COMUNIDAD DE SAN ROQUE PERTENECIENTE AL CANTÓN SUCRE. PARROQUIA CHARAPOTÓ. PROVINCIA DE MANABÍ. 2011.

\section{GRÁFICO No 11}

HIGIENE A LOS PERROS DE LAS FAMILIAS DE LA COMUNIDAD DE SAN ROQUE PERTENECIENTE AL CANTÓN SUCRE PARROQUIA CHARAPOTÓ. PROVINCIA DE MANABÍ. 2011. 


\section{GRÁFICO No 12}

HIGIENE DEL GATO EN LAS FAMILIAS DE LA COMUNIDAD 73

DE SAN ROQUE PERTENECIENTE AL CANTÓN SUCRE PARROQUIA CHARAPOTÓ. PROVINCIA DE MANABÍ. 2011.

\section{GRÁFICO No 13}

VACUNACIÓN A LOS PERROS CONTRA LA RABIA EN LA COMUNIDAD DE SAN ROQUE PERTENECIENTE AL CANTÓN SUCRE PARROQUIA CHARAPOTÓ. PROVINCIA DE MANABí. 2011.

\section{GRÁFICO No 14}

VACUNACIÓN A LOS GATOS CONTRA LA RABIA EN LA COMUNIDAD DE SAN ROQUE PERTENECIENTE AL CANTÓN SUCRE PARROQUIA CHARAPOTÓ. PROVINCIA DE MANABÍ. 2011.

\section{GRÁFICO No 15}

DESPARACITACIÓN A LOS PERROS EN LA COMUNIDAD DE SAN ROQUE PERTENECIENTE AL CANTÓN SUCRE 79 PARROQUIA CHARAPOTÓ. PROVINCIA DE MANABÍ. 2011. 


\section{GRÁFICO No 16}

DESPARACITACIÓN A LOS GATOS EN LA COMUNIDAD DE SAN ROQUE PERTENECIENTE AL CANTÓN SUCRE PARROQUIA CHARAPOTÓ. PROVINCIA DE MANABÍ. 2011.

\section{GRÁFICO No 17}

TENENCIA DE ANIMALES DE GRANJA EN LA COMUNIDAD 83

DE SAN ROQUE PERTENECIENTE AL CANTÓN SUCRE PARROQUIA CHARAPOTÓ.PROVINCIA DE MANABÍ. 2011

\section{TABLA No 18}

TIPOS DE ANIMALES DE GRANJA QUE TIENEN LAS FAMILIAS EN LA COMUNIDAD DE SAN ROQUE PERTENECIENTE AL CANTÓN SUCRE PARROQUIA CHARAPOTÓ.PROVINCIA DE MANABÍ. 2011

\section{GRÁFICO No 19}

BENEFICIOS QUE BRINDAN LOS ANIMALES DE GRANJA EN LA COMUNIDAD DE SAN ROQUE PERTENECIENTE AL CANTÓN SUCRE PARROQUIA CHARAPOTÓ.PROVINCIA DE MANABÍ. 2011. 
PERSONA DE LA FAMILIA ENCARGADA DEL CUIDADO DE ANIMALES DE GRANJA EN LA COMUNIDAD DE SAN ROQUE PERTENECIENTE AL CANTÓN SUCRE PARROQUIA CHARAPOTÓ.PROVINCIA DE MANABÍ.2011.

\section{GRÁFICO No 21}

TENENCIA DE CORRALES PARA GANADO BOVINO EN LA COMUNIDAD DE SAN ROQUE PERTENECIENTE AL

CANTÓN SUCRE PARROQUIA CHARAPOTÓ.PROVINCIA DE MANABÍ.2011.

\section{GRÁFICO No 22}

CHANCHERAS PARA PORCINOS EN LA COMUNIDAD DE SAN ROQUE PERTENECIENTE AL CANTÓN SUCRE PARROQUIA CHARAPOTÓ.PROVINCIA DE MANABÍ.2011.

GRÁFICO No 23

GALPONES PARA AVES EN LA COMUNIDAD DE SAN ROQUE PERTENECIENTE AL CANTÓN SUCRE PARROQUIA CHARAPOTÓ.PROVINCIA DE MANABÍ.2011. 


\section{GRÁFICO No 24}

LIMPIEZA DE ESTIÉRCOL DE BOVINOS EN LA COMUNIDAD DE SAN ROQUE PERTENECIENTE AL 99 CANTÓN SUCRE PARROQUIA CHARAPOTÓ.PROVINCIA DE MANABÍ.2011.

\section{GRÁFICO No 25}

FRECUENCIA DE LIMPIEZA DE ESTIÉRCOL DE BOVINOS EN LA COMUNIDAD DE SAN ROQUE PERTENECIENTE AL 102 CANTÓN SUCRE PARROQUIA CHARAPOTÓ.PROVINCIA DE MANABÍ.2011.

\section{GRÁFICO No 26}

LIMPIEZA DE ESTIÉRCOL DE PORCINOS EN LA COMUNIDAD DE SAN ROQUE PERTENECIENTE AL CANTÓN SUCRE PARROQUIA CHARAPOTÓ.PROVINCIA DE MANABÍ.2011.

\section{GRÁFICO No 27}

FRECUENCIA DE LIMPIEZA DE ESTIÉRCOL DE BOVINOS EN LA COMUNIDAD DE SAN ROQUE PERTENECIENTE AL CANTÓN SUCRE PARROQUIA CHARAPOTÓ.PROVINCIA DE MANABÍ.201 


\section{GRÁFICO No 28}

LIMPIEZA DE ESTIÉRCOL DE AVES EN LA COMUNIDAD

DE SAN ROQUE PERTENECIENTE AL CANTÓN SUCRE PARROQUIA CHARAPOTÓ.PROVINCIA DE MANABÍ.2011.

\section{GRÁFICO No 29}

FRECUENCIA DE LIMPIEZA DE ESTIÉRCOL DE AVES EN LA COMUNIDAD DE SAN ROQUE PERTENECIENTE AL CANTÓN SUCRE PARROQUIA CHARAPOTÓ.PROVINCIA DE MANABÍ.2011.

\section{GRÁFICO No 30}

VACUNACIÓN A BOVINOS EN LA COMUNIDAD DE SAN ROQUE PERTENECIENTE AL CANTÓN SUCRE PARROQUIA CHARAPOTÓ.PROVINCIA DE MANABI.2011.

\section{GRÁFICO No 31}

VACUNACIÓN A PORCINOS EN LA COMUNIDAD DE SAN ROQUE PERTENECIENTE AL CANTÓN SUCRE PARROQUIA CHARAPOTÓ.PROVINCIA DE MANABÍ.2011. 


\section{GRÁFICO No 32}

DESPARASITACIÓN A GANADO VACUNO EN LA COMUNIDAD DE SAN ROQUE PERTENECIENTE AL CANTÓN SUCRE PARROQUIA

GRÁFICO No 33

DESPARASITACIÓN A PORCINOS EN LA COMUNIDAD DE SAN ROQUE PERTENECIENTE AL CANTÓN SUCRE PARROQUIA

\section{GRÁFICO No 34}

AGUA PARA EL CONSUMO EN LA COMUNIDAD DE SAN 119 ROQUE PERTENECIENTE AL CANTÓN SUCRE PARROQUIA

\section{GRÁFICO No 35}

MANEJO DE BASURA EN LA COMUNIDAD DE SAN ROQUE PERTENECIENTE AL CANTÓN SUCRE 121 PARROQUIA CHARAPOTÓ.PROVINCIA DE MANABÍ.2011.

\section{GRÁFICO No 36}

VIVIENDAS EN MAL ESTADO EN LA COMUNIDAD DE SAN ROQUE PERTENECIENTE AL CANTÓN SUCRE PARROQUIA CHARAPOTÓ.PROVINCIA DE MANABÍ.2011. 


\section{GRÁFICO No 37}

NIÑOS QUE ANDAN DESCALZOS EN LA COMUNIDAD DE 125

SAN ROQUE PERTENECIENTE AL CANTÓN SUCRE PARROQUIA CHARAPOTÓ.PROVINCIA DE MANABÍ.2011.

\section{GRÁFICO No 38}

ADULTOS QUE ANDAN DESCALZOS EN LA COMUNIDAD

DE SAN ROQUE PERTENECIENTE AL CANTÓN SUCRE PARROQUIA CHARAPOTÓ.PROVINCIA DE MANABÍ.2011.

\section{GRÁFICO No 39}

PRESENCIA DE ROEDORES (RATAS) EN LA VIVIENDA EN LA COMUNIDAD DE SAN ROQUE PERTENECIENTE AL

CANTÓN SUCRE PARROQUIA CHARAPOTÓ.PROVINCIA DE MANABÍ.2011.

\section{GRÁFICO No 40}

NIVEL DE CONOCIMIENTOS SOBRE ZOONOSIS EN LA COMUNIDAD DE SAN ROQUE PERTENECIENTE AL CANTÓN SUCRE PARROQUIA CHARAPOTÓ.PROVINCIA DE MANABÍ.2011. 


\section{GRÁFICO No 41}

NIVEL DE CONOCIMIENTOS SOBRE LA RABIA EN LA COMUNIDAD DE SAN ROQUE PERTENECIENTE AL CANTÓN SUCRE PARROQUIA CHARAPOTÓ.PROVINCIA DE MANABÍ.2011

\section{GRÁFICO No 42}

NIVEL DE CONOCIMIENTOS SOBRE TOXOPLASMOSIS EN

LA COMUNIDAD DE SAN ROQUE PERTENECIENTE AL CANTÓN SUCRE PARROQUIA CHARAPOTÓ.PROVINCIA DE MANABÍ.2011

\section{GRÁFICO No 43}

NIVEL DE CONOCIMIENTOS SOBRE NIGUAS EN LA COMUNIDAD DE SAN ROQUE PERTENECIENTE AL CANTÓN SUCRE PARROQUIA CHARAPOTÓ.PROVINCIA DE MANABÍ.2011

\section{GRÁFICO No 44}

DE CONOCIMIENTOS SOBRE HISTOPLASMOSIS EN LA COMUNIDAD DE SAN ROQUE PERTENECIENTE AL CANTÓN SUCRE PARROQUIA CHARAPOTÓ.PROVINCIA DE MANABÍ.2011 


\section{GRÁFICO No 45}

NIVEL DE CONOCIMIENTOS SOBRE HANTAVIRUS O MAL

DE HANTA EN LA COMUNIDAD DE SAN ROQUE PERTENECIENTE AL CANTÓN SUCRE PARROQUIA CHARAPOTÓ.PROVINCIA DE MANABÍ.2011

\section{GRÁFICO No 46}

NIVEL DE CONOCIMIENTOS SOBRE LEPTOSPIROSIS EN 142 LA COMUNIDAD DE SAN ROQUE PERTENECIENTE AL CANTÓN SUCRE PARROQUIA CHARAPOTÓ.PROVINCIA DE MANABÍ.2011

\section{GRÁFICO No 47}

CONOCIMIENTOS SOBRE ZOONOSIS EN LA COMUNIDAD DE SAN ROQUE, PERTENECIENTE AL CANTÓN SUCRE 143 PARROQUIA CHARAPOTÓ. PROVINCIA DE MANABI.2011.

\section{GRÁFICO No 48}

CONOCIMIENTOS DE TRANSMISIÓN DE ZOONOSIS POR MEDIO DE VECTORES EN LA COMUNIDAD DE SAN ROQUE, PERTENECIENTE AL CANTÓN SUCRE PARROQUIA CHARAPOTÓ. PROVINCIA DE MANABI.2011 


\section{GRÁFICO No 49}

CONOCIMIENTOS SOBRE CAUSAS DE ZOONOSIS EN LA

COMUNIDAD DE SAN ROQUE, PERTENECIENTE AL CANTÓN SUCRE PARROQUIA CHARAPOTÓ. PROVINCIA DE MANABI.2011.

\section{GRÁFICO No 50}

CONOCIMIENTOS SOBRE TOXOPLASMOSIS EN LA COMUNIDAD DE SAN ROQUE, PERTENECIENTE AL CANTÓN SUCRE PARROQUIA CHARAPOTÓ.

\section{GRÁFICO No 51}

CONOCIMIENTOS SOBRE CAUSAS DE LA TOXOPLASMOSIS EN LA COMUNIDAD DE SAN ROQUE, PERTENECIENTE AL CANTÓN SUCRE PARROQUIA CHARAPOTÓ. PROVINCIA DE MANABI.2011.

\section{GRÁFICO No 52}

CONOCIMIENTOS SOBRE CONSECUENCIAS DE LA 156 TOXOPLASMOSIS EN LA COMUNIDAD DE SAN ROQUE, PERTENECIENTE AL CANTÓN SUCRE PARROQUIA CHARAPOTÓ. PROVINCIA DE MANABI.2011. 


\section{GRÁFICO No 53}

CONOCIMIENTOS SOBRE MEDIDAS DE PREVENCIÓN DE LA TOXOPLASMOSIS EN LA COMUNIDAD DE SAN ROQUE, PERTENECIENTE AL CANTÓN SUCRE PARROQUIA CHARAPOTÓ. PROVINCIA DE MANABI.2011.

\section{GRÁFICO NO 54}

LA HISTOPLASMOSIS CONOCIMIENTOS SOBRE HISTOPLASMOSIS EN LA COMUNIDAD DE SAN ROQUE, 163 PERTENECIENTE AL CANTÓN SUCRE PARROQUIA CHARAPOTÓ. PROVINCIA DE MANABI.2011.

\section{GRÁFICO No 55}

CONOCIMIENTOS SOBRE MECANISMO DE TRANSMISIÓN DE HISTOPLASMOSIS EN LA COMUNIDAD DE SAN ROQUE, PERTENECIENTE AL CANTÓN SUCRE 165 PARROQUIA CHARAPOTÓ. PROVINCIA DE MANABI.2011.

\section{GRÁFICO No 56}

CONOCIMIENTOS SOBRE PREVENCIÓN DE HISTOPLASMOSIS EN LA COMUNIDAD DE SAN ROQUE, $\begin{array}{llll}\text { PERTENECIENTE AL CANTÓN SUCRE PARROQUIA } & 168\end{array}$ CHARAPOTÓ. PROVINCIA DE MANABI.2011. 


\section{GRÁFICO No 57}

CONOCIMIENTOS SOBRE MAL DE HANTA EN LA COMUNIDAD DE SAN ROQUE, PERTENECIENTE AL CANTÓN SUCRE PARROQUIA CHARAPOTÓ. PROVINCIA DE MANABI.2011.

\section{GRÁFICO No 58}

CONOCIMIENTOS SOBRE MECANISMO DE TRANSMISIÓN DEL MAL DE HANTA EN LA COMUNIDAD DE SAN ROQUE, PERTENECIENTE AL CANTÓN SUCRE PARROQUIA CHARAPOTÓ. PROVINCIA DE MANABI.2011.

\section{GRÁFICO No 59}

CONOCIMIENTOS SOBRE CÓMO PREVENIR EL MAL DE HANTA EN LA COMUNIDAD DE SAN ROQUE, PERTENECIENTE AL CANTÓN SUCRE PARROQUIA CHARAPOTÓ. PROVINCIA DE MANABI.2011.

\section{GRÁFICO No 60}

CONOCIMIENTOS SOBRE LEPTOSPIROSIS EN LA COMUNIDAD DE SAN ROQUE, PERTENECIENTE AL CANTÓN SUCRE PARROQUIA CHARAPOTÓ. PROVINCIA DE MANABI.2011.

GRÁFICO No 61 
CONOCIMIENTOS SOBRE MECANISMO DE TRANSMISIÓN DE LA LEPTOSPIROSIS EN LA COMUNIDAD DE SAN ROQUE, PERTENECIENTE AL CANTÓN SUCRE PARROQUIA CHARAPOTÓ. PROVINCIA DE MANABI.2011

\section{GRÁFICO No 62}

CONOCIMIENTOS SOBRE MEDIDAS DE PREVENCIÓN DEL LEPTOSPIROSIS EN LA COMUNIDAD DE SAN ROQUE, PERTENECIENTE AL CANTÓN SUCRE PARROQUIA CHARAPOTÓ. PROVINCIA DE MANABI.2011.

\section{GRÁFICO No 63}

CONOCIMIENTOS SOBRE LA RABIA EN LA COMUNIDAD DE SAN ROQUE, PERTENECIENTE AL CANTÓN SUCRE 185 PARROQUIA CHARAPOTÓ. PROVINCIA DE MANABI.2011.

\section{GRÁFICO No 64}

CONOCIMIENTOS SOBRE MECANISMO DE TRANSMISIÓN DE LA RABIA EN LA COMUNIDAD DE SAN ROQUE, PERTENECIENTE AL CANTÓN SUCRE PARROQUIA 186 CHARAPOTÓ. PROVINCIA DE MANABI.2011. 


\section{GRÁFICO No 65}

CONOCIMIENTOS SOBRE MEDIDAS DE PREVENCIÓN DE 190 LA RABIA EN LA COMUNIDAD DE SAN ROQUE, PERTENECIENTE AL CANTÓN SUCRE PARROQUIA CHARAPOTÓ. PROVINCIA DE MANABI.2011.

\section{GRÁFICO No 66}

CONOCIMIENTOS SOBRE LA TUNGA PENETRANS 192 (NIGUAS) EN LA COMUNIDAD DE SAN ROQUE, PERTENECIENTE AL CANTÓN SUCRE PARROQUIA CHARAPOTÓ. PROVINCIA DE MANABI.2011.

\section{TABLA No 67}

CONOCIMIENTOS SOBRE MECANISMO DE TRANSMISIÓN DE LA TUNGA PENETRANS (NIGUAS) EN LA COMUNIDAD DE SAN ROQUE, PERTENECIENTE AL CANTÓN SUCRE PARROQUIA CHARAPOTÓ. PROVINCIA DE MANABI.2011.

\section{GRÁFICO No 68}

CONOCIMIENTOS SOBRE MEDIDAS DE PREVENCIÓN DE LA TUNGA PENETRANS (NIGUAS) EN LA COMUNIDAD DE SAN ROQUE, PERTENECIENTE AL CANTÓN SUCRE PARROQUIA CHARAPOTÓ. PROVINCIA DE MANABI.2011. 


\section{GRÁFICO No 69}

CONOCIMIENTOS SOBRE MEDIDAS DE PREVENCIÓN DE 199 ZOONOSIS EN LA COMUNIDAD DE SAN ROQUE, PERTENECIENTE AL CANTÓN SUCRE PARROQUIA CHARAPOTÓ. PROVINCIA DE MANABI.2011.

\section{GRÁFICO No 70}

CONOCIMIENTOS SOBRE MANEJO DE ESTIÉRCOL DE ANIMALES DE GRANJA EN LA COMUNIDAD DE SAN 202 ROQUE, PERTENECIENTE AL CANTÓN SUCRE PARROQUIA CHARAPOTÓ. PROVINCIA DE MANABI.2011.

\section{GRÁFICO No 71}

CONOCIMIENTOS SOBRE MANEJO DE ESTIÉRCOL DE ANIMALES DE GRANJA EN LA COMUNIDAD DE SAN ROQUE, PERTENECIENTE AL CANTÓN SUCRE PARROQUIA CHARAPOTÓ. PROVINCIA DE MANABI.2011. 


\section{INTRODUCCIÓN}

El problema de la zoonosis en el Ecuador es muy grave, principalmente en el área rural que en el área urbana tienen este problema. Penosamente los más afectados son los niños, mujeres embarazadas, y los adultos mayores, por ser la población más vulnerable y expuesta a desarrollar zoonosis.

Manabí es una provincia con gran cantidad de habitantes constituyéndose así en un lugar con mayores problemas de salud uno de ellos es la zoonosis, debido a que gran parte de la población se encuentra en el sector rural, en donde proliferan las infecciones por presencia de animales domésticos en grandes cantidades, que pueden estar cerca de los alimentos o al estar en contacto con ellos. Una de las grandes causas para esta problemática es la insalubridad, tanto en niños que están descuidados, muchas veces caminan descalzos entre basura o por el estiércol de vacas, gallinas o chanchos que constituyen una fuente de infección, o en contacto con animales domésticos; como en adultos, que no toman las medidas necesarias de protección y prevención de zoonosis, al no lavar las manos de los niños después de jugar en la tierra, en el suelo o con algún animal, es decir las condiciones de vida, de saneamiento y los servicios básicos en esta comunidad no son adecuadas, como también el bajo nivel de educación de la población hace que se incremente los problemas de zoonosis ya que al no tener conocimientos del tema, no saben cómo prevenirlos. 
En la Comunidad de San Roque, perteneciente al Cantón Sucre, parroquia Charapotó Provincia de Manabí, se ha observado grandes problemas de zoonosis debido a la insalubridad y por la cantidad de animales domésticos, que se encuentran conviviendo con las personas dentro de las viviendas por lo cual no se puede hablar de una familia saludable ni de una vivienda saludable.

Se debe considerar que la prevalencia de enfermedades zoonóticas, va relacionada con la falta de educación que lleva a bajos condiciones y normas de higiene y saneamiento en las familias, además de la escasez de recursos económicos que existen en la comunidad.

No obstante, se debe tener en cuenta que los animales pueden portar microorganismos extremadamente patógenos, cuyo desarrollo se recomienda evitar. Los animales pueden portar agentes patógenos. Si estos microorganismos se transmiten al hombre, le pueden provocar enfermedades de mayor y menor gravedad. No es necesario que el animal esté enfermo para portar los microorganismos. Determinados microorganismos se pueden diseminar a través de los excrementos del animal. (8)

En los últimos años, el interés por las enfermedades transmisibles de los animales al hombre (zoonosis) se ha incrementado notablemente. Las razones para ello son muy variadas, pero cabría resumirlas básicamente en el notable aumento de la población (cada vez más concentrada y demandando la producción de más y más alimentos) y su avance a regiones antes sólo habitadas por animales e insectos, lo que ha multiplicado el potencial infeccioso de los llamados vectores. 
Sin duda, las enfermedades comunes a las especies domésticas y salvajes conforman el grupo que recibe una mayor atención, debido a las repercusiones potenciales que éstas pueden tener en materia de sanidad animal y los aspectos comerciales con ella relacionados (como el caso del mal del ganado vacuno ). Sin embargo también es importante considerar enfermedades que aún identificadas siguen causando grandes desastres en regiones subdesarrolladas del planeta, como el caso de la malaria. (7) 


\section{JUSTIFICACIÓN}

La Zoonosis ocupa el primer lugar entre las enfermedades de los trópicos húmedos; por ello son conocidas como enfermedades tropicales, están muy difundidas y constituyen un serio problema para la salud especialmente en zonas como Manabí por poseer este tipo de clima que oscila entre subtropical seco y tropical húmedo; la temperatura no es uniforme, podemos citar a Portoviejo, cuya temperatura media es de 25 grados centígrados. (8)

Pero también hay que considerar que la prevalencia de enfermedades zoonóticas, va relacionada con la falta de educación que lleva a bajos condiciones y normas de higiene y saneamiento en las familias, además de la escasez de recursos económicos que existen en la comunidad.

La Zoonosis constituye un serio problema de salud pública a nivel mundial. De ser una condición aparentemente limitada a determinados grupos. Manabí se encuentra como la tercera Provincia que concentra más de la mitad (55\%) de la población nacional, luego de Guayas que es la primera y Pichincha la Segunda

(7). Es por eso que a mayor población mayor son los problemas de salud y uno de ellos la zoonosis.

En el área rural hay menos departamentos y más ranchos o chozas que en la urbana; especialmente en la costa como en Manabí. (7).Es por eso que en las comunidades la mayor parte de la población, por estar ubicados en la zona 
rural se dedica a criar porcinos, ganado vacuno, y aviar para su alimentación y ayuda económica y también existe gran cantidad de perros encargados de cuidar la vivienda y gatos. Es por eso que se observa que "la Costa ocupa el tercer lugar entre las regiones con respecto a problemas zoonóticos (27.9\%)" (7). Por estar en continuo contacto con animales domésticos, y consumo de agua contaminada en especial las zonas rurales que es donde se presentan las cifras más altas de parasitosis y por su clima.

Todavía, en ésta como en otras provincias la zoonosis es una realidad en la población. Las soluciones (educación y saneamiento ambiental básico, mejora del nivel de vida, alimentación, vivienda saludable, higiene de la vivienda, manejo adecuado de animales domésticos) son conocidas desde hace mucho tiempo, pero no son difundidas y aplicadas en la comunidad, resultando insuficientes. Además según la Organización Mundial de la Salud (OMS) nos dice que "No debemos olvidar que las enfermedades zoonóticas tienen una etiología social”. (4)

Conocer el tipo, características de la vivienda, y forma de tenencia de la misma, así como la disponibilidad de agua, servicio higiénico, servicio eléctrico, servicio telefónico, formas de eliminación de la basura, eliminación de excretas de animales, manejo de animales domésticos y otros servicios, determina las condiciones sociales, económicas y de salud en las que vive la población.

La población de animales domésticos en la comunidad de San Roque ha experimentado un importante crecimiento en la actualidad. Todas las familias poseen animales domésticos. El mayor número registrado corresponde en su 
mayoría porcinos, ganado vacuno, aviar gatos y perros. Hoy en día la variedad de animales que se alojan en los hogares es mayor, ya que algunas personas tienen ganado vacuno, que son un aporte económico para las familias. $Y$ al haber crecimiento de animales domésticos en la comunidad También se da un crecimiento de enfermedades transmitidas por estos animales domésticos (zoonosis), como por ejemplo: la rabia, la toxoplasmosis, triquinosis, niguas y el hanta; enfermedades cuyos agentes vectores son: el perro, el gato, los porcinos, ganado vacuno y los roedores.

Atendiendo a lo anteriormente expresado y teniendo en cuenta la ausencia de atención de gobiernos locales y casas de Salud en este aspecto dentro de la comunidad; como proyecto de investigación, se plantea realizar un Programa educativo para prevenir la Zoonosis en las familias de la Comunidad San Roque, para a través de la educación e información acerca de las enfermedades a la que están expuestas las familias puedan mejorar sus condiciones y estilos de vida hacia una familia saludable y con ello a una Vivienda Saludable de este grupo poblacional.

Las enfermedades Zoonóticas ocasionadas por animales domésticos en los hogares es un tema de Salud Pública, que consta como línea prioritaria de Investigación a la Escuela de Promoción y Cuidados de la Salud, ya que como Promotores de salud somos los responsables de buscar e implementar estrategias para motivar a la comunidad a optar por estilos y condiciones de vida saludable que garantice su buen estado de salud. 


\section{OBJETIVOS}

\section{A. GENERAL}

Implementar un Programa Educativo para prevenir "La Zoonosis" en las familias de la Comunidad de San Roque del Cantón Sucre Parroquia Charapotó. Provincia de Manabí 2011.

\section{B. ESPECÍFICOS}

- Identificar características socio demográficas del grupo de estudio.

- Determinar los principales factores de riesgo de las familias y la comunidad.

- Diagnósticar el nivel de conocimientos de la comunidad sobre las enfermedades Zoonóticas más comunes ocasionadas por animales domésticos.

- Ejecutar y Evaluar el Programa Educativo 


\section{III.- MARCO TEÓRICO}

\section{A.- Zoonosis}

Zoonosis esta palabra proviene del griego zoon (animal) y nósos (enfermedad), por lo que su definición médica podría ser: Enfermedad o infección que se da en los animales y que es transmisible al hombre en condiciones naturales. (1) Es decir se refiere a todas aquellas enfermedades propias de los animales transmitidos de forma natural de los animales vertebrados al hombre o viceversa por ejemplo por vectores como (insectos y animales), al ser humano.

1. Antropozoonosis.- La antropozoonosis es una enfermedad que se transmite del animal al hombre.

2. Zooantroponosis.- La Zooantroponosis es una enfermedad que se transmite de las personas a los animales.

3. Zoonosis de transmisión directa.- Se llama zoonosis de transmisión directa la que se da a partir de un "reservorio animal" y el contacto que se da con el animal vivo, o a través de los alimentos de el obtenidos, de sus subproductos o de sus desechos.

4. Zoonosis transmitida por medio de vectores.-Se llama Zoonosis transmitida por vectores a los medios móviles que sirven de transporte y mantienen la cadena de transmisión de la enfermedad entre los animales y el hombre.(9) 


\section{B.- Enfermedades Zoonóticas}

Las enfermedades zoonóticas son una afección y alteración infecciosa del funcionamiento del organismo caracterizada por un desequilibrio físico, mental, y social causada por bacterias, virus, hongos, protozoos que son parásitos; los cuales encuentran en el huésped las condiciones favorables para su anidamiento, desarrollo, multiplicación y virulencia, de modo que pueda ocasionar una enfermedad. (10)

C.- Vector.- En biología un vector es un agente generalmente orgánico que sirve como medio de transmisión que puede propagar o transmitir una enfermedad de un organismo a otro. Los vectores biológicos se estudian por ser causas de enfermedades, pero también como posibles curas para el ser humano. Por lo general los vectores pueden ser un insecto o un animal que transporta el microorganismo.

1. Vector epidemiológico.-. Es decir un vector epidemiológico es aquel que actúa como medio de transporte de un agente infeccioso desde individuos enfermos propagándolo a otros que no están enfermos. Por ejemplo los mosquitos .La mayor parte de los vectores son insectoshematófagos, puesto que los virus y bacterias encuentran un medio fácil de transmisión por contacto directo a la circulación sanguínea.

2. Vector genético.- En genética, un vector es una agente que transfiere información genética, por algún tipo de medio, de un organismo a otro. 
También se les puede considerar vectores genéticos a todo tipo de virus, puesto que su principal función es insertar información genética en otras células.

D.- Agente se conoce como agente a la excesiva presencia o relativa ausencia de microorganismos que puede producir una enfermedad. Excesiva presencia porque tiene que estar presente una cantidad de microorganismos para que se produzca las enfermedades. Relativa ausencia porque hay enfermedades que se producen por la falta de, por ejemplo las carencias vitamínicas.

1. Agentes biológicos.- se conocen cono agentes biológicos a aquellos agentes causales vivos.

2. Agentes físicos.- se conoce como agentes físicos a aquellos agentes causales inanimados.

3. Agentes químicos los agentes químicos son aquellas sustancias no vivas que representan un grupo de agentes causales.(11)

E.- Fuente de infección es el ser animado (animales o artrópodos) o inanimado (alimentos, agua, o fómites). Desde donde pasa el agente etiológico al huésped o más conocido como punto de origen del agente infeccioso al agente susceptible. Además una fuente también puede ser reservorio. Es así que el hombre es la fuente de infección más importante, para que el ser humano pueda ser fuente de infección el microorganismo debe poder salir del enfermo.

F.- Reservorio Es el hábitat natural es la casa que tiene el microorganismo donde él puede vivir relajadamente y se puede multiplicar. Cuando el agente 
pasa desde el reservorio al hombre susceptible actúa como fuente de infección .Este reservorio puede ser el hombre, un animal o un foco ambiental.

\section{Tipos de reservorio}

El enfermo clínico.- el enfermo clínico es aquel que está sufriendo la enfermedad, ya que el microorganismo se encuentra situado en su interior, y es ahí donde se multiplica, se desarrolla ya que está en su hábitat.

El enfermo subclínico.- el enfermo subclínico es el enfermo que presenta síntomas vagos, que se pueden atribuir a varias enfermedades, y al estar enfermo se lo aísla del resto de personas que se encuentran cerca de él.

Reservorios animales.- el agente causal de una enfermedad, puede ser transmitido al hombre a través de los animales enfermos o sus carnes.

Portador.- portador es la persona infectada que posee el microorganismo en su organismo pero no produce la enfermedad, y que se encuentra sin padecer signos ni síntomas pero se encuentra eliminando microorganismos que afectan a los que se encuentran a su alrededor.(12)

Portador sano.- es aquel que tiene el microorganismo en su cuerpo, pero este no desarrolla la enfermedad y no presenta ni signos ni síntomas, para que uno pueda decir que la persona este enferma, no padece la enfermedad porque posee cierto grado de inmunidad frente al agente etiológico que porta.

Portador en período de incubación.- El portador en periodo de incubación es aquel que tiene el microorganismo en su cuerpo, pero que todavía no ha 
producido signos de enfermedad se encuentra en periodo latente. En este paciente se puede eliminar los microorganismos antes que aparezca la enfermedad que está incubando.

Portador convaleciente.- El portador convaleciente es la persona que tuvo la enfermedad, se mejoro y se encuentra recuperándose, sin embargo sigue eliminando microorganismos patógenos. (13)

G.- Puertas de entrada y salida.- las puertas de entrada y salida de estos microorganismos son los órganos por los que ingresan estos agentes causales y son el aparato digestivo, aparato respiratorio, piel y mucosas, y por vía urinaria principalmente. También puede ser a través de la salida de algunas glándulas salivales, a través de alguna herida, por la piel delgada. (14)

H.- Mecanismo de transmisión.- El mecanismo de transmisión es el medio por el cual el agente viaja hasta encontrar una puerta de entrada que le sea favorable. Pero para ello tiene que haber un medio entre el agente y el huésped los más comunes son por vehículo, por vector, y por el aire a larga distancia.

Mecanismo de trasmisión por vehículo.- El mecanismo de transmisión por vehículo pueden ser por alimentos contaminados, utensilios de cocina, la cama o sea las sábanas, la ropa, los juguetes, es decir es un vehículo por el cual de un huésped enfermo o portador sano pasa el microorganismo y va a un huésped sano pero susceptible y ce introduce ese microorganismo a su cuerpo. 
Mecanismo de transmisión por vector.- Por lo general el mecanismo de trasmisión por vector es un insecto, un animal que transporta el microorganismo.

Mecanismo de transmisión por vector biológico.- Esta etapa se da cuando el microorganismo hace alguna etapa de multiplicación o desarrollo. Como el caso del dengue.

Mecanismo de transmisión por vector mecánico.- Es cuando el vector solo transporta el microorganismo por ejemplo solo lo lleva en sus patas como el caso de las moscas.es decir no existe ninguna etapa de de multiplicación ni de desarrollo solo transporte.

Mecanismo de transmisión por medio del aire.- Este mecanismo es la vía de transporte más frecuente, es cuando los microorganismos se ubican en pequeñas partículas de polvo, o pelusitas y viajan un poco más allá, con la ayuda del viento hacia otro huésped es decir no es un contacto directo frente a frente. (15)

I.- Hospedador o huésped.- Se llama así a la especie parasitada que puede sufrir daños o lesiones ocasionadas por el parásito durante una interacción biológica el Hospedador es el que da el beneficio al parásito para que este se aloje en él, se nutra y se reproduzca causándole daños o enfermando al organismo hospedante.

J.- Parásito Parásito es aquel ser vivo que vive temporalmente, periódicamente o permanentemente sobre o dentro de un organismo vivo y se 
nutren siendo huéspedes que necesitan de un hospedador para sobrevivir sin aportar ningún beneficio para este hospedador, sin embargo estos Huéspedes encuentran en el Hospedador protección contra depredadores o competidores, y también protección para sus propias crías, pudiendo producir daños o lesiones en el ser humano. (16)

Estos parásitos pueden ser hongos, protozoos, virus, bacterias y riquetsias que en muchos casos dañan o causan enfermedades al organismo hospedante.

1. Endoparásitos.- son aquellos parásitos que viven dentro en el interior del huésped u organismo hospedador, como los protozoos parásitos de la sangre. Hay varios endoparásitos que pueden causar enfermedades graves, como los plasmodios, causantes de la malaria.

2. Ectoparásitos.- Son aquellos parásitos que viven fuera del Huésped u organismo hospedador y son aquellos que se fijan a la piel del huésped para perforarla y así poder alimentarse de sangre o linfa, es decir que este tipo de parásitos habitan sobre la superficie del que los hospeda. Ejemplos muy comunes de ectoparásitos son las garrapatas, las pulgas y los piojos.

3. Parásitos internos obligados: son aquellos parásitos que no pueden sobrevivir fuera de un Huésped, además estos parásitos sólo se alimentan de los residuos del metabolismo de su huésped. Si éste se enfermara o se muriera, también el parásito provocaría su exterminio.

4. Parásitos facultativos: son los parásitos que sobreviven en el Huésped u hospedador pero sólo temporalmente. Además estos pueden alimentarse tanto de seres vivos como de materia muerta. 
5. Parásitos temporales: Son parásitos temporales aquellos que se fijan en el huésped únicamente para alimentarse, pero viven la mayor parte de su vida en otro lugar. Como en el caso de las garrapatas, que viven en la hierba pero se fijan a los animales para beber sangre hasta que están llenas, luego, vuelven a sujetarse a las plantas. También estos parásitos viven durante un breve periodo en el huésped, y son organismos de vida libre durante el resto de su ciclo vital.

6. Parásitos periódicos: Son aquellos organismos que se comportan como parásitos sólo en una etapa de su ciclo de vida. Por ejemplo, algunos crustáceos viven libres en estado larvario, pero como adultos viven parasitando a algunos peces.

7. Parásitos permanentes: los parásitos permanentes son aquellos que viven en un huésped todo su ciclo de vida y estos pasan la mayor parte de su ciclo vital dentro o sobre el organismo al que parasitan.

8. Parasitoide.- se conoce con el nombre de parasitoide a aquellos parásitos que matan al organismo donde se hospedan, es decir son parásitos que ocasionan la muerte a su huésped u hospedador. (17)

K.- Parasitosis La parasitosis es una enfermedad que sucede cuando los parásitos encuentran en el huésped las condiciones favorables para su anidamiento, desarrollo, multiplicación y virulencia, de modo que pueda ocasionar una enfermedad. Y que para ampliar su capacidad de supervivencia utiliza a otras especies para que cubran sus necesidades básicas y vitales como nutricionales y reproductivas de la especie parásita. (18) 
También la parasitosis es una interacción biológica entre dos organismos, en la que uno de los organismos que es el parásito, consigue la mayor parte del beneficio de una relación estrecha con otro, que es el huésped u hospedador.

L.- Patogenicidad.- La patogenicidad es la capacidad de producir una enfermedad y esta se mide estableciendo una relación entre el número de personas que se enferman clínicamente dividido para el número de personas expuestas a la infección.

M.- Infectividad.- La infectividad es la cantidad de microbios que se necesita para causar una infección en los hospederos susceptibles.

1. Dosis infectiva.- Se llama dosis infectiva a la cantidad mínima de microorganismos que se debe introducir al huésped para producir la enfermedad. (19)

N.- Virulencia La virulencia es la encargada de medir la agresividad que tiene un microorganismo y que hace que una enfermedad sea más o menos grave que otra. (19)

1.- Poder antigénico.- Es la capacidad que tiene un agente de provocar cierto grado de resistencia específica en el hospedador, es decir estimula la producción de defensas específicas.

2.- Susceptibilidad.- La susceptibilidad es la falta de resistencia al ataque de un agente patógeno, que ocasiona la posibilidad de contraer la enfermedad correspondiente. 
3.- Inmunidad.- La inmunidad es el estado de resistencia que se encuentra asociada a los anticuerpos necesarios y suficientes para proteger el organismo contra agentes causales de enfermedades o de sus toxinas. (20)

Ñ.- Periodo de transmisibilidad El periodo de transmisibilidad es el periodo en el que el Hospedador causa la propagación de la enfermedad en la comunidad.

O.- Animales Domésticos Los animales domésticos son aquellos que viven con el ser humano y que están domesticados. Y estos animales dependen de los seres humanos para desarrollar su vida y cuando no están con ellos la mayoría muere. Es decir son dependientes.

Casi todas las necesidades básicas de estos animales giran en torno al ser humano. Son los animales que hemos habituado a vivir con los seres humanos tales como perros, gatos, vacas, cabras y ovejas, gatos, por ejemplo, que habitan en granjas o en el campo. (21)

Los animales de compañía, como los animales de granja pertenecen al grupo de animales domésticos. Por lo tanto no solo son animales domésticos los perros y los gatos, también se puede considerar dentro de animales domésticos a los porcinos, ganado vacuno, y aviar. 


\section{P.- Enfermedades zoonóticas Ocasionadas por Animales domésticos}

\section{1.- TOXOPLASMOSIS}

Es una enfermedad parasitaria que se da especialmente en los gatos y es ocasionada por el virus protozoario Toxoplasma Gondii, (el gato es el hospedador definitivo es portador de la forma adulta del parásito). (22)

Este parásito infecta a los gatos que comen, aves, ratones, o carne contaminada.Y los gatos son anfitriones de esta enfermedad es que su transmisión se da por las heces, afecta a las personas.

La toxoplasmosis está presente en todo el mundo. El porcentaje de adultos que han pasado la enfermedad a lo largo de su vida es muy elevado, en torno al $50 \%$, dependiendo de la región, los hábitos higiénicos y las condiciones sanitarias son muy importantes para prevenir esta enfermedad. En la mayor parte de los casos apenas aparecen síntomas pero estos son leves, por lo cual la población generalmente no es consciente de haber padecido la infección que solo puede comprobarse mediante un análisis de sangre que demuestre positividad para anticuerpos específicos de tipo $\lg \mathrm{G}$ o $\lg M$. (23)

A quienes afecta.-Esta enfermedad afecta principalmente a las mujeres embarazadas, que pueden incluso causar aborto involuntario o lesiones al feto. La Toxoplasmosis, provoca graves malformaciones en el feto a través de la madre; y el escenario se agrava aún más si el embarazo es el primero. 
La infección en una mujer embarazada puede producir una Toxoplasmosis congénita en el recién nacido, aparece en un $65 \%$ de los casos en los que la mujer se infesta por primera vez. En la madre va a ser asintomática, en el feto la gravedad depende del momento de la gestación. Durante el primer mes de gestación pueden producirse abortos, aunque no son frecuentes, las consecuencias más graves aparecen entre el segundo y sexto mes: hidrocefalia, retraso psicomotor, calcificaciones cerebrales y lesiones oculares.

Las madres que ya estaban infestadas antes de la concepción están inmunizadas y el feto no sufrirá infección. Solamente hay riesgo en mujeres embarazadas con un título de anticuerpos negativo y que por lo tanto no han estado en contacto con el parásito anteriormente. Este dato se conoce a través de los análisis que rutinariamente se hacen o deben hacerse a todas las embarazadas.

En las personas se debe diferenciar entre la infestación producida por Toxoplasma y la enfermedad que este puede llegar a producir ya que en la mayoría de los casos no se llegan a producir manifestaciones clínicas, calculándose que el $80 \%$ de las personas mayores de 45 años son seropositivas a Toxoplasmosis. (24)

Mecanismo de transmisión.- Los gatos adquieren el Toxoplasma al alimentarse con carne infestada, al comer ratones o aves y luego eliminan ocistos con las heces y estos pasan al ganado o a las personas. Los gatos se infectan al consumir roedores y aves, que son huéspedes intermediarios que contienen los quistes que mantienen una infección crónica en estos animales. 
Hospedador.- El hospedador definitivo es el gato y otras 6 especies de felinos. (25)

Causas.- Durante el primer mes de gestación pueden producirse abortos, aunque no son frecuentes, las consecuencias más graves aparecen entre el segundo y sexto mes:

Hidrocefalia,

Retraso psicomotor,

Calcificaciones cerebrales y lesiones oculares.

Signos y síntomas.- Más del $80 \%$ de las infecciones son asintomáticas, sin embargo en un individuo en buen estado inmunitario, es decir con buenas defensas en su sistema inmunológico se puede producir un cuadro leve con:

Fiebre baja

Inflamación de ganglios

Debilidad

Dolor muscular. (26)

En individuos inmunodeprimidos, es decir que tienen bajas sus defensas del sistema inmunológico, la enfermedad es grave y puede afectar a cualquier órgano pero con predilección al Sistema Nervioso Central produciendo:

Encefalitis 
Meningitis e incluso puede ser mortal.

Diagnóstico.- Se debe realizar exámenes de sangre o pruebas capaces de detectar los anticuerpos serológicos o en orina, creados por el sistema inmune para combatir el parásito, especialmente un incremento en los niveles de lgG y/o la presencia de anticuerpos específicos de lgM. (27)

Tratamiento El parásito Toxoplasma gondii es sensible a los fármacos Pirimetamina y las Sulfamidas, las que se usan en combinación para el tratamiento de la toxoplasmosis incrementando más de 6 veces el efecto de ellos individualmente.Debido a que la Pirimetamina bloquea el uso del ácido fólico, se debe añadir al tratamiento el ácido folínico, el cual puede ser usado por la médula ósea del paciente, más no por el parásito. ${ }^{(28)}$

\section{Prevención}

- Se puede controlar y prevenir ésta enfermedad

- Evitando jugar con los gatos, y no se les debe dar la carne cruda.

- No se debe permitir que los gatos cacen y que ingieran sus presas

- Se debe limpiar diariamente el cajón donde defeca el gato con agua hirviendo (o usar bolsas de plástico para los cajones) y usar guantes al manipular la arena.

\section{TUNGA PENETRANS TUNGIASIS (NIGUA)}

Es una pulga que ataca la piel. Afecta principalmente la piel de los pies; se introduce en ella y produce prurito intenso. Popularmente se le conoce como 
"niguas" o "pique" (Ecuador), y parasitológicamente como tungiasis.La nigua se llama Tunga penetrans, por la costumbre que tiene de penetrar en la piel. Es una pulga, aunque de una familia diferente a las pulgas normales, pertenece a la familia Tungidae.

a) Desarrollo de la nigua La nigua es de color café y mide aproximadamente $1 \mathrm{~mm}$ de largo, aunque la hembra inseminada puede llegar a tener el tamaño de un guisante.

Los adultos, como otras pulgas, se alimentan intermitentemente pero se adhieren al huésped. Cuando la hembra está inseminada, se introduce en la pie, y a menudo entre los dedos del pie o debajo de las uñas y en la planta del pie, aunque ninguna parte del cuerpo está exenta de su ataque.

b) A quienes afecta: Las niguas Puede atacar a humanos, cerdos y otros animales domésticos. Se suele contraer al pisar suelos mojados y sucios, pero en especial afectan a los cerdos y a las vacas y de estos se transmiten al ser humano estar en contacto con estos especialmente en las zonas rurales y comunidades donde existen cantidad de cerdos y vacas cerca de la vivienda. Es curioso, las niguas afectan los pies del cerdo pero también la trompa, en el macho también se alojan sobre el escroto, en las hembras se alojan sobre las tetas, impidiendo la producción de leche y por consecuencia provocando la muerte de los lechones. 
Mecanismo de transmisión.- Las niguas viven generalmente en los corrales de las vacas y chanchos, si alguien camina descalzo o con sandalias es probable que contraiga uno de éstos parásitos. (27)

Signos y síntomas Cuando una persona está infectada por Tungiasis (niguas) al inicio se siente:

Comezón Principalmente

Irritación muy fuerte

La cavidad en la que se encuentran se llena de pus

Conforme pasan los días se forma un nódulo,

La piel pasa de un color rojizo a morado y se empieza a sentir dolor.

Las ulceraciones causadas por numerosas niguas pueden provocar infecciones serias, gangrena o tétanos.

c) Tratamiento Cuando alguien se ha infectado por niguas debe sacarlas de la piel, con una aguja o una navaja puntuda y filosa, previamente hervidos o bien desinfectados. Es necesario tomar cuidado de limpiar bien las heriditas para evitar infecciones.La forma de extraerlo es haciendo una incisión en el nódulo y presionando hasta que salga el parásito. Posteriormente hay que hacer un curetage a la herida

d) Prevención Para evitar el dolor de sacar las niguas, es mejor tomar algunas medidas de prevención. 
1) En zonas donde existan las niguas, es necesario lavarse bien los pies y revisarlos a diario para sacar las niguas antes de que produzcan infecciones.

2) Desde luego el hecho de dejar entrar los cerdos y los perros en la casa es un factor que permite la contaminación de muchas enfermedades y en este caso permite a las niguas pasarse de los cerdos o los perros a los habitantes de la casa. Es por eso que no se debe permitir entrar a los cerdos dentro de la vivienda para prevenir este problema.

3) Otra medida de prevención es caminar con zapatos cerrados. Especialmente si tienen cerdos o vacas y al limpiar las heces de estos animales es recomendable hacerlo en los corrales utilizando botas.

4) No se debe caminar sin zapatos dentro ni fuera de los hogares ni los niños, ni las personas adultas.

Si se respetan estas medidas de prevención y si se mata las niguas que hay, en poco tiempo esta plaga desaparece sin necesidad de veneno.

\section{3.- MAL DE HANTA}

Es un virus que vive en el ratón silvestre y que al transmitirse al hombre produce una enfermedad que puede ser mortal. Este virus está presente en casi todos los países del mundo. En América, produce fiebre con insuficiencia respiratoria que ha provocado la muerte de cerca del $50 \%$ de los infectados. 
A quienes afecta este virus afecta a Trabajadores agrícolas, forestales y aserradores, a escolares de establecimientos rurales o suburbanos, a las personas que viven en la costa en las zonas rurales y comunidades en donde existe gran cantidad de roedores.

Mecanismo de transmisión por vector y por medio del aire .- El portador de este virus, identificado hasta hoy, es el ratón silvestre de cola larga, pudiendo adquirirse:

Al respirar aire contaminado por excrementos (deposiciones), orina o saliva del ratón silvestre.

Al consumir alimentos o agua contaminados por excrementos, orina o saliva de estos roedores.

Al ser mordido por un ratón.

Al tomar un roedor con las manos descubiertas.

Sus síntomas son:

Fiebre, dolor de cabeza, dolores abdominales y a las articulaciones.

Dolores en la parte baja de la columna, náuseas y vómitos.

Posteriormente los síntomas se agudizan y se agregan:

Brusca alza de la temperatura 
Su síntoma principal es la dificultad para respirar, causada por acumulación de líquido en los pulmones.

Tratamiento

Para esta enfermedad todavía no existe cura ni vacuna. Mientras más rápido se reciba atención médica, más alta es la posibilidad de recuperación.

Prevención

Su prevención considera:

Eliminar los ratones de su casa

Conservar sus alimentos en envases bien cerrados

Mantener la basura en recipientes con tapa

No dejar restos de comida sobre muebles, piso, mesas, etc.

Tapar agujeros con material firme.

Enterrar la basura.

Cortar a ras de suelo malezas y pastizales.

Alejar bodegas y leñeras de su casa

Desratizar y sellar casas, bodegas y galpones.

Mantener su letrina o fosa séptica en buenas condiciones de higiene 
Si no dispone de agua potable, consumir hervida.

No consumir alimentos mordidos por ratones. (29)

\section{4.- LA HISTOPLASMOSIS}

La histoplasmosis es una infección micótica causada por el hongo Histoplasma .Esta infección ingresa al cuerpo a través de los pulmones. El hongo histoplasma crece como un hongo en el suelo y la infección resulta de la inhalación de partículas transportadas por el aire. El suelo contaminado con los excrementos de aves tiene mayores concentraciones de histoplasma.

Mecanismo de transmisión por medio del aire.- Este hongo histoplasma crece en el suelo y la infección resulta de la inhalación de partículas transportadas por el aire del suelo contaminado con excrementos de aves.

Signos y síntomas La histoplasmosis puede ser asintomática. La mayoría de las personas que sí desarrollan síntomas tendrán un síndrome seudogripal y padecimientos pulmonares relacionados con una neumonía o con otro compromiso pulmonar.

Aproximadamente el $10 \%$ de las personas con histoplasmosis desarrollará inflamación (irritación e hinchazón) en respuesta a la infección inicial. Esto puede afectar la piel, los huesos o las articulaciones, o el revestimiento del corazón (pericardio). Estos síntomas no se deben a la infección micótica de esas partes del cuerpo, sino a la inflamación. 
A quienes afecta.- Esta histoplasmosis afecta a las personas muy jóvenes, muy ancianas o aquellas con un sistema inmunitario debilitado (debido por ejemplo a personas con Síndrome de Inmunodeficiencia Adquirida (SIDA, cáncer o un trasplante) están en mayor riesgo de padecer histoplasmosis diseminada.

\section{a) Síntomas}

Los síntomas dependen del tipo de infección:

Histoplasmosis pulmonar asintomática aguda: no se presentan síntomas

Histoplasmosis pulmonar sintomática aguda:

1) Fiebre

2) Escalofríos

3) Tos

4) Dolor torácico al inspirar

Histoplasmosis pulmonar crónica:

1) Dolor torácico

2) Tos, posiblemente expectorando sangre

3) Fiebre

4) Dificultad respiratoria

5) Sudoración

Otros síntomas de histoplasmosis: 
1) dolor articular

2) salpullidos

3) nódulos cutáneos (protuberancias rojas llamadas eritema nudoso), casi siempre en la parte baja de las piernas

4) seudogripales, dolor torácico, tos y dificultad para respirar

b) Diagnóstico.- La forma de diagnosticar la histoplasmosis depende de las partes del cuerpo comprometidas. Los exámenes que se pueden realizar abarcan:

1) Biopsia de piel

2) Exámenes de orina, sangre o esputo para buscar signos de la infección de histoplasmosis

3) Tomografía computarizada del tórax

4) Radiografía de tórax

5) Punción raquídea para buscar signos de la infección en el líquido cefalorraquídeo (LCR)

\section{c) Tratamiento}

El principal tratamiento para la histoplasmosis son los fármacos antimicóticos. La anfotericina B, el itraconazol y el ketoconazol son los tratamientos usuales.

Los antimicóticos se pueden administrar por vía intravenosa, dependiendo de la forma o etapa de la enfermedad. En algunos casos, se puede necesitar un tratamiento prolongado con antimicóticos. 


\section{d) Prevención}

La histoplasmosis se puede prevenir

Reduciendo la exposición al polvo en galpones para pollos, cuevas de murciélagos y otros lugares de alto riesgo.

Utilice máscaras y otros equipos de protección para limpiar los excrementos de los pollos

Si tiene en los hogares gallinas de campo limpiar diariamente sus excrementos que se encuentran en el suelo utilizando mascarillas

No permitir que ingresen los pollos a la vivienda o que duerman dentro de la vivienda. (29)

\section{5.- LA RABIA}

La rabia es una enfermedad agudainfecciosaviral del sistema nervioso central ocasionada por un Rhabdovirus que causa encefalitis aguda con una letalidad cercana al $100 \%$. Es la zoonosis viral conocida más antigua. Ataca a los mamíferos domésticos y salvajes, incluyendo al hombre. Se encuentra en la saliva y en las secreciones de los animales infectados y se inocula al hombre cuando éstos lo atacan y provocan en el hombre alguna lesión por mordedura; además puede ser transfundido cuando un individuo que tiene algún corte en la piel (vía de entrada del virus) tiene contacto con las secreciones salivales de un animal infectado. (30) 
Vector de la rabia.- El principal vector y reservorio en el mundo es el perro

Transmisión por vector.- La rabia se transmite a través de mordedura o contacto directo de mucosas o heridas con saliva del animal infectado. La rabia es un virus que puede ser trasmitido a cualquier mamífero. Los vectores de transmisión más comunes son perros y gatos en zonas urbanas o rurales.El virus se presenta comúnmente en el sistema nervioso o en la saliva del animal afectado. Comúnmente, pero no siempre, el virus es transmitido debido a una mordedura.

\section{Signos y síntomas}

La rabia se manifiesta por un periodo prodrómico que dura de dos a diez días con signos y síntomas inespecíficos como:

Cansancio

Cefalea

Fiebre

Anorexia

Náusea

Vómito

Parestesias en el sitio de la herida 
Seguidas de dificultad para la deglución, horror al agua entre el 17 y 50\%de los casos,

Desorientación,

Alucinaciones visuales u olfatorias,

Crisis convulsivas focales o generalizadas,

En el $20 \%$ de los casos aproximadamente la rabia puede manifestarse como una parálisis flácida; estas manifestaciones clínicas son seguidas por un periodo de coma y eventualmente el fallecimiento en la gran mayoría de los casos.

\section{Tratamiento}

El tratamiento inmediato después de la exposición al virus de la rabia (ej. mordedura) impide el desarrollo de los síntomas, los cuales en ausencia de tratamiento conducirían irremediablemente a la muerte. Es recomendable lavar con agua y jabón, cuidadosamente y sin raspar la herida, ya que de este modo se ayuda a eliminar el virus, y acudir de inmediato a un centro hospitalario para recibir atención especializada. Tal atención en general consiste en la aplicación de la vacuna post exposición en los dos días siguientes a la mordedura. Las medidas de prevención de rabia en humanos comprenden tanto el tratamiento profiláctico pre o post exposición como las de intervención sobre los huéspedes del virus de la rabia. 
1) Aseo local de la herida con agua y jabón; posteriormente se puede emplear cloruro de benzalconio al $1 \%$, soluciones yodadas al $5 \%$ o alcohol del 40 al $70 \%$.

2) La sutura de la herida debe diferirse; en caso contrario, deberá infiltrarse la herida con gammaglobulina humana antirrábica o suero.

3) La administración de antibióticos y toxoide tetánico debe valorarse en cada caso particular.

4) Inmunoprofilaxia. Suero hiperinmune o gammaglobulina y vacuna antirrábica.

\section{Prevención.}

La rabia urbana se presenta mayoritariamente en zonas cuya densidad poblacional canina es alta; por ello, la forma de prevención más eficaz para detener el ciclo de transmisión vírica son las campañas masivas de vacunación, de este modo se consigue la disminución de perros susceptibles a la enfermedad. Y las familias deben acudir a vacunar a sus animales perros y gatos para evitar la Rabia cuando existan o les visiten las campañas de vacunación del ministerio de Salud Pública.

Si observa un perro furioso evite pasar cerca de él, aléjese

Si en la comunidad existe un perro que está atacando a la población informe en el Ministerio de Salud al departamento de Sanidad para que se lo elimine.

Acuda a un centro de salud más cercano en caso de haber sido atacado por un perro rabioso. (30) 


\section{6.- LA LEPTOSPIROSIS}

La Leptospirosis es una antropozoonosis de distribución mundial, causada por espiroquetas patógenas del género Leptospira y caracterizada por una vasculitis generalizada.

La Leptospirosis es una de las zoonosis más comunes y un importante problema de salud pública, aunque se desconoce la prevalencia real de esta enfermedad. La infección es comúnmente transmitida a humanos cuando agua que ha sido contaminada por orina animal se pone en contacto directo con lesiones en la piel, ojos o por las mucosas. En zonas no tropicales, los casos de leptospirosis muestran relativamente marcadas estaciones, donde la mayoría ocurren entre agosto y septiembre o entre febrero y marzo.

a).- Síntomas: En esta primera fase la enfermedad se muestra con síntomas similares a los del resfriado común, una presentación clínica que es muy similar al dengue, fiebre amarilla, malaria, influenza y muchas otras enfermedades tropicales, caracterizada por fiebre, dolor de cabeza y dolor muscular, haciendo que ese período inicial sea difícil de diagnosticar y orientar un tratamiento oportuno. La infección puede ser más o menos aguda y en general algunos de los síntomas que pueden aparecer son falta de apetito (no comen ni beben), depresión, fiebre, vómitos y hemorragias, lo que puede conducir a la muerte. En casos menos agudos, puede llegar a producir alteración hepática y renal, junto con conjuntivitis y signos respiratorios (tos, dificultad respiratoria, etc.). $\mathrm{Si}$ superan esta infección, pueden desarrollar alteraciones hepática y renal crónicas. 
b).- Diagnóstico.- El diagnóstico serológico es el diagnóstico más solicitado en caso de sospecha de leptospirosis. Los métodos utilizados son indirectos; hay diferentes técnicas de tamizaje y una técnica de confirmación.

La técnica ELISA es útil para el diagnóstico temprano ante cuadros inespecíficos como Leptospirosis, detecta infecciones recientes, es sensible y tiene buena concordancia con MAT.

c).- Tratamiento.- Los antibióticos de elección son penicilina 1,5 MUI c/6 horas i/v o tetraciclinas, preferentemente doxiciclina $100 \mathrm{mg} \mathrm{c} / 12$ horas por vía oral, durante 7 días. Además de la quimioterapia específica son necesarias las medidas sintomáticas, la corrección de las alteraciones hemodinámicas, del equilibrio hidroelectrolítico, la asistencia renal y otras medidas de soporte vital.

d).-Prevención.- Las medidas de prevención a tener en cuenta son: mejorar las condiciones socioeconómicas y el autocuidado y la autoprotección utilizando métodos de barrera, que protejan piel y mucosas, cuando se realizan actividades con riesgo de contaminación.

Se recomienda vacunar a los animales domésticos, en especial perros. Aunque la infección renal puede ocurrir en animales vacunados y se han descrito casos de hombres que adquirieron la enfermedad a partir de perros vacunados, ello es infrecuente. La vacuna no protege totalmente porque hay muchas tipos de leptospiras y la vacuna no inmuniza contra todos 


\section{V.- METODOLOGÍA}

\section{A.- LOCALIZACIÓN Y TEMPORALIZACIÓN}

La presente investigación se realizó en la Comunidad San Roque del Cantón Sucre Parroquia Charapotó. Provincia de Manabí. Tuvo una duración de 6 meses en el periodo contemplado de Abril-Octubre 2011.

\section{B.- VARIABLES}

\section{1.- Identificación}

- Características Socio-demográficas

- Factores de riesgo

- Conocimientos

\section{2.- Definiciones}

Características Socio demográficas.- Se refiere al grupo de estudio como sexo, edad, características de la vivienda, manejo de animales domésticos.

Factores de riesgo.- Un factor de riesgo es toda circunstancia o situación que aumenta las probabilidades de una persona de contraer una enfermedad.

Conocimientos.- Son hechos o datos de información adquiridos por una persona a través de la experiencia o la educación, comprensión teórica o práctica de un tema u objeto de la realidad. Son definiciones y conceptos que el hombre aprende para desarrollar sus capacidades para el bienestar de su salud y de su familia. 


\section{3.- OPERACIONALIZACIÓN}

\begin{tabular}{|c|c|c|}
\hline VARIABLE & CATEGORIA/ESCALA & INDICADOR \\
\hline \multirow{3}{*}{$\begin{array}{l}\text { CARACTERÍSTICAS } \\
\text { SOCIO } \\
\text { DEMOGRÁFICAS }\end{array}$} & $\begin{array}{l}\text { Edad } \\
12-22 \\
23-33 \\
34-44 \\
45-55 \\
56-65\end{array}$ & $\begin{array}{l}\text { Porcentaje de madres de } \\
\text { familia según edad. }\end{array}$ \\
\hline & $\begin{array}{l}\text { Grado de escolaridad } \\
\qquad \begin{aligned} & \text { - } \text { Primaria } \\
& \text { - Secundaria } \text { Superior } \\
& \text { - Ninguno }\end{aligned}\end{array}$ & $\begin{array}{l}\text { Porcentaje de madres de la } \\
\text { familia según grado de escolaridad }\end{array}$ \\
\hline & $\begin{array}{l}\text { Embarazadas } \\
\text { - Si } \\
\text { - No }\end{array}$ & $\begin{array}{l}\text { Porcentaje de madres } \\
\text { embarazadas o que tienen } \\
\text { embarazadas en el hogar }\end{array}$ \\
\hline
\end{tabular}




\begin{tabular}{|c|c|c|}
\hline VARIABLE & CATEGORIA/ESCALA & INDICADOR \\
\hline \multirow[t]{3}{*}{$\begin{array}{l}\text { FACTORES } \\
\text { RIESGO }\end{array}$} & $\begin{array}{l}\text { Animales domésticos que tienen } \\
\text { en el hogar: } \\
\text { - Perros } \\
\text { - Gatos } \\
\text { - Otros }\end{array}$ & $\begin{array}{l}\text { Porcentaje de familias según } \\
\text { especie de animales domésticos } \\
\text { que tienen en el hogar. }\end{array}$ \\
\hline & $\begin{array}{l}\text { Beneficios que brindan los } \\
\text { animales domésticos en el hogar } \\
\text { Seguridad } \\
\text { Cazadores } \\
\text { Mascota } \\
\text { Otros }\end{array}$ & $\begin{array}{l}\text { Porcentaje de madres de la } \\
\text { familia según beneficios que } \\
\text { obtienen de animales domésticos } \\
\text { Porcentaje de personas de la }\end{array}$ \\
\hline & $\begin{array}{l}\text { Persona de la familia que } \\
\text { mantiene contacto directo con } \\
\text { perros en el hogar. } \\
\text { Niños } \\
\text { Adultos }\end{array}$ & $\begin{array}{l}\text { familia que mantienen contacto } \\
\text { directo con perros en el hogar }\end{array}$ \\
\hline
\end{tabular}




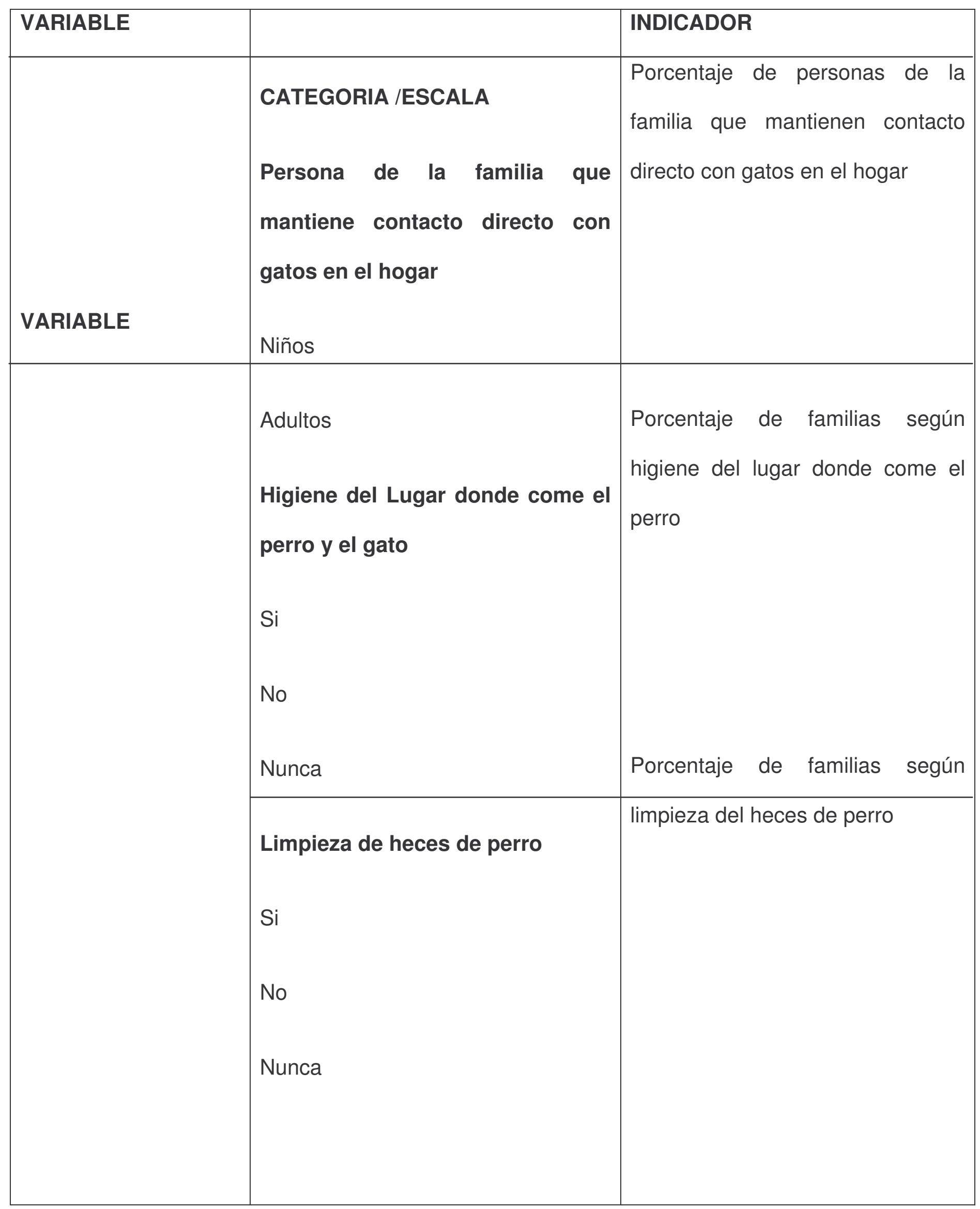




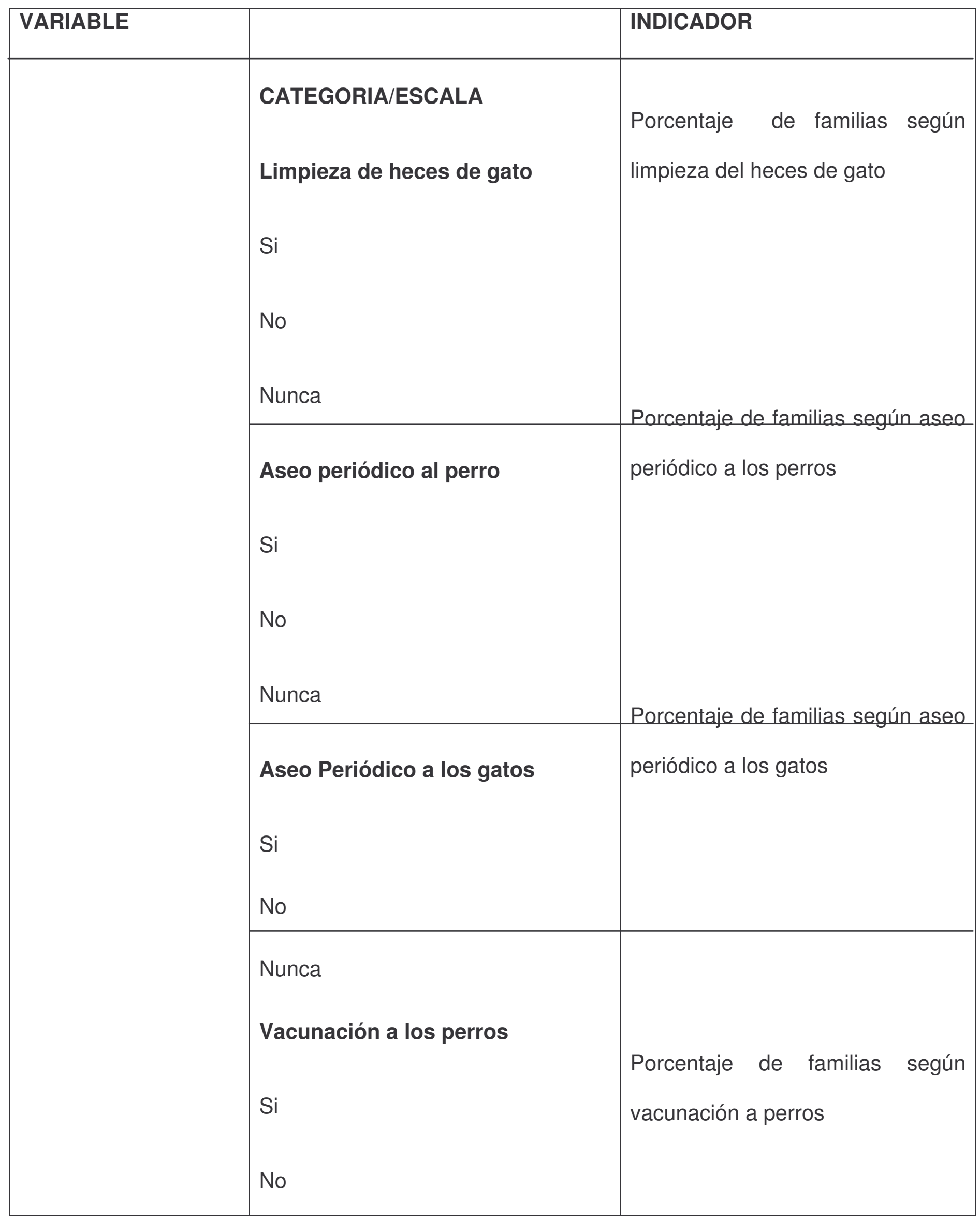




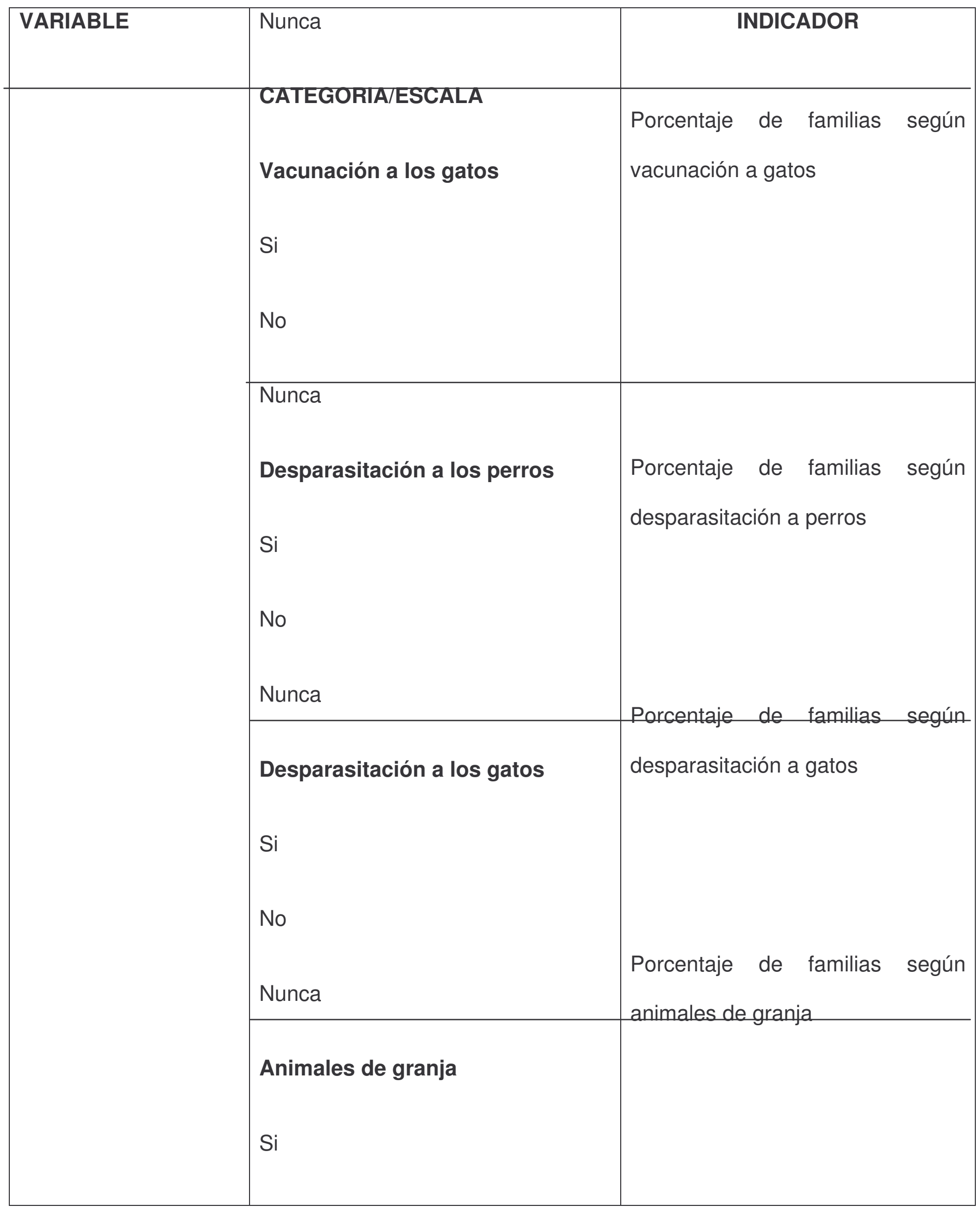




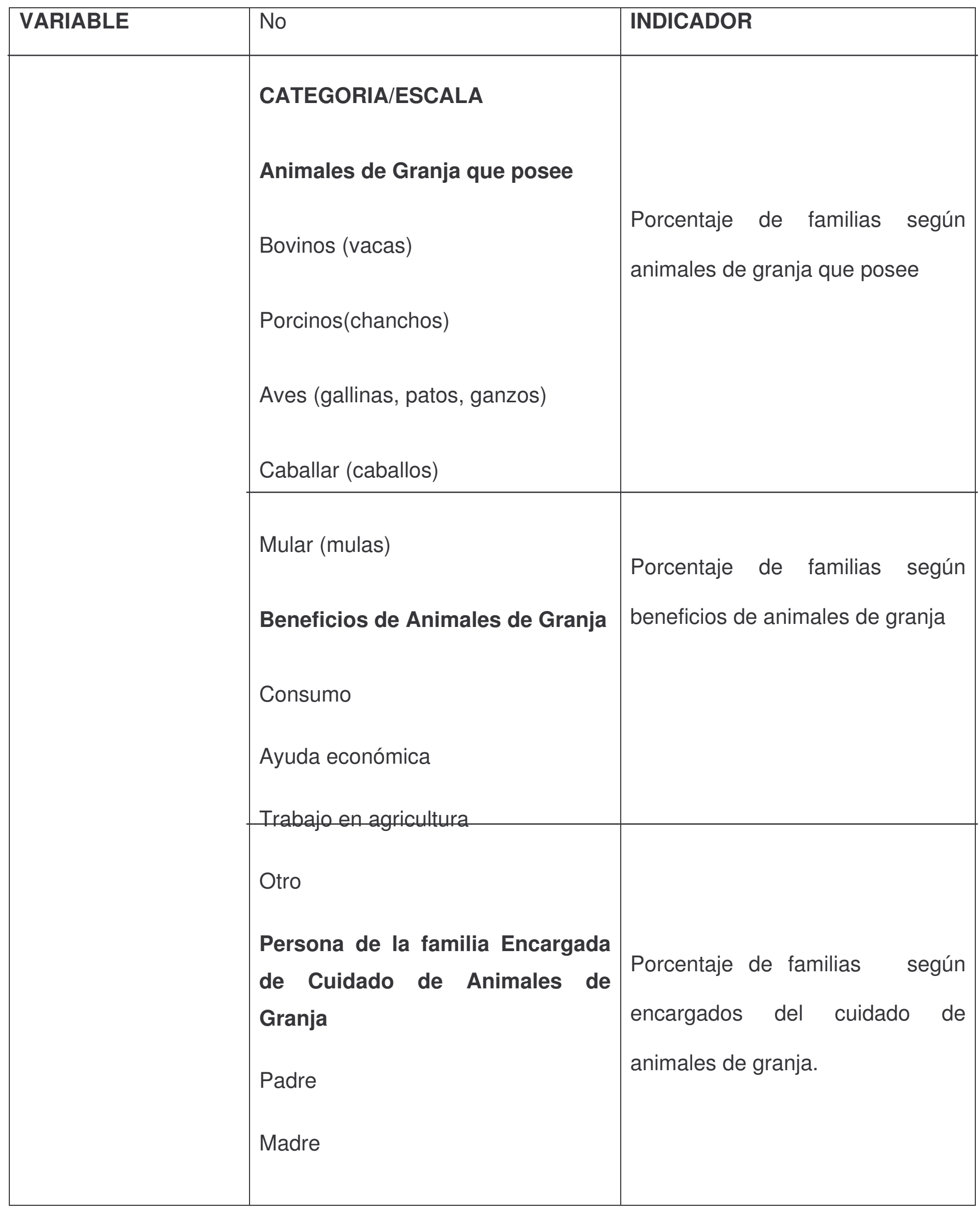




\begin{tabular}{|c|c|c|}
\hline VARIABLE & $\begin{array}{l}\text { Hijos } \\
\text { Otro } \\
\text { CATEGORIA/ESCALA }\end{array}$ & $\begin{array}{l}\text { INDICADOR } \\
\text { Porcentaje de familias según } \\
\text { corrales para Bovinos }\end{array}$ \\
\hline & $\begin{array}{l}\text { Corrales para Bovinos } \\
\mathrm{Si}\end{array}$ & \\
\hline & $\begin{array}{l}\text { No } \\
\text { Chancheras para Porcinos } \\
\mathrm{Si}\end{array}$ & $\begin{array}{l}\text { Porcentaje de familias según } \\
\text { cancheras para porcinos }\end{array}$ \\
\hline & $\begin{array}{l}\text { No } \\
\text { Galpones para Aves } \\
\mathrm{Si} \\
\text { No }\end{array}$ & $\begin{array}{l}\text { Porcentaje de familias según } \\
\text { galpones para aves } \\
\text { Porcentaje de familias según } \\
\text { limpieza de estiércol de bovinos }\end{array}$ \\
\hline & $\begin{array}{l}\text { Limpieza estiércol de Bovinos } \\
\text { Si } \\
\text { No }\end{array}$ & \\
\hline
\end{tabular}




\begin{tabular}{|c|c|}
\hline CATEGORIA/ESCALA & INDICADOR \\
\hline $\begin{array}{l}\text { Frecuencia de Limpieza de } \\
\text { estiércol de Bovinos } \\
\text { Diariamente } \\
\text { Una vez por semana } \\
\text { Cada } 15 \text { días } \\
\text { Mensualmente } \\
\text { A veces } \\
\text { Nunca }\end{array}$ & $\begin{array}{l}\text { Porcentaje de familias según } \\
\text { frecuencia de limpieza de estiércol } \\
\text { de bovinos. } \\
\text { Porcentaje de familias según }\end{array}$ \\
\hline $\begin{array}{l}\text { Limpieza Estiércol Porcinos } \\
\text { Si } \\
\text { No }\end{array}$ & limpieza de estiércol de porcinos \\
\hline $\begin{array}{l}\text { Frecuencia de Limpieza de } \\
\text { Estiércol de Porcinos } \\
\text { Diariamente } \\
\text { Una vez por semana } \\
\text { Cada } 15 \text { días } \\
\text { Mensualmente } \\
\text { A veces }\end{array}$ & $\begin{array}{l}\text { Porcentaje de familias según } \\
\text { frecuencia de limpieza de estiércol } \\
\text { de Porcinos }\end{array}$ \\
\hline
\end{tabular}




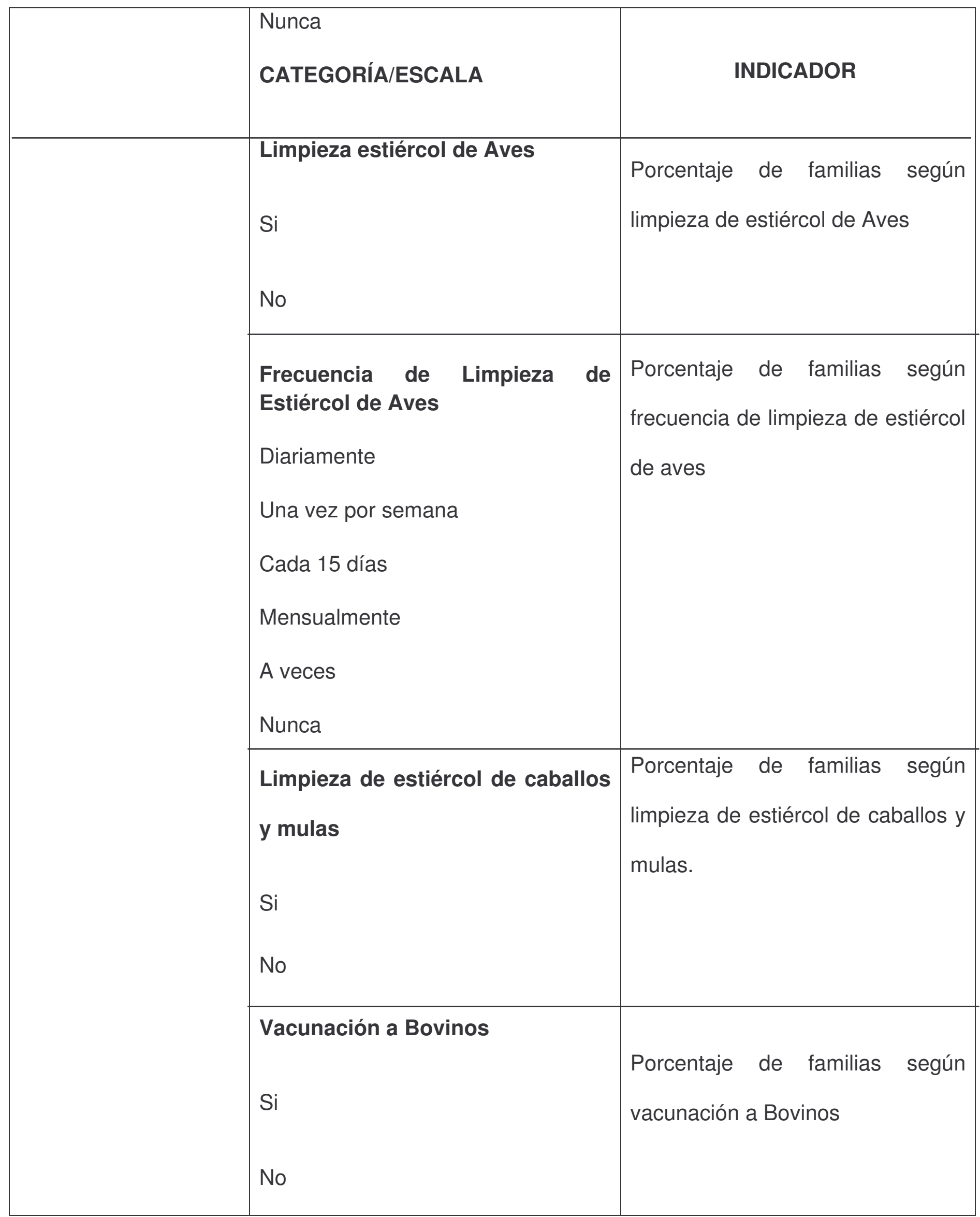




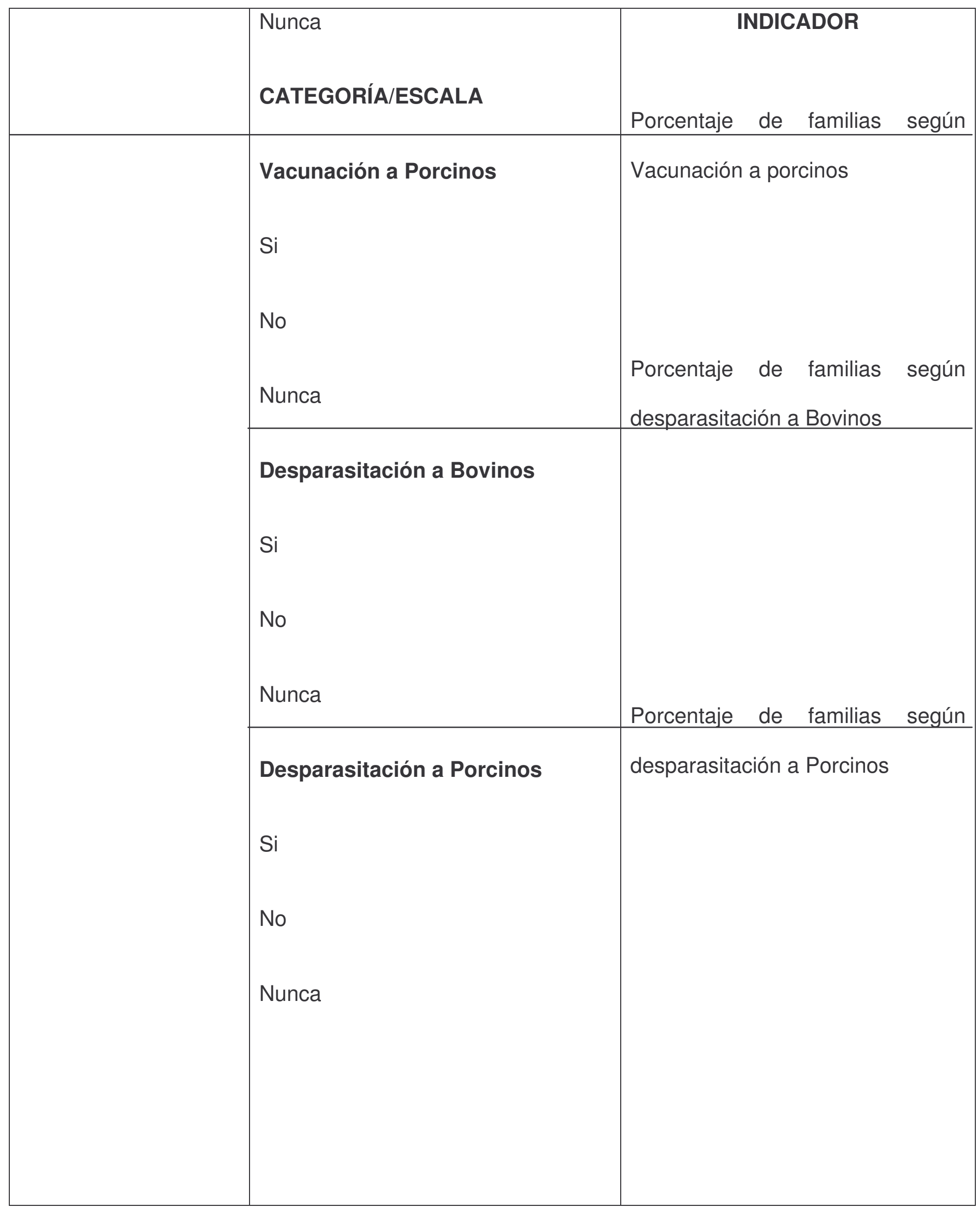




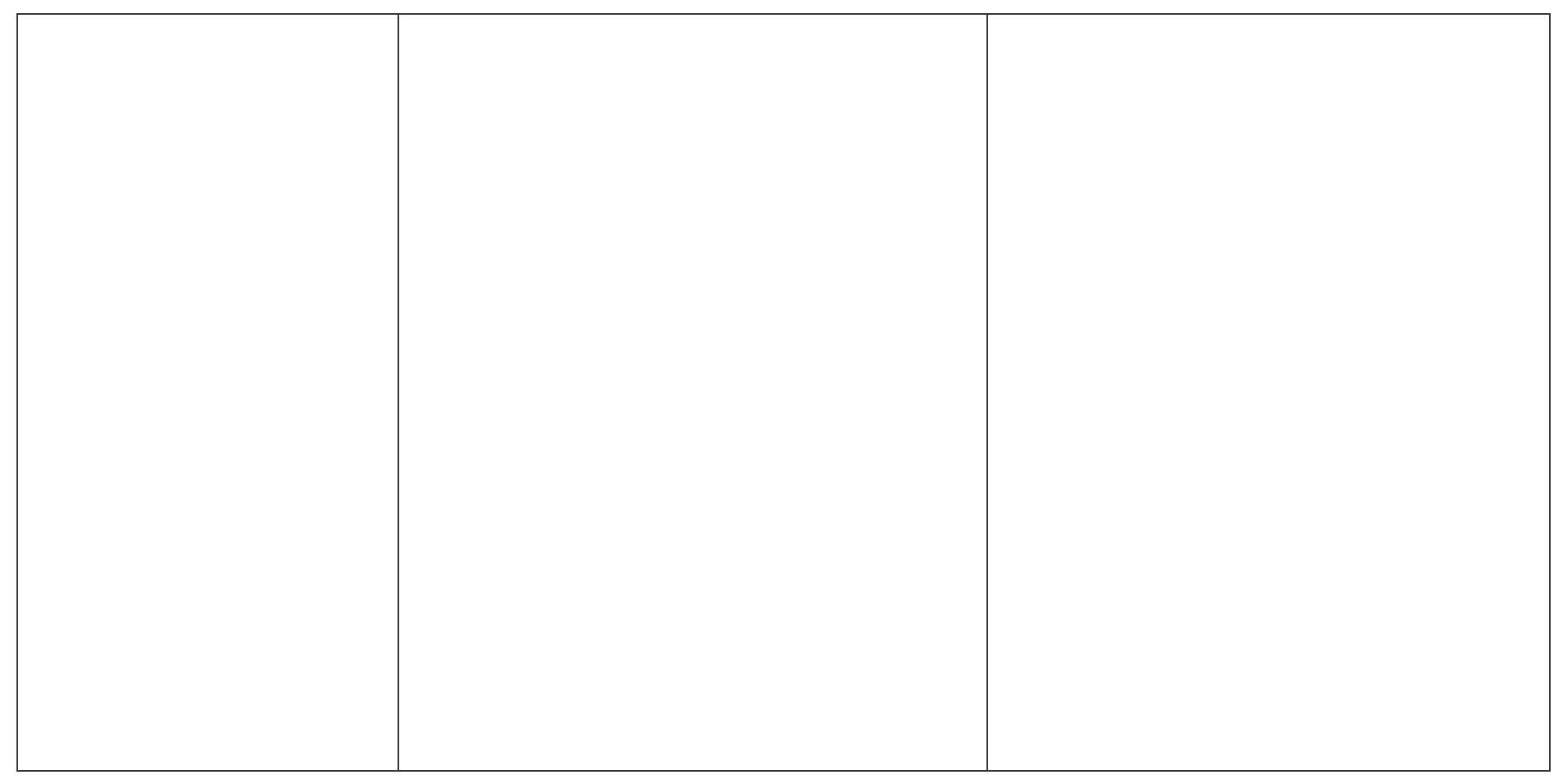




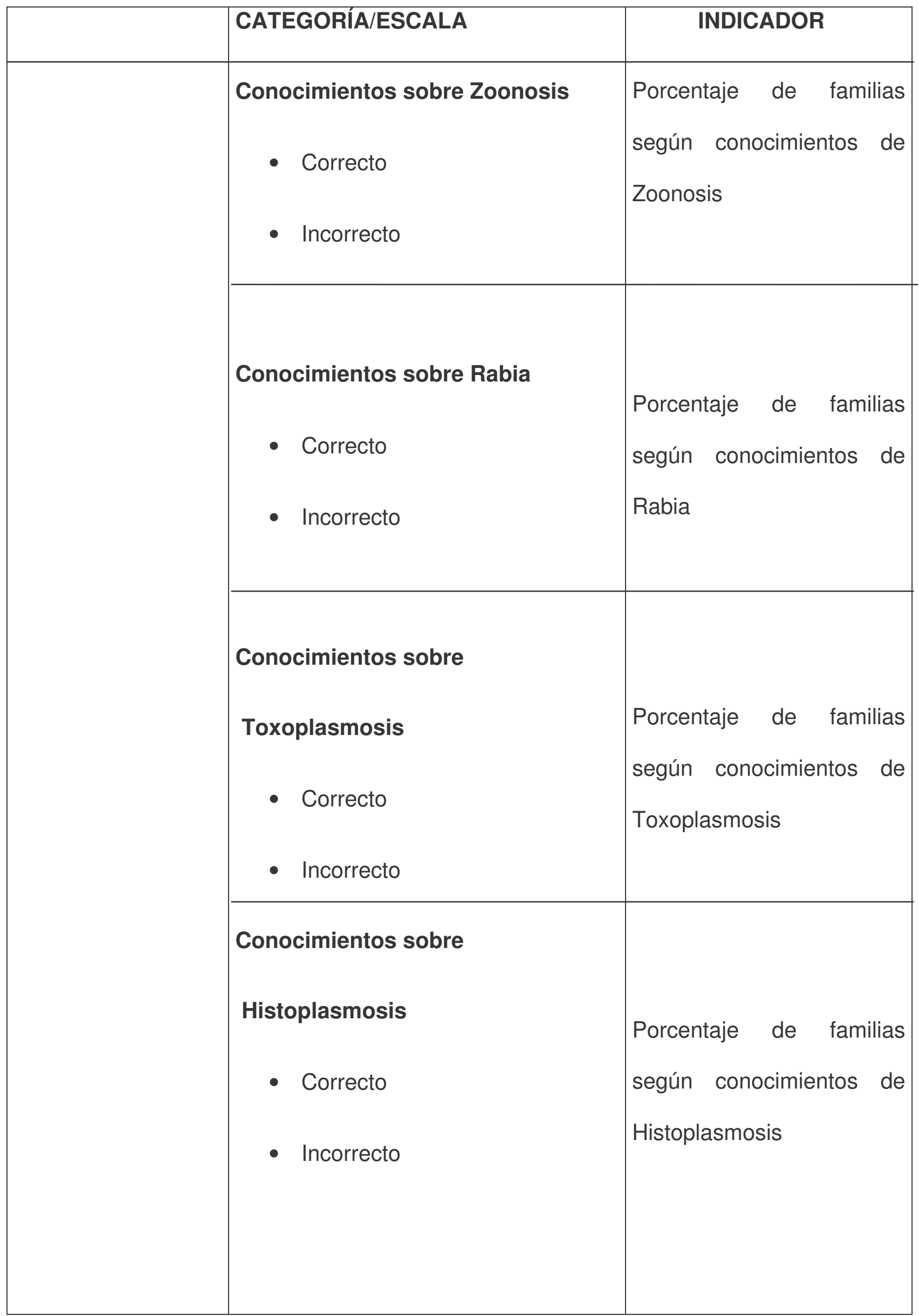




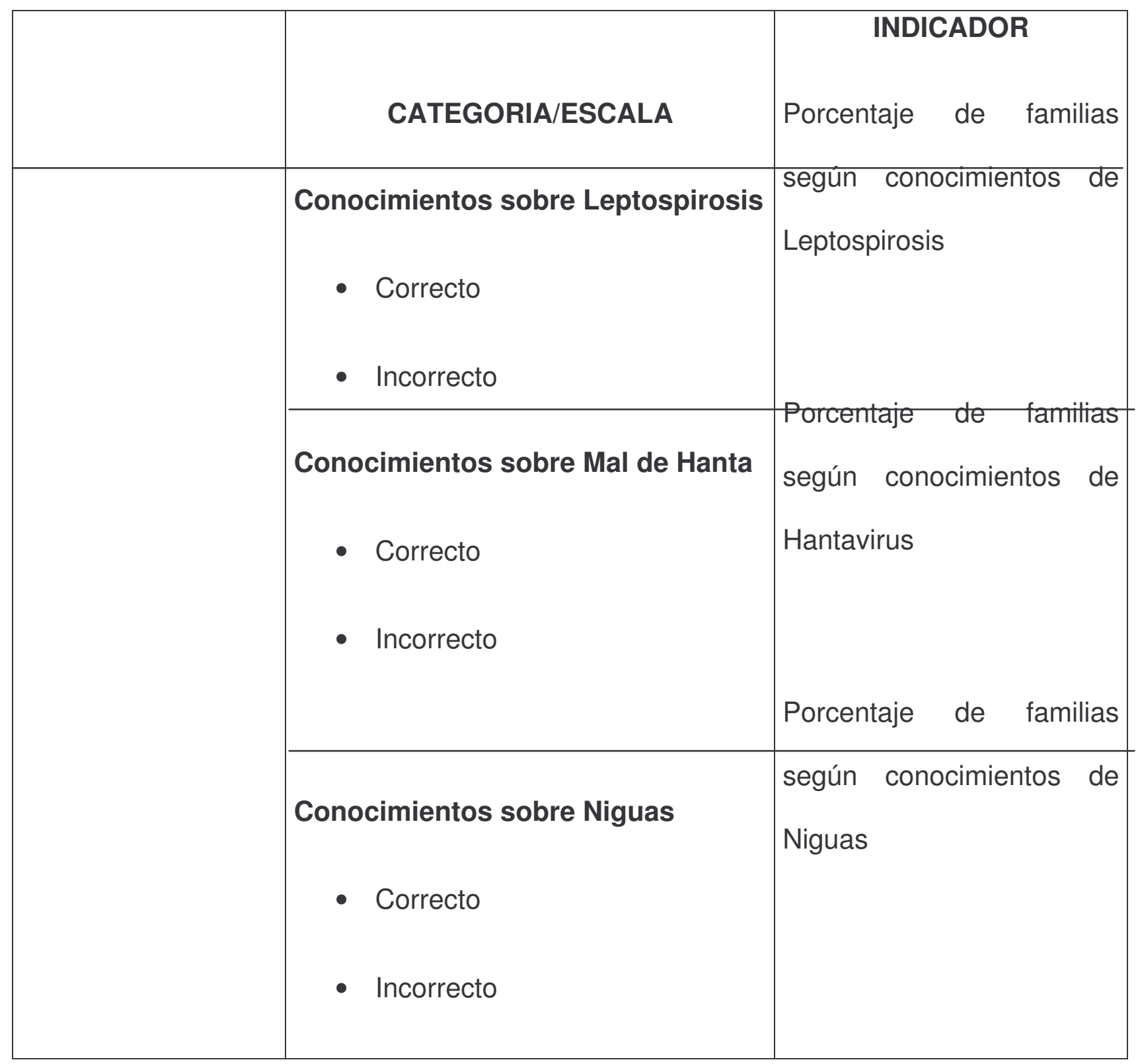




\section{C.- TIPO DE DISEÑO DE LA INVESTIGACIÓN}

Este estudio tuvo un Diseño descriptivo de corte

\section{D.-. POBLACIÓN, MUESTRA O GRUPO DE ESTUDIO}

Se trabajó con las 40 familias de cobertura Plan Internacional

\section{E.- DESCRIPCIÓN DE PROCEDIMIENTOS}

Para cumplir con el objetivo $\mathrm{N}^{\circ} 1$ y 3 . "Identificar las características socio demográficas del grupo de estudio" y "Diagnosticar el nivel de conocimientos sobre La Zoonosis, se realizó una búsqueda de información sobre sexo, edad, mujeres embarazadas y en edad fértil, nivel de conocimientos de las familias, y se aplicó una encuesta a una muestra de las familias de la comunidad. (ver Anexo $\mathrm{N}^{\circ 1}$ )

Para cumplir con el objetivo $\mathrm{N}$ ² "Determinar los principales factores de riesgo de las familias y la comunidad". Se realizó una encuesta a una muestra de las familias de la comunidad en estudio. (Ver anexo $\left.N^{\circ} 1\right)$

Para cumplir con el objetivo $\mathrm{N}^{\circ} 4$ y 5 "Ejecutar el Programa Educativo" y Evaluar el Programa Educativo" la metodología a utilizar fueron talleres Teórico-prácticos con programación estructurada de acuerdo al diagnóstico que se obtuvo de las encuestas, se trabajó con una guía didáctica, planes de clase, lluvia de ideas, sociodramas, y se realizó en la Guardería de la Comunidad con la participación de una muestra tomada a conveniencia de 40 
familias de la comunidad. Al finalizar los talleres se evaluó Cuantitativamente en base a la retroalimentación y en base a un test.

Para cumplir con el Objetivo $N^{\circ} 1,2$ y 3 . Se diseñó un formulario para la validación de las encuestas, esta validación fue realizada por un experto en la temática, un profesional de Plan Internacional, y un dos docente de la Facultad de salud Pública, posteriormente los formularios fueron calificados según los criterios de cada profesional. (Ver Anexo 2).

La encuesta fue modificada según la validación de los expertos. Por lo que la recolección de la información se realizó mediante la encuesta validada.

Para realizar el procesamiento de los datos que se recolectaron se utilizó el programa Microsoft Excel 2007. 
VI RESULTADOS Y DISCUSIÓN

\section{A.- CARACTERÍSTICAS SOCIO DEMOGRÁFICAS}

1. EDAD.

Tabla No 1

EDAD DE LAS MADRES DE FAMILIA DE LA COMUNIDAD DE SAN ROQUE. PERTENECIENTE AL CANTÓN SUCRE PARROQUIA CHARAPOTÓ. PROVINCIA DE MANABí.2011

\begin{tabular}{lll}
\hline EDAD & $\mathbf{f}$ & $\%$ \\
$\mathbf{1 2 2 2}$ & 20 & $50 \%$ \\
$\mathbf{2 3 - 3 3}$ & 8 & $20 \%$ \\
$\mathbf{3 4 - 4 4}$ & 5 & $12 \%$ \\
$\mathbf{4 5 - 5 5}$ & 4 & $10 \%$ \\
$\mathbf{5 6 - 6 5}$ & 3 & $8 \%$ \\
TOTAL & 40 & $\mathbf{1 0 0}$ \\
\hline
\end{tabular}




\section{Gráfico No 1}

EDAD DE LAS MADRES DE FAMILIA DE LA COMUNIDAD DE SAN

ROQUE. PERTENECIENTE AL CANTÓN SUCRE PARROQUIA

CHARAPOTÓ. PROVINCIA DE MANABÍ.2011

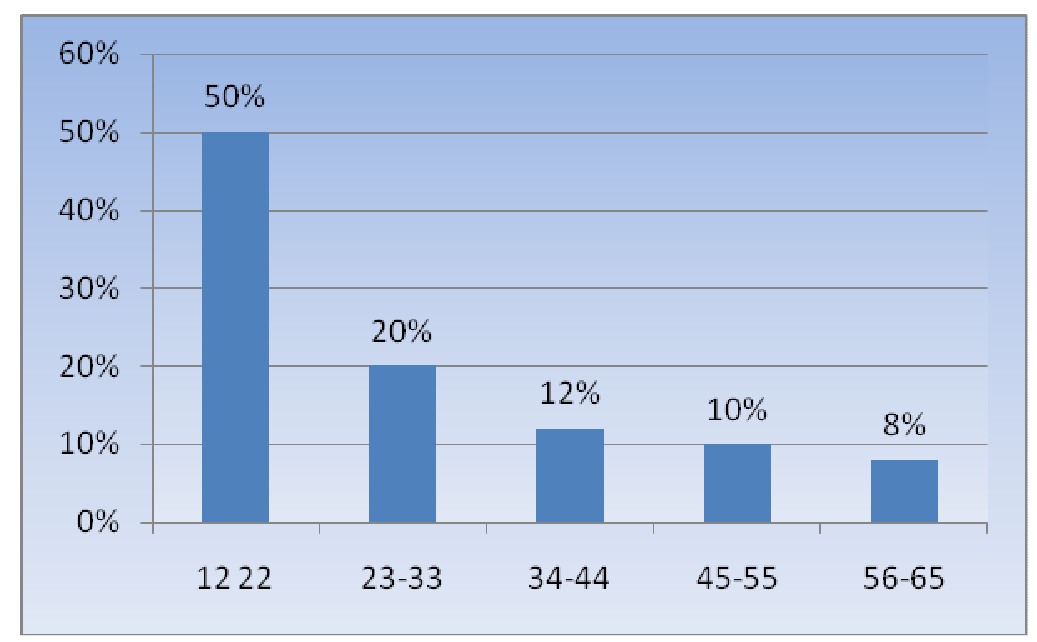

Fuente: Tabla No 1

El $50 \%$ del total de la muestra de 40 madres de familia encuestadas de la Comunidad de San Roque se encuentran en un rango de edad de 12 a 22 años, el $20 \%$ en un rango de 23 a 33 años; sólo el $8 \%$ se encuentran en un rango de 55 a 65 años.

En esta comunidad la mayor parte de la población es relativamente joven. Como en el caso de la Provincia de Manabí según datos estadísticos del INEC Manabí es la tercera provincia con mayor población en el Ecuador la población total es 1.370.734 habitantes y, gran parte de la población se encuentra en el sector rural pese al crecimiento acelerado de la población urbana. Los habitantes de esta provincia son relativamente jóvenes. 
2.

Escolaridad

Tabla No 2

ESCOLARIDAD DE LAS MADRES DE FAMILIA DE LA COMUNIDAD DE

SAN ROQUE. PERTENECIENTE AL CANTÓN SUCRE PARROQUIA CHARAPOTÓ. PROVINCIA DE MANABÍ.2011

\begin{tabular}{lcc}
\hline Escolaridad & $\mathbf{f}$ & $\%$ \\
Primaria & 17 & $42 \%$ \\
Secundaria & 10 & $25 \%$ \\
Ninguna & 13 & $33 \%$ \\
TOTAL & 40 & $100 \%$ \\
\hline
\end{tabular}

Fuente: datos de la encuesta aplicada 


\section{Gráfico No 2}

\section{ESCOLARIDAD DE LAS MADRES DE FAMILIA DE LA COMUNIDAD DE SAN ROQUE. PERTENECIENTE AL CANTÓN SUCRE PARROQUIA CHARAPOTÓ. PROVINCIA DE MANABÍ.2011}

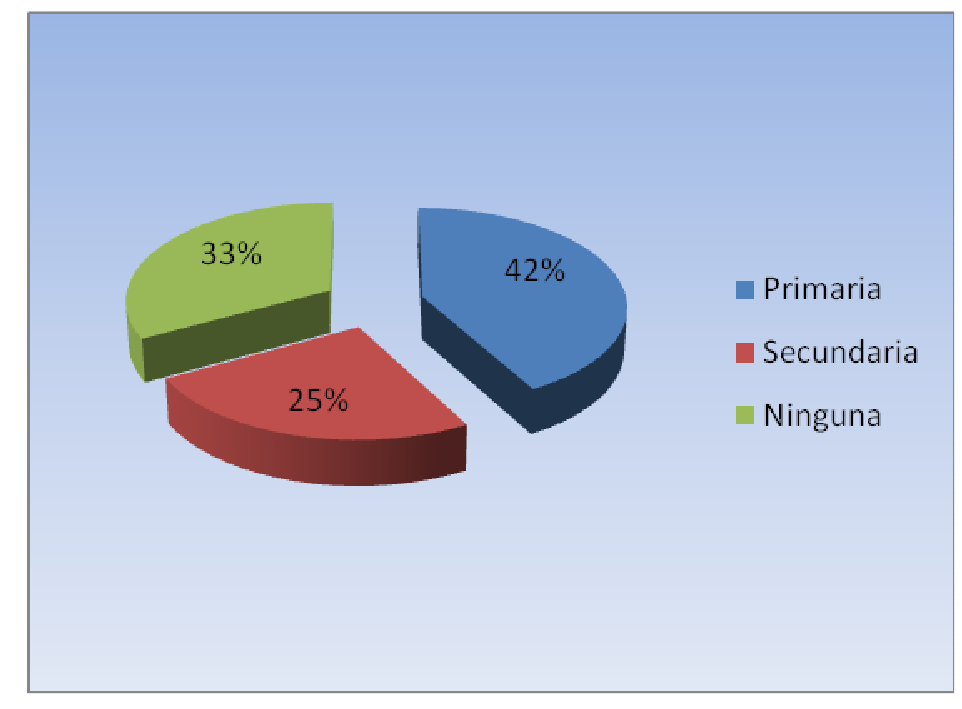

Fuente: tabla No 2

El $42 \%$ del total de la muestra de 40 madres de familia encuestadas que corresponde al mayor porcentaje únicamente han culminado la Primaria frente a un $33 \%$ que no han estudiado.

Existe un alto índice de analfabetismo que es preocupante, la falta de educación es uno de los principales factores de riesgo para que se presenten los problemas de salud como la insalubridad y la zoonosis por la falta de conocimientos sobre manejo adecuado de animales domésticos y de granja.

La prevalencia de enfermedades zoonóticas, va relacionada con la falta de educación que lleva a bajos condiciones de vida, falta de higiene y 
saneamiento en las familias, además de la escasez de recursos económicos que existen en la comunidad.

3. Embarazadas

Tabla No 3

EMBARAZADAS DE LA COMUNIDAD DE SAN ROQUE. PERTENECIENTE AL CANTÓN SUCRE PARROQUIA CHARAPOTÓ. PROVINCIA DE MANABÍ.2011

\begin{tabular}{lll}
\hline Embarazadas & $\mathbf{f}$ & $\%$ \\
Si & 28 & $70 \%$ \\
No & 12 & $30 \%$ \\
TOTAL & 40 & $100 \%$ \\
\hline
\end{tabular}

Fuente: datos de la encuesta aplicada 


\section{Gráfico No 3}

\section{EMBARAZADAS DE LA COMUNIDAD DE SAN ROQUE. PERTENECIENTE}

AL CANTÓN SUCRE PARROQUIA CHARAPOTÓ. PROVINCIA DE MANABí.2011

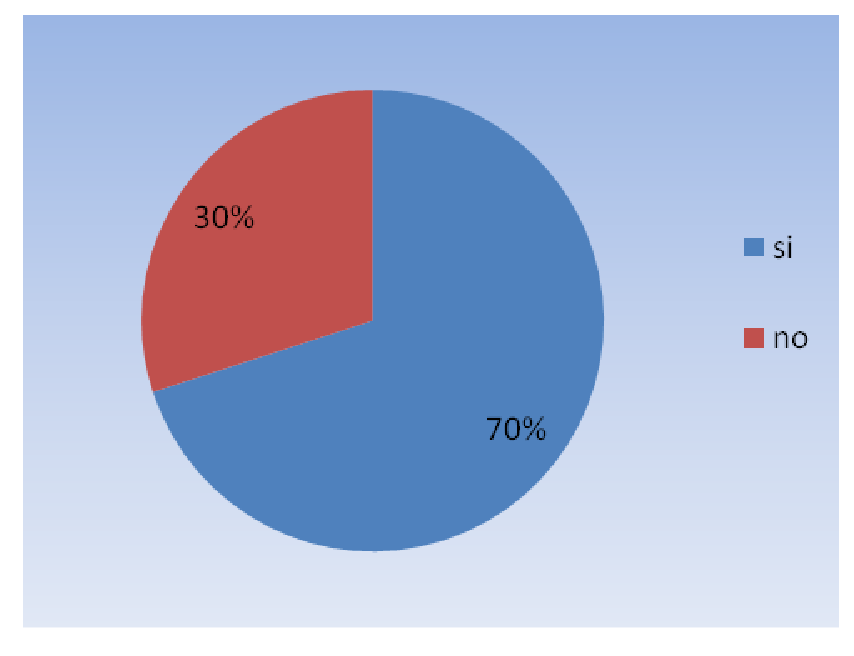

Fuente: tabla No 3

En la comunidad de San Roque mediante una muestra de 40 madres de familia el $70 \%$ de mujeres están Embarazadas o tienen embarazadas en el hogar frente a un $30 \%$ que no están embarazadas.

La comunidad manifiesta que en la actualidad la tasa de natalidad ha aumentado en relación a la tasa de mortalidad.

Existen un alto porcentaje de mujeres embarazadas las cuales se encuentran dentro de la población vulnerable a adquirir algún problema de zoonosis; una zoonosis en las mujeres embarazadas, pueden causar aborto involuntario o lesiones como malformaciones en el feto a través de la madre; y el escenario se agrava aún más si el embarazo es el primero. 
B.- DATOS HIGIÉNICOS SANITARIOS

4. ANIMALES DOMÉSTICOS

Tabla No 4

ANIMALES DOMÉSTICOS QUE TIENEN LAS MADRES DE FAMILIA DE LA COMUNIDAD DE SAN ROQUE PERTENECIENTE AL CANTÓN SUCRE PARROQUIA CHARAPOTÓ. PROVINCIA DE MANABÍ. 2011.

\begin{tabular}{ccc}
\hline Animal & $\mathbf{f}$ & $\%$ \\
Perro y gato & 30 & $75 \%$ \\
Perro & 5 & $12 \%$ \\
Gato & 4 & $10 \%$ \\
Otros & 1 & $3 \%$ \\
TOTAL & 40 & $100 \%$ \\
\hline
\end{tabular}

Fuente: datos de la encuesta aplicada 


\section{Gráfico No 4}

\section{ANIMALES DOMÉSTICOS QUE TIENEN LAS MADRES DE FAMILIA DE LA COMUNIDAD DE SAN ROQUE PERTENECIENTE AL CANTÓN SUCRE}

PARROQUIA CHARAPOTÓ. PROVINCIA DE MANABÍ. 2011

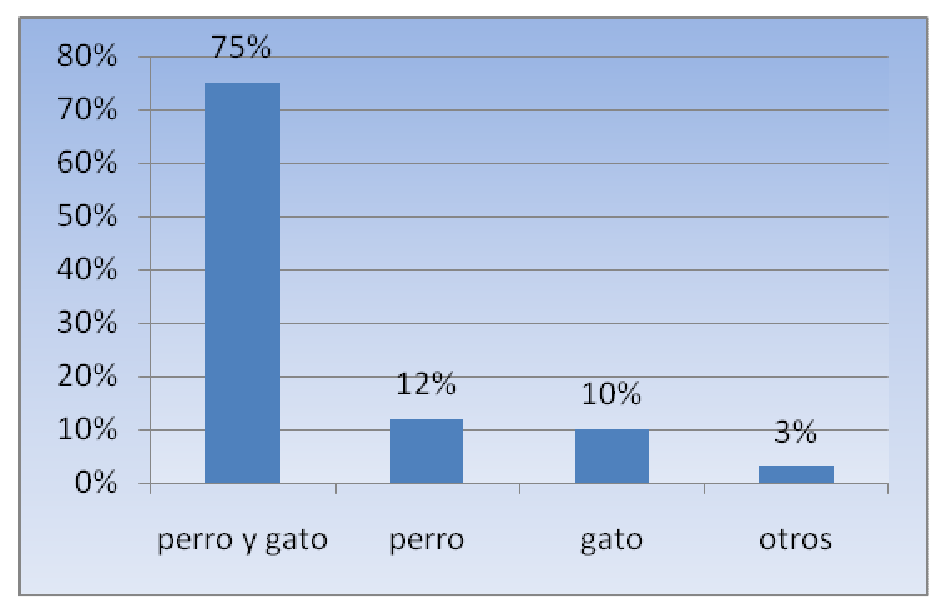

Fuente: tabla No 4

En la comunidad el $75 \%$ de las madres de familia encuestadas tienen en sus viviendas perro y gato que corresponde al mayor porcentaje; un $12 \%$ tienen en sus viviendas solo perro y el $10 \%$ gatos.

EL porcentaje de perros y gatos en la comunidad de San Roque es alto, lo que constituye un factor de riesgo para contraer alguna zoonosis como toxoplasmosis cuyo principal agente transmisor es el gato; y la rabia cuyo agente transmisor es el perro. Es por eso que se observa que "la Costa ocupa el tercer lugar entre las regiones con respecto a problemas zoonóticos (27.9\%)". Por estar en continuo contacto las personas con animales domésticos. 
Ante esta elevada tasa de animales domésticos en la Comunidad lo más recomendable es que se apliquen las respectivas medidas sanitarias a los animales, especialmente porque estos se encuentran en continuo contacto con las personas.

5.-. UTILIDAD DE LOS ANIMALES DOMÉSTICOS

TABLA No.5

UTILIDAD DE ANIMALES DOMÉSTICOS QUE TIENEN LAS MADRES DE FAMILIA DE LA COMUNIDAD DE SAN ROQUE PERTENECIENTE AL CANTÓN SUCRE PARROQUIA CHARAPOTÓ. PROVINCIA DE MANABÍ.2011

\begin{tabular}{ccc}
\hline $\begin{array}{c}\text { Utilidad animales } \\
\text { domésticos }\end{array}$ & $\mathbf{f}$ & $\%$ \\
Cuidar la casa & 28 & $70 \%$ \\
Cazar Ratones & 5 & $12 \%$ \\
Mascota & 2 & $5 \%$ \\
TOTAL & 40 & $100 \%$ \\
\hline
\end{tabular}

Fuente: datos de la encuesta 


\section{GRÁFICO No 5}

\section{UTILIDAD DE ANIMALES DOMÉSTICOS QUE TIENEN LAS MADRES DE}

FAMILIA DE LA COMUNIDAD DE SAN ROQUE PERTENECIENTE AL CANTÓN SUCRE PARROQUIA CHARAPOTÓ. PROVINCIA DE MANABÍ.2011

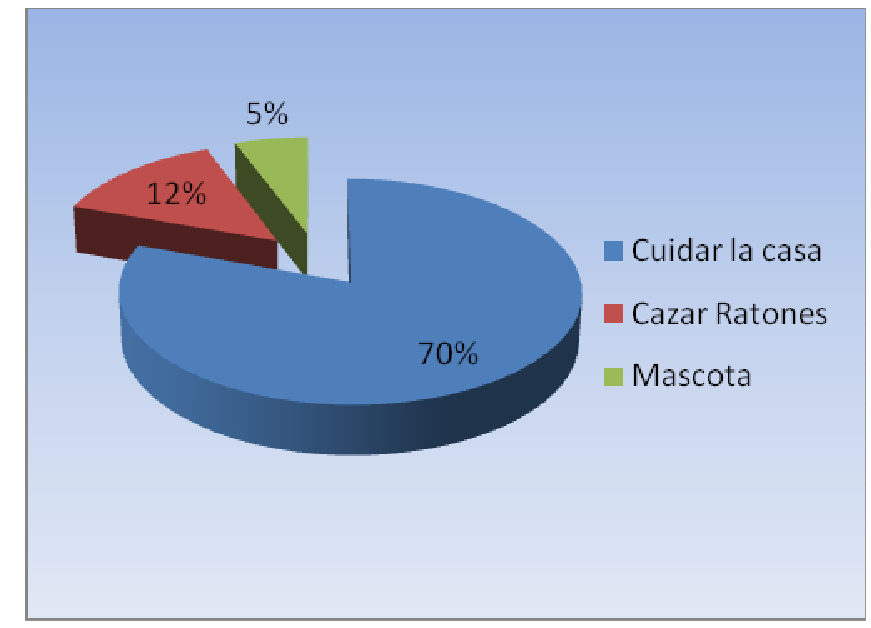

Fuente: tabla No 5

La población encuestada tienen animales domésticos por las siguientes razones: el $70 \%$ para cuidar la casa, el $25 \%$ cazar roedores, el $5 \%$ como mascota.

Como se observa en el gráfico la mayoría se la población encuestada tiene a los animales domésticos para cuidar la casa de la delincuencia existente y para cazar roedores que muchas veces ingresan a la vivienda y que son causantes de enfermedades. 
El clima de Portoviejo oscila entre subtropical seco y tropical húmedo lo que ocasiona hace que los roedores se reproduzcan más rápidamente con relación a la sierra.

Es recomendable que tanto gatos y perros se los vacune y desparasite periódicamente para evitar zoonosis como la rabia y la toxoplasmosis por estar expuestos a infecciones y enfermedades causadas por la insalubridad.

6.- PERSONAS DE LA FAMILIA QUE TIENEN CONTACTO DIRECTO CON PERROS EN EL HOGAR

Tabla No. 6

PERSONAS DE LA FAMILIA QUE TIENEN CONTACTO DIRECTO CON PERROS EN EL HOGAR EN LA COMUNIDAD DE SAN ROQUE PERTENECIENTE AL CANTÓN SUCRE PARROQUIA CHARAPOTÓ. PROVINCIA DE MANABÍ. 2011

\begin{tabular}{lll}
\hline VARIABLE & $\mathbf{f}$ & PORCENTAJE \\
Niños & 37 & $92 \%$ \\
Adultos & 3 & $8 \%$ \\
TOTAL & 40 & $100 \%$ \\
\hline
\end{tabular}

Fuente: datos de la encuesta aplicada 
Gráfico No 6

PERSONAS DE LA FAMILIA QUE TIENEN CONTACTO DIRECTO CON

PERROS EN EL HOGAR EN LA COMUNIDAD DE SAN ROQUE

PERTENECIENTE AL CANTÓN SUCRE PARROQUIA CHARAPOTÓ.

PROVINCIA DE MANABÍ. 2011

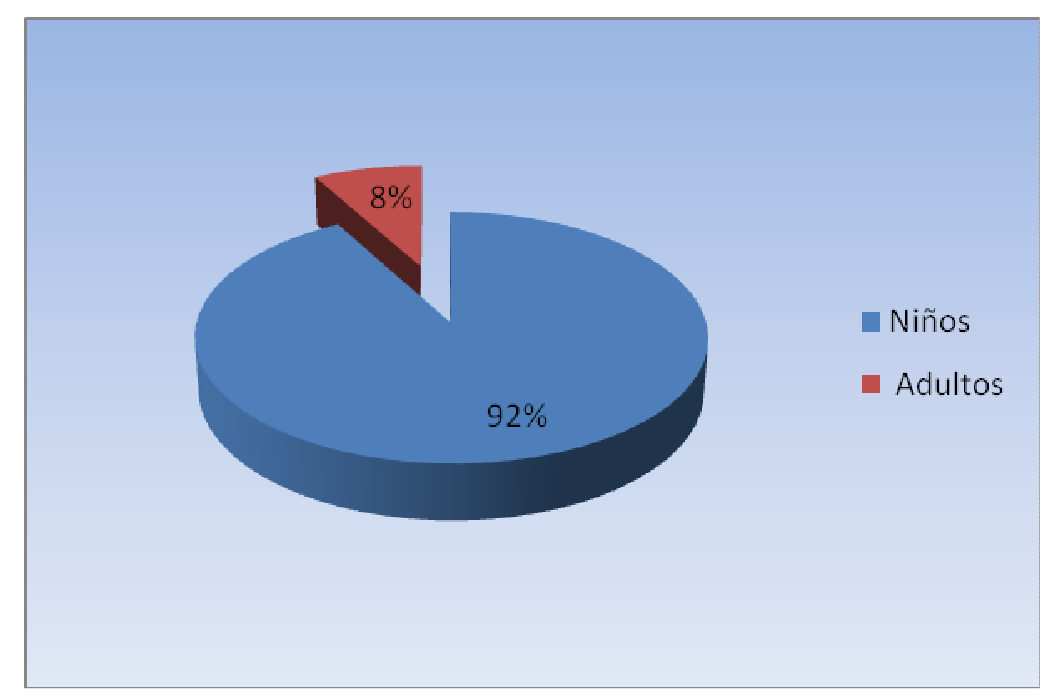

Fuente: Tabla No 6

Las madres encuestadas de la comunidad respondieron que el $92 \%$ de los niños tiene contacto con los perros, y el $8 \%$ de los adultos.

Las madres de familia manifiestan que las razones por las que los niños están en mayor contacto con los perros son las siguientes: juegan con ellos, son graciosos, llaman su atención.

Como se demuestra en el gráfico los niños son quienes mantienen mayor contacto con los animales en este caso el perro. 
El Desconocimiento de las madres y el analfabetismo son una de las causas por las que en las familias no se aplican medidas de prevención como la higiene de los animales y de los niños luego de estar en contacto con estos; penosamente los más afectados son los niños, los que se encuentran dentro de la población Vulnerable a sufrir problemas de zoonosis porque sus defensas todavía no se han desarrollado completamente.

Ante este problema lo mar recomendable sería que se apliquen las medidas de prevención como el correcto lavado y desinfección con alcohol de manos luego de manipular a los animales y aplicar una higiene adecuada a los animales.

\section{7.- PERSONAS DE LA FAMILIA QUE TIENEN CONTACTO DIRECTOS CON GATOS EN EL HOGAR}

Tabla No 7

PERSONAS DE LA FAMILIA QUE TIENEN CONTACTO DIRECTO CON

GATOS EN EL HOGAR EN LA COMUNIDAD DE SAN ROQUE

PERTENECIENTE AL CANTÓN SUCRE PARROQUIA CHARAPOTÓ.

PROVINCIA DE MANABÍ. 2011

\begin{tabular}{ccc}
\hline VARIABLE & $\mathbf{f}$ & PORCENTAJE \\
Niños & 39 & $98 \%$ \\
Adultos & 1 & $2 \%$ \\
TOTAL & $4 \%$ & $100 \%$ \\
\hline
\end{tabular}

Fuente: datos de la encuesta aplicada 
Gráfico No 7

DE LA FAMILIA QUE TIENEN CONTACTO DIRECTO CON GATOS EN EL HOGAR EN LA COMUNIDAD DE SAN ROQUE PERTENECIENTE AL

CANTÓN SUCRE PARROQUIA CHARAPOTÓ. PROVINCIA DE MANABÍ.2011

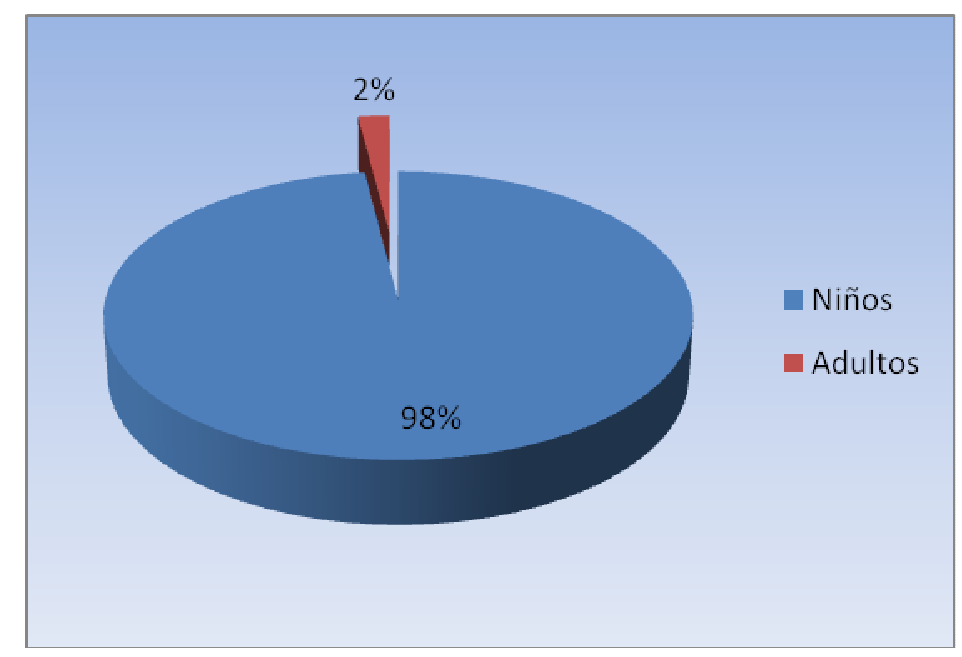

Fuente: Tabla No 7

Las madres encuestadas de la comunidad respondieron que el $98 \%$ de los niños mantienen mayor contacto con los gatos en el hogar y un $2 \%$ los adultos.

Según las madres las razones por las que los niños están en contacto con los felinos son las siguientes: juegan con ellos, llaman su atención, les gustan.

Por esta razón los niños son una población en riesgo de contraer una zoonosis, especialmente si a los gatos no se les tiene con las debidas medidas higiénico-sanitarias. 
Es por esta razón que a los gatos obligatoriamente deberían bañarlos, vacunarlos y desparasitarlos; porque estos al ser cazadores se convierten en la principal fuente de infección para que se dé una zoonosis si no se les cuida y asea

8.- HIGIENE DEL LUGAR DONDE COME EL PERRO Y EL GATO

Tabla No 8

HIGIENE DEL LUGAR DONDE COME EL PERRO Y GATO EN LA

COMUNIDAD DE SAN ROQUE PERTENECIENTE AL CANTÓN SUCRE

PARROQUIA CHARAPOTÓ. PROVINCIA DE MANABÍ. 2011

\begin{tabular}{llc}
\hline VARIABLE & $\mathbf{f}$ & $\%$ \\
$\mathrm{Si}$ & 6 & $15 \%$ \\
No & 34 & $85 \%$ \\
TOTAL & $\mathbf{4 0}$ & $\mathbf{1 0 0 \%}$
\end{tabular}

Fuente: datos de la encuesta aplicada 


\section{Gráfico No 8}

\section{HIGIENE DEL LUGAR DONDE COME EL PERRO Y GATO EN LA COMUNIDAD DE SAN ROQUE PERTENECIENTE AL CANTÓN SUCRE}

PARROQUIA CHARAPOTÓ. PROVINCIA DE MANABÍ. 2011

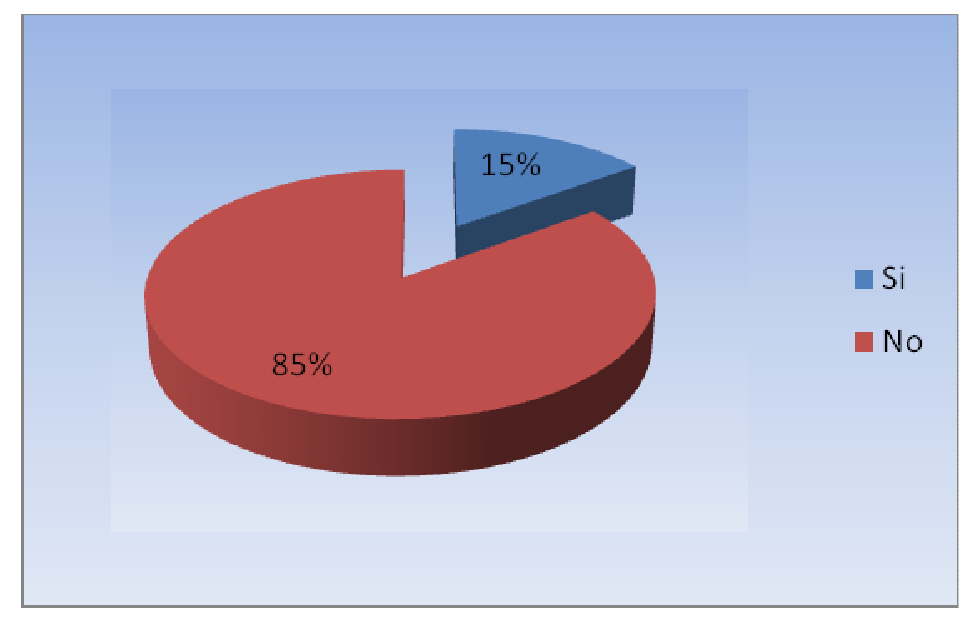

Fuente: Tabla No 8

El $85 \%$ de las madres encuestadas no limpian ni desinfectan el plato donde come el perro, frente a un $15 \%$ que si lo hace.

Como se observa en el gráfico la mayor parte de la población encuestada no limpia ni desinfecta el lugar donde come el perro, convirtiéndose estos recipientes en reservorios de parásitos causantes de parasitosis en los animales, y en una fuente de infección para los que se encuentran en contacto con estos que por lo general son los niños según manifiestan las madres de familia encuestadas.

La falta de educación y de enseñanza aprendizaje en las madres de la comunidad es la causa de este problema de insalubridad por lo que se debería 
capacitar e incentivar técnicamente la práctica de condiciones y estilos de vida saludables donde prime la higiene ante todo.

9.-HIGIENE DEL LUGAR DONDE DEFECA EL PERRO

Tabla No 9

HIGIENE DEL LUGAR DONDE DEFECA EL PERRO EN LA COMUNIDAD DE SAN ROQUE PERTENECIENTE AL CANTÓN SUCRE. PARROQUIA CHARAPOTÓ. PROVINCIA DE MANABÍ. 2011

\begin{tabular}{lll}
\hline VARIABLE & $\mathbf{f}$ & $\%$ \\
Si & 10 & $25 \%$ \\
No & 30 & $75 \%$ \\
TOTAL & $\mathbf{4 0}$ & $\mathbf{1 0 0 \%}$
\end{tabular}

Fuente: Datos de la encuesta aplicada 
Gráfico No 9

HIGIENE DEL LUGAR DONDE DEFECA EL PERRO EN LA COMUNIDAD DE SAN ROQUE PERTENECIENTE AL CANTÓN SUCRE. PARROQUIA CHARAPOTÓ. PROVINCIA DE MANABÍ. 2011

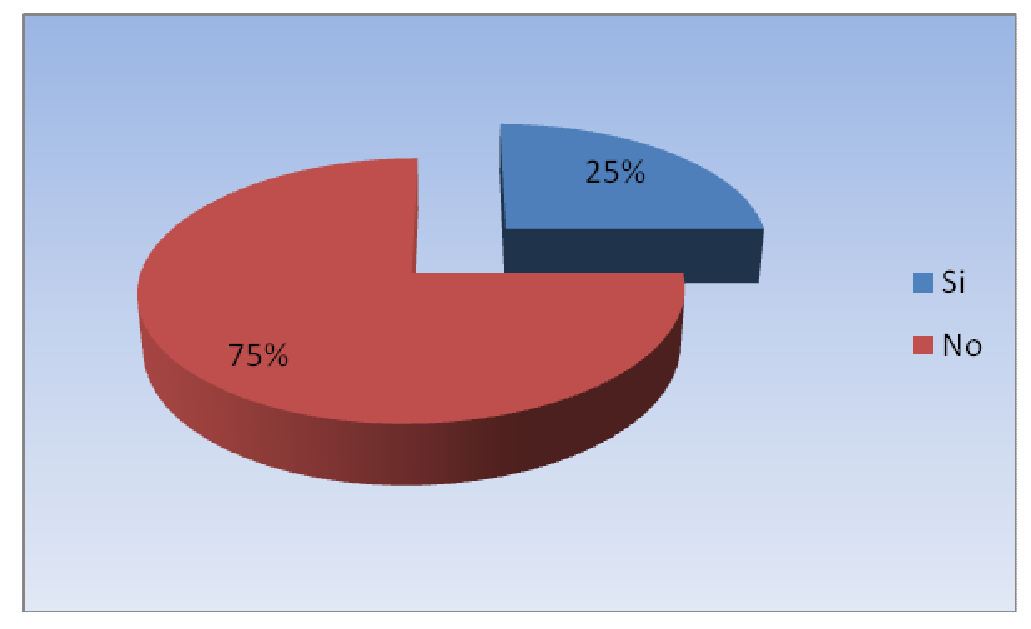

Fuente: Tabla No 9

El $75 \%$ de las madres encuestadas no limpia ni desinfecta el lugar donde defeca el perro, frente a un $25 \%$ que es un menor porcentaje que si lo hace.

Las mayorías de las madres manifiestan que no limpian el lugar donde el perro hace sus necesidades biológicas por las siguientes razones: andan sueltos, no tiene un lugar fijo donde hacer sus necesidades, van por el campo, y desinterés.

La leptospirosis es una enfermedad ocasionada por la orina de los animales como perros, caballos, mulas especialmente en épocas de lluvia y la población debe evitar los lugares de agua con presencia de orina de animales, como ríos, quebradas y pozas. 
En épocas de lluvias que con el calor se evapora y se producen infecciones virales.

10.- HIGIENE DEL LUGAR DONDE DEFECA EL GATO

Tabla No 10

HIGIENE DEL LUGAR DONDE DEFECA EL GATO EN LA COMUNIDAD DE SAN ROQUE PERTENECIENTE AL CANTÓN SUCRE. PARROQUIA CHARAPOTÓ. PROVINCIA DE MANABÍ. 2011

\begin{tabular}{lll}
\hline VARIABLE & $\mathbf{f}$ & $\%$ \\
Si & 8 & $20 \%$ \\
No & 32 & $80 \%$ \\
TOTAL & 40 & $100 \%$ \\
\hline
\end{tabular}

Fuente: datos de la encuesta 
Gráfico No 10

HIGIENE DEL LUGAR DONDE DEFECA EL GATO EN LA COMUNIDAD DE SAN ROQUE PERTENECIENTE AL CANTÓN SUCRE. PARROQUIA CHARAPOTÓ. PROVINCIA DE MANABÍ. 2011.

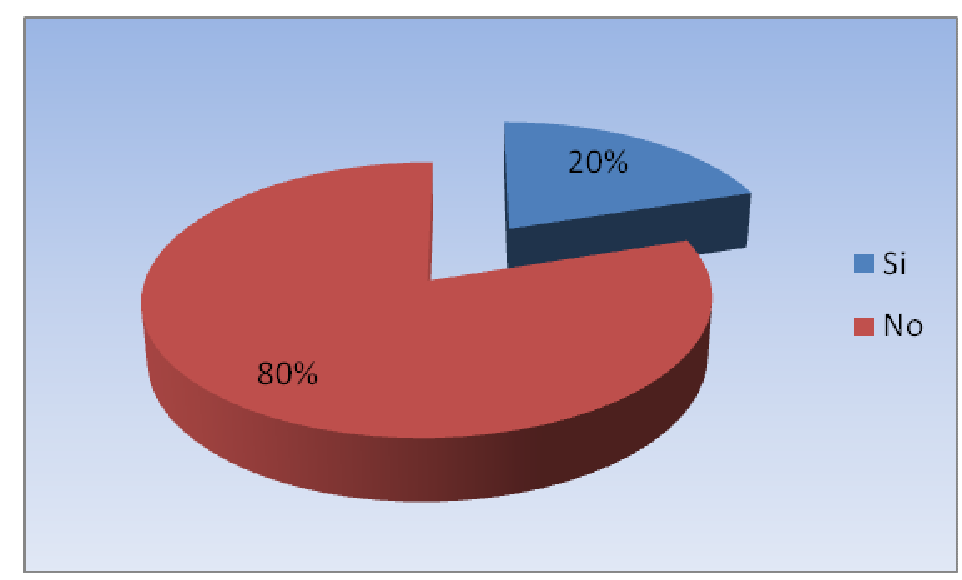

Fuente: Tabla No 10

El $80 \%$ de madres no limpia ni desinfecta el lugar donde defeca el gato, un $20 \%$ si lo hace.

El que no se limpie y desinfecte el lugar donde defeca el gato puede ser debido a que estos andan libres y en las zonas rurales existe campo abierto para los gatos y estos se encargan de enterrar las heces en la tierra. Sin embargo infectan sus patas con el virus Toxoplasma Gondii al tapar sus heces, y este virus es el causante de Toxoplasmosis que es una zoonosis muy peligrosa especialmente en poblaciones vulnerables como son niños, mujeres embarazadas y ancianos.

El analfabetismo y desconocimiento de las enfermedades es la principal causa para que se presenten casos de zoonosis. 
Es recomendable realizar una profilaxis que consiste en: aseo, vacunación y desparasitación a los felinos para prevenir una posible cadena epidemiológica.

11.- HIGIENE DEL PERRO

Tabla No 11

HIGIENE A LOS PERROS DE LAS FAMILIAS DE LA COMUNIDAD DE SAN ROQUE PERTENECIENTE AL CANTÓN SUCRE PARROQUIA CHARAPOTÓ. PROVINCIA DE MANABÍ. 2011.

\begin{tabular}{lll}
\hline VARIABLE & $\mathbf{f}$ & $\%$ \\
Si & 17 & $43 \%$ \\
No & 23 & $57 \%$ \\
TOTAL & 40 & $100 \%$ \\
\hline
\end{tabular}

Fuente: datos de la encuesta aplicada 


\section{Gráfico No 11}

\section{HIGIENE A LOS PERROS DE LAS FAMILIAS DE LA COMUNIDAD DE SAN}

ROQUE PERTENECIENTE AL CANTÓN SUCRE PARROQUIA CHARAPOTÓ. PROVINCIA DE MANABÍ. 2011.

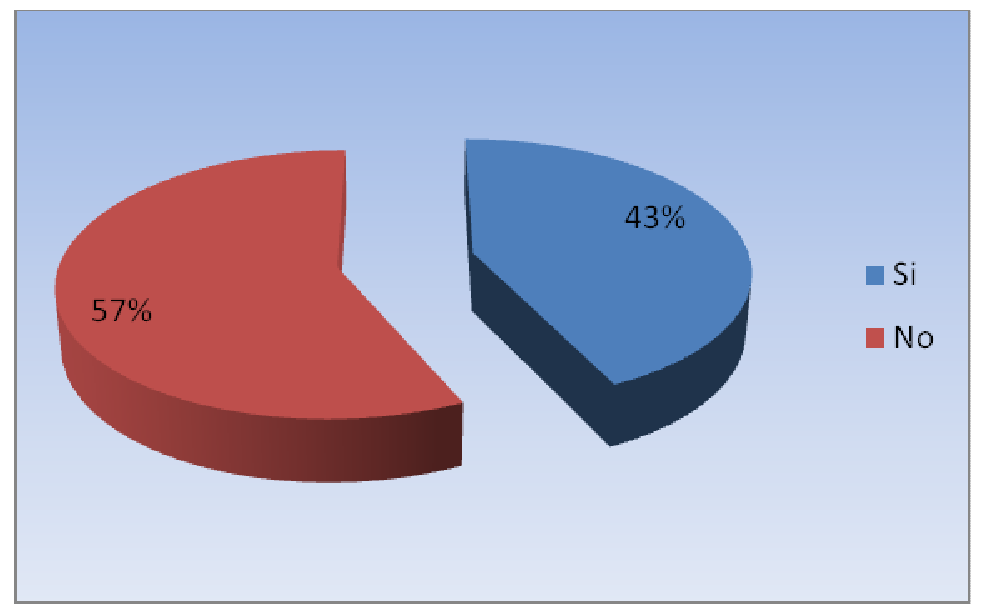

Fuente: Tabla No 11

El $57 \%$ de madres de familia encuestadas de la comunidad de San Roque no baña a los perros, un $43 \%$ de madres si lo hace.

Como se observa en el gráfico la falta de aseo periódico a los animales, en este caso el perro ocasiona que en este se presenten pulgas, sarnas, moscas, problemas de la piel convirtiéndose estos en una fuente de infección; y a los niños en agentes vulnerables a sufrir una zoonosis porque gran parte de su tiempo están en contacto con los animales en el hogar.

Las madres son las encargadas del hogar y pero muchas veces influyen las condiciones de vida, educación y saneamiento para que se apliquen medidas higiénico sanitarias en el hogar. 
Desde hace mucho tiempo el perro está ligado a la historia del hombre y su relación con él es de compañía, guardia, caza y el hecho de que estén dentro de la vivienda y en contacto especialmente con el hombre requiere de higiene y cuidado.

12.- HIGIENE DEL GATO

Tabla No 12

HIGIENE DEL GATO EN LAS FAMILIAS DE LA COMUNIDAD DE SAN ROQUE PERTENECIENTE AL CANTÓN SUCRE PARROQUIA CHARAPOTÓ. PROVINCIA DE MANABÍ. 2011.

\begin{tabular}{lll}
\hline VARIABLE & $\mathbf{f}$ & $\%$ \\
$\mathrm{Si}$ & 1 & $3 \%$ \\
Nunca & 39 & $97 \%$ \\
TOTAL & 40 & $100 \%$ \\
\hline
\end{tabular}

Fuente: datos de la encuesta aplicada 


\section{Gráfico No 12}

\section{HIGIENE DEL GATO EN LAS FAMILIAS DE LA COMUNIDAD DE SAN \\ ROQUE PERTENECIENTE AL CANTÓN SUCRE PARROQUIA \\ CHARAPOTÓ. PROVINCIA DE MANABÍ. 2011.}

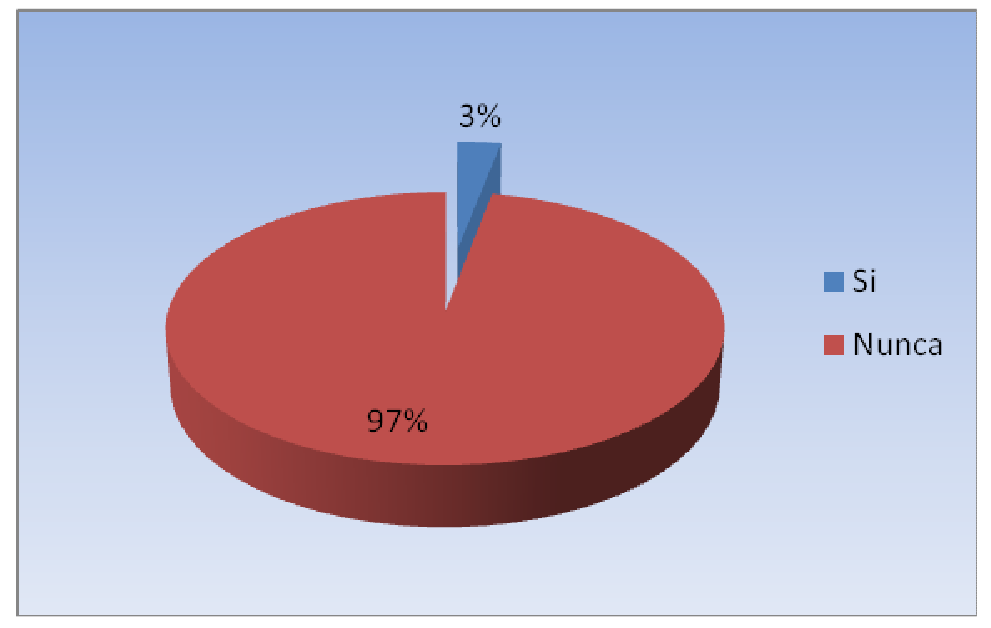

Fuente: tabla No 12

El $97 \%$ de las madres nunca ha bañado a los gatos, un $3 \%$ si los baña que es el menor porcentaje.

Las madres que no bañas a los gatos manifiestan que no lo hacen por las siguientes razones: mitos, son agresivos, no les gusta el agua.

El que sea un mito nunca bañar a los gatos, puede estar influenciada por la costumbre; al gato es el que mayor higiene debe tener en la vivienda y se lo debe acostumbrara a bañarlos desde pequeños para que no sean agresivos especialmente porque llevan los virus en sus patas que están en contacto con tierra y sus heces, que podrán ser transmitidos a los miembros de la familia 
especialmente los niños que son vulnerables a contraer infecciones al igual que mujeres embarazadas y ancianos.

Al gato no le gusta el agua. Por esta razón, es importante habituarlo al baño desde su más tierna edad, alrededor de los tres meses y la costumbre quitará su agresividad.

13.- VACUNACIÓN A LOS PERROS CONTRA LA RABIA

Tabla No 13

VACUNACIÓN A LOS PERROS CONTRA LA RABIA EN LA COMUNIDAD DE SAN ROQUE PERTENECIENTE AL CANTÓN SUCRE PARROQUIA CHARAPOTÓ. PROVINCIA DE MANABÍ. 2011.

\begin{tabular}{lll}
\hline VARIABLE & $\mathbf{f}$ & $\%$ \\
$\mathrm{Si}$ & 12 & $30 \%$ \\
No & 28 & $70 \%$ \\
TOTAL & $\mathbf{4 0}$ & $\mathbf{1 0 0 \%}$ \\
\hline
\end{tabular}

Fuente: datos de la encuesta aplicada 
VACUNACIÓN A LOS PERROS CONTRA LA RABIA EN LA COMUNIDAD DE SAN ROQUE PERTENECIENTE AL CANTÓN SUCRE PARROQUIA CHARAPOTÓ. PROVINCIA DE MANABÍ. 2011.

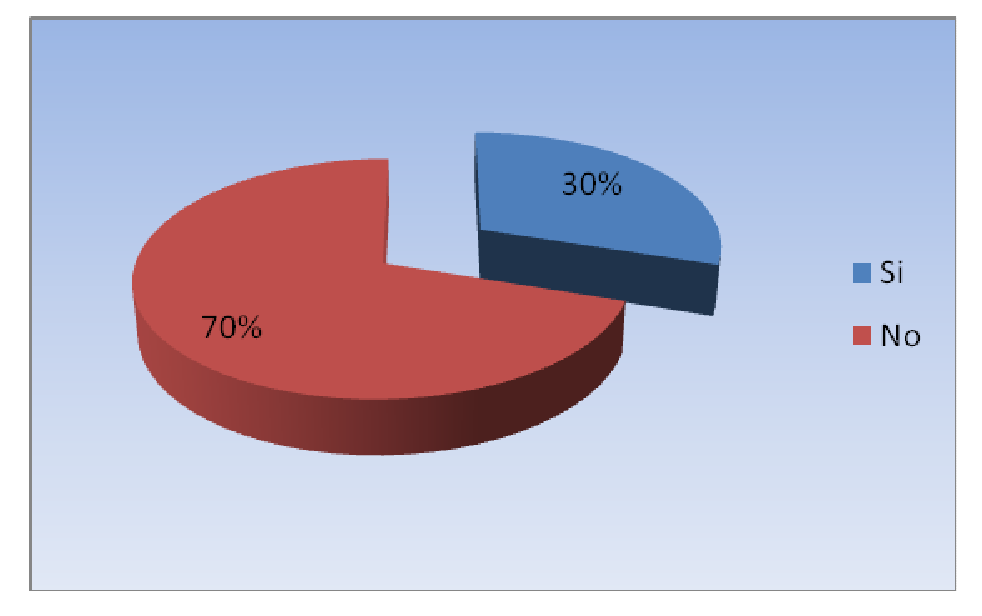

Fuente: Tabla No 13

El $70 \%$ de las madres no llevan a vacunar a los perros que tienen en la vivienda frente a un $30 \%$ que si los lleva a vacunar para evitar la rabia.

La mayor parte de madres encuestadas como se observa en el gráfico no llevan a vacunar a sus perros y están expuestas a contraer la rabia, que es una enfermedad muy peligrosa que puede trasmitirse al ser humano.

Una de las causas por las que no los vacunan podría ser: desconocimientos de la gravedad de la enfermedad, causas, consecuencias, signos y síntomas, prevención. 
Por esta razón es altamente recomendable y obligatorio, vacunar a los perros cada año.

Si un perro se pasara toda la vida encerrado dentro de la casa, no sería necesario las vacunas porque no está en contacto con otros animales que podrían llegar a contagiarlo, pero en la comunidad de San Roque es una comunidad rural de Portoviejo en donde los perros están en contacto con perros callejeros aumentando el riesgo de contraer enfermedades si no ce les vacuna.

14.- VACUNACIÓN A LOS GATOS CONTRA LA RABIA

Tabla No 14

VACUNACIÓN A LOS GATOS CONTRA LA RABIA EN LA COMUNIDAD DE SAN ROQUE PERTENECIENTE AL CANTÓN SUCRE PARROQUIA CHARAPOTÓ. PROVINCIA DE MANABÍ. 2011.

\begin{tabular}{lll}
\hline VARIABLE & $\mathbf{f}$ & $\%$ \\
Si & 15 & $38 \%$ \\
No & 25 & $62 \%$ \\
TOTAL & 40 & $100 \%$ \\
\hline
\end{tabular}

Fuente: datos de la encuesta aplicada 


\section{Gráfico No 14}

VACUNACIÓN A LOS GATOS CONTRA LA RABIA EN LA COMUNIDAD

DE SAN ROQUE PERTENECIENTE AL CANTÓN SUCRE PARROQUIA

CHARAPOTÓ. PROVINCIA DE MANABÍ. 2011.

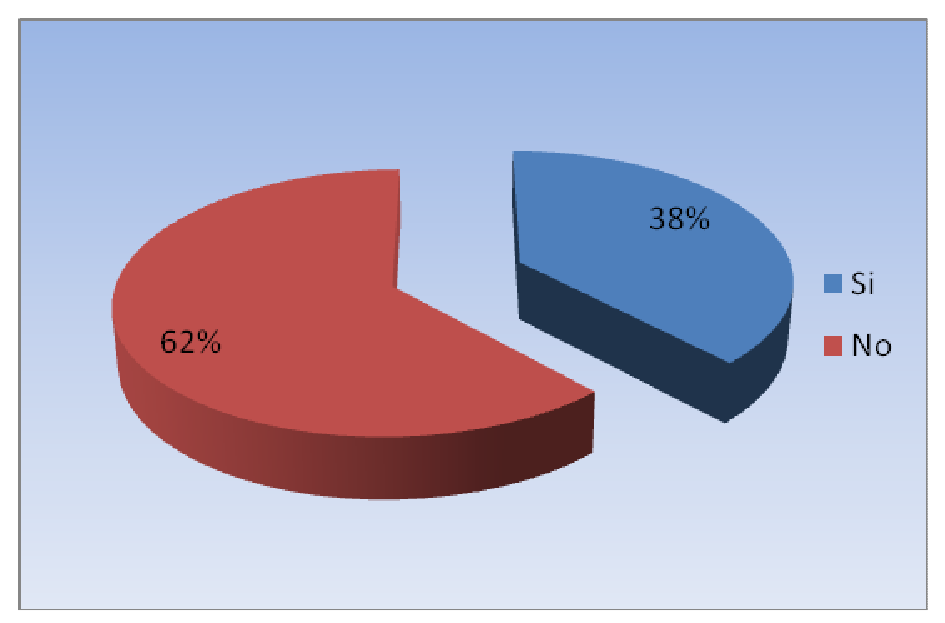

Fuente: Tabla No 14

El $62 \%$ del total de la muestra encuestada no lleva a vacunar a los gatos contra la rabia tan solo un $38 \%$ los lleva a vacunar.

Las madres no llevan a vacunar a los gatos por las siguientes razones: falta de tiempo, descuido, desinterés.

La mayoría de las madres desconocen la gravedad de esta enfermedad causándoles desinterés, y muchas veces la causa principal es la falta de información y analfabetismo existente en la comunidad, la falta de campañas de salud y capacitaciones por parte de sub centros, casas de salud, y del Ministerio de salud Pública sobre la importancia de la vacunación y las causas, consecuencias, y prevención de la rabia.

La rabia se transmite a través de mordedura o contacto directo de mucosas o heridas con saliva del animal infectado, y si no ce vacuna a los gatos en la 
comunidad se encuentran expuestos a la rabia, y especialmente porque son animales libres y cazadores por experiencia convirtiéndose en portadores de este mal.

15.- DESPARACITACIÓN A LOS PERROS

Tabla No 15

DESPARACITACIÓN A LOS PERROS EN LA COMUNIDAD DE SAN ROQUE PERTENECIENTE AL CANTÓN SUCRE PARROQUIA CHARAPOTÓ. PROVINCIA DE MANABÍ. 2011.

\begin{tabular}{lll}
\hline VARIABLE & $\mathbf{f}$ & $\%$ \\
Si & 5 & $12 \%$ \\
No & 9 & $23 \%$ \\
Nunca & 26 & $65 \%$ \\
TOTAL & 40 & $100 \%$ \\
\hline
\end{tabular}

Fuente: datos de la encuesta aplicada 
Gráfico No 15

DESPARACITACIÓN A LOS PERROS EN LA COMUNIDAD DE SAN ROQUE PERTENECIENTE AL CANTÓN SUCRE PARROQUIA CHARAPOTÓ. PROVINCIA DE MANABÍ. 2011.

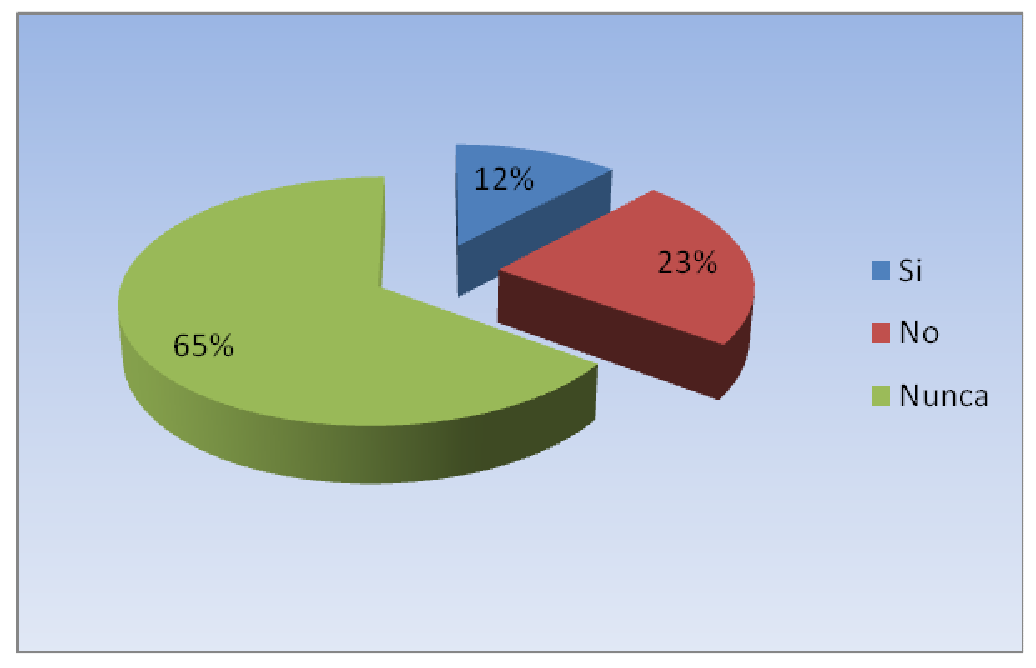

Fuente: Tabla No 15

El $65 \%$ de las madres encuestadas nunca han desparasitado a sus perros tan solo el $12 \%$ ha desparasitado alguna vez a su perro.

La causa principal podría ser desconocimiento de periodos de desparasitación, bajo recursos económicos, desinterés entre otros.

El principal factor para que no se realice la desparasitación a los animales es el desinterés que existe principalmente en la zona rural y la falta de información; el desinterés porque estos animales no aportan ningún ingreso económico en el hogar convirtiéndose en guardianes de las vivienda, y falta 
de información sobre enfermedades que estos pueden transmitir al hombre si no se los desparasita.

Los animales con los que convivimos pueden albergar parásitos tanto externos como internos. Por eso es muy recomendable que periódicamente ce desparasite a los animales con los productos adecuados.

16.- DESPARASITACIÓN A LOS GATOS

Tabla No 16

DESPARACITACIÓN A LOS GATOS EN LA COMUNIDAD DE SAN ROQUE PERTENECIENTE AL CANTÓN SUCRE PARROQUIA CHARAPOTÓ. PROVINCIA DE MANABÍ. 2011.

\begin{tabular}{lll}
\hline VARIABLE & $\mathbf{f}$ & $\%$ \\
Si & 8 & $20 \%$ \\
No & 32 & $80 \%$ \\
TOTAL & 40 & $100 \%$ \\
\hline
\end{tabular}

Fuente: datos de la encuesta aplicada 
Gráfico No 16

\section{DESPARACITACIÓN A LOS GATOS EN LA COMUNIDAD DE SAN ROQUE PERTENECIENTE AL CANTÓN SUCRE PARROQUIA CHARAPOTÓ.} PROVINCIA DE MANABÍ. 2011.

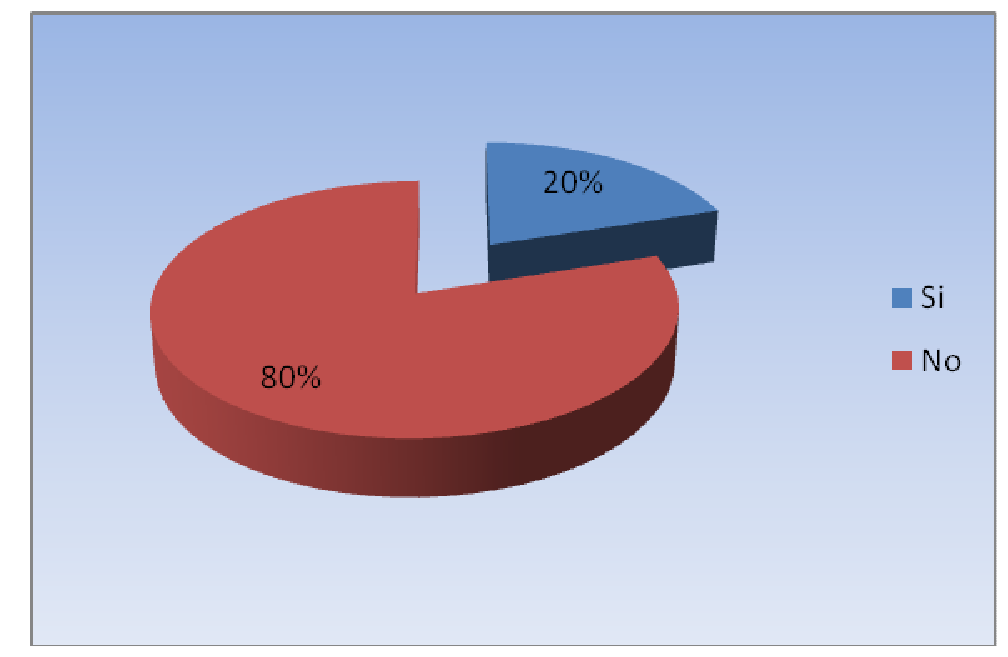

Fuente: Tabla No 17

El $80 \%$ del total de la muestra encuestada no desparasita a los gatos frente a un $20 \%$ que si lo hace.

El desinterés y la falta de información, asociada al analfabetismo constituyen factores de riego para que no se realicen programas de desparasitación a animales en este caso los felinos.

La cifra es alta de las madres de familia que no se preocupan por desparasitar a los felinos.

De ahí la gran importancia de la desparasitación interna en nuestros animales de compañía sobre todo si conviven con niños pequeños, los cuales suelen 
jugar en el suelo, en la tierra, y a veces no se lavan las manos antes de meterlas en la boca.

Los gatos al ser grandes cazadores se convierten en un factor de riesgo especialmente para quienes mantienen contacto con estos es por eso la importancia de la desparasitación como una medida de prevención de zoonosis.

17.- ANIMALES DE GRANJA

Tabla N 17

TENENCIA DE ANIMALES DE GRANJA EN LA COMUNIDAD DE SAN ROQUE PERTENECIENTE AL CANTÓN SUCRE PARROQUIA CHARAPOTÓ.PROVINCIA DE MANABÍ. 2011.

\begin{tabular}{ccc}
\hline Variable & $\mathbf{f}$ & $\%$ \\
Si & 40 & $100 \%$ \\
No & 0 & $0 \%$ \\
TOTAL & 40 & $100 \%$ \\
\hline
\end{tabular}

Fuente: datos de la encuesta aplicada

El $100 \%$ de las madres de familia encuestadas de un total de 40 tienen animales de granja que es la totalidad de la muestra encuestada.

En la comunidad de San Roque la mayor parte de la población, por estar ubicados en la zona rural se dedica a criar porcinos, ganado vacuno, y aviar para su alimentación y ayuda económica principalmente. 
Es por eso que se observa que "la Costa ocupa el tercer lugar entre las regiones con respecto a problemas zoonóticos (27.9\%)". Por la cantidad de animales existentes en las comunidades, insalubridad ocasionada por la falta de conocimientos, y el clima que ocasiona la propagación de enfermedades.

Los animales de granja requieren de cuidados como desparasitación, vacunaciones, y condiciones higiénicas sanitarias favorables, para prevenir posibles enfermedades en el ganado y en las familias. 
18.- TIPOS DE ANIMALES DE GRANJA QUE TIENEN LAS FAMILIAS

Tabla No 18

TIPOS DE ANIMALES DE GRANJA QUE TIENEN LAS FAMILIAS EN LA COMUNIDAD DE SAN ROQUE PERTENECIENTE AL CANTÓN SUCRE PARROQUIA CHARAPOTÓ.PROVINCIA DE MANABÍ. 2011

\begin{tabular}{lll}
\hline Variable & $\mathbf{f}$ & $\%$ \\
Vacas & 5 & $12 \%$ \\
Cerdos & 8 & $20 \%$ \\
Gallinas & 8 & $20 \%$ \\
Patos & 2 & $5 \%$ \\
Caballos & 3 & $7 \%$ \\
Mulas & 3 & $8 \%$ \\
Vacas y cerdos & 3 & $8 \%$ \\
cerdos y gallinas & 5 & $12 \%$ \\
vacas y gallinas & 1 & $3 \%$ \\
gallinas y patos & 2 & $5 \%$ \\
TOTAL & $\mathbf{4 0}$ & $\mathbf{1 0 0} \%$ \\
\hline
\end{tabular}

Fuente: datos de la encuesta aplicada 
GRÁFICO No 18

TIPOS DE ANIMALES DE GRANJA QUE TIENEN LAS FAMILIAS EN LA COMUNIDAD DE SAN ROQUE PERTENECIENTE AL CANTÓN SUCRE PARROQUIA CHARAPOTÓ.PROVINCIA DE MANABÍ. 2011.

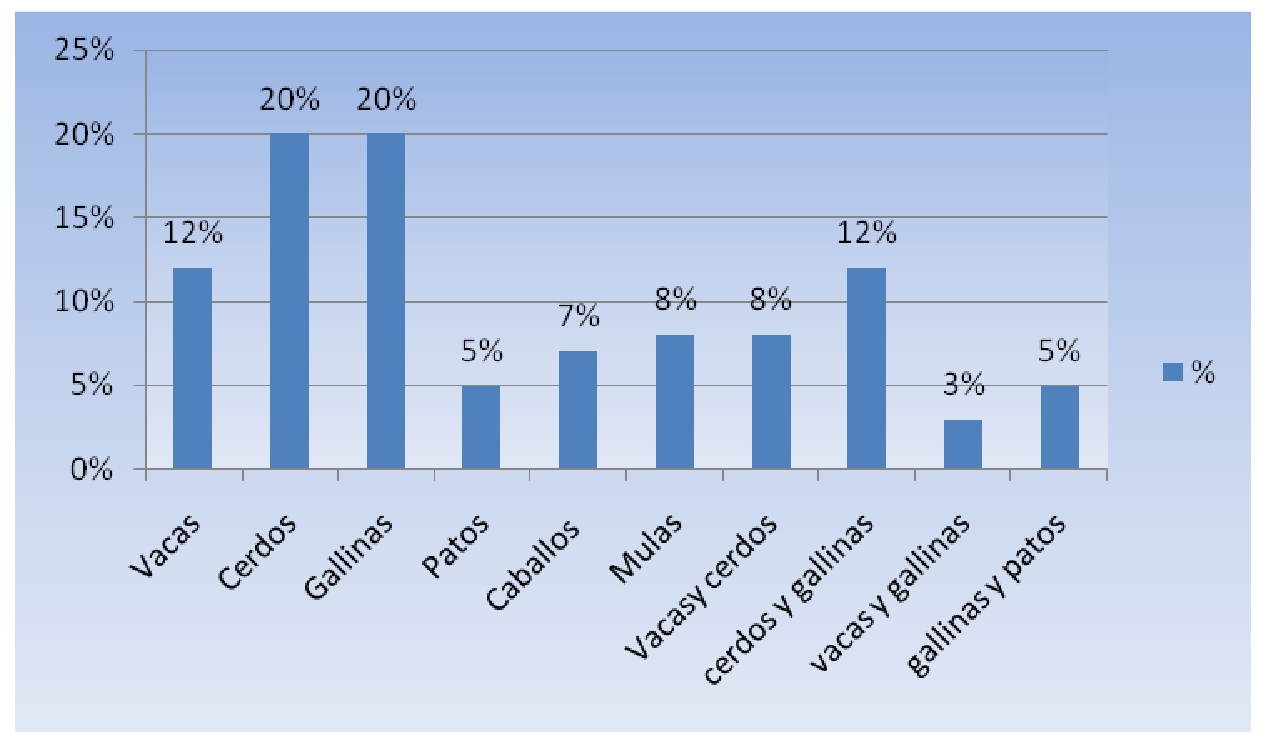

Fuente: Tabla No 18

Los animales de granja que tienen las amas de casa son los siguientes: $20 \%$ tiene gallinas de campo, otro $20 \%$ tiene porcinos, $12 \%$ tiene ganado vacuno, $12 \%$ tiene gallinas y porcinos

Como se observa en el gráfico, un alto porcentaje de madres encuestadas tienen animales de granja de acuerdo a sus posibilidades económicas y laborales, muchos de estos son animales adquiridos para negocio, consumo, y para el trabajo dependiendo de la necesidad y el interés para los que se los adquirió. 
Existe gran cantidad de animales de granja especialmente aves de corral, porcinos y vacunos, todas las amas de casa encuestadas tienen animales de granja, lo que significa que a mayor población mayor cantidad de animales, aumentan los problemas de zoonosis e insalubridad si no se aplican medidas de prevención.

Cuando es mayor el número de animales existentes en la comunidad con mayor razón se deberán aplicar las medidas profilácticas sanitarias es decir vacunación, desparasitación, limpieza y desinfección de establos, y la asistencia técnica de profesionales zootecnistas que brinden información oportuna sobre manejo y crianza adecuado de animales de granja periodos de desparasitación y de vacunación. 
19.- BENEFICIOS QUE BRINDAN LOS ANIMALES DE GRANJA

Tabla No19

BENEFICIOS QUE BRINDAN LOS ANIMALES DE GRANJA EN LA COMUNIDAD DE SAN ROQUE PERTENECIENTE AL CANTÓN SUCRE PARROQUIA CHARAPOTÓ.PROVINCIA DE MANABÍ. 2011.

\begin{tabular}{lll}
\hline Variable & $\mathbf{f}$ & $\%$ \\
Consumo & 14 & $35 \%$ \\
Ingreso económico & 20 & $50 \%$ \\
Agricultura & 6 & $15 \%$ \\
Total & $\mathbf{4 0}$ & $\mathbf{1 0 0 \%}$ \\
\hline
\end{tabular}

Fuente: datos de la encuesta aplicada 
BENEFICIOS QUE BRINDAN LOS ANIMALES DE GRANJA EN LA COMUNIDAD DE SAN ROQUE PERTENECIENTE AL CANTÓN SUCRE PARROQUIA CHARAPOTÓ.PROVINCIA DE MANABÍ. 2011.

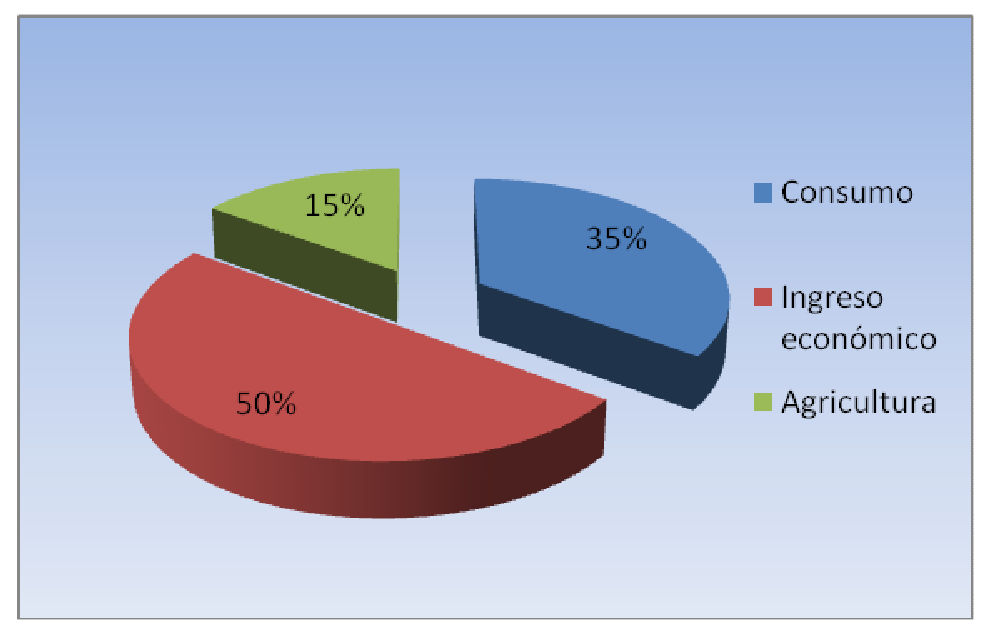

Fuente: Tabla No 19

Lapoblación encuestada responde que tiene animales de granja por las siguientes razones: el $50 \%$ por aporte económico, 35\% consumo, $15 \%$ agricultura.

La adquisición de animales en la comunidad de San Roque responde a las necesidades de la comunidad como ayuda económica, para un sano consumo, y para reducir el esfuerzo del trabajo en la agricultura.

La mayor parte de las amas de casa de la comunidad se ocupan del cuidado y alimentación especialmente de los animales que les generan aporte económico en el hogar para sustentar sus necesidades básicas, y de consumo. 
Un animal de granja es un animal salvaje que ha sido domesticado para ayudarse de su fuerza en el trabajo como el caballo o para alimentarse de su carne como en el caso del cerdo. Son animales a los que se les ha domesticado para su uso alimenticio o laboral. La mayoría de los animales de la granja tienen la función de proporcionar alimentos a sus propietarios, ya sea al ser comidos estos mismos animales o gracias a los productos alimenticios que ellos generan, como el caso de la leche o los huevos. La mayoría de los animales de granja sirven sólo para alimentación como en el caso de las gallinas de campo, pero otros son útiles sólo para el trabajo, como el caballo o el mular. Son animales con mucha fuerza que son muy útiles para el transporte o la labranza de los campos. 
20.- PERSONA DE LA FAMILIA ENCARGADA DEL CUIDADO DE ANIMALES DE GRANJA.

Tabla No 20

PERSONA DE LA FAMILIA ENCARGADA DEL CUIDADO DE ANIMALES DE GRANJA EN LA COMUNIDAD DE SAN ROQUE PERTENECIENTE AL CANTÓN SUCRE PARROQUIA CHARAPOTÓ.PROVINCIA DE MANABÍ.2011.

\begin{tabular}{lll}
\hline Variable & $\mathbf{f}$ & $\%$ \\
Padre & 3 & $8 \%$ \\
Madre & 25 & $63 \%$ \\
Hijos & 7 & $17 \%$ \\
Todos & 5 & $12 \%$ \\
Total & 40 & $100 \%$ \\
\hline
\end{tabular}

Fuente: datos de la encuesta aplicada 
Gráfico No 20

\section{PERSONA DE LA FAMILIA ENCARGADA DEL CUIDADO DE ANIMALES DE GRANJA EN LA COMUNIDAD DE SAN ROQUE PERTENECIENTE AL CANTÓN SUCRE PARROQUIA CHARAPOTÓ.PROVINCIA DE MANABí.2011.}

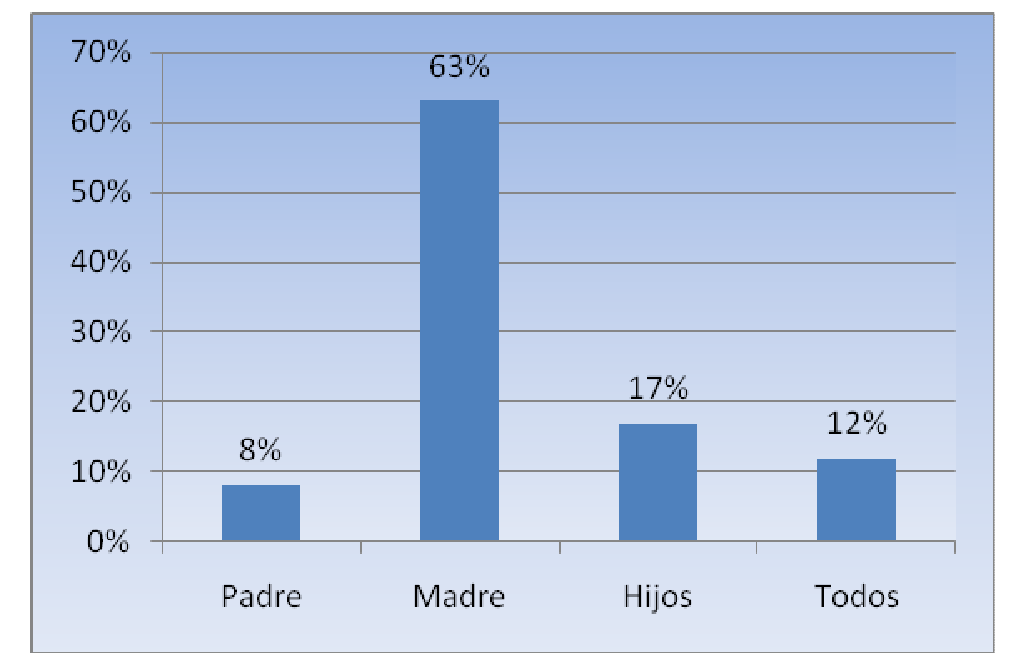

Fuente: tabla No 20

El $65 \%$ de las madres de familia encuestadas de la Comunidad de san Roque son las responsables del cuidado de los animales de granja y en un $17 \%$ sus hijos.

Las madres de familia son las amas de casa que se encargan del cuidado de los animales de granja y muchas veces son ayudadas por sus hijos mientras que sus esposos se dedican principalmente a la agricultura.

Al ser las madres las encargadas del cuidado ganadero, porcino, aviar son las responsables de aplicar las medidas higiénico sanitarias como limpieza, 
desparasitación, vacunación, pero la falta de educación y capacitación, y de costumbre genera insalubridad es por esta razón que la comunidad debería gestionar con el del Ministerio de Salud Pública para que estos realicen un programa de atención Primaria de salud en sonde se realice un diagnostico, prevención, curación y rehabilitación del problema, aplicando el programa "Salud para Todos" mejorando la calidad de atención a la salud y combatiendo enfermedades zoonóticas en la zona.

21.- CORRALES PARA GANADO BOVINO

Tabla No 21

TENENCIA DE CORRALES PARA GANADO BOVINO EN LA COMUNIDAD DE SAN ROQUE PERTENECIENTE AL CANTÓN SUCRE PARROQUIA CHARAPOTÓ.PROVINCIA DE MANABÍ.2011.

\begin{tabular}{ccc}
\hline Variable & $\mathbf{f}$ & $\%$ \\
Si & 6 & $15 \%$ \\
No & 34 & $85 \%$ \\
TOTAL & 40 & $\mathbf{1 0 0} \%$ \\
\hline
\end{tabular}

Fuente: datos de la encuesta 


\section{TENENCIA DE CORRALES PARA GANADO BOVINO EN LA COMUNIDAD}

DE SAN ROQUE PERTENECIENTE AL CANTÓN SUCRE PARROQUIA

CHARAPOTÓ.PROVINCIA DE MANABÍ.2011.

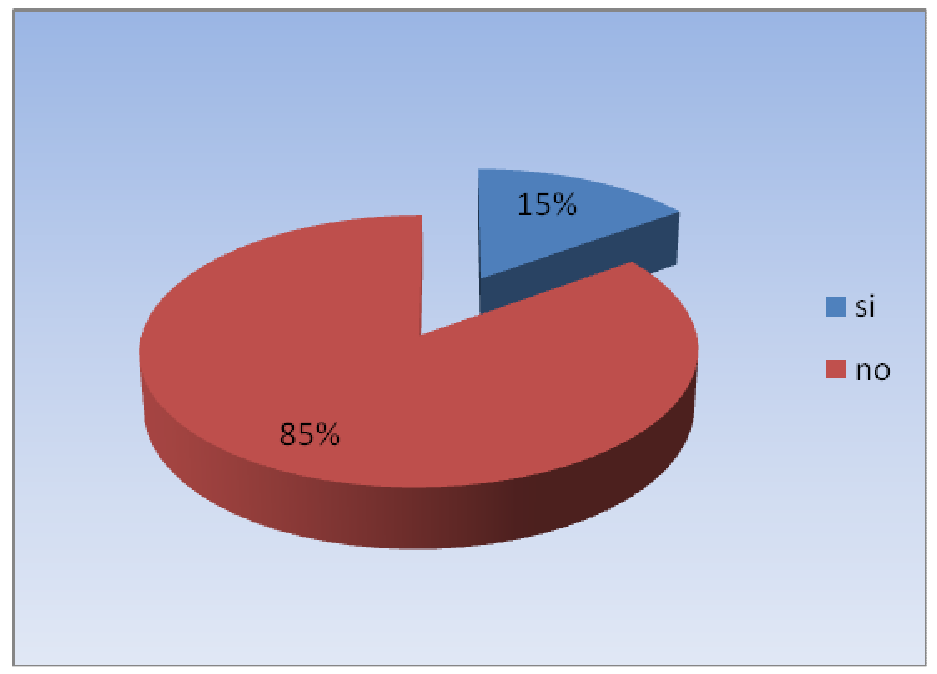

Fuente: tabla No 21

El $85 \%$ de La madres no tienen corrales para bovinos, solo un $15 \%$ tiene corrales para bovinos.

La mayoría de madres encuestadas responden que no tienen corrales por las siguientes razones: falta de dinero, poco espacio físico, falta de capacitación y asistencia técnica para la confección de establos, y por costumbre.

Todas estas manifestaciones de la comunidad nos permiten identificar que muchas de ellas administran la ganadería por costumbres de sus antepasados, y muchos de ellos son reacios al cambio.

El tener corrales para los animales nos ayuda a prevenir problemas de insalubridad y zoonosis ya que existe un solo lugar donde se encuentra el 
ganado y es mucho más fácil limpiar el estiércol y de esta manera prevenir la zoonosis provocada por estiércol de ganado vacuno.

Además en la práctica se observa que la comunidad no busca capacitación ni asistencia técnica para la cría del ganado de una forma técnica y sanitaria con instituciones propias para ellas como el Ministerio de Agricultura y Ganadería (MAGAP).

22.- CHANCHERAS PARA PORCINOS

Tabla No 22

CHANCHERAS PARA PORCINOS EN LA COMUNIDAD DE SAN ROQUE PERTENECIENTE AL CANTÓN SUCRE PARROQUIA CHARAPOTÓ.PROVINCIA DE MANABÍ.2011.

\begin{tabular}{ccc}
\hline Variable & $\mathbf{f}$ & $\%$ \\
Si & 10 & $25 \%$ \\
No & 23 & $75 \%$ \\
TOTAL & 40 & $\mathbf{1 0 0 \%}$ \\
\hline
\end{tabular}

Fuente: datos de la encuesta aplicada 
Gráfico No 22

\section{CHANCHERAS PARA PORCINOS EN LA COMUNIDAD DE SAN ROQUE PERTENECIENTE AL CANTÓN SUCRE PARROQUIA CHARAPOTÓ.PROVINCIA DE MANABÍ.2011.}

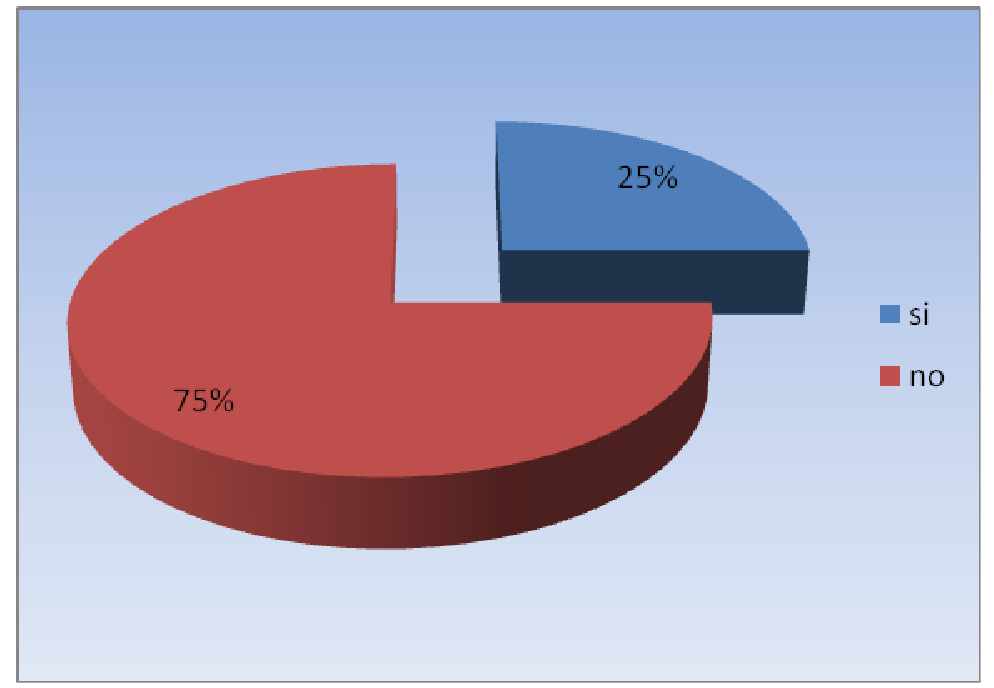

Fuente: Tabla No 22

EL $75 \%$ de la muestra encuestada no tienen chancheras para los porcinos y estos se encuentran fuera de las viviendas a veces atados y otras libres; solo un $25 \%$ de madres encuestadas tiene chancheras en la comunidad.

La mayoría de la población de la Comunidad San Roque como se demuestra en el gráfico, manifiestan que no construyen chancheras por las siguientes razones:

Falta de dinero, falta de espacio físico, los animales se estresan encerrados y ce flaquean. 
Estos criterios de la comunidad son erróneos y no tienen base técnica, por lo que se concluye que están acostumbrados a mantener sus animales por costumbres de sus antepasados, la comodidad, falta de capacitación y asistencia técnica, es necesaria para que les permita optimizar recursos materiales existentes, mantener una cría de porcinos saludable y evitar enfermedades zoonóticas, niguas, hongos, enfermedades de la piel entre otras.

\section{3.- GALPONES PARA AVES}

Tabla No 23

GALPONES PARA AVES EN LA COMUNIDAD DE SAN ROQUE PERTENECIENTE AL CANTÓN SUCRE PARROQUIA CHARAPOTÓ.PROVINCIA DE MANABÍ.2011.

\begin{tabular}{ccc}
\hline Variable & $\mathbf{f}$ & $\%$ \\
Si & 5 & $13 \%$ \\
No & 35 & $87 \%$ \\
TOTAL & 40 & $\mathbf{1 0 0} \%$ \\
\hline
\end{tabular}

Fuente: datos de la encuesta 


\section{Gráfico No 23}

\section{GALPONES PARA AVES EN LA COMUNIDAD DE SAN ROQUE PERTENECIENTE AL CANTÓN SUCRE PARROQUIA CHARAPOTÓ.PROVINCIA DE MANABÍ.2011.}

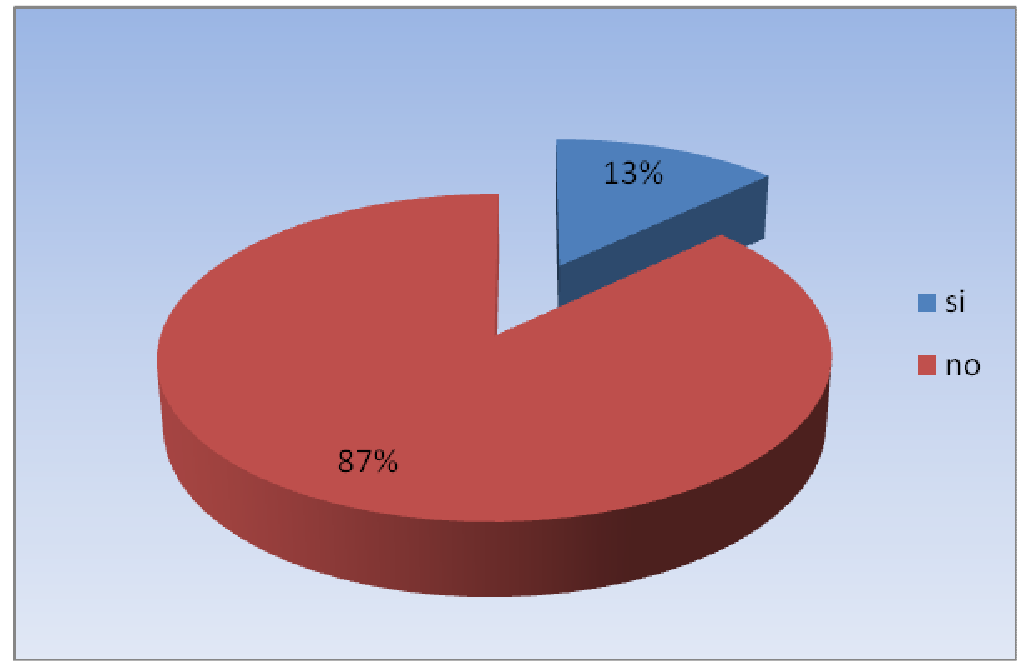

Fuente: Tabla No 23

El $87 \%$ de la población encuestada no tiene galpones o corrales para sus gallinas, tan solo un $13 \%$ tiene galpones para optimizar la cría de sus gallinas.

Las madres encuestadas de la Comunidad de San Roque no tienen galpones para sus gallinas de campo por los siguientes motivos: tienen que estar libres no encerradas, se flaquean, no ponen sus huevos, necesitan menos comida.

Los galpones para criar gallinas son muy importantes ya que en este lugar se asegura el cuidado y crecimiento sano de las mismas con una alimentación adecuada en un lugar limpio. Sin embargo las madres opinan que al dejarlas libres por el campo hacen que las gallinas necesiten menos comida que 
reteniéndolas en un gallinero; se flaquean, no ponen sus huevos son frases sin fundamento técnico; sin tomar en cuenta que si campan a su libre albedrío pueden sufrir el ataque de predadores, perderse o enfermar.

El objetivo de que en el campo se tenga galpones es para evitar problemas como histoplasmosis ocasionada por estiércol de aves cerca de la vivienda o en contacto con la familia, y para tener una limpieza y desinfección que garantice sanidad a las aves, el galpón con una superficie de cemento que facilita el lavado, desinfección, control de plagas y se evitaría problemas de zoonosis, que se dan al tener a las aves a libre albedrío de esta forma si se podría decir que es más saludable comer una gallina de galpón que una gallina de campo, si no se aplican las medidas sanitarias necesarias para el cuidado de las aves de campo. 
24.- LIMPIEZA DE ESTIÉRCOL DE BOVINOS

Tabla No 24

LIMPIEZA DE ESTIÉRCOL DE BOVINOS EN LA COMUNIDAD DE SAN ROQUE PERTENECIENTE AL CANTÓN SUCRE PARROQUIA CHARAPOTÓ.PROVINCIA DE MANABÍ.2011.

\begin{tabular}{lcc}
\hline Variable & $\mathbf{f}$ & $\%$ \\
Si & 7 & $78 \%$ \\
No & 2 & $22 \%$ \\
TOTAL & 9 & $100 \%$ \\
\hline
\end{tabular}

Fuente: datos de la encuesta aplicada 


\section{Gráfico No 24}

\section{LIMPIEZA DE ESTIÉRCOL DE BOVINOS EN LA COMUNIDAD DE SAN ROQUE PERTENECIENTE AL CANTÓN SUCRE PARROQUIA CHARAPOTÓ.PROVINCIA DE MANABÍ.2011.}

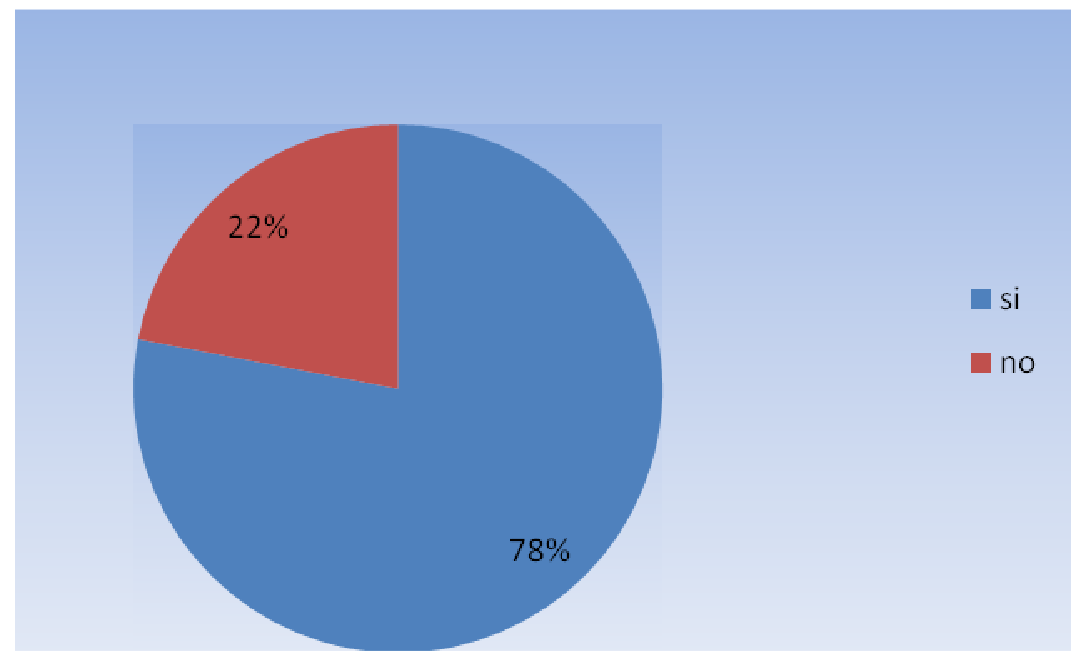

Fuente: Tabla No 24

El $78 \%$ de las madres de familia si limpian el estiércol del ganado que es el mayor porcentaje, mientras que el $22 \%$ no lo limpia.

La mayor parte de madres de familia limpia el estiércol de vacunos porque: causa malos olores, proliferación de moscas e insectos, lluvias.

Otro porcentaje que es menor no lo limpia porque: acumulan y venden como abono, descuido, despreocupación, y por costumbre.

En la comunidad se limpia el estiércol de animales principalmente por malos olores, moscas, y por la lluvias que causan un lodo que profundiza el olor haciéndolo más fétido, pero nadie lo hace como una medida de prevención 
primaria antes de que se produzca una enfermedad, siendo su objetivo principal el impedir o retrasar la aparición de la misma.

Pero esto se da por falta de capacitaciones en atención sanitaria por parte del Ministerio de salud y departamentos de sanidad, casas de salud, entre otras.

Las madres que no limpian el estiércol de vacunos responden que no lo hacen porque lo acumulan para venderlo como abono, pero estas acumulaciones se las podría realizar en bodegas o lugares alejados de la vivienda no en las afueras de la misma y el descuido y despreocupación pueden ser la causa de enfermedades zoonóticas por falta de educación, capacitación e investigación del problema. 
25.- FRECUENCIA DE LIMPIEZA DE ESTIÉRCOL DE BOVINOS

Tabla No 25

FRECUENCIA DE LIMPIEZA DE ESTIÉRCOL DE BOVINOS EN LA COMUNIDAD DE SAN ROQUE PERTENECIENTE AL CANTÓN SUCRE PARROQUIA CHARAPOTÓ.PROVINCIA DE MANABÍ.2011.

\begin{tabular}{ccc}
\hline Variable & $\mathbf{f}$ & $\%$ \\
& & \\
A diario & 1 & $14 \%$ \\
Una vez por Semana & 6 & $86 \%$ \\
Total & 7 & $100 \%$ \\
\hline
\end{tabular}

Fuente: datos de la encuesta aplicada

Gráfico No 25 


\section{FRECUENCIA DE LIMPIEZA DE ESTIÉRCOL DE BOVINOS EN LA COMUNIDAD DE SAN ROQUE PERTENECIENTE AL CANTÓN SUCRE PARROQUIA CHARAPOTÓ.PROVINCIA DE MANABÍ.2011.}

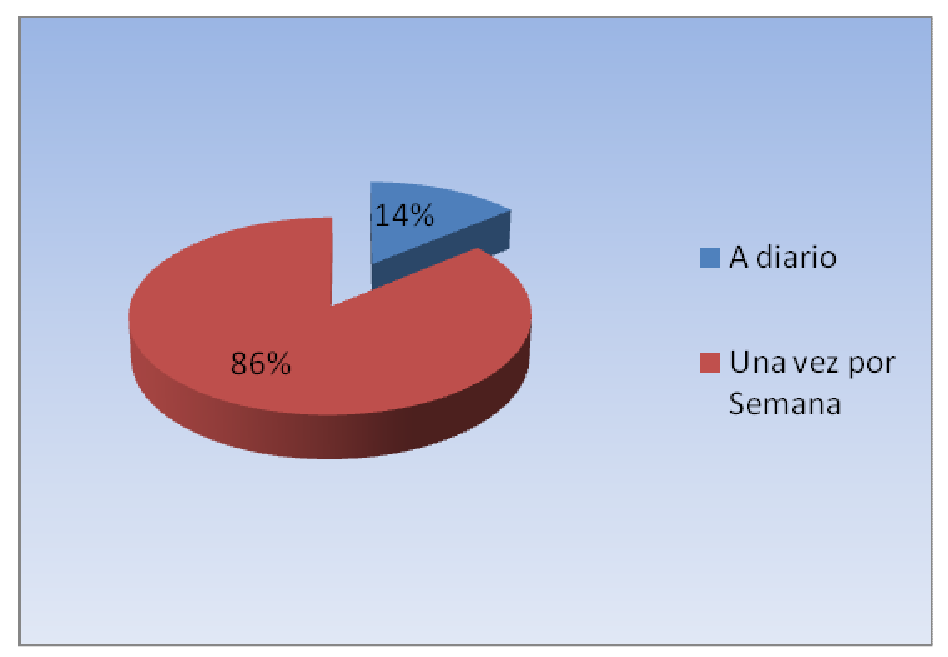

Fuente: Tabla No 25

El $86 \%$ de las madres que si limpian el estiércol de bovinos lo hacen una vez por semana y el $14 \%$ lo hace a diario.

Muchas de las madres de la comunidad de San Roque no realizan la limpieza diaria de estiércol de bovinos muchas veces por el calor, despreocupación, ocio, dejando que la acumulación ocasione proliferación de moscas e insectos, malos olores e insalubridad que afecta a la familia y a la comunidad.

La importancia de educación e implementación de un programa sanitario es fundamental para concienciar a la gente sobre el problema e incentivar al adquirir modos, condiciones y estilos de vida saludable mediante la promoción y prevención de salud logrando una familia saludable y con ello a una vivienda saludable. 
26.-LIMPIEZA DE ESTIÉRCOL DE LOS PORCINOS

Tabla No 26

LIMPIEZA DE ESTIÉRCOL DE PORCINOS EN LA COMUNIDAD DE SAN ROQUE PERTENECIENTE AL CANTÓN SUCRE PARROQUIA CHARAPOTÓ.PROVINCIA DE MANABÍ.2011.

\begin{tabular}{ccc}
\hline Variable & $\mathbf{f}$ & $\%$ \\
si & 13 & $93 \%$ \\
no & 1 & $7 \%$ \\
TOTAL & $\mathbf{1 4}$ & $\mathbf{1 0 0 \%}$ \\
\hline
\end{tabular}

Fuente: datos de la encuesta aplicada

Gráfico No 26 


\section{LIMPIEZA DE ESTIÉRCOL DE PORCINOS EN LA COMUNIDAD DE SAN ROQUE PERTENECIENTE AL CANTÓN SUCRE PARROQUIA CHARAPOTÓ.PROVINCIA DE MANABÍ.2011.}

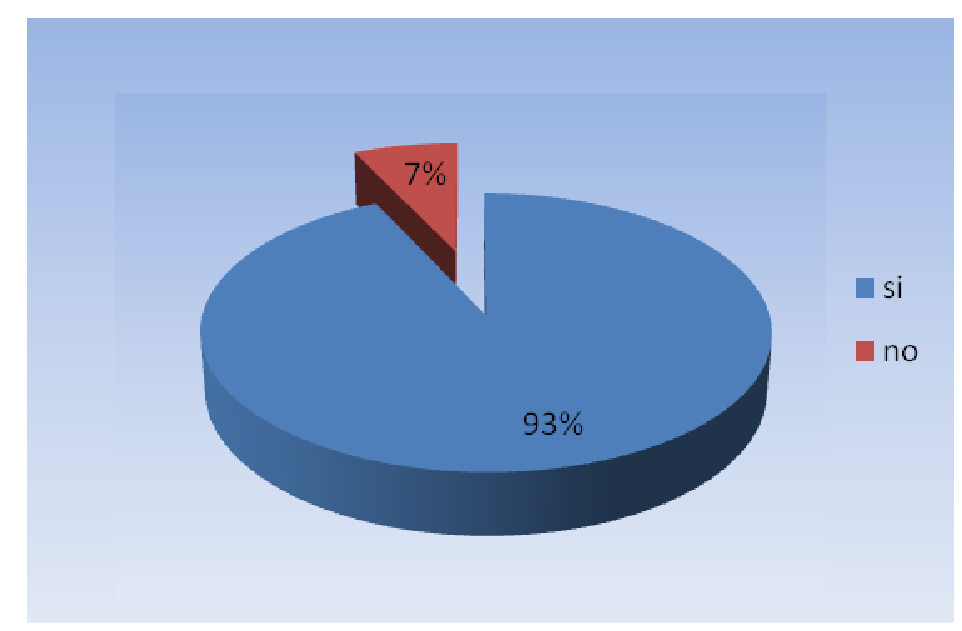

Fuente: tabla No 26

El 93\% del total de la muestra encuestada si realiza la limpieza del estiércol de porcinos, el $7 \%$ no lo hace.

Las madres limpian el estiércol de porcinos decido a: mal olor, proliferación de moscas, lluvias. Un menor porcentaje no lo hace por: ocio, descuido, desconocimiento de posibles problemas de salud que pueden causar.

La mayoría de madres deberían realizar la limpieza de estiércol de porcinos como una medida de prevención de zoonosis, o con el objetivo de mantener la higiene de la vivienda, pero las principales causas son: la falta de actividades de promoción de salud, educación sanitaria, prevención de enfermedades, asistencia sanitaria, mantenimiento y recuperación de la salud. 
Ante este problema es necesario aplicar un programa de atención primaria de salud para concienciar a la población sobre las causas y consecuencias que puede ocasionar la falta de higiene de los animales y la importancia de la prevención como una alternativa para reducir problemas de zoonosis.

27.- FRECUENCIA DE LIMPIEZA DE ESTIÉRCOL DE PORCINOS

Tabla No 27

FRECUENCIA DE LIMPIEZA DE ESTIÉRCOL DE BOVINOS EN LA COMUNIDAD DE SAN ROQUE PERTENECIENTE AL CANTÓN SUCRE PARROQUIA CHARAPOTÓ.PROVINCIA DE MANABÍ.2011.

\begin{tabular}{ccc}
\hline Variable & $\mathbf{f}$ & $\%$ \\
A diario & 8 & $57 \%$ \\
Una vez por Semana & 6 & $43 \%$ \\
Total & 14 & $100 \%$ \\
\hline
\end{tabular}

Fuente: datos de la encuesta aplicada

Gráfico No 27 


\section{FRECUENCIA DE LIMPIEZA DE ESTIÉRCOL DE BOVINOS EN LA COMUNIDAD DE SAN ROQUE PERTENECIENTE AL CANTÓN SUCRE PARROQUIA CHARAPOTÓ.PROVINCIA DE MANABÍ.2011.}

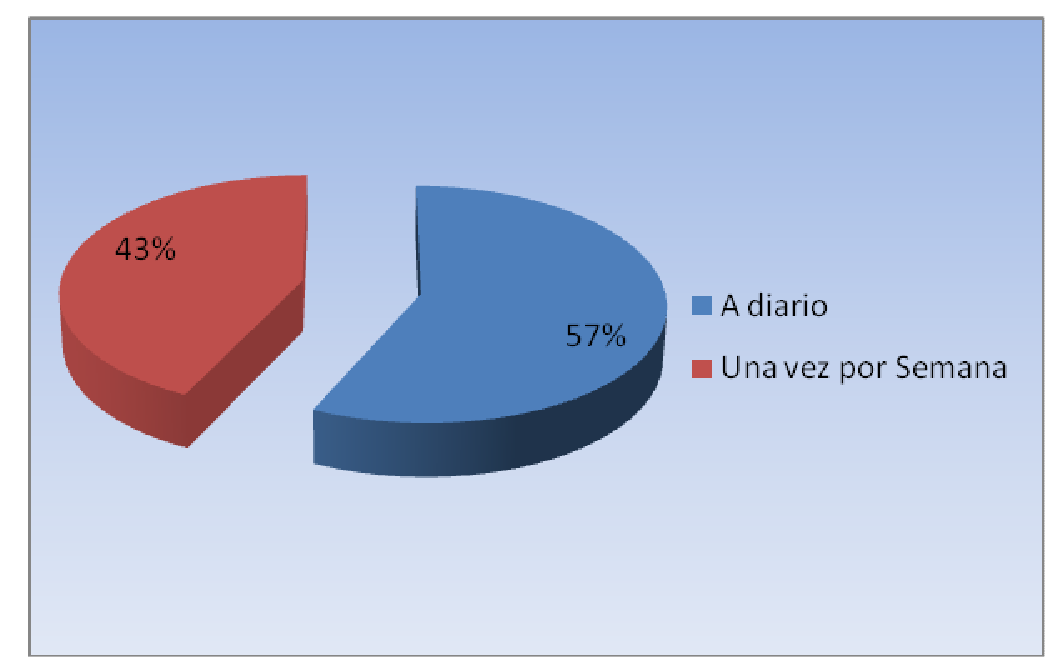

Fuente: Tabla No 27

El $57 \%$ de madres realizan la limpieza de los porcinos a diario, un $43 \%$ lo hace una vez a la semana.

En la comunidad la mayor parte de madres realizan la limpieza de los porcinos pero el problema radica en que no todas la realizan diariamente los motivos podrían ser: ocio, calor, trabajo en el hogar, desinterés.

El problema radica en la frecuencia de la higiene que propicia la sanidad en las viviendas; cuando no existe frecuencia en la higiene los problemas de salud aumentan; la prevención no es solo la acción sino la continuidad con la que se realiza. 
Lo más recomendable en la limpieza del estiércol de porcinos es realizarla a diario para evitar la presencia de moscas y evitar la insalubridad especialmente en épocas de lluvias que es donde más proliferan los problemas de salud.

28.- LIMPIEZA DE ESTIÉRCOL DE AVES

Tabla No 28

LIMPIEZA DE ESTIÉRCOL DE AVES EN LA COMUNIDAD DE SAN ROQUE PERTENECIENTE AL CANTÓN SUCRE PARROQUIA CHARAPOTÓ.PROVINCIA DE MANABÍ.2011.

\begin{tabular}{lll}
\hline Variable & $\mathbf{f}$ & $\%$ \\
si & 7 & $39 \%$ \\
no & 11 & $61 \%$ \\
TOTAL & 18 & $100 \%$ \\
\hline
\end{tabular}

Fuente: datos de la encuesta aplicada 


\section{LIMPIEZA DE ESTIÉRCOL DE AVES EN LA COMUNIDAD DE SAN ROQUE PERTENECIENTE AL CANTÓN SUCRE PARROQUIA CHARAPOTÓ.PROVINCIA DE MANABÍ.2011.}

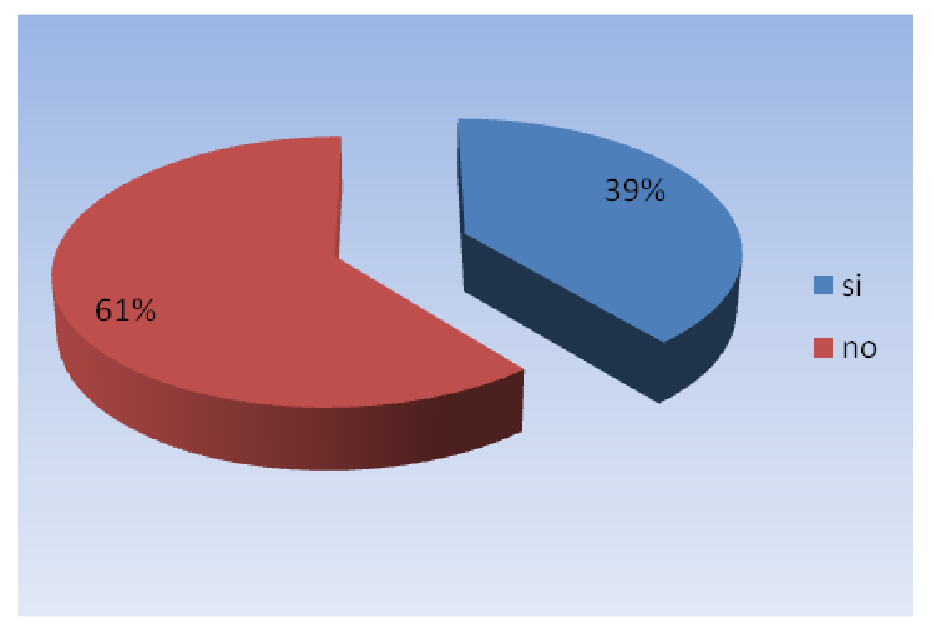

Fuente: Tabla No 28

El $61 \%$ de madres encuestadas realizan la limpieza de estiércol avícola, el 39\% no lo hace.

El mayor porcentaje de madres de familia realizan la limpieza del estiércol de aves, y en menor porcentaje no lo hacen debido a que: andan en libertad, no tienen corrales o galpones, ocio, acumulan como abono.

La mayoría de las madres de la comunidad de San Roque aplican medidas sanitarias en recolección de estiércol avícola pero también como se observa en el gráfico otras no lo hacen principalmente porque acumulan este estiércol para venderlo como abono orgánico, fomentando un factor de riesgo para que se presente enfermedades zoonóticas como histoplasmosis, este hongo 
histoplasma crece en el suelo y la infección resulta de la inhalación de partículas transportadas por el aire del suelo contaminado con excrementos de aves. Es por eso que es importante tener a las aves en galpones y corrales para facilitar la limpieza y evitar la insalubridad de que las gallinas dejen su estiércol por todas partes e incluso dentro de la vivienda.

29.- FRECUENCIA DE LIMPIEZA DE ESTIÉRCOL DE AVES

Tabla No 29

FRECUENCIA DE LIMPIEZA DE ESTIÉRCOL DE AVES EN LA COMUNIDAD DE SAN ROQUE PERTENECIENTE AL CANTÓN SUCRE PARROQUIA CHARAPOTÓ.PROVINCIA DE MANABÍ.2011.

\begin{tabular}{lll}
\hline Variable & $\mathbf{f}$ & $\%$ \\
Cada 15 días & 3 & $16 \%$ \\
A veces & 10 & $56 \%$ \\
Nunca & 5 & $28 \%$ \\
Total & 18 & $100 \%$ \\
\hline
\end{tabular}

Fuente: datos de la encuesta aplicada 
Gráfico No 29

\section{FRECUENCIA DE LIMPIEZA DE ESTIÉRCOL DE AVES EN LA COMUNIDAD \\ DE SAN ROQUE PERTENECIENTE AL CANTÓN SUCRE PARROQUIA \\ CHARAPOTÓ.PROVINCIA DE MANABÍ.2011.}

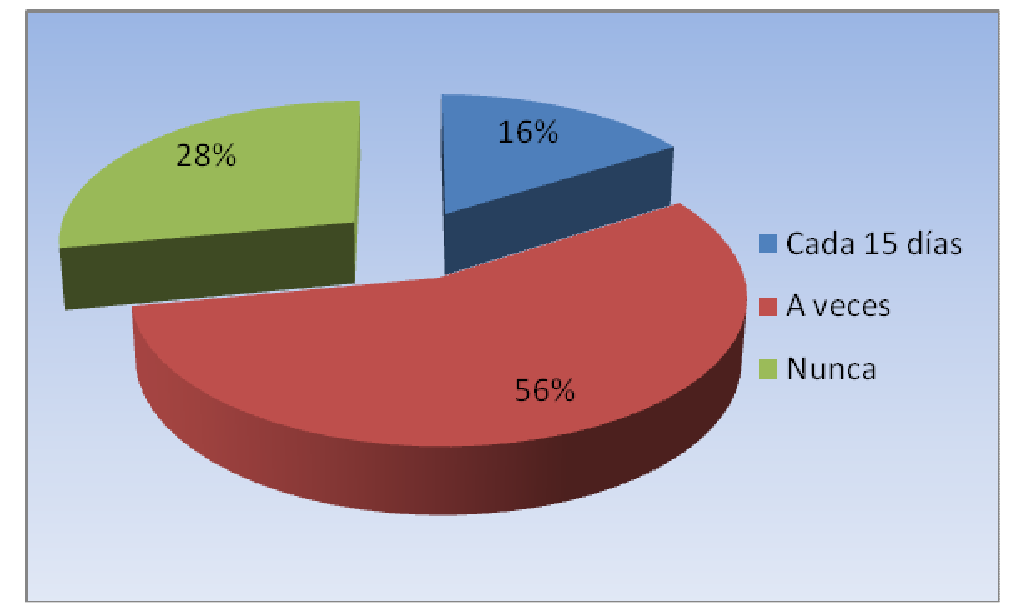

Fuente: Tabla No 29

El $56 \%$ de madres de familia realizan la limpieza de estiércol de aves a veces, el $28 \%$ no lo hace nunca, y el $16 \%$ lo realiza cada 15 días.

Las madres dicen que no limpian a diario es estiércol de las aves porque: estan libres, acumulan para venderlo como abono orgánico, ocio, costumbre.

El hecho de que las aves estén en completa libertad no justifica que no se limpie el lugar donde defecan, es por eso que radica la importancia de tener galpones para estas aves, de tal manera que facilite la limpieza diaria de estiércol. 
En el caso de que las personas acumulen y vendan este estiércol como abono no justifica que no apliquen medidas sanitarias como el almacenamiento en bodegas alejadas de la vivienda y que la distribución sea pronta para prevenir problemas de salud.

30.- VACUNACIÓN A BOVINOS

Tabla N 30

VACUNACIÓN A BOVINOS EN LA COMUNIDAD DE SAN ROQUE

PERTENECIENTE AL CANTÓN SUCRE PARROQUIA

CHARAPOTÓ.PROVINCIA DE MANABI.2011.

\begin{tabular}{ccc}
\hline Variable & f & $\%$ \\
si & 9 & $100 \%$ \\
TOTAL & 9 & $100 \%$ \\
\hline
\end{tabular}

Fuente: datos de la encuesta aplicada

El $100 \%$ de las madres encuestadas que tienen ganado bovino vacuna a su ganado lo que corresponde a la totalidad.

La totalidad de madres encuestadas vacunan a los bovinos por las siguientes razones: para engordarlos, aumentar su ingreso económico, evitar que se enfermen. 
Las madres de la comunidad desparasitan a sus bovinos debido a que al desparasitarlos evitan que estos se flaqueen o enfermen y evitan pérdidas económicas.

Es obligación de todo ganadero aplicar las medidas profilácticas como vacunación a bovinos para prevenir enfermedades propias de estos, así como prevención de zoonosis.

Es recomendable que las madres encargadas de la ganadería mantengan un programa sanitario y de medicina preventiva como correctiva, esta consiste en asesoría de especialistas en medicina veterinaria. 
31.- VACUNACIÓN A PORCINOS

Tabla No 31

VACUNACIÓN A PORCINOS EN LA COMUNIDAD DE SAN ROQUE PERTENECIENTE AL CANTÓN SUCRE PARROQUIA CHARAPOTÓ.PROVINCIA DE MANABÍ.2011.

\begin{tabular}{ccc}
\hline Variable & f & $\%$ \\
si & 6 & $43 \%$ \\
Nunca & 5 & $36 \%$ \\
TOTAL & 3 & $21 \%$ \\
\hline
\end{tabular}

Fuente: datos de la encuesta aplicada 


\section{Gráfico No 31}

\section{VACUNACIÓN A PORCINOS EN LA COMUNIDAD DE SAN ROQUE PERTENECIENTE AL CANTÓN SUCRE PARROQUIA CHARAPOTÓ.PROVINCIA DE MANABÍ.2011.}

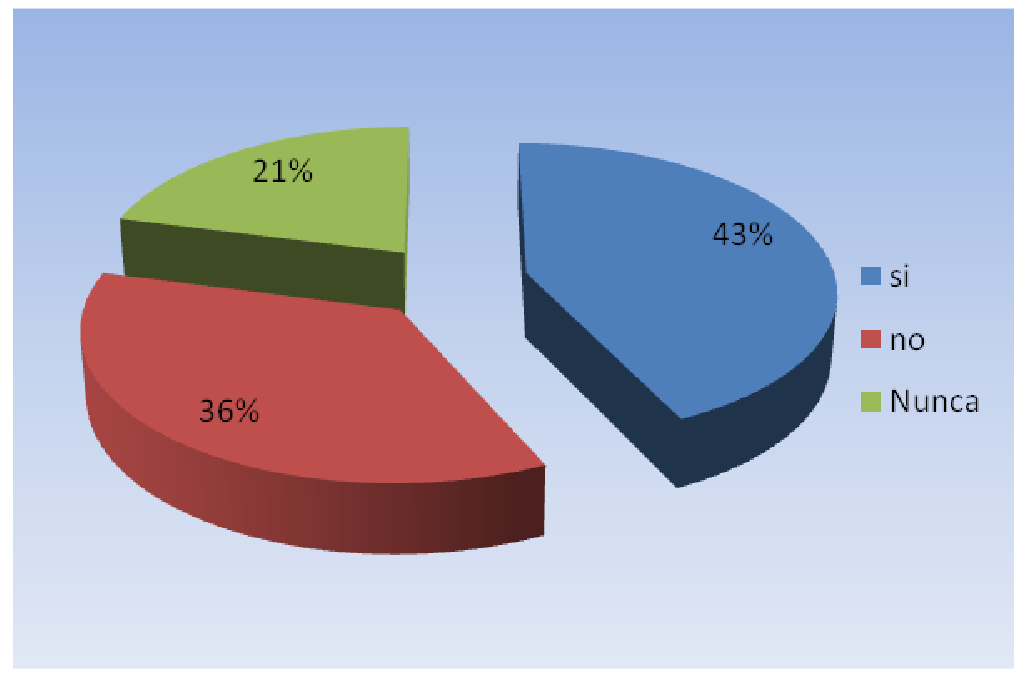

Fuente: Tabla No 31

El $43 \%$ de las madres ponen las vacunas correspondientes a sus porcinos, $36 \%$ no los vacuna, y el $21 \%$ nunca lo ha hecho.

Las madres de la comunidad no vacunan a los porcinos por los siguientes motivos: baja economía, desconocimiento, desinterés.

La vacunación a porcinos es muy importante al momento de prevenir una zoonosis; un alto porcentaje como se observa en el gráfico si lo hace pero otro porcentaje importante no lo hace; la economía es un factor importante que se lo puede solucionar con la autogestión a organismos o entidades como la Secretaria de Agricultura, Ganadería, Desarrollo rural, Pesca y Alimentación 
(SAGARPA). El desconocimiento de periodos de vacunación y el desinterés también se puede solucionar con capacitaciones y asesorías técnicas por parte de profesionales de la misma institución.

32.- DESPARASITACIÓN A GANADO BOVINO

Tabla N 32

DESPARASITACIÓN A GANADO VACUNO EN LA COMUNIDAD DE SAN ROQUE PERTENECIENTE AL CANTÓN SUCRE PARROQUIA CHARAPOTÓ.PROVINCIA DE MANABÍ.2011.

\begin{tabular}{ccc}
\hline Variable & f & $\%$ \\
si & 8 & $89 \%$ \\
no & 1 & $11 \%$ \\
TOTAL & 9 & $100 \%$ \\
\hline
\end{tabular}

Fuente: datos de la encuesta aplicada 


\section{Gráfico No 32}

\section{DESPARASITACIÓN A GANADO VACUNO EN LA COMUNIDAD DE SAN}

ROQUE PERTENECIENTE AL CANTÓN SUCRE PARROQUIA CHARAPOTÓ.PROVINCIA DE MANABÍ.2011.

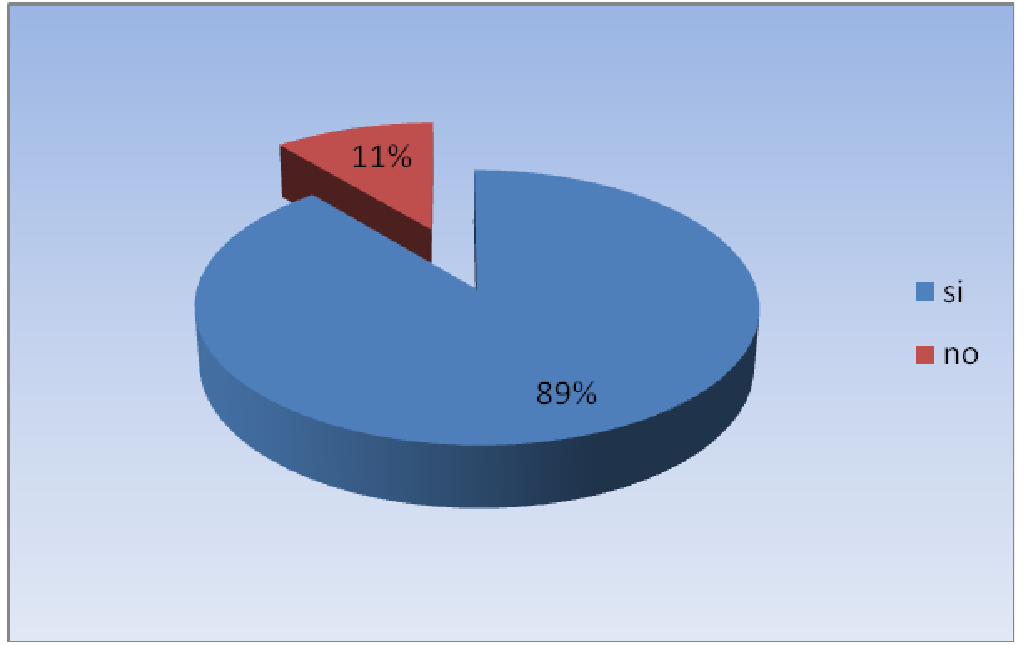

Fuente: Tabla No 32

El $89 \%$ de madres de la Comunidad San Roque si desparasita al ganado vacuno, un $11 \%$ no lo hace.

Las madres que no desparasitan como se observa en el gráfico es un menor porcentaje, no lo hace por: desconocimiento, no tiene ganado vacuno lechero, y por costumbre.

Es importante aplicar las medidas profilácticas como vacunación, desparasitación y control veterinario a bovinos especialmente al lechero para: aumentar la producción lechera, mayor ingreso económico, y mejorar la 
salubridad. Lo cual se podrá lograr con un programa sanitario basado en control de las parasitosis y de las enfermedades infecciosas.

Los animales en explotaciones extensivas y pastoreo se someterán a un plan de desparasitación muy riguroso, con dos tratamientos al año.

En las vacas de ordeño, al existir un buen control de los alimentos ingeridos, los tratamientos antiparasitarios se realizarán con menos frecuencia (anualmente).

33.- DESPARASITACIÓN A PORCINOS

Tabla No 33

DESPARASITACIÓN A PORCINOS EN LA COMUNIDAD DE SAN ROQUE PERTENECIENTE AL CANTÓN SUCRE PARROQUIA CHARAPOTÓ.PROVINCIA DE MANABÍ.2011.

\begin{tabular}{ccc}
\hline Variable & $\mathbf{f}$ & $\%$ \\
Si & 4 & $29 \%$ \\
No & 9 & $64 \%$ \\
Nunca & 1 & $7 \%$ \\
TOTAL & 14 & $100 \%$ \\
\hline
\end{tabular}

Fuente: datos de la encuesta aplicada 
Gráfico No 33

\section{DESPARASITACIÓN A PORCINOS EN LA COMUNIDAD DE SAN ROQUE PERTENECIENTE AL CANTÓN SUCRE PARROQUIA} CHARAPOTÓ.PROVINCIA DE MANABÍ.2011.

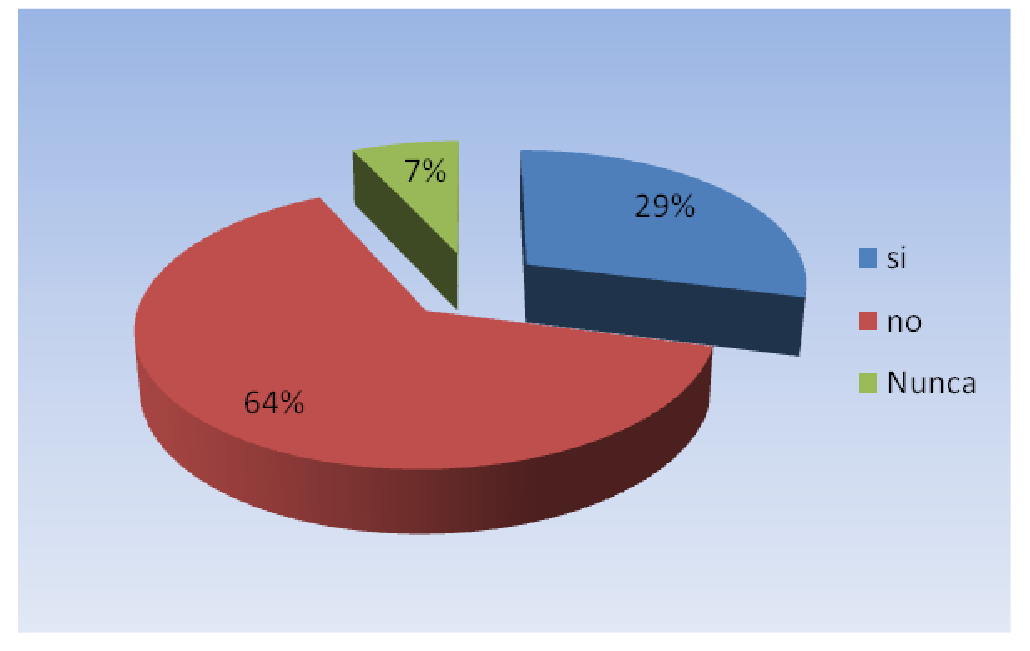

Fuente: Tabla No 33

El $64 \%$ de madres no desparasita a los porcinos, el $29 \%$ si desparasitan a sus porcinos, un $7 \%$ no lo hace nunca.

Como se puede observar en el gráfico la mayor parte de madres no desparasitan a sus porcinos, por las siguientes razones: poca economía, desinformación, desinterés.

La desparasitación a los porcinos en la costa, es muy necesario debido a la insalubridad que existe especialmente en la comunidad donde existe gran cantidad de desechos orgánicos e inorgánicos que son eliminados a campo 
abierto, quebradas y ríos, y posteriormente esta agua es ingerida por los porcinos, constituyéndose en la principal fuente de infección.

Es por esta razón la importancia de aplicar medidas profilácticas en este caso la desparasitación a los porcinos, y la necesidad de asistencia técnica sobre periodos de vacunación es una de las principales acciones de prevención de zoonosis.

34.- AGUA PARA EL CONSUMO

Tabla No 34

AGUA PARA EL CONSUMO EN LA COMUNIDAD DE SAN ROQUE PERTENECIENTE AL CANTÓN SUCRE PARROQUIA CHARAPOTÓ.PROVINCIA DE MANABÍ.2011.

\begin{tabular}{ccc}
\hline Variable & f & $\%$ \\
Entubada & 40 & $100 \%$ \\
TOTAL & 40 & $100 \%$ \\
\hline
\end{tabular}

Fuente: datos de la encuesta

El $100 \%$ de la población de madres encuestadas encuestada que corresponde a su totalidad tienen agua entubada en sus casas. 
El acceso al agua de calidad es ya considerado un derecho fundamental de toda persona. Lamentablemente en nuestro país y en la costa principalmente aún hay mucho por hacer al respecto.

En la costa se capta el agua de los ríos o pozos pero luego son tratadas antes de distribuirla a las casas, pero lo que pasa en el interior del país es que se capta el agua y esta se va directo a una tubería que llega hasta las casas, a esto se llama "agua entubada" que no es igual al agua potable que es agua apta para el consumo; es por esta razón que la cifras de parasitosis cada vez es mayor en la costa que en la sierra al igual que la zoonosis.

Esta situación de agua entubada se da por varios factores: Primero porque se considera a los manantiales como fuentes seguras. Si bien en la sierra existen manantiales con agua de buena calidad, no ocurre así en la selva ni en la costa, debido a la contaminación por materia orgánica debido a los vertimientos de desagües. 
Tabla No 35

MANEJO DE BASURA EN LA COMUNIDAD DE SAN ROQUE PERTENECIENTE AL CANTÓN SUCRE PARROQUIA CHARAPOTÓ.PROVINCIA DE MANABÍ.2011.

\begin{tabular}{|c|c|c|}
\hline Variable & $f$ & $\%$ \\
\hline Quema & 19 & $48 \%$ \\
\hline Bota en Campo Abierto & 8 & $20 \%$ \\
\hline Bota en & 6 & $15 \%$ \\
\hline Quebradas & & \\
\hline $\begin{array}{l}\text { Manda en el carro } \\
\text { recolector }\end{array}$ & 7 & $17 \%$ \\
\hline Total & 40 & $100 \%$ \\
\hline
\end{tabular}

Fuente: datos de la encuestan aplicada 


\section{Gráfico No 35}

\section{MANEJO DE BASURA EN LA COMUNIDAD DE SAN ROQUE PERTENECIENTE AL CANTÓN SUCRE PARROQUIA}

CHARAPOTÓ.PROVINCIA DE MANABÍ.2011.

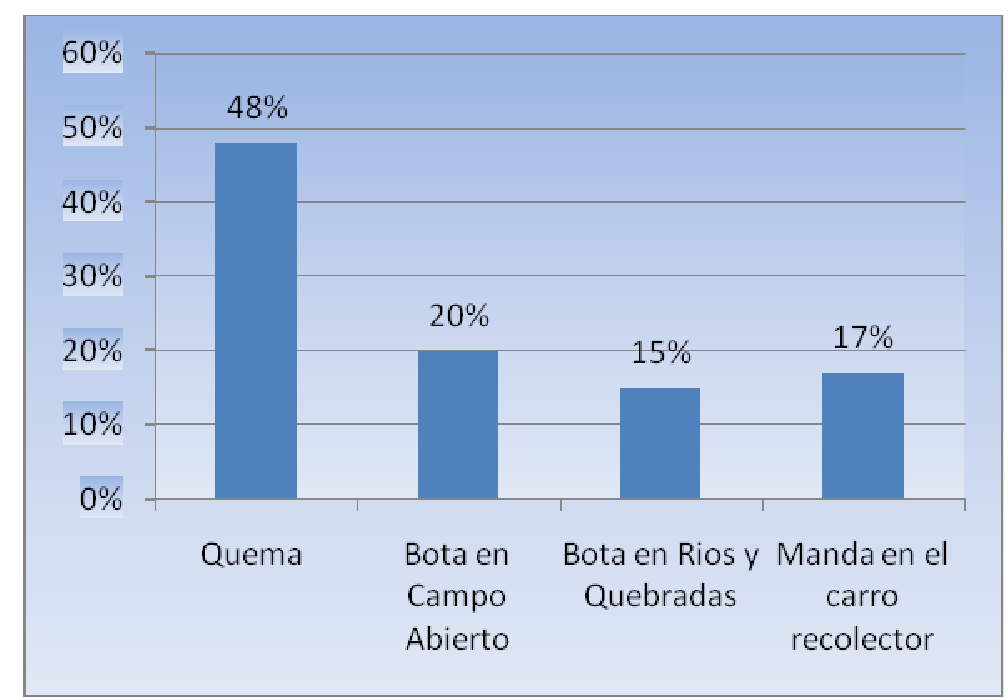

Fuente: Tabla No 35

El $48 \%$ de madres quema los desechos sólidos, $20 \%$ los bota en el campo abierto, $17 \%$ los manda en el carro recolector, y el $15 \%$ bota en ríos y quebradas.

La mayor parte de madres como se puede ver en el gráfico quema la basura por las siguientes razones: ausencia de carro recolector, exceso de basura, exceso de malezas, costumbre.

Es por esta situación que existe insalubridad en la comunidad y los animales crecen y desarrollan en medio de la basura, en ríos y quebradas de donde 
beben agua los animales de granja y el problema es más grave si no se los desparasita.

Ante este problema la comunidad carece de autogestión por parte de autoridades y directivos de la comunidad con el Municipio para solicitar que el Recolector realice su recorrido con mayor frecuencia por la comunidad.

36.- VIVIENDA EN MAL ESTADO

Tabla No 36

VIVIENDAS EN MAL ESTADO EN LA COMUNIDAD DE SAN ROQUE

PERTENECIENTE AL CANTÓN SUCRE PARROQUIA

CHARAPOTÓ.PROVINCIA DE MANABÍ.2011.

\begin{tabular}{ccc}
\hline Variable & $\mathbf{f}$ & $\%$ \\
Si & 14 & $35 \%$ \\
No & 26 & $65 \%$ \\
Total & 40 & $100 \%$ \\
\hline
\end{tabular}

Fuente: datos de la encuesta aplicada 


\section{VIVIENDAS EN MAL ESTADO EN LA COMUNIDAD DE SAN ROQUE PERTENECIENTE AL CANTÓN SUCRE PARROQUIA CHARAPOTÓ.PROVINCIA DE MANABÍ.2011.}

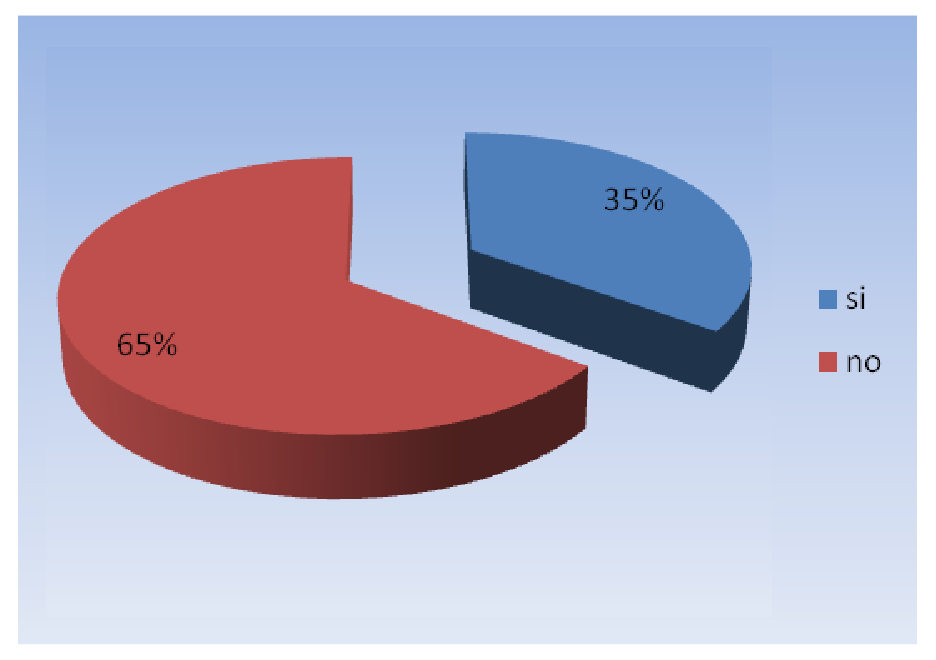

Fuente: Tabla No 36

El $65 \%$ de las madres encuestadas manifiestan que no tiene huecos y agujeros en sus viviendas, y un 35\% manifiesta que si tienen agujeros y huecos en sus viviendas.

La mayoría de las casas de la comunidad que tienen huecos y agujeros se debe a los siguientes motivos: lluvias fuertes, deterioro de la vivienda, mala construcción.

La mayor parte de viviendas en la costa son elaboradas con caña guadua y esta no es completamente cerrada tiene espacios para la ventilación de la misma; pero los huecos y agujeros son muy diferentes es por esta razón que 
se los debe tapar, pero muchas veces el desinterés es ocasionado por la falta de instrucción y educación, la prevención primaria de salud es la que propiciará el cambio.

El clima de la costa constituye un factor para la propagación rápida de roedores, y es por esta razón por la que existe la necesidad de que se tapen huecos y agujeros en las viviendas para prevenir que estos roedores ingresen y causen una zoonosis.

37.- $\quad$ NIÑOS DESCALZOS

Tabla No 37

NIÑOS QUE ANDAN DESCALZOS EN LA COMUNIDAD DE SAN ROQUE PERTENECIENTE AL CANTÓN SUCRE PARROQUIA CHARAPOTÓ.PROVINCIA DE MANABÍ.2011.

\begin{tabular}{ccc}
\hline Variable & $\mathbf{f}$ & $\%$ \\
Si & 28 & $70 \%$ \\
No & 4 & $10 \%$ \\
Nunca & 8 & $20 \%$ \\
TOTAL & 40 & $100 \%$ \\
\hline
\end{tabular}

Fuente: datos de la encuesta aplicada 


\section{NIÑOS QUE ANDAN DESCALZOS EN LA COMUNIDAD DE SAN ROQUE PERTENECIENTE AL CANTÓN SUCRE PARROQUIA CHARAPOTÓ.PROVINCIA DE MANABÍ.2011.}

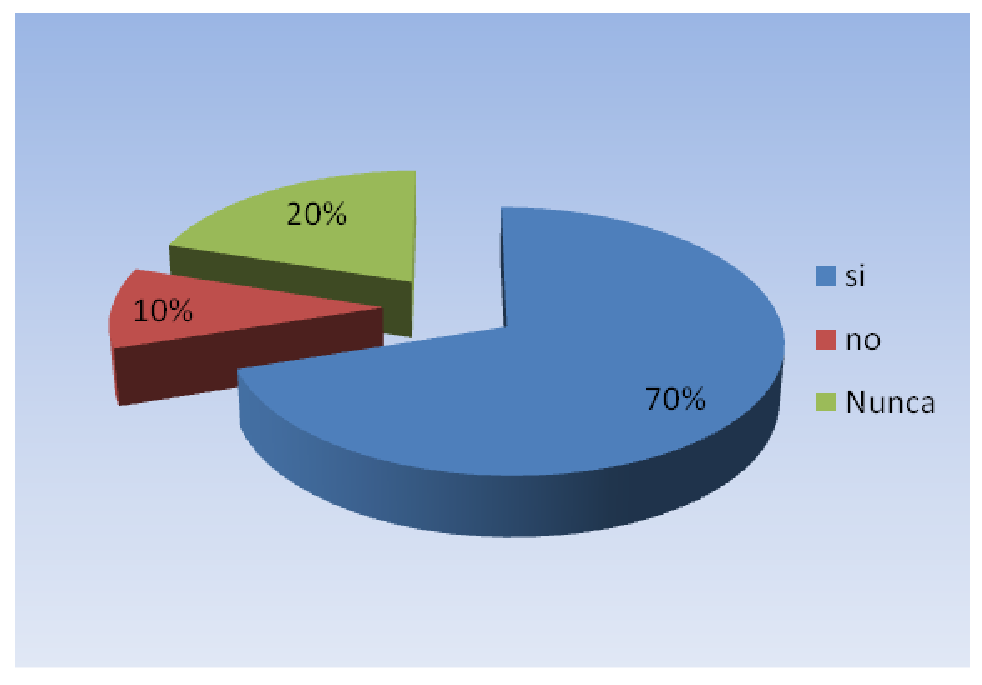

Fuente: Tabla No 37

Las madres encuestadas respondieron que el $70 \%$ de los niños en sus familias andan descalzos, el $10 \%$ no andan descalzos, y el $20 \%$ nunca han andado descalzos.

Una de las grandes causas para esta problemática es: insalubridad, niños descuidados, que caminan descalzos entre basura o por el estiércol de vacas, gallinas o chanchos que constituyen una fuente de infección, o en contacto con animales domésticos.

Y los principales responsables son los adultos que no toman las medidas necesarias de protección y prevención de zoonosis debido al desconocimiento y falta de información sobre enfermedades zoonóticas y factores de riesgo. 
Uno de los problemas de salud en la comunidad son las niguas una zoonosis que se transmiten de los porcinos especialmente a los niños por andan descalzos, y cada vez son más y más los niños que llegan a los sub centros y casas de salud con este problema.

Es por eso que a los niños no se los debe permitir andar descalzos.

38.- ADULTOS DESCALZOS

Tabla No 38

ADULTOS QUE ANDAN DESCALZOS EN LA COMUNIDAD DE SAN ROQUE PERTENECIENTE AL CANTÓN SUCRE PARROQUIA

CHARAPOTÓ.PROVINCIA DE MANABÍ.2011.

\begin{tabular}{ccc}
\hline Variable & $\mathbf{f}$ & $\%$ \\
si & 17 & $42 \%$ \\
no & 8 & $20 \%$ \\
TOTAL & 15 & $38 \%$ \\
\hline
\end{tabular}

Fuente: datos de la encuesta aplicada

Gráfico No 38 


\section{ADULTOS QUE ANDAN DESCALZOS EN LA COMUNIDAD DE SAN ROQUE PERTENECIENTE AL CANTÓN SUCRE PARROQUIA CHARAPOTÓ.PROVINCIA DE MANABÍ.2011.}

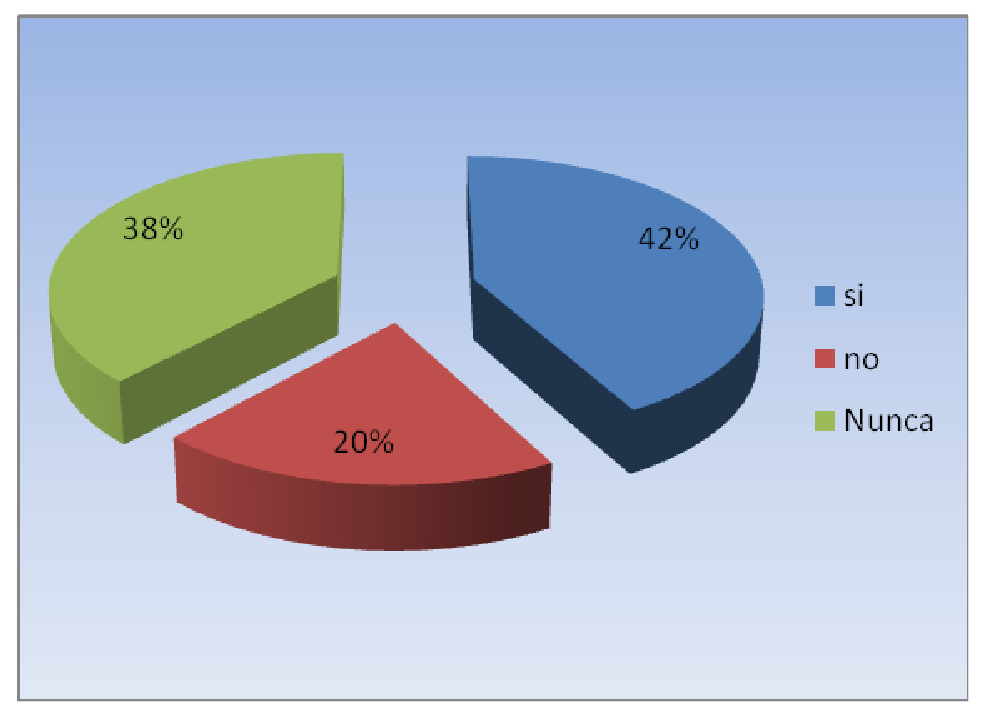

Fuente: Tabla No 38

Según la encuesta aplicada a una muestra de 40 madres de familia, el $42 \%$ es el mayor porcentaje de personas adultas de la familia que si andan sin zapatos dentro de la vivienda, un 38\% responde que nunca andan sin zapatos.

Es decir que también los adultos caminan descalzos exponiéndose a contraer: infecciones, hongos o niguas por la insalubridad existente.

El utilizar calzado es importante pero como se observa en el gráfico el mayor porcentaje de adultos caminan descalzos por: costumbre, calor, baja economía, comodidad, entre otras.

El uso de calzado es una medida higiénico sanitaria de prevención primaria para evitar que se propaguen los problemas de salud y zoonosis como las 
niguas especialmente por la insalubridad existente en el campo, ríos, la cantidad de desechos, el clima que son factores que propician la propagación de endemias e infecciones.

39.- PRESENCIA DE ROEDORES (RATAS) EN LA VIVIENDA

Tabla No 39

PRESENCIA DE ROEDORES (RATAS) EN LA VIVIENDA EN LA COMUNIDAD DE SAN ROQUE PERTENECIENTE AL CANTÓN SUCRE PARROQUIA CHARAPOTÓ.PROVINCIA DE MANABÍ.2011.

\begin{tabular}{ccc}
\hline Variable & $\mathbf{f}$ & $\%$ \\
ni & 8 & $20 \%$ \\
Tal Vez & 24 & $60 \%$ \\
TOTAL & 8 & $20 \%$ \\
\hline
\end{tabular}

Fuente: datos de la encuesta aplicada

Gráfico No 39 


\section{PRESENCIA DE ROEDORES (RATAS) EN LA VIVIENDA EN LA \\ COMUNIDAD DE SAN ROQUE PERTENECIENTE AL CANTÓN SUCRE \\ PARROQUIA CHARAPOTÓ.PROVINCIA DE MANABÍ.2011.}

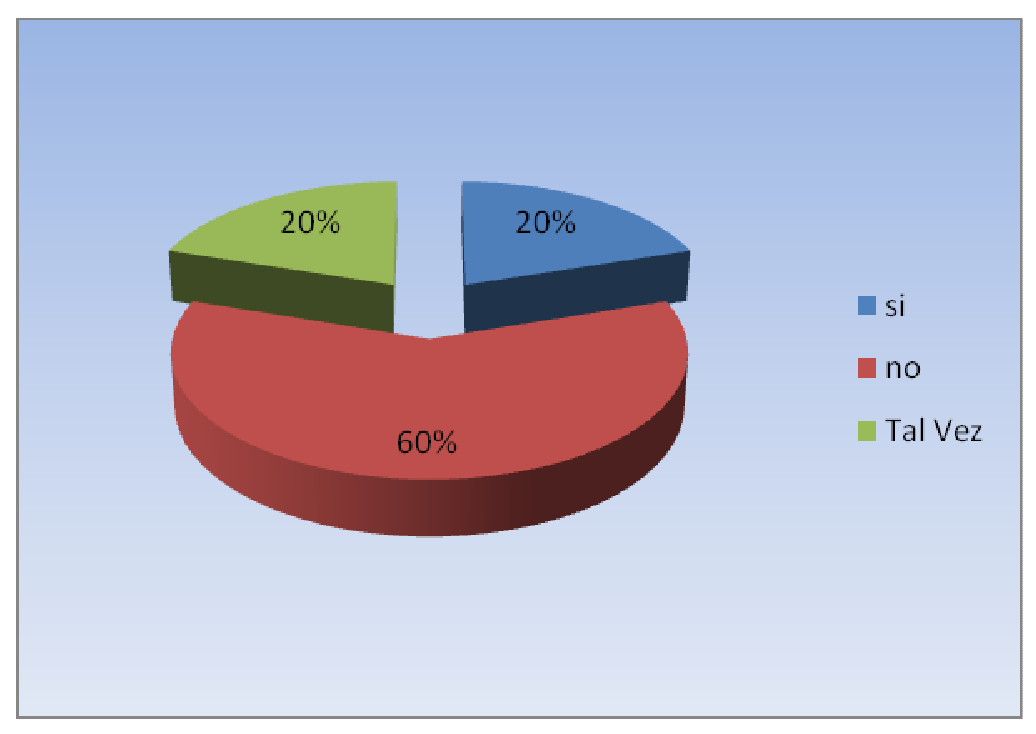

Fuente: Tabla No 39

El $60 \%$ de la muestra encuestada no tiene la presencia de roedores en sus viviendas, un $20 \%$ si existen roedores en la vivienda, y otro $20 \%$ dice que tal vez.

El mayor porcentaje de madres como se observa en el gráfico no tiene roedores en sus viviendas y esto es debido a: presencia de felinos, casas altas, uso de plaguicidas; otro porcentaje manifiesta que si tiene presencia de roedores en la vivienda y otros desconocen; las causas de la presencia de roedores en la vivienda podrían ser las siguientes: ausencia de felinos, casas bajas, agujeros en la vivienda, exceso de basura, acumulación de estiércol. 
Por tal motivo se ve la necesidad de un manejo adecuado de basura, tapar los agujeros de la vivienda especialmente si es de caña, utilizar plaguicidas, conservar los alimentos en lugares limpios, frescos y cerrados, mantener la higiene en la vivienda.

C.- CONOCIMIENTOS

1.- NIVEL DE CONOCIMIENTOS SOBRE ZOONOSIS

Tabla No 40

NIVEL DE CONOCIMIENTOS SOBRE ZOONOSIS EN LA COMUNIDAD DE SAN ROQUE PERTENECIENTE AL CANTÓN SUCRE PARROQUIA CHARAPOTÓ.PROVINCIA DE MANABÍ.2011.

\begin{tabular}{ccc}
\hline Variable & f & $\%$ \\
Correcto & 2 & $5 \%$ \\
Incorrecto & 38 & $95 \%$ \\
Total & 40 & $100 \%$ \\
\hline
\end{tabular}

Fuente: datos de la encuesta aplicada 
Gráfico No 40

NIVEL DE CONOCIMIENTOS SOBRE ZOONOSIS EN LA COMUNIDAD DE SAN ROQUE PERTENECIENTE AL CANTÓN SUCRE PARROQUIA CHARAPOTÓ.PROVINCIA DE MANABÍ.2011

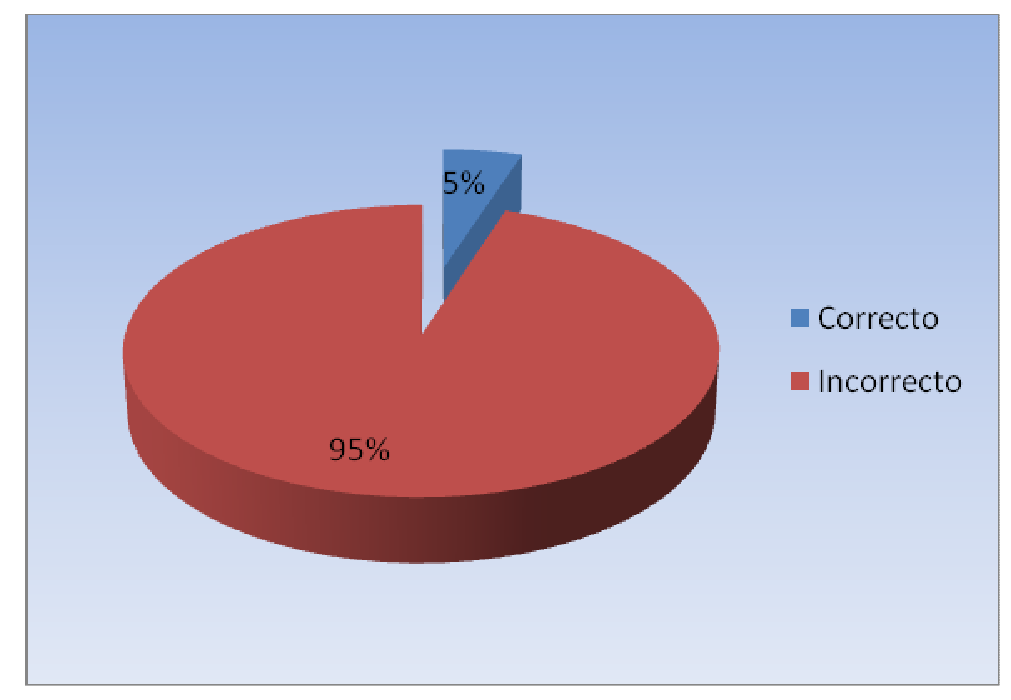

Fuente: Tabla No 40

El 95\% de madres tienen conocimientos erróneos sobre lo que es la zoonosis tan solo el $5 \%$ ha respondido correctamente.

La zoonosis son enfermedades transmisibles de los animales al ser humano, es decir se refiere a todas aquellas enfermedades propias de los animales transmitidas de forma natural de los animales vertebrados al hombre 0 viceversa por ejemplo por vectores como (insectos y animales), al ser humano.

Lo que significa que la mayor parte desconoce lo que es la zoonosis y tiene conocimientos erróneos sobre el tema. 
2.- NIVEL DE CONOCIMIENTOS SOBRE LA RABIA

Tabla No 41

NIVEL DE CONOCIMIENTOS SOBRE LA RABIA EN LA COMUNIDAD DE SAN ROQUE PERTENECIENTE AL CANTÓN SUCRE PARROQUIA CHARAPOTÓ.PROVINCIA DE MANABÍ.2011

\begin{tabular}{ccc}
\hline Variable & f & $\%$ \\
Correcto & 32 & $80 \%$ \\
& & \\
Incorrecto & 8 & $20 \%$ \\
Total & 40 & $100 \%$ \\
\hline
\end{tabular}

Fuente: datos de la encuesta aplicada 
Gráfico No 41

NIVEL DE CONOCIMIENTOS SOBRE LA RABIA EN LA COMUNIDAD DE SAN ROQUE PERTENECIENTE AL CANTÓN SUCRE PARROQUIA CHARAPOTÓ.PROVINCIA DE MANABÍ.2011

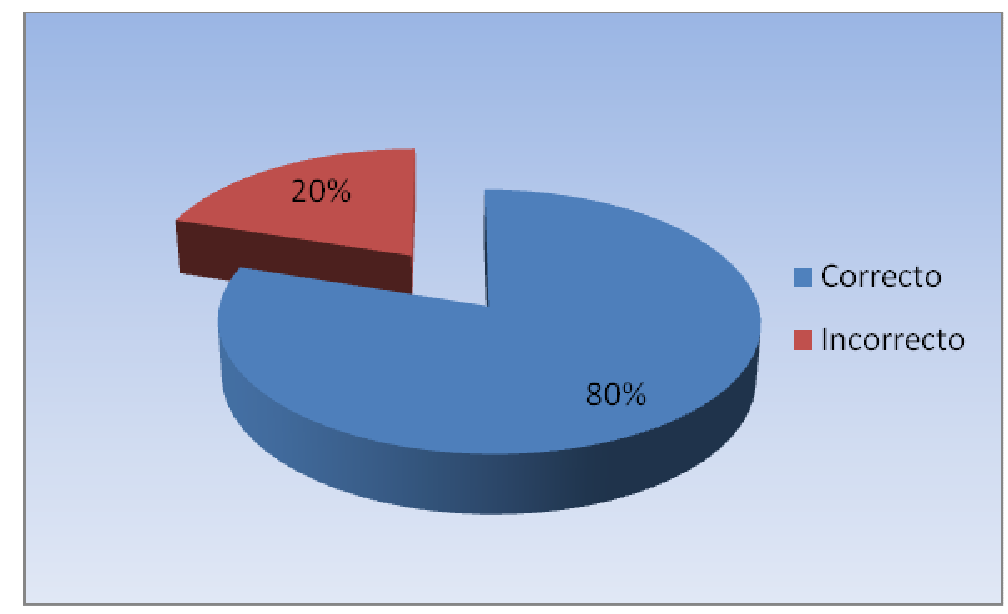

Fuente: Tabla No 41

El $80 \%$ de las madres encuestadas tiene conocimientos correctos sobre lo que es la rabia o la relacionan con el perro como el principal portador de la rabia, el $20 \%$ tiene conocimientos erróneos sobre la rabia.

Lo que significa que el mayor porcentaje de madres de familia conocen que es la rabia sin embargo no todas vacunan a los perros y gatos tan solo el $34 \%$ de madres encuestadas vacuna a los perros y el $15 \%$ vacuna a los gatos contra la rabia otra solo les vacunan en campañas de vacunación del Ministerio de Salud Pública MSP, es por eso la importancia de asistencia y asesoría técnica 
sanitaria sobre esta y otras zoonosis que son comunes especialmente en las zonas rurales.

\section{3.- NIVEL DE CONOCIMIENTOS SOBRE TOXOPLASMOSIS}

Tabla No 42

NIVEL DE CONOCIMIENTOS SOBRE TOXOPLASMOSIS EN LA

COMUNIDAD DE SAN ROQUE PERTENECIENTE AL CANTÓN SUCRE

PARROQUIA CHARAPOTÓ.PROVINCIA DE MANABÍ.2011

\begin{tabular}{ccc}
\hline Variable & f & $\%$ \\
Correcto & 0 & $0 \%$ \\
Incorrecto & 40 & $100 \%$ \\
Total & 40 & $100 \%$ \\
\hline
\end{tabular}

Fuente: Tabla No 42

El $100 \%$ de las madres encuestadas tienen conocimientos erróneos osbre lo que es la Toxoplasmosis, porque nuncxa han escuchado este término.

Es decir que la mayoría de las madres encuestadas desconoce que es la toxoplasmosis que es una de las principales zoonosis que se presentan especialmente en las zonas rurales donde existe insalubridad y gran cantidad de animales domésticos y de granja.

Sin embargo a este enfermedad ellas lo asocian con el mal del gato mas no como toxoplasmosis. 
4.- NIVEL DE CONOCIMIENTOS SOBRE LA TUNGA PENETRANS (Niguas)

Tabla No 43

NIVEL DE CONOCIMIENTOS SOBRE NIGUAS EN LA COMUNIDAD DE SAN ROQUE PERTENECIENTE AL CANTÓN SUCRE PARROQUIA CHARAPOTÓ.PROVINCIA DE MANABÍ.2011

\begin{tabular}{lcc}
\hline Variable & $\mathbf{f}$ & $\%$ \\
Correcto & 29 & $72 \%$ \\
Incorrecto & 11 & $28 \%$ \\
Total & 40 & $100 \%$ \\
& Fuente: datos de la encuesta aplicada \\
\hline
\end{tabular}

Fuente: datos de la encuesta aplicada 
Gráfico No 43

NIVEL DE CONOCIMIENTOS SOBRE NIGUAS EN LA COMUNIDAD DE SAN ROQUE PERTENECIENTE AL CANTÓN SUCRE PARROQUIA CHARAPOTÓ.PROVINCIA DE MANABÍ.2011

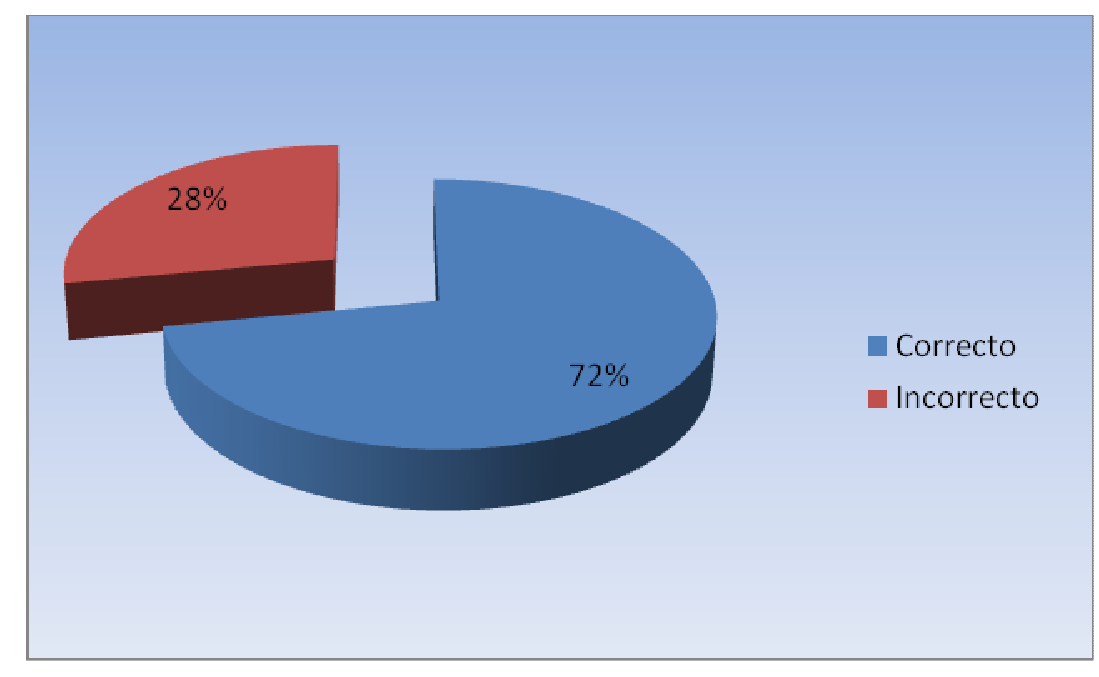

Fuente: Tabla No 43

El $72 \%$ de las encuestadas han respondido correctamente es decir tienen conocimiento de esta zoonosis, mientras que un $28 \%$ ha respondido de forma incorrecta.

Las niguas se encuentran en el pasto alto y las malezas, y su picadura produce una picazón severa. Las niguas se encuentran en ciertas áreas al aire libre, como los sembrados de bayas, pastos y malezas altas, y en el estiércol de animales. Las niguas pican a los humanos, en los tobillos o en los pliegues cálidos de la piel, las picaduras ocurren con más frecuencia en los meses de verano y otoño. 
Los caballos y porcinos quienes andan en libertad por el campo adquieren este ácaro al pasar por estas malezas que luego es transmitido a los humanos especialmente aquellos niños o adultos descalzos. Por esta razón se recomienda andar con zapatos siempre especialmente por el campo donde se desarrolla este ácaro y especialmente en época de verano y otoño.

\section{5.- NIVEL DE CONOCIMIENTOS DE HISTOPLASMOSIS}

Tabla No 44

NIVEL DE CONOCIMIENTOS SOBRE HISTOPLASMOSIS EN LA COMUNIDAD DE SAN ROQUE PERTENECIENTE AL CANTÓN SUCRE PARROQUIA CHARAPOTÓ.PROVINCIA DE MANABÍ.2011

\begin{tabular}{lcc}
\hline Variable & f & $\%$ \\
Correcto & 7 & $18 \%$ \\
Incorrecto & 33 & $83 \%$ \\
Total & 40 & $100 \%$
\end{tabular}

Fuente: datos de la encuesta aplicada 


\section{Gráfico No 44}

\section{NIVEL DE CONOCIMIENTOS SOBRE HISTOPLASMOSIS EN LA COMUNIDAD DE SAN ROQUE PERTENECIENTE AL CANTÓN SUCRE PARROQUIA CHARAPOTÓ.PROVINCIA DE MANABÍ.2011}

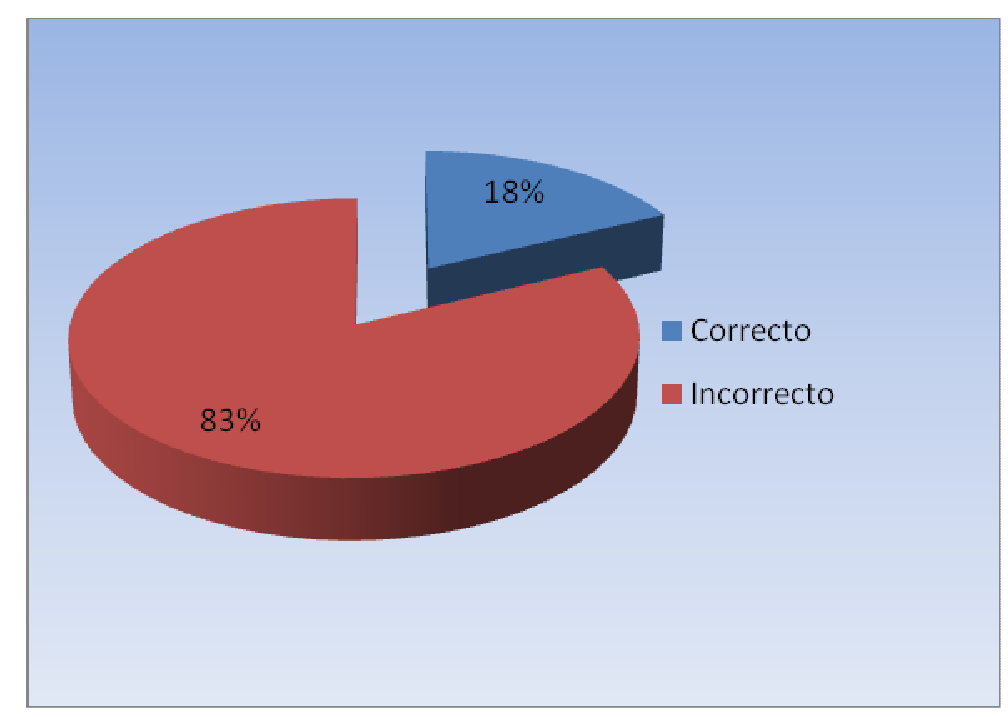

Fuente: Tabla No 44

El $83 \%$ de encuestadas desconocen sobre la histoplasmosis, tan solo un $18 \%$ tiene conocimientos sobre histoplasmosis.

En el gráfico se demuestre que un alto porcentaje de madres encuestadas desconocen sobre la histoplasmosis, y esto es debido a la falta de programa de prevención primaria de salud, y al bajo nivel de educación.

En la comunidad ya se han presentado casos de muerte por histoplasmosis; pero la comunidad no define a estos casos como histoplasmosis sino que la confunden con pulmonía. 
La histoplasmosis es una infección micótica y se presenta en todo el mundo. La infección ingresa al cuerpo a través de los pulmones. El hongo histoplasma crece como un hongo en el suelo y la infección resulta de la inhalación de partículas transportadas por el aire. El suelo contaminado con los excrementos de aves 0 de murciélagos puede tener mayores concentraciones de histoplasma.

\title{
6.- NIVEL DE CONOCIMIENTOS DE HANTAVIRUS O MAL DE HANTA
}

\author{
Tabla No 45
}

NIVEL DE CONOCIMIENTOS SOBRE HANTAVIRUS O MAL DE HANTA EN LA COMUNIDAD DE SAN ROQUE PERTENECIENTE AL CANTÓN SUCRE PARROQUIA CHARAPOTÓ.PROVINCIA DE MANABÍ.2011

\begin{tabular}{ccc}
\hline Variable & $\mathbf{f}$ & $\%$ \\
Correcto & 0 & $0 \%$ \\
Incorrecto & 40 & $100 \%$ \\
Total & 40 & $100 \%$ \\
\hline
\end{tabular}

Fuente: datos de la encuesta aplicada

El $100 \%$ de madres encuestadas desconocen completamente sobre Hantavirus o Mal de Hanta.

El que la población desconozca sobre lo que es el Mal de Hanta es normal debido a que la población desconoce términos científicos, sin embargo si se les 
hablara sobre las enfermedades que ocasiona la orina de ratas, contestarían correctamente.

El hantavirus se trasmite a los seres humanos al respirar el aire contaminado con orina, excreta ó saliva del roedor. Puede también ser transmitida manipulando roedores ó al tocarse la nariz ó la boca después de manipularlos. La mordedura de un roedor puede también trasmitir el virus. No hay evidencia que los gatos ó perros transmitan la enfermedad a los seres humanos. Usted no puede adquirir el virus por el contacto con otra persona.

7.- NIVEL DE CONOCIMIENTOS DE LEPTOSPIROSIS

Tabla No 46

NIVEL DE CONOCIMIENTOS SOBRE LEPTOSPIROSIS EN LA COMUNIDAD DE SAN ROQUE PERTENECIENTE AL CANTÓN SUCRE PARROQUIA CHARAPOTÓ.PROVINCIA DE MANABÍ.2011

\begin{tabular}{ccc}
\hline Variable & f & $\%$ \\
Correcto & 2 & $5 \%$ \\
Incorrecto & 38 & $95 \%$ \\
Total & 40 & $100 \%$ \\
\hline
\end{tabular}

Fuente: datos de la encuestaaplicada 
Gráfico No 46

NIVEL DE CONOCIMIENTOS SOBRE LEPTOSPIROSIS EN LA COMUNIDAD DE SAN ROQUE PERTENECIENTE AL CANTÓN SUCRE PARROQUIA CHARAPOTÓ.PROVINCIA DE MANABí.2011

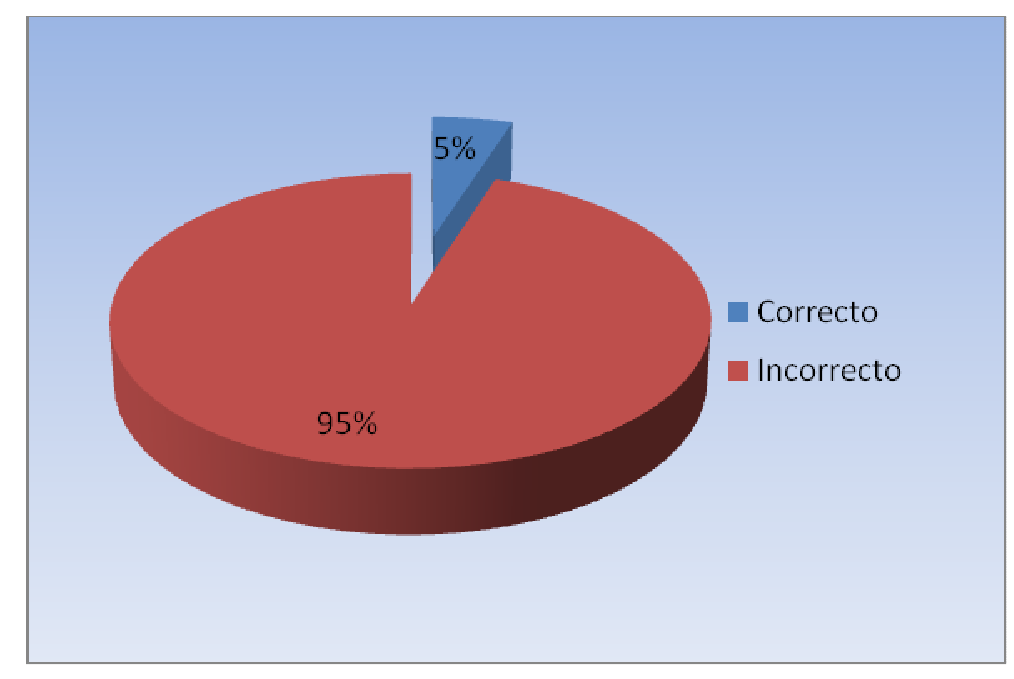

Fuente: Tabla No 46

95\% de madres encuestadas desconocen sobre la Leptospirosis, solo un $5 \%$ sabe lo que es la Leptospirosis.

La comunidad de San Roque desconoce sobre laLeptospirosis, sin embargo se han presentado varios casos de Leptospirosis en la comunidad y la han confundido con Dengue, debido a que los signos y síntomas de la enfermedad son similares, sin embargo la leptospirosis es una enfermedad mucho más grave, y el desconocimiento por parte de la población ocasiona muchas veces la muerte, si no es diagnosticada o tratada a tiempo.

La leptospirosis es una de las zoonosis más comunes y un importante problema de salud pública, aunque se desconoce la prevalencia real de esta 
enfermedad. La infección es comúnmente transmitida a humanos cuando agua que ha sido contaminada por orina animal se pone en contacto directo con lesiones en la piel, ojos o por las mucosas. En zonas no tropicales, los casos de leptospirosis muestran relativamente marcadas estaciones, donde la mayoría ocurren entre agosto y septiembre o entre febrero y marzo.

El microorganismo entra en el huésped por lesiones en la piel o por las mucosas, después de una multiplicación transitoria en partes del cuerpo acaba estableciéndose en el riñón e hígado, transmitiéndose a otros huéspedes mediante el contacto con la orina del individuo infectado.

La infección se produce por contacto directo con la orina o los tejidos del animal infectado o por medio del agua o el suelo contaminado. Se observa ictericia, hemorragia cutánea, fiebre, escalofríos y dolor muscular. Tiene una mortalidad muy elevada. 
IX RESULTADOS DE LAS EVALUACIONES DE CONOCIMIENTOS ADQUIRIDOS LUEGO DE LAS INTERVENCIONES EDUCATIVAS.

A.- LA ZOONOSIS UN PROBLEMA DE SALUD

1.- CONOCIMIENTOS DE ZOONOSIS

TABLA No 47

CONOCIMIENTOS SOBRE ZOONOSIS EN LA COMUNIDAD DE SAN ROQUE, PERTENECIENTE AL CANTÓN SUCRE PARROQUIA CHARAPOTÓ. PROVINCIA DE MANABI.2011.

\begin{tabular}{lcc}
\hline VARIABLE & $\mathbf{f}$ & $\%$ \\
CORRECTO & 37 & $93 \%$ \\
INCORRECTO & 3 & $7 \%$ \\
TOTAL & 40 & $\mathbf{1 0 0 \%}$ \\
\hline
\end{tabular}

Fuente: Encuesta de evaluación de Zoonosis 
GRÁFICO No 47

CONOCIMIENTOS SOBRE ZOONOSIS EN LA COMUNIDAD DE SAN

ROQUE, PERTENECIENTE AL CANTÓN SUCRE PARROQUIA

CHARAPOTÓ. PROVINCIA DE MANABI. 2011.

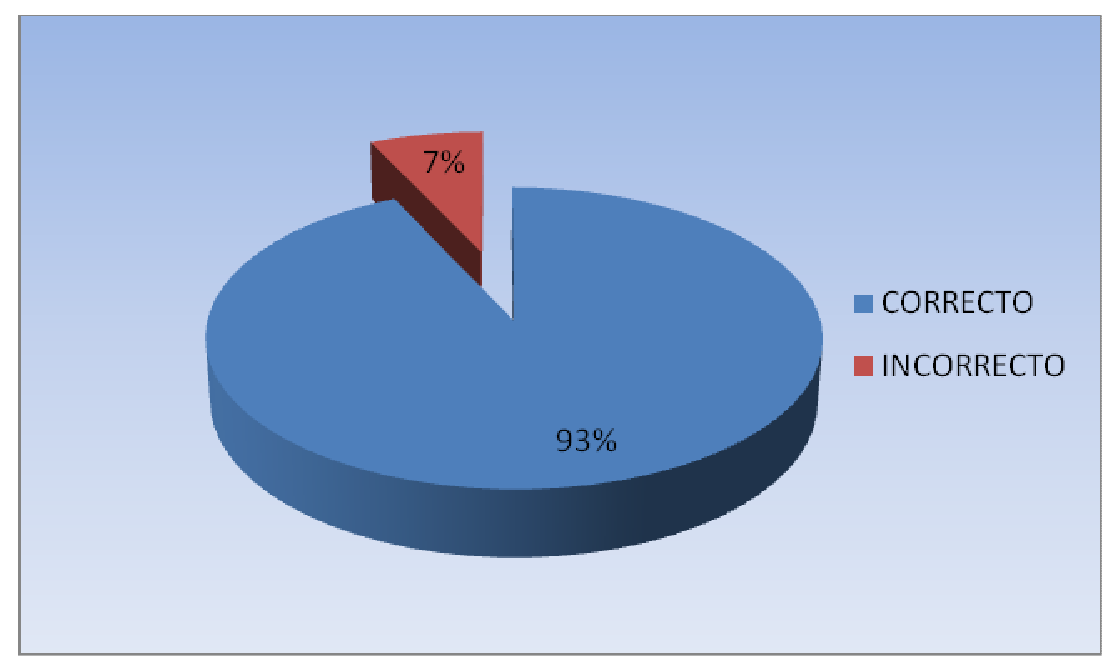

Fuente: Tabla No 47

Se puede observar en el gráfico el $93 \%$ de las madres capacitadas han adquirido conocimientos sobre lo que es la zoonosis, tan solo un $7 \%$ no tiene conocimientos claros sobre lo que es la zoonosis.

Las madres de familia que asistieron al taller de capacitación con el tema "La Zoonosis un Problema de salud" tienen conocimientos correctos sobre lo que es la zoonosis, y un mínimo porcentaje se han confundido, y esto es debido a la falta de atención, desconcentración, distracciones y también por un grado de analfabetismo existente.

La Facultad de Medicina Veterinaria, Departamento de Ciencias Pecuarias, Universidad de Concepción, en Chile se condujo un programa de educación 
sanitaria dirigido a apoderados de una escuela básica de El Rosal, comuna de Pinto. A través de una encuesta diagnóstica se encontró que un $96,5 \%$ de apoderados desconocían la palabra zoonosis, y un $100 \%$ que no sabe su concepto. Posterior a los talleres educativos el porcentaje de apoderados que reconocían la palabra zoonosis aumentó a un 45,6\% quienes mencionan el significado de esta palabra correctamente. La intervención fue eficaz en el mejoramiento de conocimientos.

La facultad de salud Pública, Escuela de Promoción y Cuidados de la salud, en Ecuador, se aplicó un programa educativo para prevenir la zoonosis en la cual a través de una encuesta diagnóstica aplicada en la comunidad de San Roque perteneciente al Cantón Sucre Parroquia Charapotó. Provincia de Manabí, y se encontró que el $70 \%$ de madres encuestadas desconocen que es la zoonosis, y un $95 \%$ no sabe su concepto. Posterior a los talleres educativos el porcentaje de asistentes que reconocían la palabra zoonosis y conocían su significado aumentó a un 93\%, encontrándose una diferencia de 47,4\% a favor es decir se alcanzó un porcentaje mayor de conocimientos en la comunidad con relación al porcentaje obtenido en Chile, y esto se debe a la metodología utilizada por el capacitador para llegar a la gente de forma clara, sencilla y entendible.

El desconocimiento, falta de educación y de asesoramiento técnico ocasionan serios problemas de zoonosis en la comunidad y a nivel de países, porque si se aplicara la prevención primaria de salud es decir un conjunto de actividades sanitarias que se realizan tanto por la comunidad o los gobiernos, como por el personal sanitario antes de que aparezca una determinada enfermedad, seguro 
que no existirían problemas de zoonosis en la comunidad, y la gente estaría capacitada para definir que es la zoonosis y la gravedad del problema.

Mediante el taller de capacitación de zoonosis se logró inculcar conocimientos sobre el tema y su importancia que nos ayudarán a reducir la incidencia y prevalencia del problema a través de la educación que es la que nos lleva al cambio, y la motivación hacia un estilo de vida saludable para todos y todas en la comunidad de San Roque.

2.- CONOCIMIENTOS SOBRE MÉTODO DE TRANSMISIÓN DIRECTA DE ZOONOSIS

TABLA No 48

MÉTODO DE TRANSMISIÓN DIRECTA DE ZOONOSIS EN LA COMUNIDAD DE SAN ROQUE, PERTENECIENTE AL CANTÓN SUCRE PARROQUIA CHARAPOTÓ. PROVINCIA DE MANABI.2011.

\begin{tabular}{lll}
\hline VARIABLE & $\mathbf{f}$ & $\%$ \\
CORRECTO & 38 & $95 \%$ \\
INCORRECTO & 2 & $5 \%$ \\
TOTAL & 40 & $100 \%$ \\
\hline
\end{tabular}

Fuente: Encuesta de evaluación de la Zoonosis 
GRÁFICO No 48

\section{MÉTODO DE TRANSMISIÓN DIRECTA DE ZOONOSIS EN LA COMUNIDAD DE SAN ROQUE, PERTENECIENTE AL CANTÓN SUCRE PARROQUIA \\ CHARAPOTÓ. PROVINCIA DE MANABI.2011.}

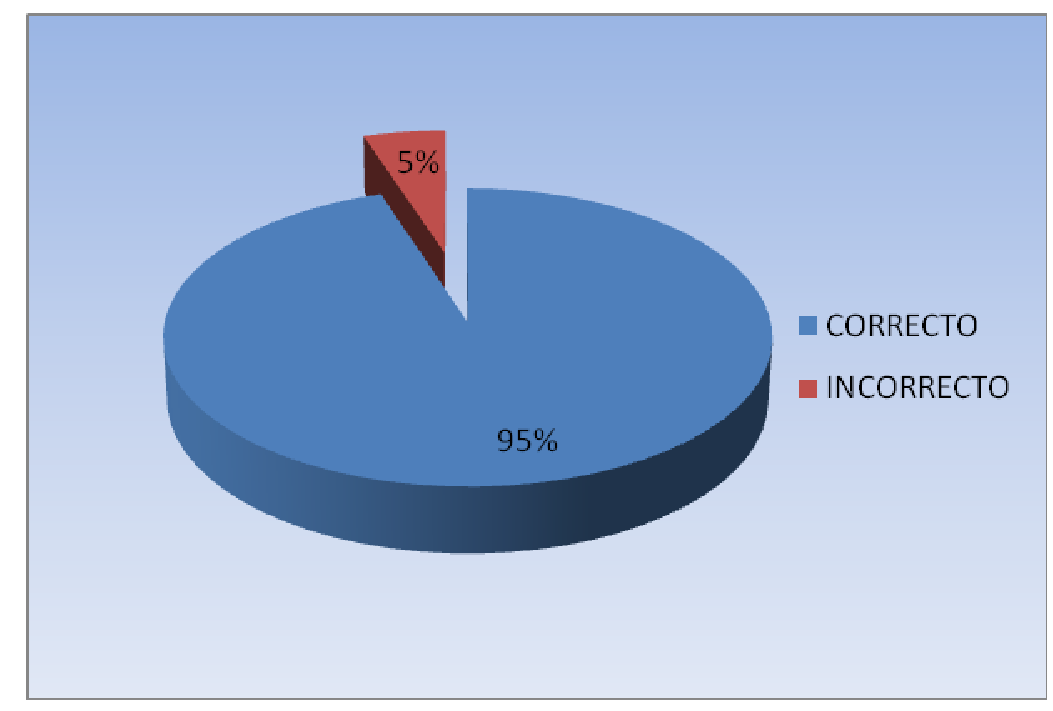

Fuente: Tabla No 48

El 95\% de las madres de familia que asistieron al taller de "La Zoonosis un Problema de salud" tienen conocimientos correctos sobre lo que es el método de transmisión directa de zoonosis que corresponde al mayor porcentaje; tan solo un $5 \%$ que corresponde a 2 personas han respondido incorrectamente.

Como se observa en el gráfico un mínimo porcentaje ha respondido a la evaluación de forma incorrecta y esto se debe a indiferencia, pereza y un grado de analfabetismo que existe en la comunidad. 
La Facultad de Medicina Veterinaria, Departamento de Ciencias Pecuarias, Universidad de Concepción, en Chile se condujo un programa de educación sanitaria dirigido a apoderados de una escuela básica de El Rosal, comuna de Pinto. A través de una encuesta diagnóstica se solicitó a los apoderados reconocer posibles vías de transmisión de zoonosis, para luego realizar una intervención educativa; luego de la cual estos señalaron: en un 91,22\% contacto directo con animales infectados, Alimentos y Medio Ambiente contaminado, como vías más reconocidas. La intervención fue eficaz en el mejoramiento de conocimientos.

La facultad de salud Pública, Escuela de Promoción y Cuidados de la salud, en Ecuador, se aplicó un programa educativo para prevenir la zoonosis en la cual a través de intervenciones educativas en la comunidad de San Roque perteneciente al Cantón Sucre Parroquia Charapotó. Provincia de Manabí, y se logró inculcar conocimientos correctos sobre el mecanismo de transmisión directa de la zoonosis alcanzando un porcentaje del 95\% de asistentes quienes tenían conocimientos correctos sobre este mecanismo de transmisión de zoonosis, lo cual representa que nuestro programa ha obtenido mayores resultados estableciéndose una diferencia de $3.78 \%$ a favor, en relación al porcentaje obtenido por la Universidad Chilena, y esto se debe a la acogida e interés de la comunidad sobre el tema, así como a la metodología y técnicas utilizadas por el educador para llegar a la gente.

La participación activa, interés, asistencia, preocupación, el deseo de superación y de adquirir conocimientos son métodos y medidas de prevención 
para lograr una comunidad libre de zoonosis donde la lucha empieza por uno y este motiva a los demás y se llega a obtener resultados satisfactorios.

3.- CONOCIMIENTOS SOBRE MÉTODO DE TRANSMISIÓN DE ZOONOSIS POR MEDIO DE VECTORES

TABLA No 49

CONOCIMIENTOS DE TRANSMISIÓN DE ZOONOSIS POR MEDIO DE VECTORES EN LA COMUNIDAD DE SAN ROQUE, PERTENECIENTE AL CANTÓN SUCRE PARROQUIA CHARAPOTÓ. PROVINCIA DE MANABI.2011

\begin{tabular}{lll}
\hline VARIABLE & $\mathbf{f}$ & $\%$ \\
CORRECTO & 37 & $93 \%$ \\
INCORRECTO & 3 & $7 \%$ \\
TOTAL & $\mathbf{4 0}$ & $\mathbf{1 0 0 \%}$ \\
\hline
\end{tabular}

Fuente: encuesta de evaluación de Zoonosis 
GRÁFICO No 49

CONOCIMIENTOS DE TRANSMISIÓN DE ZOONOSIS POR MEDIO DE

VECTORES EN LA COMUNIDAD DE SAN ROQUE, PERTENECIENTE AL

CANTÓN SUCRE PARROQUIA CHARAPOTÓ. PROVINCIA DE

MANABI.2011

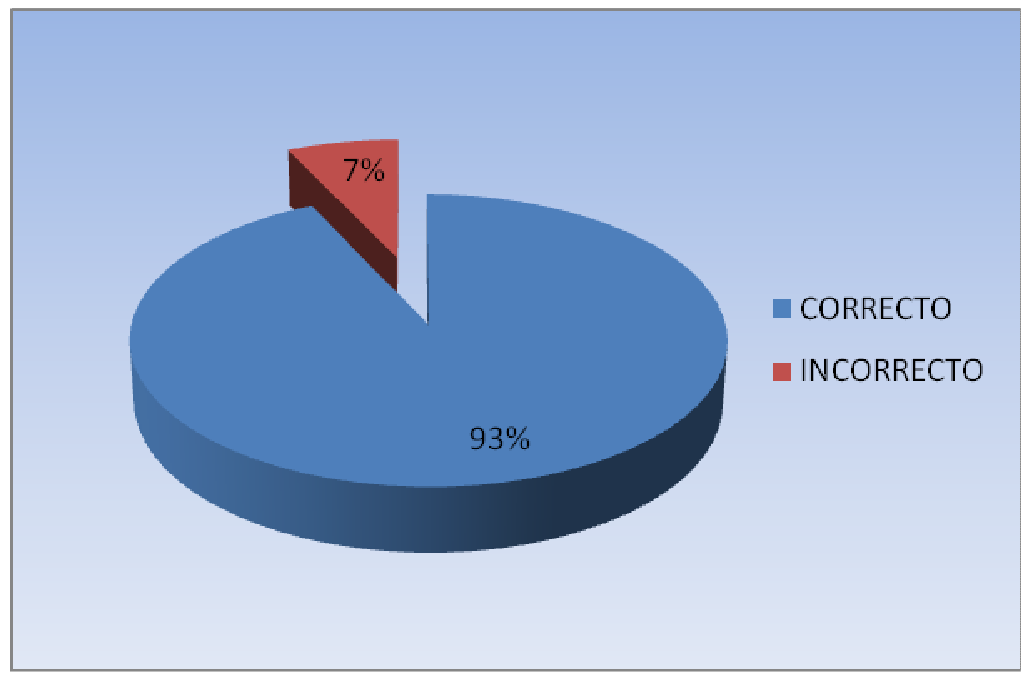

Fuente: tabla No 49

El $93 \%$ de las madres asistentes de un total de 40 han respondido correctamente a la evaluación del taller sobre el método de transmisión de zoonosis por medio de vectores, y un 7\% que corresponde a 3 madres que respondieron de forma incorrecta.

Como se encuentra representado en el gráfico la mayor parte de madres asistentes al taller tienen conocimientos correctos sobre el tema, y un menor porcentaje ha respondido de forma incorrecta probablemente por la dificultad de comprensión y por su condición de analfabetismo. 
Fruto de la evaluación el mayor porcentaje de las madres tiene conocimientos de la transmisión por medio de vectores, así sabrán cómo cuidar su salud y la de sus familias alejando y evitando a estos vectores de sus viviendas aplicando las medidas profilácticas de prevención.

B.- CAUSAS DE LA ZOONOSIS

1.- CONOCIMIENTOS SOBRE CAUSAS DE ZOONOSIS

TABLA No 50

CONOCIMIENTOS SOBRE CAUSAS DE ZOONOSIS EN LA COMUNIDAD DE SAN ROQUE, PERTENECIENTE AL CANTÓN SUCRE PARROQUIA CHARAPOTÓ. PROVINCIA DE MANABI.2011.

\begin{tabular}{lcc}
\hline VARIABLE & f & $\%$ \\
CORRECTO & 38 & $95 \%$ \\
INCORRECTO & 2 & $5 \%$ \\
TOTAL & 40 & $\mathbf{1 0 0 \%}$ \\
\hline Fuente: Encuesta de evaluación de las causas de la zoonosis
\end{tabular}


GRÁFICO No 50

CONOCIMIENTOS SOBRE CAUSAS DE ZOONOSIS EN LA COMUNIDAD DE SAN ROQUE, PERTENECIENTE AL CANTÓN SUCRE PARROQUIA CHARAPOTÓ. PROVINCIA DE MANABI

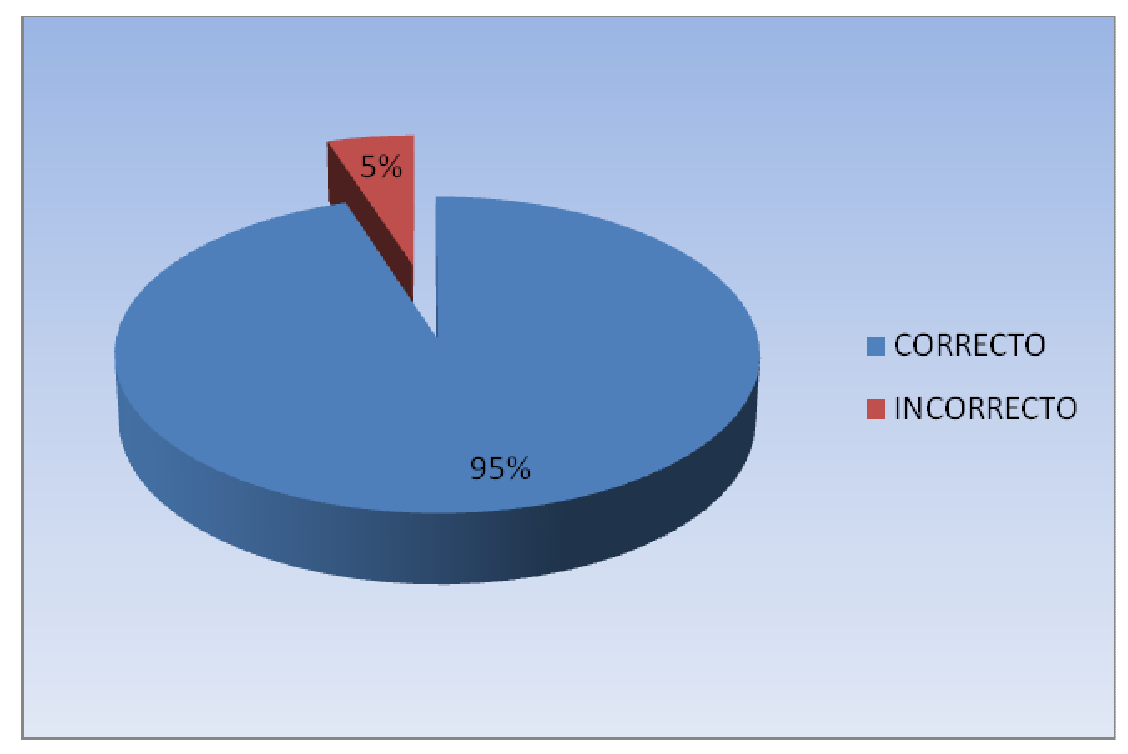

Fuente: Tabla No 50

El más alto porcentaje que corresponde al 95\% identifican correctamente las causas de la zoonosis, tan solo un $5 \%$ que corresponde al menor porcentaje respondió incorrectamente.

Un menor porcentaje ha contestado de forma incorrecta esto puede ser debido a su dificultad de captar, procesar y dominar la información y luego en desarrollarla, y al grado de analfabetismo existente.

Las madres de familia de la comunidad responden que es importante conocer las causas de la zoonosis por las siguientes razones: para no votar basura al 
campo abierto, manejo adecuado de animales, aplicar medidas profilácticas como bañar, vacunar, y desparasitar a los animales, para prevenir las diversas zoonosis.

La falta de educación, capacitación, asesoramiento, asistencia técnica, estilo de vida, e insalubridad, de verdad constituyen una de las principales causas de zoonosis y de morbilidad y mortalidad en los países pobres, donde afectan a millones de personas y están estrechamente vinculadas con la pobreza y los sectores sociales más desamparados; ausencia de programas de salud y campañas para evitar la zoonosis, esto se debe a la falta de gestión comunitaria, el desinterés, ineficiencia, poca atención de casas y centros de salud pertenecientes al Ministerio de Salud Pública, quienes son los principales encargados de velar por la salud de la población como un derecho al que tenemos acceso así como a tener atención primaria en salud la cual se orienta a los principales problemas de salud de la comunidad y presta los servicios de promoción, prevención, tratamiento, y rehabilitación necesarios para resolver los problemas de salud mediante un proceso permanente de asistencia sanitaria. 
C.- LA TOXOPLASMOSIS UN AGRAVE ENFERMEDAD ZOONÓTICA

1.- CONOCIMIENTOS ADQUIRIDOS SOBRE TOXOPLASMOSIS

TABLA No 51

CONOCIMIENTOS SOBRE TOXOPLASMOSIS EN LA COMUNIDAD DE SAN ROQUE, PERTENECIENTE AL CANTÓN SUCRE PARROQUIA CHARAPOTÓ. PROVINCIA DE MANABI.2011.

\begin{tabular}{ccc}
\hline VARIABLE & $\mathbf{f}$ & $\%$ \\
CORRECTO & 39 & $98 \%$ \\
INCORRECTO & 1 & $2 \%$ \\
TOTAL & $\mathbf{4 0}$ & $\mathbf{1 0 0 \%}$ \\
\hline
\end{tabular}

Fuente: encuesta de evaluación de la toxoplasmosis 
GRÁFICO No 51

CONOCIMIENTOS SOBRE TOXOPLASMOSIS EN LA COMUNIDAD DE SAN ROQUE, PERTENECIENTE AL CANTÓN SUCRE PARROQUIA

CHARAPOTÓ. PROVINCIA DE MANABI

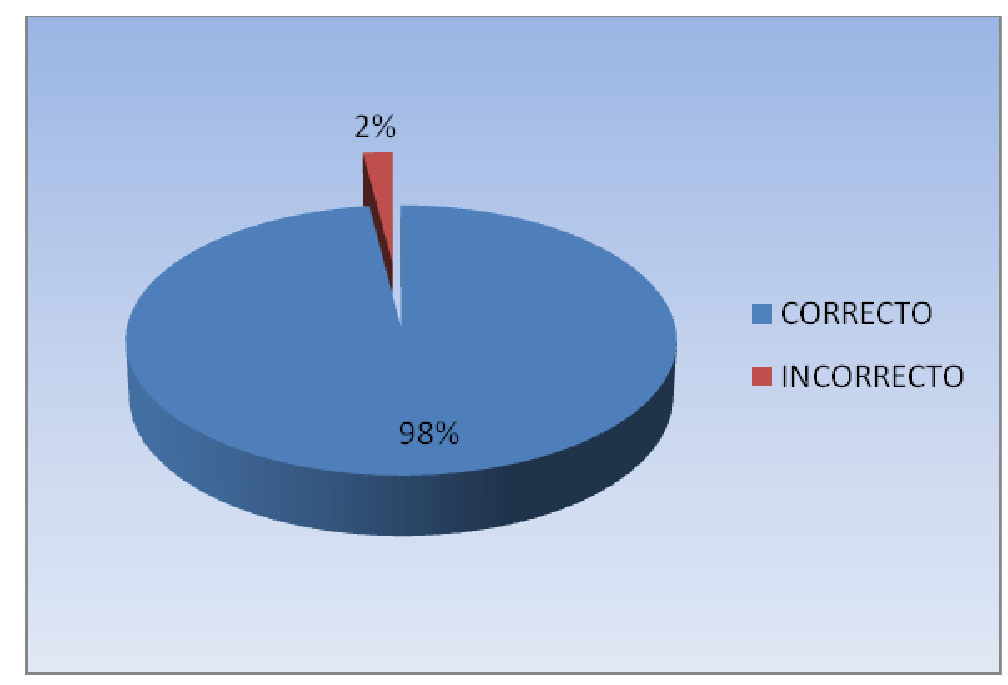

Fuente: Tabla No 51

El 98\% de las madres de familia que asistieron al taller que corresponden a 39 tienen conocimientos correctos sobre lo que es la toxoplasmosis, solo el $2 \%$ desconocen sobre la toxoplasmosis.

Es así que como se puede observar en el gráfico que el más alto porcentaje de las madres respondieron correctamente. Lo cual significa que este tema fue de gran interés en la comunidad por su importancia y por la variedad de casos de toxoplasmosis que se han presentado en la comunidad, un mínimo porcentaje ha respondido de forma incorrecta y esto es debido al grado de analfabetismo que existe en la comunidad. 
Las madres de la comunidad manifiestan conocer a la toxoplasmosis como el mal del gato o la enfermedad del gato, pero técnica y científicamente es conocida como toxoplasmosis.

La Universidad del Magdalena en convenio con la Universidad Nacional de Colombia. Mediante un estudio sobre prevalencia de infección por Toxoplasma gondii en mujeres embarazadas en Valledupar Cesar, que asistían al programa de control prenatal del Hospital Eduardo Arredondo Daza. Con una muestra de 300 mujeres embarazadas, a las cuales se les aplicó una encuesta para obtener información sobre conocimientos, situación socio demográfica, y de factores de riesgo asociados a la adquisición de toxoplasmosis, luego se les tomó una muestra de sangre para determinar anticuerpos de Toxoplasma gondii. Resultados: De las 300 madres estudiadas se encontraron 174 positivas y 126 negativas. En este estudio se encontró que el $58 \%$ de ellas conoce lo que es la toxoplasmosis, y un $42 \%$ desconoce lo cual representa un serio problema de salud pública en esta región. Además se encontró que el hecho de consumir alimentos por fuera de la casa, y de tener un bajo nivel de escolaridad, estaba asociado estadísticamente como factor de riesgo en la infección por toxoplasmosis. Luego se aplicó una capacitación sobre el tema y en la evaluación del nivel de conocimientos se elevó a un $89 \%$ de asistentes que conoce sobre la toxoplasmosis siendo satisfactoria la aplicación de esta intervención educativa e investigativa.

La Escuela Superior Politécnica de Chimborazo, Facultad de Salud Pública, Escuela de promoción y cuidados de la Salud, aplicó una intervención educativa a una muestra de 40 madres de familia de la Comunidad de San 
Roque perteneciente al Cantón Sucre, Parroquia Charapotó. Provincia de Manabí, en la cual se realizó primero encuestas para sacar un diagnóstico sobre nivel de conocimientos sobre Toxoplasmosis en el cual el $100 \%$ de encuestados desconocen sobre la toxoplasmosis, y su definición, y el desconocimiento principalmente puede deberse a que comúnmente esta enfermedad es conocida como enfermedad del gato e identificada en términos sencillos y no de forma técnica. Posteriormente se aplicó una intervención Educativa sobre la toxoplasmosis en la comunidad, y al evaluar el nivel de conocimientos adquiridos luego de la intervención se logró elevar el nivel de conocimiento a un $98 \%$.

Estableciendo una comparación entre los resultados obtenidos por la Universidad de Magdalena y nuestro estudio antes de la intervención existe mayores conocimientos por parte de las madres de Colombia con un 58\% mientras que en Ecuador el 100\% desconoce científicamente del tema, pero luego de la intervención educativa, los conocimientos se elevaron en la audiencia Colombiana como en la Ecuatoriana es así que en Colombia los conocimientos se elevaron a un 89\%; mientras que en Ecuador se logró elevar el nivel de conocimientos a un $98 \%$ de las asistentes; obteniendo un $9 \%$ a nuestro favor en relación con el Programa aplicado en Colombia, y muchas veces este resultado se debe al sistema de enseñanza aprendizaje utilizado para llegar a la comunidad que debe ser de acuerdo al nivel de instrucción de la población, despertando el interés de todos y todas. 
2.- CONOCIMIENTOS ADQUIRIDOS SOBRE CAUSAS DE LA TOXOPLASMOSIS

TABLA No 52

CONOCIMIENTOS SOBRE CAUSAS DE LA TOXOPLASMOSIS EN LA COMUNIDAD DE SAN ROQUE, PERTENECIENTE AL CANTÓN SUCRE PARROQUIA CHARAPOTÓ. PROVINCIA DE MANABI.2011.

\begin{tabular}{lcc}
\hline VARIABLE & $\mathbf{f}$ & $\%$ \\
CORRECTO & 38 & $95 \%$ \\
INCORRECTO & 2 & $5 \%$ \\
TOTAL & 40 & $\mathbf{1 0 0 \%}$ \\
\hline
\end{tabular}

Fuente: encueta de evaluación de toxoplasmosis 
GRÁFICO No 52

CONOCIMIENTOS SOBRE CAUSAS DE LA TOXOPLASMOSIS EN LA COMUNIDAD DE SAN ROQUE, PERTENECIENTE AL CANTÓN SUCRE PARROQUIA CHARAPOTÓ. PROVINCIA DE MANABI.2011.

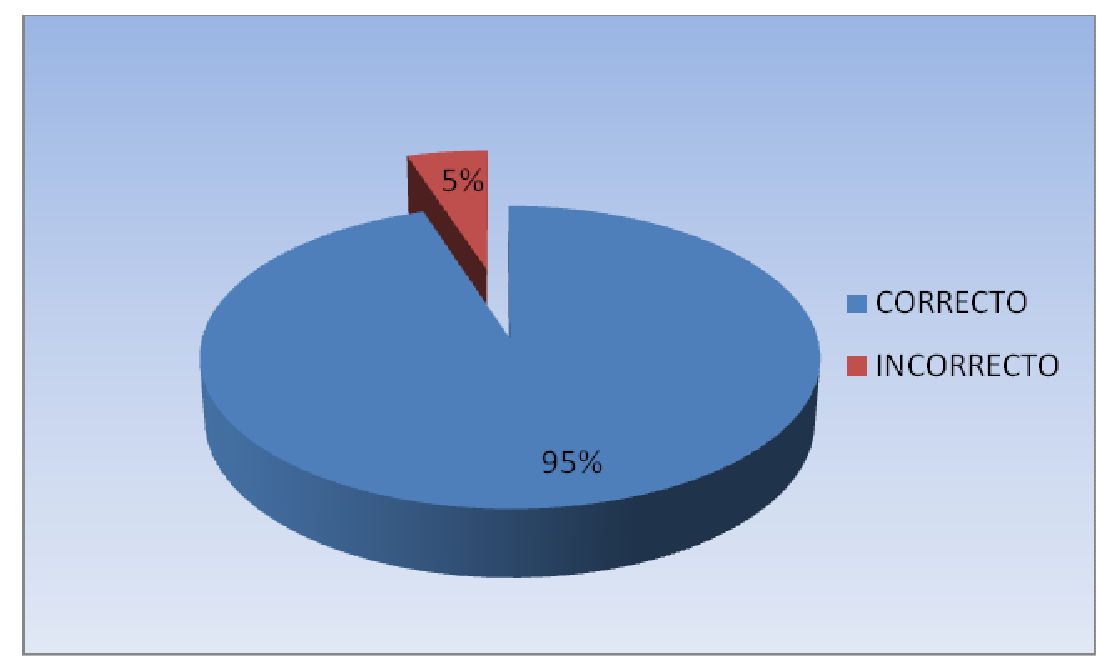

Fuente: tabla No 52

El $95 \%$ de madres asistentes al taller tienen conocimientos correctos sobre las causas de la toxoplasmosis que se trató en el taller, tan solo un $5 \%$ tiene respuestas incorrectas sobre el tema.

Fruto de la evaluación se llega a la conclusión de que el mayor porcentaje de madres de familia tienen conocimientos sobre las causas de la toxoplasmosis, pero la situación de pobreza en la que viven no les permite adquirir medios adecuados para prevenir esta enfermedad, puesto que viven con sus animales domésticos en condiciones inadecuadas, sin embargo un menor porcentaje desconoce las causas de la toxoplasmosis y esto puede deberse a : problemas 
a nivel individual, familiar y social, agotamiento físico, Voluntad débil, y analfabetismo.

3.- CONOCIMIENTOS SOBRE LAS CONSECUENCIAS DE LA TOXOPLASMOSIS

TABLA No 53

CONOCIMIENTOS SOBRE CONSECUENCIAS DE LA TOXOPLASMOSIS EN LA COMUNIDAD DE SAN ROQUE, PERTENECIENTE AL CANTÓN SUCRE PARROQUIA CHARAPOTÓ. PROVINCIA DE MANABI.2011.

\begin{tabular}{lll}
\hline VARIABLE & $\mathbf{f}$ & $\%$ \\
CORRECTO & 36 & $90 \%$ \\
INCORRECTO & 4 & $10 \%$ \\
TOTAL & $\mathbf{4 0}$ & $\mathbf{1 0 0 \%}$ \\
\hline
\end{tabular}

Fuente: encuesta de evaluación de toxoplasmosis 
GRÁFICO No 53

CONOCIMIENTOS SOBRE CONSECUENCIAS DE LA TOXOPLASMOSIS EN LA COMUNIDAD DE SAN ROQUE, PERTENECIENTE AL CANTÓN SUCRE PARROQUIA CHARAPOTÓ. PROVINCIA DE MANABI.2011.

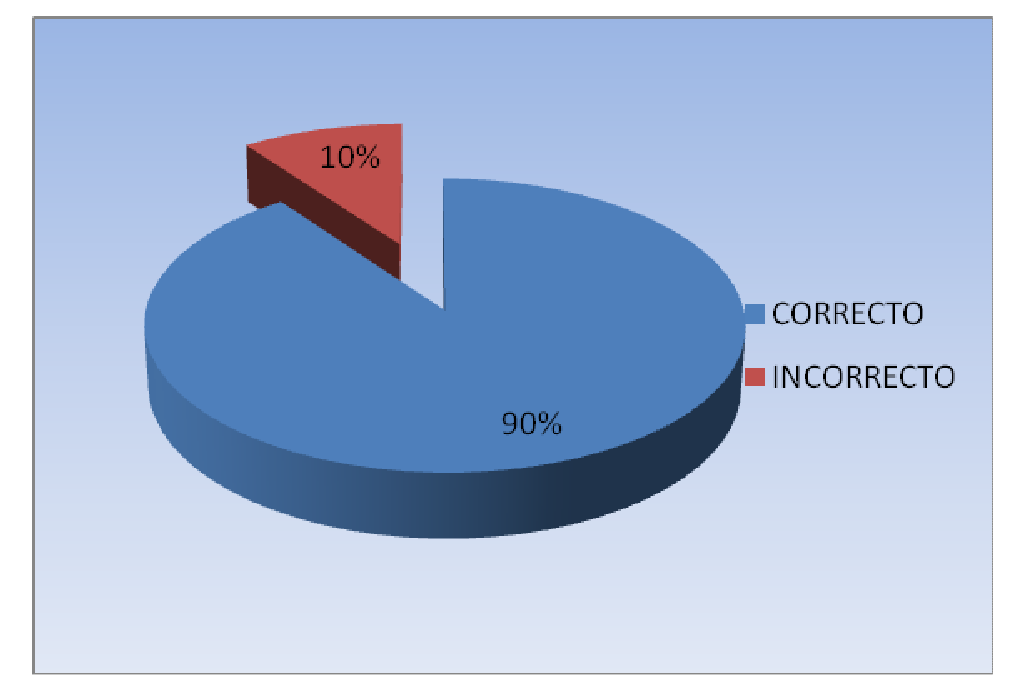

Fuente: Tabla No 53

El $90 \%$ de las madres asistentes al taller han adquirido conocimientos correctos sobre las consecuencias de la toxoplasmosis, y un $10 \%$ que es un menor porcentaje tiene conocimientos incorrectos sobre el tema.

Como se encuentra representado en el gráfico el mayor porcentaje tienen conocimientos correctos sobre las consecuencias de la toxoplasmosis, y un porcentaje inferior no ha captado correctamente la información, posiblemente las causas pueden ser desconcentración, preocupaciones, y analfabetismo y falta de educación.

La necesidad de tener felinos en la vivienda es por una situación de necesidad de que estos impidan la entrada de roedores a la vivienda. 
De dos a 10 por cada 1.000 nacidos vivos en Colombia tendrían toxoplasmosis congénita, lo que significa que con 300.000 nuevos nacimientos por año habría entre 600 y 3.000 niños con infección congénita y de éstos, entre 150 y 750 presentarían las manifestaciones características de la enfermedad en los primeros meses de vida.

La incidencia de toxoplasmosis ocular es de tres nuevos episodios por 100.000 habitantes, que resulta supremamente alta cuando se compara con Inglaterra, en donde es de 0,008 nuevos episodios por 100.000 habitantes.

La toxoplasmosis congénita es la segunda causa de ceguera infantil en ciudades como Cali,

Colombia y no está lejos de pasar a ser la primera causa. La comunidad desconoce la magnitud del problema y cuando tiene conocimiento de éste, no sabe cómo prevenirlo.

En el Ecuador La toxoplasmosis es una zoonosis que se encuentra con frecuencia en la selva húmeda y particularmente en la Costa (Lumbreras y Muñoz, 1963, Lumbreras et al. 1971). En algunas zonas de la región amazónica y en la Costa se observa la presenta de anticuerpos en un $75 \%$ o más de los pobladores. El gato es el huésped definitivo, pero todos los demás animales, incluyendo las aves, son susceptibles a la infección. El hombre puede adquirir la infección cuando ingiere carnes insuficientemente cocidas que contienen quistes de toxoplasmas. 
4.- CONOCIMIENTOS DE MEDIDAS DE PREVENCIÓN DE LA TOXOPLASMOSIS

TABLA No 54

CONOCIMIENTOS SOBRE MEDIDAS DE PREVENCIÓN DE LA TOXOPLASMOSIS EN LA COMUNIDAD DE SAN ROQUE, PERTENECIENTE AL CANTÓN SUCRE PARROQUIA CHARAPOTÓ. PROVINCIA DE MANABI.2011.

\begin{tabular}{lcc}
\hline VARIABLE & $\mathbf{f}$ & $\%$ \\
CORRECTO & 38 & $95 \%$ \\
INCORRECTO & 2 & $5 \%$ \\
TOTAL & 40 & $100 \%$ \\
\hline
\end{tabular}

Fuente: encuesta de evaluación de toxoplasmosis 
GRÁFICO No 54

CONOCIMIENTOS DE MEDIDAS DE PREVENCIÓN DE LA

TOXOPLASMOSIS EN LA COMUNIDAD DE SAN ROQUE,

PERTENECIENTE AL CANTÓN SUCRE PARROQUIA CHARAPOTÓ.

PROVINCIA DE MANABI.2011.

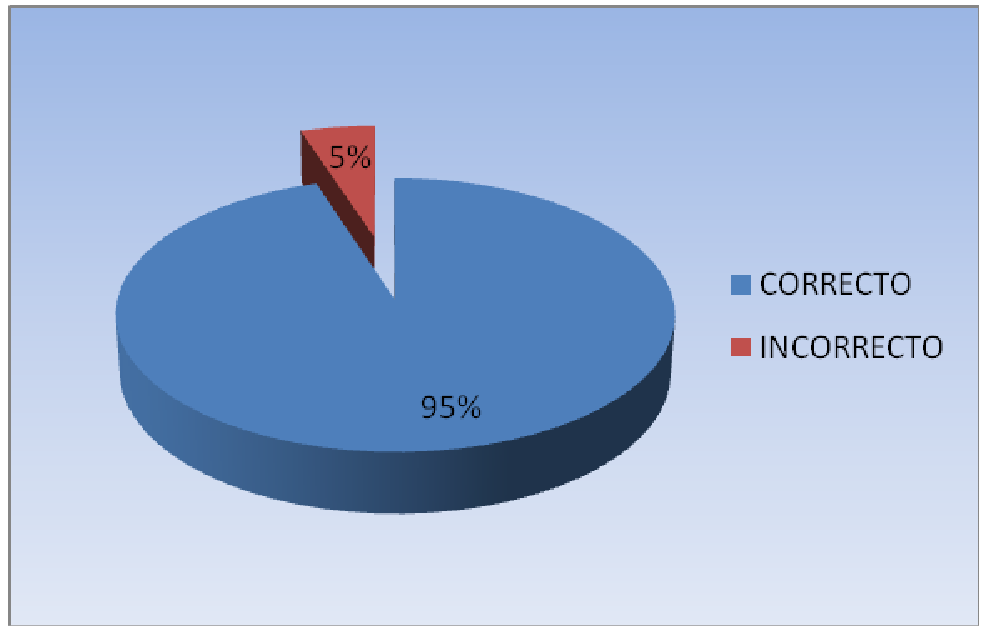

Fuente: Tabla No 54

El 95\% de las madres asistentes al taller de capacitación que corresponde al mayor porcentaje tiene conocimientos sobre las medidas para prevenir la Toxoplasmosis, y un 5\% tiene conocimientos erróneos sobre el tema.

El mayor porcentaje como lo demuestra el gráfico corresponde a las madres de familia quienes tienen conocimientos sobre cómo prevenir la toxoplasmosis y un menor porcentaje ha respondido incorrectamente debido a: falta de atención, poca capacidad de retención, y analfabetismo.

Es decir que el taller ha sido de gran interés y atención por parte de las asistentes, también ha sido muy benéfico la utilización de videos, y casos 
clínicos sobre la toxoplasmosis para llamar la atención en las asistentes y concienciar la gravedad del tema.

Las técnicas utilizadas sirvieron para llamar la atención de las participantes quienes en su mayoría tienen conocimientos sobre las medidas de prevención de la toxoplasmosis, y su actitud de admiración y de temor va a propiciar un cambio en sus condiciones y estilos de vida, empezando por evitar el contacto con estos animales y aplicando medidas profilácticas como baño, vacunación y desparasitación a estos animales domésticos para prevenir este problema de salud.

D.- PONTE ALERTA CON LA HISTOPLASMOSIS

1.- CONOCIMIENTOS SOBRE LA HISTOPLASMOSIS

TABLA No 55

LA HISTOPLASMOSIS CONOCIMIENTOS SOBRE HISTOPLASMOSIS EN LA COMUNIDAD DE SAN ROQUE, PERTENECIENTE AL CANTÓN SUCRE PARROQUIA CHARAPOTÓ. PROVINCIA DE MANABI.2011.

\begin{tabular}{lcc}
\hline VARIABLE & $\mathbf{f}$ & $\%$ \\
CORRECTO & 36 & $88 \%$ \\
INCORRECTO & 4 & $12 \%$ \\
TOTAL & $\mathbf{4 0}$ & $\mathbf{1 0 0 \%}$ \\
\hline
\end{tabular}

Fuente: encuesta de evaluación de la Histoplasmosis 
GRÁFICO No 55

CONOCIMIENTOS SOBRE HISTOPLASMOSIS EN LA COMUNIDAD DE SAN ROQUE, PERTENECIENTE AL CANTÓN SUCRE PARROQUIA CHARAPOTÓ. PROVINCIA DE MANABI.2011.

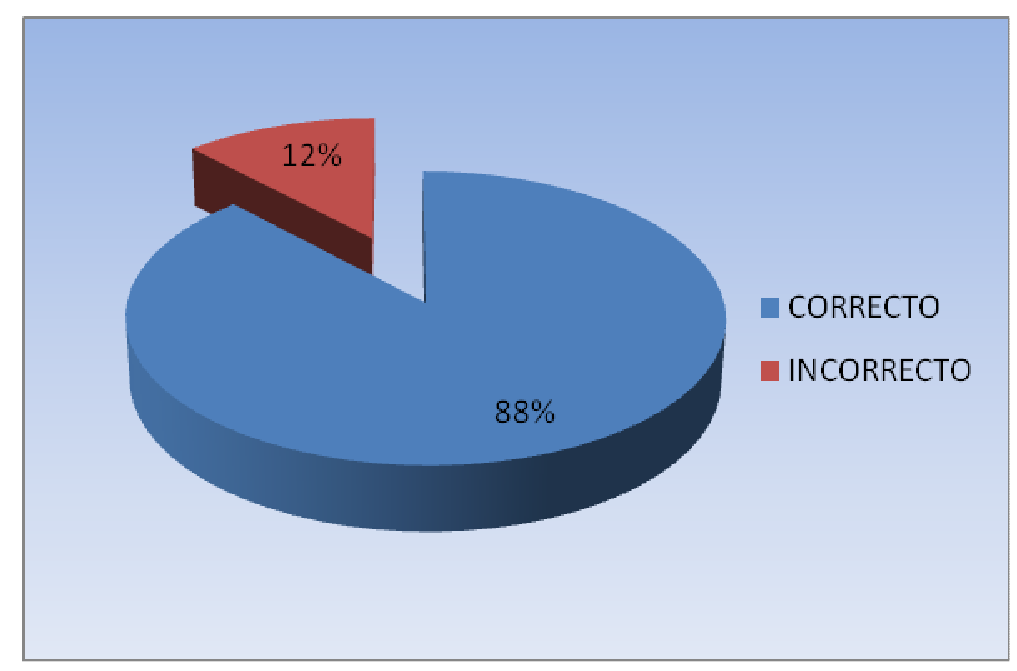

Fuente: Tabla No 55

$88 \%$ de madres asistentes al taller de histoplasmosis tienen conocimientos correctos sobre el tema y un $12 \%$ tiene conocimientos erróneos sobre el tema.

Fruto de la evaluación se llega a la conclusión de que el mayor porcentaje de madres de familia tienen conocimientos sobre Histoplasmosis, y un menor porcentaje ha respondido de forma incorrecta por los siguientes motivos: atraso, desconcentración, analfabetismo, indisciplina, y bulla.

En conclusión la capacitación ha sido adecuada y se recomienda que apliquen los conocimientos, y se los difunda a todos quienes conforman la comunidad para que conozcan la gravedad del problema y se busque la manera de evitarlo, especialmente si ya se han presentado casos de Histoplasmosis en la 
comunidad. La educación es la mejor medida de prevención, y la práctica es la evaluación final del cambio de actitud de la gente.

Los conocimientos que existen en Venezuela sobre la histoplasmosis no están bien sistematizados, debido a la ausencia de un programa de vigilancia epidemiológica de las micosis. Si se realizaran estudios epidemiológicos se revelaría posiblemente la existencia de un número importante de brotes; sin embargo, como las micosis endémicas no son de denuncia obligatoria, no se puede apreciar el problema real en toda su dimensión. La falta de información ha hecho que las micosis no se consideren un problema de salud pública importante y, en consecuencia, han ocupado posiciones muy bajas en la escala de prioridades nacionales. Los esfuerzos conjuntos de los grupos de trabajo en Micología, haciendo revisiones periódicas de las experiencias diagnósticas, han revelado que la morbilidad de la histoplasmosis es significativa; pero estos esfuerzos no abarcan todo el territorio nacional.

Dada la distribución ubicua de Histoplasmosis, evitar el contacto con este hongo es una tarea difícil; además, el público desconoce la existencia de la enfermedad y cómo se adquiere alcanzando un porcentaje del $78 \%$ de desconocimientos por su parte. Tampoco resulta fácil, hasta los momentos, evitar que la enfermedad ocurra, ya que el hongo posee una gran capacidad de adaptación, que le permite sobrevivir en el suelo.

El desconocimiento que existe en Ecuador con respecto a la Histoplasmosis es del 97\% mayor al porcentaje de desconocimiento de esta micosis en Venezuela que es de $78 \%$, la diferencia es del $19 \%$ para nuestro país sin 
embargo en Venezuela el problema queda sin resolver, mientras que en Ecuador al obtener estos resultados hemos visto la necesidad de aplicar intervenciones Educativas para Prevenir esta zoonosis utilizando la metodología de enseñanza aprendizaje en una muestra de personas de la Comunidad de San Roque perteneciente a la costa de Manabí, Cantón Sucre Parroquia Charapotó, quienes luego fueron evaluadas sobre el nivel de conocimientos adquiridos obteniendo como resultado que el $88 \%$ de asistentes tienen conocimientos sobre histoplasmosis y cómo prevenirla.

Fruto de la evaluación podemos decir que las intervenciones han sido satisfactorias, ya que esto lo podemos medir en los resultados obteniendo un aumento en el nivel de conocimientos en esta población después de la intervención del 88\%. 
2.- CONOCIMIENTOS SOBRE LA FORMA DE TRANSMISIÓN DE LA HISTOPLASMOSIS A LAS PERSONAS.

TABLA No 56

CONOCIMIENTOS SOBRE MECANISMO DE TRANSMISIÓN DE HISTOPLASMOSIS EN LA COMUNIDAD DE SAN ROQUE, PERTENECIENTE AL CANTÓN SUCRE PARROQUIA CHARAPOTÓ. PROVINCIA DE MANABI.2011.

\begin{tabular}{lcc}
\hline VARIABLE & $\mathbf{f}$ & $\%$ \\
CORRECTO & 37 & $93 \%$ \\
INCORRECTO & 3 & $7 \%$ \\
TOTAL & $\mathbf{4 0}$ & $\mathbf{1 0 0 \%}$ \\
\hline
\end{tabular}

Fuente: encuesta de evaluación de la Histoplasmosis 
GRÁFICO No 56

CONOCIMIENTOS SOBRE MECANISMO DE TRANSMISIÓN DE HISTOPLASMOSIS EN LA COMUNIDAD DE SAN ROQUE, PERTENECIENTE AL CANTÓN SUCRE PARROQUIA CHARAPOTÓ. PROVINCIA DE MANABI.2011.

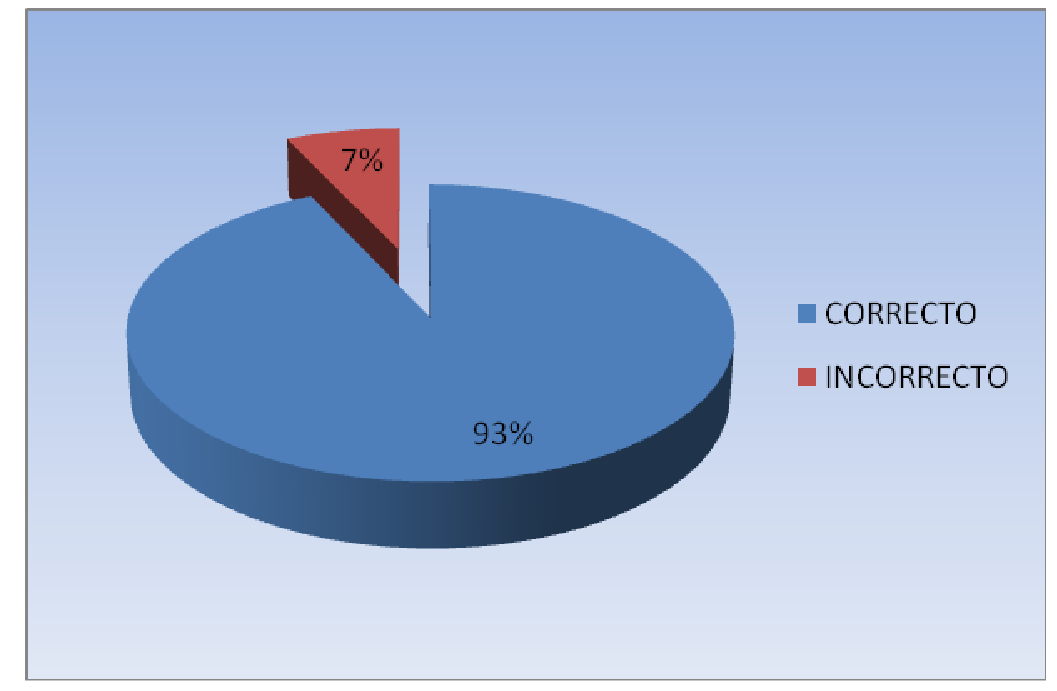

Fuente: Tabla No 56

El 93\% de madres asistentes al los talleres han respondido correctamente, y un $7 \%$ ha respondido de forma incorrecta.

Como se observa en el gráfico el mayor porcentaje de madres que asistieron al taller de histoplasmosis tiene conocimientos sobre el mecanismo de transmisión de la histoplasmosis, sin embargo un menor porcentaje no tiene conocimientos claros sobre el tema las causas son: desconcentración, poca memorización, y analfabetismo. 
En México esta micosis debería ser considerada con más atención por las autoridades de salud para reconsiderar su reincorporación al Sistema Nacional de Vigilancia Epidemiológica. Debido a la necesidad de incrementar estudios epidemiológicos para definir criterios de endemicidad, realizar muestreos de suelo y excretas, sobre todo en sitios públicos de riesgo por actividades recreativas u ocupacionales, determinar y actualizar los datos de prevalencia de la histoplasmosis, además de implementar estudios de posibles reservorios del hongo en la naturaleza, implementar talleres educativos para educar a la gente sobre el tema, mecanismo de transmisión, y de prevención como parte de un Programa Nacional de Vigilancia Epidemiológica, ya que los índices de infección y letalidad en el país son de los más altos del mundo.

Por lo expuesto, implementar una Red de Monitoreo de la Histoplasmosis en México y Latinoamérica contribuiría a los programas epidemiológicos de la enfermedad además de su vigilancia, y posibilitaría en futuro cercano establecer acciones efectivas que reduzcan el riesgo de infección para las poblaciones más susceptibles.

En Ecuador también se han presentado casos de histoplasmosis, y muchas veces se debe al mecanismo de transmisión de esta micosis causada por estiércol de aves y pájaros que defecan en el suelo y afecta por la inhalación de esta bacteria, especialmente en la costa el clima constituye un factor de riesgo para acelerar su propagación de esta micosis y por la tenencia de animales y principalmente de aves y gallinas de corral en casi todas las viviendas. Por esta razón también es recomendable mantener un sistema de 
control y educación epidemiológica en los sectores con mayores problemas de zoonosis para educar a la población sobre posibles enfermedades zoonóticas como la histoplasmosis, conocer de que se trata, su mecanismo de transmisión y de prevención.

3.- CONOCIMIENTOS SOBRE LA PREVENCIÓN DE LA HISTOPLASMOSIS

TABLA No 57

CONOCIMIENTOS SOBRE PREVENCIÓN DE HISTOPLASMOSIS EN LA COMUNIDAD DE SAN ROQUE, PERTENECIENTE AL CANTÓN SUCRE PARROQUIA CHARAPOTÓ. PROVINCIA DE MANABI.2011.

\begin{tabular}{lcc}
\hline VARIABLE & $\mathbf{f}$ & $\%$ \\
CORRECTO & 38 & $95 \%$ \\
INCORRECTO & 2 & $5 \%$ \\
TOTAL & 40 & $100 \%$
\end{tabular}

Fuente: encuesta de evaluación de la Histoplasmosis 
GRÁFICO No 57

CONOCIMIENTOS SOBRE PREVENCIÓN DE HISTOPLASMOSIS EN LA COMUNIDAD DE SAN ROQUE, PERTENECIENTE AL CANTÓN SUCRE

PARROQUIA CHARAPOTÓ. PROVINCIA DE MANABI.2011.

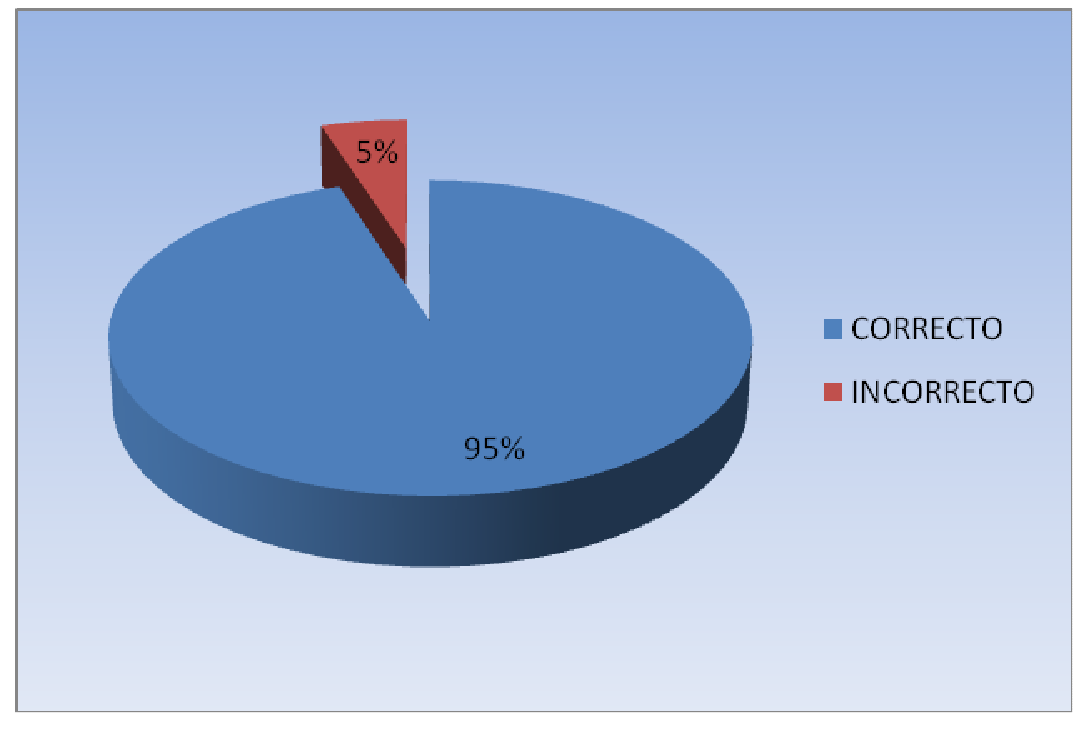

Fuente: Tabla No 57

El $95 \%$ de las madres que fueron evaluadas luego del taller tiene conocimientos correctos sobre las medidas para prevenir la histoplasmosis que es el mayor porcentaje, y un $5 \%$ correspondiente al menor porcentaje tiene conocimientos erróneos sobre el tema.

Por medio de la evaluación se llega a la conclusión de que el mayor porcentaje de madres de familia tienen conocimientos de cómo prevenir la Histoplasmosis, 
y un menor porcentaje desconoce las medidas de prevención por su distracción, bullicio, desconcentración, y analfabetismo.

La capacitación ha sido adecuada y se recomienda que apliquen sus conocimientos, de una forma saludable, cuidando de sus familias y practicando las medidas higiénico sanitarias que nos ayudan a prevenir el problema evitando riesgos sin olvidar que la pobreza no es una escusa para mantener limpia la vivienda, y manejo adecuado de estiércol de animales de granja.

E.- MAL DE HANTA

1.- CONOCIMIENTOS DEL MAL DE HANTA

TABLA No 58

CONOCIMIENTOS SOBRE MAL DE HANTA EN LA COMUNIDAD DE SAN

ROQUE, PERTENECIENTE AL CANTÓN SUCRE PARROQUIA

CHARAPOTÓ. PROVINCIA DE MANABI.2011.

\begin{tabular}{lll}
\hline \multicolumn{1}{c}{ VARIABLE } & f & $\%$ \\
CORRECTO & 37 & $93 \%$ \\
INCORRECTO & 3 & $7 \%$ \\
TOTAL & 40 & $100 \%$ \\
\hline
\end{tabular}

Fuente: encuesta de evaluación del Mal de Hanta 
GRÁFICO No 58

CONOCIMIENTOS SOBRE MAL DE HANTA EN LA COMUNIDAD DE SAN ROQUE, PERTENECIENTE AL CANTÓN SUCRE PARROQUIA

CHARAPOTÓ. PROVINCIA DE MANABI.2011.

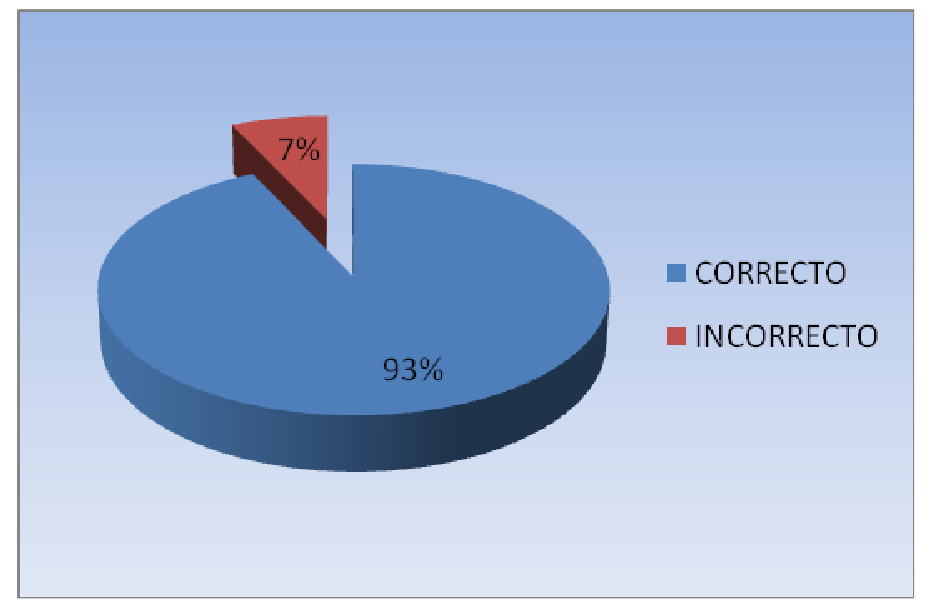

Fuente: Tabla No 58

El $93 \%$ de las madres que asistieron al taller tienen conocimientos correctos sobre lo que es el mal de Hanta, y un $7 \%$ tiene conocimientos incorrectos del tema.

En el gráfico se demuestra que el mayor porcentaje de madres de familia tiene conocimientos correctos sobre lo que es el Mal de hanta, y un menor porcentaje desconoce sobre el tema y han respondido de forma incorrecta, las causas son: falta de atención, exceso de ruido, memoria baja, analfabetismo. 
Sin embargo las condiciones en las que viven, el clima, la estructura de sus viviendas y por estar en la zona rural de Portoviejo existe gran cantidad de roedores causantes de este mal y este es un problema de salubridad que le corresponde al departamento de Sanidad del Ministerio de Salud Pública.

En Cuba De un total de 20 participantes a un Programa de prevención del Hantavirus, el 89\% concluyó que las actividades les aportaron nuevos conocimientos; el $78 \%$ de los materiales entregados fueron juzgados como muy buenos; el $86 \%$ consideró que los conocimientos adquiridos pueden ser aplicados en sus actividades laborales y en el hogar; el $80 \%$ consideró que la modalidad de la actividad se había ajustado a sus necesidades.

En Ecuador mediante un programa Educativo de prevención de zoonosis y en este caso de Hantavirus, se realizaron intervenciones educativas y al término de estas se evaluó obteniendo el 93\% de participantes quienes adquirieron conocimientos sobre Hantavirus, transmisión y prevención, y evaluaron a la intervención como interesante, clara y entendible, divertida y concreta.

Mediante la evaluación se logró inculcar a las madres asistentes al taller conocimientos que servirán para sensibilizar y concientizar la importancia de este problema de salud, para prevenir aplicando medidas preventivas que se encuentran a su alcance. 
2.- CONOCIMIENTOS DE MECANISMO DE TRANSMISIÓN DEL MAL DE HANTA

TABLA No 59

CONOCIMIENTOS SOBRE MECANISMO DE TRANSMISIÓN DEL MAL DE HANTA EN LA COMUNIDAD DE SAN ROQUE, PERTENECIENTE AL CANTÓN SUCRE PARROQUIA CHARAPOTÓ. PROVINCIA DE MANABI.2011.

\begin{tabular}{ccc} 
Variable & f & $\%$ \\
CORRECTO & 38 & $95 \%$ \\
INCORRECTO & 2 & $5 \%$ \\
TOTAL & 40 & $100 \%$ \\
\hline
\end{tabular}

Fuente: encuesta de evaluación del Mal de Hanta 
GRÁFICO No 59

CONOCIMIENTOS SOBRE MECANISMO DE TRANSMISIÓN DEL MAL DE HANTA EN LA COMUNIDAD DE SAN ROQUE, PERTENECIENTE AL CANTÓN SUCRE PARROQUIA CHARAPOTÓ. PROVINCIA DE MANABI.2011.

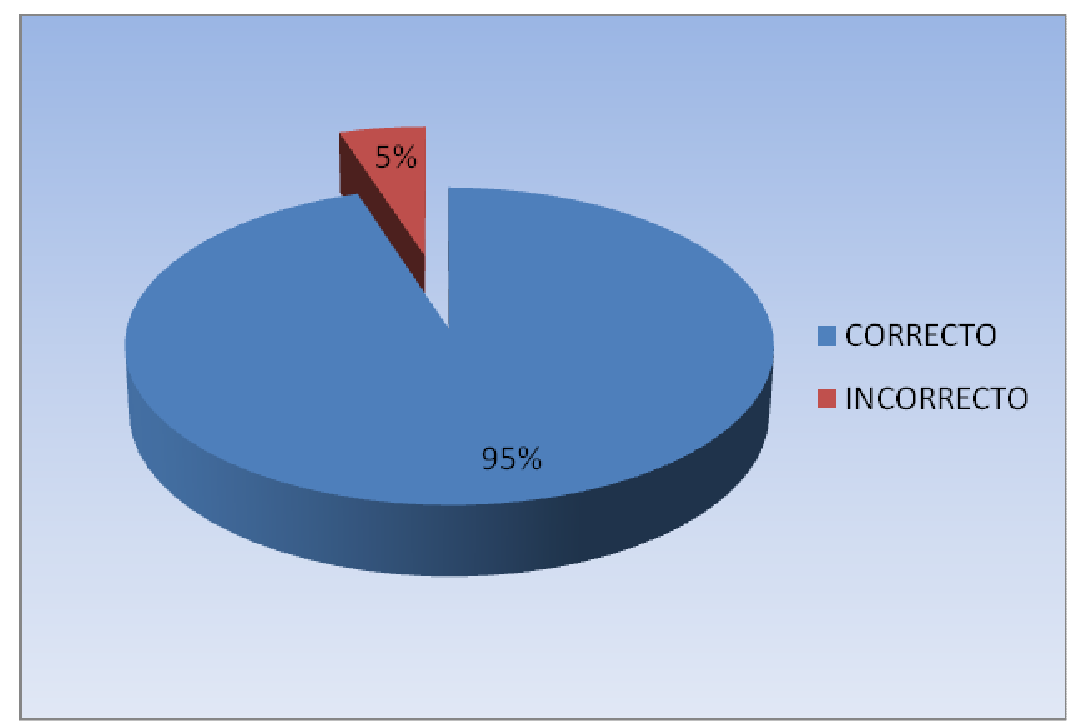

Fuente: tabla No 59

El $95 \%$ de las madres asistentes al taller han respondido de forma correcta sobre el mecanismo de transmisión del Mal de Hanta, que es el mayor porcentaje, un $5 \%$ ha respondido de forma incorrecta, por su distracción, y por analfabetismo

En el gráfico se demuestra que el mayor porcentaje de madres que asistieron al taller han adquirido conocimientos correctos sobre la forma de transmisión; 
sin embargo la insalubridad existente en la comunidad, la presencia de basura eliminada al campo abierto, hierbas altas y pastizales hace que se propaguen cada vez más y más cantidades de roedores, tomando en cuenta que el clima propicia a su reproducción, y estos problemas no están a su alcance para poder resolverlos.

Es por esto que se recomienda un manejo adecuado de basura para prevenir esta zoonosis, y evitar que cada vez sean más los roedores quienes se encuentren dentro o fuera de la vivienda, cortar los pastizales altos, y de esta manera prevenir todo lo que se encuentra a nuestro alcance.

3.- CONOCIMIENTOS SOBRE CÓMO PREVENIR EL MAL DE HANTA

TABLA No 60

CONOCIMIENTOS SOBRE CÓMO PREVENIR EL MAL DE HANTA EN LA COMUNIDAD DE SAN ROQUE, PERTENECIENTE AL CANTÓN SUCRE PARROQUIA CHARAPOTÓ. PROVINCIA DE MANABI.2011.

\begin{tabular}{lcc}
\hline VARIABLE & & $\mathbf{f}$ \\
CORRECTO & 36 & $90 \%$ \\
INCORRECTO & 4 & $10 \%$ \\
TOTAL & $\mathbf{4 0}$ & $\mathbf{1 0 0 \%}$ \\
\hline
\end{tabular}

Fuente: encuesta de evaluación del Mal de Hanta 
Gráfico No 60

CONOCIMIENTOS SOBRE CÓMO PREVENIR EL MAL DE HANTA EN LA COMUNIDAD DE SAN ROQUE, PERTENECIENTE AL CANTÓN SUCRE PARROQUIA CHARAPOTÓ. PROVINCIA DE MANABI.2011.

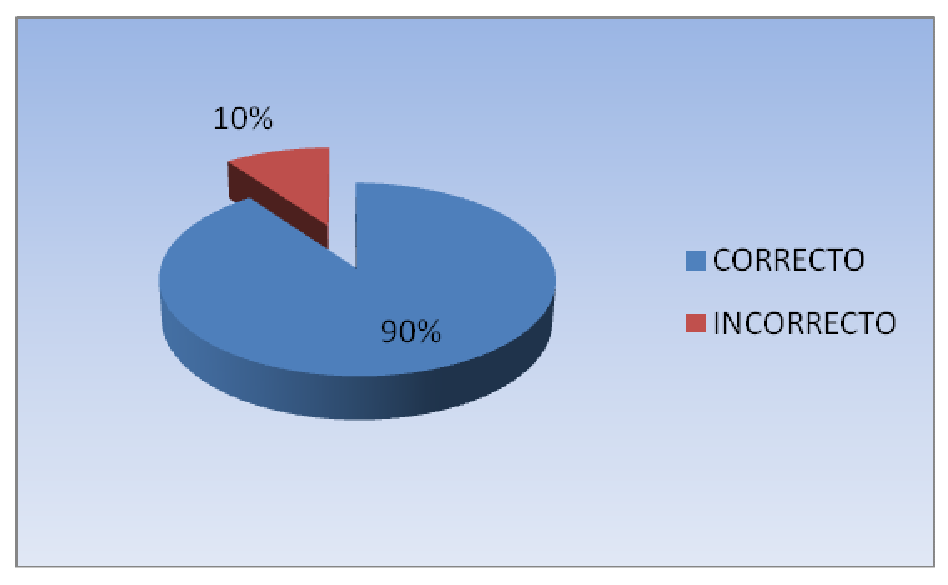

Fuente: Tabla No 60

El $90 \%$ de madres de familia que asistieron al taller tienen conocimientos correctos sobre las medidas de prevención del Mal de Hanta, y un menor porcentaje que representa al $10 \%$ han respondido de forma incorrecta.

Como lo demuestra el gráfico el mayor porcentaje de madres tienen conocimientos correctos de cómo prevenir esta zoonosis, sin embargo un menor porcentaje ha respondido de forma incorrecta, debido a: falta de 
atención, bulla, procesan la información de una forma más lenta y principalmente analfabetismo.

Fruto de la evaluación el mayor porcentaje de madres conoce cómo prevenir esta zoonosis desde sus hogares, pero hasta que no se suscite este problema en la comunidad puede pasar desapercibido.

Es por esto que se debe poner en práctica los conocimientos adquiridos no esperar a que pasé, en la educación está la prevención en el compromiso de cada una de las madres como amas de casa encargadas de velar por la salud de sus familias.

F) LA LEPTOSPIROSIS UNA ENFERMEDAD DE ALERTA

1.- CONOCIMIENTOS SOBRE LA LEPTOSPIROSIS

TABLA No 61

CONOCIMIENTOS SOBRE LEPTOSPIROSIS EN LA COMUNIDAD DE SAN ROQUE, PERTENECIENTE AL CANTÓN SUCRE PARROQUIA CHARAPOTÓ. PROVINCIA DE MANABI.2011.

\begin{tabular}{|c|c|c|}
\hline VARIABLE & $f$ & $\%$ \\
\hline CORRECTO & 39 & $97 \%$ \\
\hline
\end{tabular}




\begin{tabular}{lll}
\hline INCORRECTO & 1 & $3 \%$ \\
TOTAL & $\mathbf{4 0}$ & $\mathbf{1 0 0 \%}$ \\
\hline
\end{tabular}

Fuente: encuesta de evaluación del la leptospirosis

GRAFICO No 61

CONOCIMIENTOS SOBRE LEPTOSPIROSIS EN LA COMUNIDAD DE SAN

ROQUE, PERTENECIENTE AL CANTÓN SUCRE PARROQUIA

CHARAPOTÓ. PROVINCIA DE MANABI.2011.

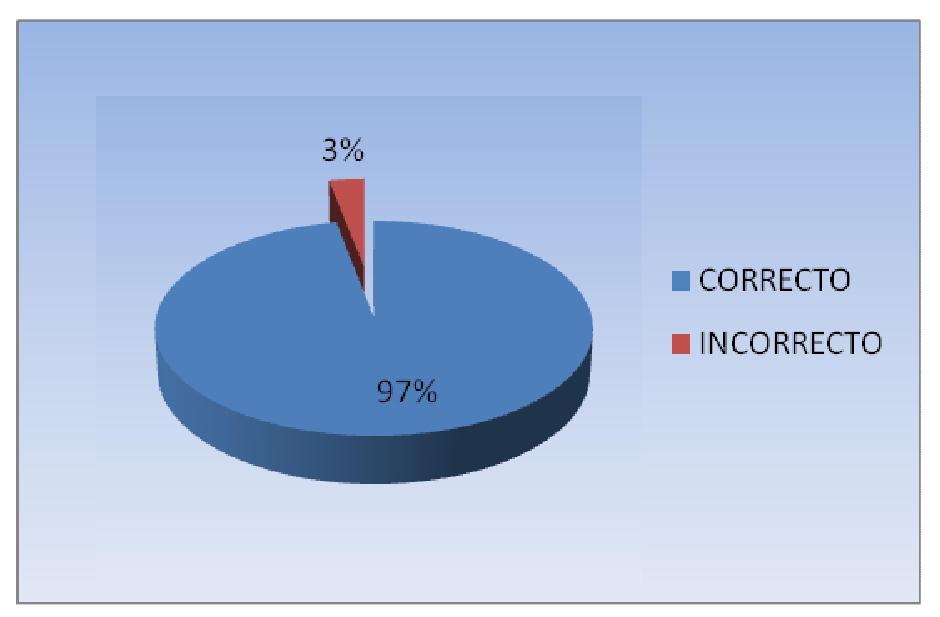

Fuente: Tabla No 61

97\% de madres asistentes al taller han respondido correctamente sobre la leptospirosis, que es el mayor porcentaje, frente a un $3 \%$ que ha respondido la evaluación de forma incorrecta.

El mayor porcentaje encuestado tiene conocimientos correctos sobre lo que es la leptospirosis, pero un menor porcentaje ha respondido de forma incorrecta y 
esto puede deberse a:Impulsiva distracción, baja atención, y bajo nivel de instrucción.

La evaluación de conocimientos sobre el tema difundido representa un alto porcentaje de asistentes quienes ponen interés en el tema especialmente porque se han presentado casos de muerte por leptospirosis, en niños de la comunidad, pero la realidad está en que el tema se hace más interesante y llama la atención el momento en el que se han dado casos de leptospirosis en la comunidad y que han causado morbilidad y mortalidad, porque si no fuese grave el problema pasaría desapercibido.

En Cuba, el Programa Nacional de Prevención y Control de la leptospirosis es actualmente uno de los priorizados del Ministerio de Salud Pública. Tiene entre sus objetivos reducir la incidencia en la morbilidad y mortalidad por esta enfermedad en el país,teniendo en cuenta que durante los últimos años la leptospirosis nos ha afectado notablemente y ha provocado brotes vinculados fundamentalmente a adversidades climáticas, en los que se han demostrado las dificultades que enfrentamos en cuanto a su vigilancia clínica, epidemiológica y microbiológica.

En el Ecuador, la insalubridad, ubicación de las viviendas y el clima de la costa propician la propagación de enfermedades es por eso que se recomienda limpiar dentro y fuera de las viviendas, realizar mingas de limpieza, no acumular agua estancadas cerca de la vivienda, también se han identificado como factores de riesgo bañarse o vivir cerca del rio, vivir en áreas con pobres condiciones sanitarias y no usar zapatos. 
La mayor parte de asistentes al taller de leptospirosis va a poner en práctica los conocimientos por la gravedad del caso y además se comprometen a difundirlo en la comunidad.

2.- CONOCIMIENTOS SOBRE MECANISMO DE TRANSMISIÓN DE LA LEPTOSPIROSIS

TABLA No 62

CONOCIMIENTOS SOBRE MECANISMO DE TRANSMISIÓN DE LA LEPTOSPIROSIS EN LA COMUNIDAD DE SAN ROQUE, PERTENECIENTE AL CANTÓN SUCRE PARROQUIA CHARAPOTÓ. PROVINCIA DE MANABI.2011

\begin{tabular}{ccc}
\hline VARIABLE & f & $\%$ \\
CORRECTO & 37 & $93 \%$ \\
INCORRECTO & 3 & $7 \%$ \\
TOTAL & 40 & $100 \%$ \\
\hline
\end{tabular}

Fuente: encuesta de evaluación de leptospirosis 
GRÁFICO No 62

CONOCIMIENTOS SOBRE MECANISMO DE TRANSMISIÓN DE LA

LEPTOSPIROSIS EN LA COMUNIDAD DE SAN ROQUE, PERTENECIENTE AL CANTÓN SUCRE PARROQUIA CHARAPOTÓ. PROVINCIA DE MANABI.2011.

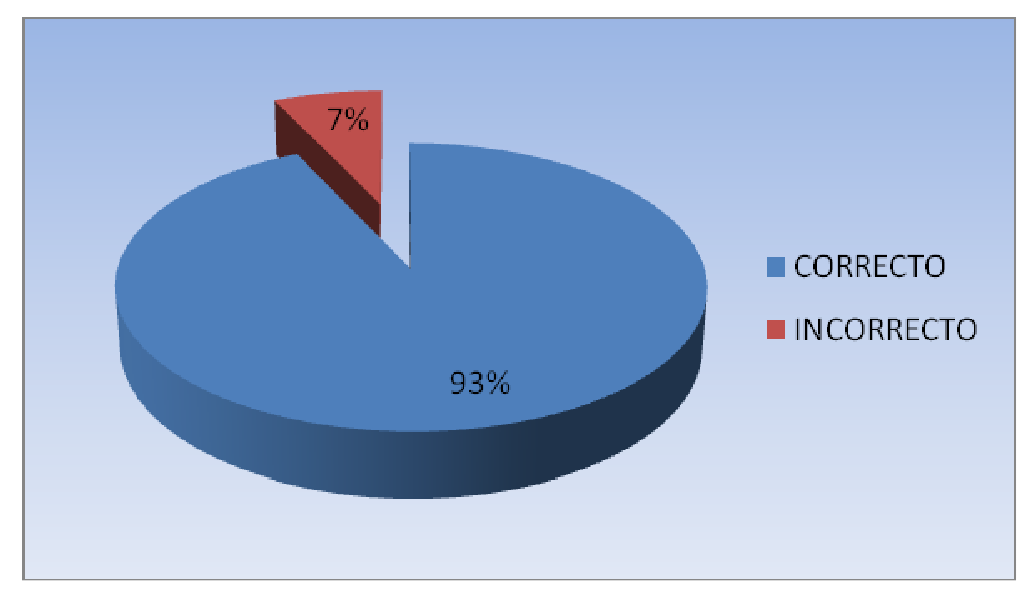

Fuente Tabla No 62

El $93 \%$ de madres de la comunidad que asistieron al taller han respondido correctamente la evaluación del taller de Leptospirosis, tan solo un 7\% lo ha hecho de forma incorrecta. 
El mayor porcentaje de madres asistentes al taller tienen conocimiento correcto sobre el mecanismo de transmisión de Leptospirosis, y un menor porcentaje a respondido de forma incorrecta y esto puede deberse a: poca atención, dificultad para organizar e integrar los pensamientos, procesan la información de forma más lenta que los demás, y especialmente por un grado de analfabetismo.

Al obtener un porcentaje satisfactorio de los conocimientos adquiridos por las madres que asistieron al taller de Leptospirosis, va ayudar a la prevención, tomando en cuenta que también es un deber de organismos e instituciones encargadas de velar por el bienestar de la población empezando por campañas masivas de salubridad.

Se recomienda que los conocimientos se conviertan en compromisos por parte de las madres de familia y de la comunidad, y se evite contraer estas zoonosis causantes de muertes si no son tratadas a tiempo.

\section{3.- CONOCIMIENTOS SOBRE MEDIDAS DE PREVENCIÓN DE LA LEPTOSPIROSIS.}

TABLA No 63

CONOCIMIENTOS SOBRE MEDIDAS DE PREVENCIÓN DEL

LEPTOSPIROSIS EN LA COMUNIDAD DE SAN ROQUE, PERTENECIENTE

AL CANTÓN SUCRE PARROQUIA CHARAPOTÓ. PROVINCIA DE

MANABI.2011.

f $\%$




\begin{tabular}{ccc}
\hline CORRECTO & 39 & $97 \%$ \\
INCORRECTO & 1 & $3 \%$ \\
TOTAL & $\mathbf{4 0}$ & $\mathbf{1 0 0 \%}$ \\
\hline
\end{tabular}

Fuente: encuesta de evaluación de la Leptospirosis

GRÁFICO No 63

CONOCIMIENTOS SOBRE MEDIDAS DE PREVENCIÓN DEL

LEPTOSPIROSIS EN LA COMUNIDAD DE SAN ROQUE, PERTENECIENTE

AL CANTÓN SUCRE PARROQUIA CHARAPOTÓ. PROVINCIA DE

MANABI.2011.

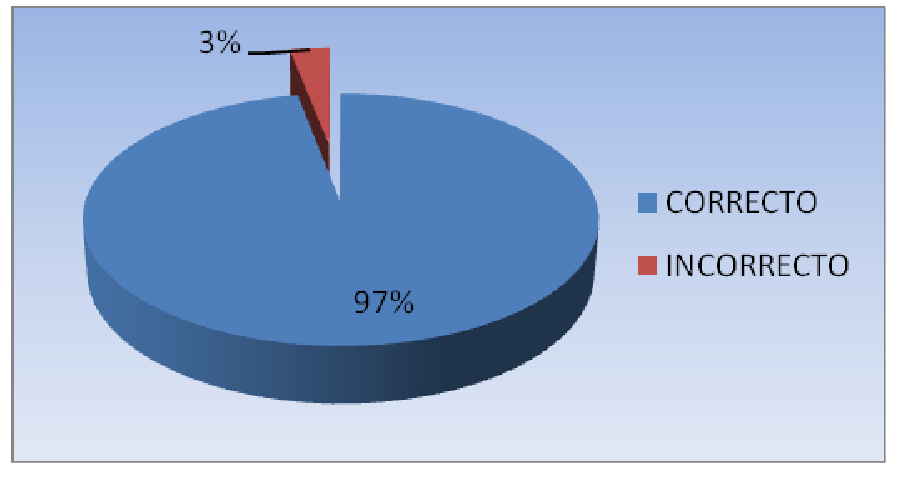

Fuente: Tabla No 63

$97 \%$ de madres que asistieron al taller han respondido de forma correcta la pregunta de evaluación sobre prevención de Leptospirosis, tan solo un 3\% ha respondido de forma incorrecta. 
El gráfico demuestra que el mayor porcentaje de madres han adquirido conocimientos sobre cómo prevenir la Leptospirosis, y un menor porcentaje ha contestado de forma incorrecta, este resultado puede ser debido a: preocupaciones, problemas familiares, y al nivel de escolaridad.

Los organismos sanitarios no pueden estar trabajando en función de salirle al paso a cada nueva epidemia, se tiene que incrementar la prevención.

Estamos frente a una enfermedad de comportamiento cíclico de entre 4 y 5 años y que además se caracteriza por ser endemo epidémica, lo que significa que van a suceder casos de forma permanente y que en algún momento se sale de control resultando en un brote epidémico especialmente en época de lluvias donde se reproduce más rápidamente esta bacteria leptospira, es por eso la importancia de educar hacia la prevención para reducir el riesgo de contraer esta zoonosis.

\author{
G.- PONTE ALERTA CONTRA LA RABIA \\ 1.- CONOCIMIENTOS SOBRE LA RABIA
}

TABLA No 64

CONOCIMIENTOS SOBRE LA RABIA EN LA COMUNIDAD DE SAN ROQUE, PERTENECIENTE AL CANTÓN SUCRE PARROQUIA

CHARAPOTÓ. PROVINCIA DE MANABI.2011. 


\begin{tabular}{ccc}
\hline VARIABLE & $\mathbf{f}$ & $\%$ \\
CORRECTO & 39 & $97 \%$ \\
INCORRECTO & 1 & $3 \%$ \\
TOTAL & $\mathbf{4 0}$ & $\mathbf{1 0 0 \%}$ \\
\hline
\end{tabular}

Fuente: encuesta de evaluación de la Rabia

GRÁFICO No 64

CONOCIMIENTOS SOBRE LA RABIA EN LA COMUNIDAD DE SAN ROQUE, PERTENECIENTE AL CANTÓN SUCRE PARROQUIA CHARAPOTÓ. PROVINCIA DE MANABI.2011.

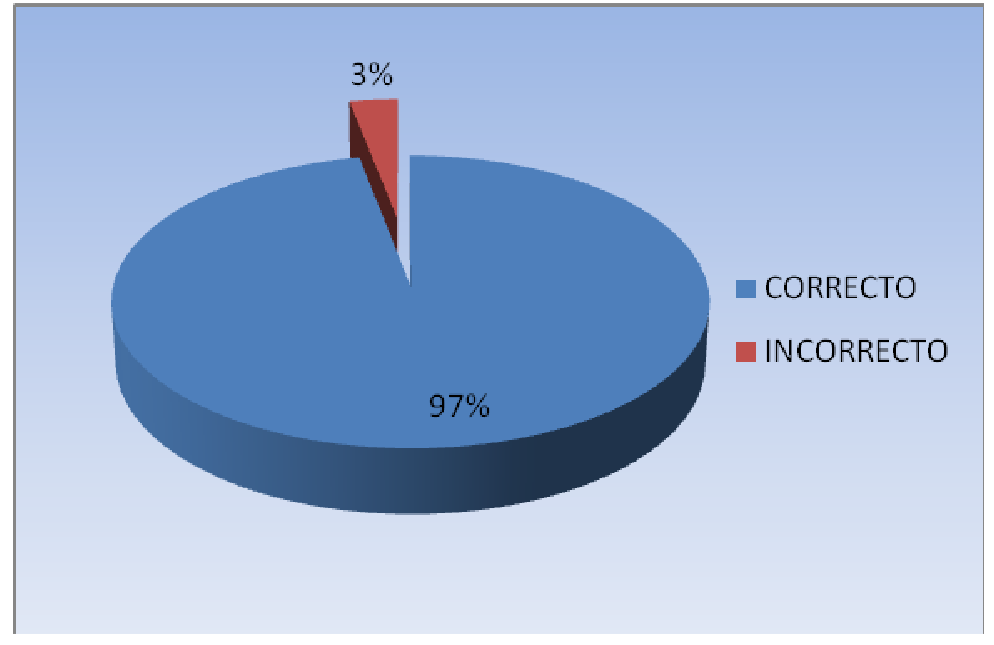

Fuente: Tabla No 64

97\% de madres que asistieron al taller de la Rabia tienen conocimientos correctos sobre lo que es la rabia, tan solo un $3 \%$ ha respondido de forma incorrecta. 
El mayor porcentaje de madres tienen conocimientos correctos sobre la rabia, pero un menor porcentaje ha respondido de forma incorrecta y puede ser debido a : distracciones, perturbaciones, ruidos y el analfabetismo existente.

El que las madres de familia de la comunidad tengan conocimientos sobre lo que es la rabia es un buen resultado porque nos ayudará a prevenir el problema en la comunidad, sin embargo el número de perros callejeros existentes en la comunidad constituyen un factor de riesgo ya que son perros abandonados que no tienen un dueño quien les aplique las medidas profilácticas y les de los cuidados necesarios.

Cabe destacar que la eliminación de los perros de la calle es un método ortodoxo, pero ante la falta de centros de recolección de animales y la colaboración de los propietarios de los perros tienen que recurrir a este método, el cual se contempla dentro del Ministerio de Salud.

Por otro lado, la campaña de descanización busca evitar la propagación de 12 enfermedades entre ellas la rabia.

Los rresultados obtenidos al aplicar un Programa de Salud para combatir y prevenir la Rabia en Bolivia Uruguay entre los logros se encontraban (bajar la incidencia de rabia en más del 60\% en comparación con la Gestión 2005 ycontrolar la epidemia y epizootia de esa gestión) son frutos del trabajo realizado por el Ministeriode Salud y Deportes en coordinación interinstitucional con sectores de Salud de niveles departamentales, municipales y con el apoyo de la OPS/OMS. 
Se realizó la Campaña Nacional de vacunación Antirrábica con una cobertura del $83 \%$ a nivel nacional.

Se elaboraron las Normas Técnicas para el Tratamiento de la Rabia; donde se actualiza y se capacita en el tratamiento profiláctico y específico para el tratamiento a personas expuestas a accidentes rábicos; se actualiza y estandariza los métodos de toma, envió y diagnostico de Rabia; se conforma la Red de Laboratorios de Diagnostico de Rabia con la incorporación de laboratorios de diagnostico veterinario se estandariza métodos de diagnostico y emisión de reportes.

En el Ecuador se elaboran técnicas y programas con la ayuda del departamento de sanidad del Ministerio de Salud Pública eliminado a la cantidad de perros callejeros de la comunidad, especialmente si se han presentado casos de rabia, es decir que la prevención total de la rabia no se puede lograr solos, sino con la ayuda de organismos, instituciones, y casas de salud.

2.- CONOCIMIENTOS SOBRE MECANISMO DE TRANSMISIÓN DE LA RABIA

TABLA No 65

CONOCIMIENTOS SOBRE MECANISMO DE TRANSMISIÓN DE LA RABIA EN LA COMUNIDAD DE SAN ROQUE, PERTENECIENTE AL CANTÓN SUCRE PARROQUIA CHARAPOTÓ. PROVINCIA DE MANABI.2011. 


\begin{tabular}{ccc}
\hline VARIABLE & $\mathbf{f}$ & $\%$ \\
CORRECTO & 37 & $93 \%$ \\
INCORRECTO & 3 & $7 \%$ \\
TOTAL & $\mathbf{4 0}$ & $\mathbf{1 0 0 \%}$ \\
\hline
\end{tabular}

Fuente: encuesta de evaluación de la Rabia

GRÁFICO No 65

CONOCIMIENTOS SOBRE MECANISMO DE TRANSMISIÓN DE LA RABIA

EN LA COMUNIDAD DE SAN ROQUE, PERTENECIENTE AL CANTÓN SUCRE PARROQUIA CHARAPOTÓ. PROVINCIA DE MANABI.2011.

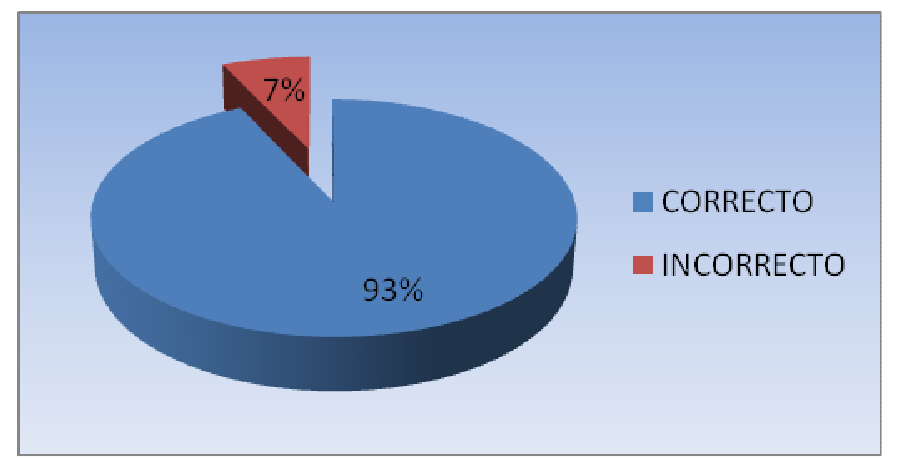

Fuente: Tabla No 65

El 93\% de madres de la comunidad que asistieron al taller de capacitación sobre Mecanismo de transmisión de la Rabia han respondido de forma correcta, tan solo un $7 \%$ ha respondido de forma incorrecta. 
Como se demuestra en el gráfico el mayor porcentaje de madres evaluadas tienen conocimientos del mecanismo de transmisión de la Rabia, en relación a un menor porcentaje que respondió de forma incorrecta y puede deberse a: nivel de instrucción, perturbaciones, ruido.

Es importante conocer sobre el mecanismo de transmisión de la rabia pero existen casos de animales que pueden transmitir la rabia sin presentar signos clínicos, entonces es más difícil detectar la rabia, es por eso que lo mejor es evitar el contacto con perros callejeros, que no han sido vacunados, y perros enfermos.

La rabia en zonas rurales se presenta mayoritariamente en zonas cuya densidad poblacional canina es alta; por ello, la forma de prevención más eficaz para detener el ciclo de transmisión vírica son las campañas masivas de vacunación, de este modo se consigue la disminución de perros susceptibles a la enfermedad.

3.- CONOCIMIENTOS SOBRE MEDIDAS DE PREVENCIÓN DE LA RABIA

TABLA No 66

CONOCIMIENTOS SOBRE MEDIDAS DE PREVENCIÓN DE LA RABIA EN LA COMUNIDAD DE SAN ROQUE, PERTENECIENTE AL CANTÓN SUCRE PARROQUIA CHARAPOTÓ. PROVINCIA DE MANABI.2011. 


\begin{tabular}{ccc}
\hline VARIABLE & $\mathbf{f}$ & $\%$ \\
CORRECTO & 39 & $98 \%$ \\
INCORRECTO & 1 & $2 \%$ \\
TOTAL & 40 & $100 \%$ \\
\hline
\end{tabular}

Fuente: encuesta de evaluación de la rabia

GRÁFICO No 66

CONOCIMIENTOS SOBRE MEDIDAS DE PREVENCIÓN DE LA RABIA EN LA COMUNIDAD DE SAN ROQUE, PERTENECIENTE AL CANTÓN SUCRE PARROQUIA CHARAPOTÓ. PROVINCIA DE MANABI.2011.

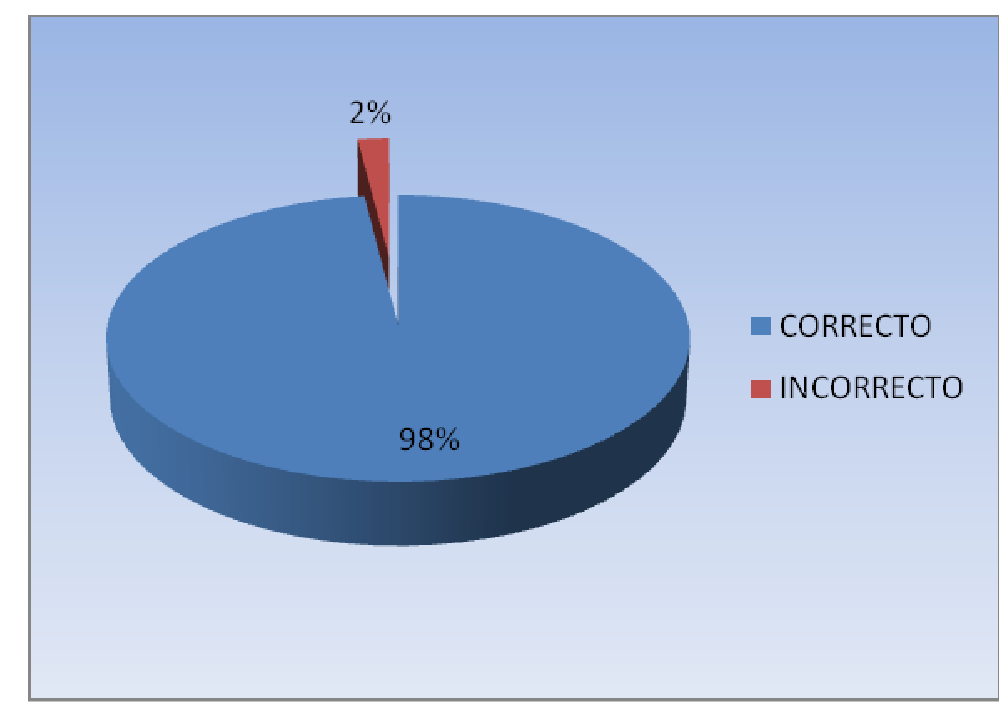

Fuente: Tabla No 66 
98\% que corresponde al mayor porcentaje de madres de familia respondieron correctamente las medidas de prevención de la rabia, tan solo un $2 \%$ que es un mínimo porcentaje no respondió de forma incorrecta la evaluación.

El mayor número de asistentes saben cómo prevenir la zoonosis, sin embargo un mínimo porcentaje no lo sabe porque respondió de forma incorrecta debido a su estado de ánimo, preocupaciones, distracciones, y analfabetismo.

La rabia es una enfermedad bastante grave que ha cobrado miles de vidas humanas en el mundo, y que no ha sido erradicada de nuestra región, por lo que es importante que cada año todos los perros y los gatos sean vacunados. Una de las principales causas, por la que no se ha logrado controlar la enfermedad en un $100 \%$, es el número tan elevado de animales callejeros. Constituyen un gran foco de infección de ésta, así como de muchas otras enfermedades. Desgraciadamente, la sociedad no atiende las campañas para el control de la población de pequeñas especies, e incluso defienden a perros y gatos callejeros. Con todo, es importante que los vacunen y desparasiten, y aprovechen las campañas de esterilización gratuita con el fin de evitar el crecimiento desmedido de estos animales que muchas veces sólo tienen dueños ocasionales. Sólo así puede controlarse la transmisión de la rabia, así como de muchas otras epidemias. 
H) COMO ATACAN LAS NIGUAS

1.- CONOCIMIENTOS SOBRE LA TUNGA PENETRANS (NIGUAS)

TABLA No 67

CONOCIMIENTOS SOBRE LA TUNGA PENETRANS (NIGUAS) EN LA COMUNIDAD DE SAN ROQUE, PERTENECIENTE AL CANTÓN SUCRE PARROQUIA CHARAPOTÓ. PROVINCIA DE MANABI.2011.

\begin{tabular}{ccc}
\hline VARIABLE & $\mathbf{f}$ & $\%$ \\
Correcto & 36 & $90 \%$ \\
Incorrecto & 4 & $10 \%$ \\
\hline
\end{tabular}


Fuente: Encuesta de evaluación de las niguas

GRÁFICO No 67

CONOCIMIENTOS SOBRE LA TUNGA PENETRANS (NIGUAS) EN LA COMUNIDAD DE SAN ROQUE, PERTENECIENTE AL CANTÓN SUCRE PARROQUIA CHARAPOTÓ. PROVINCIA DE MANABI.2011.

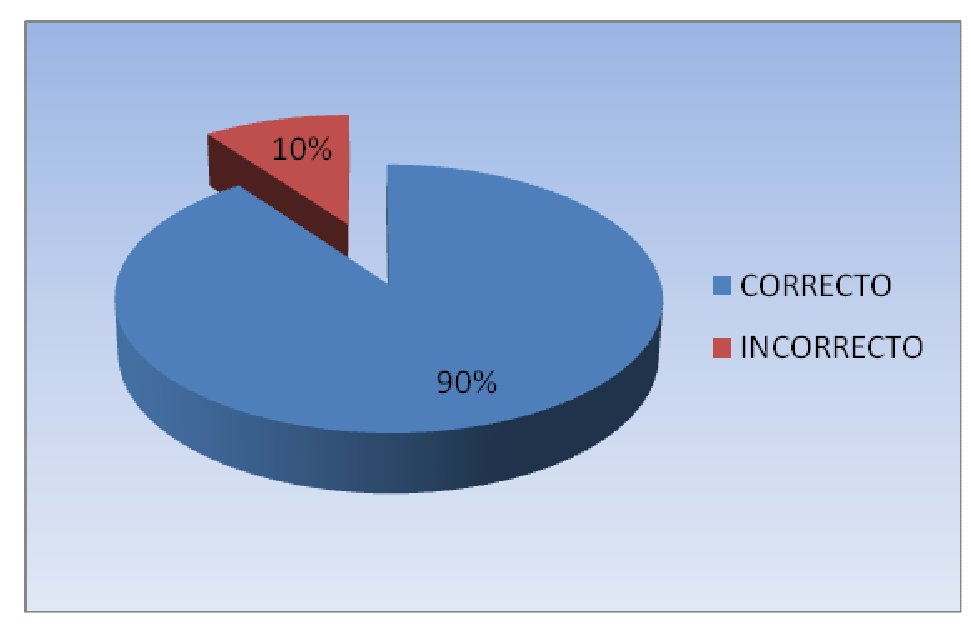

Fuente: Tabla No 1 
$90 \%$ de las madres que asistieron al taller respondieron de forma correcta la pregunta de evaluación sobre las niguas; un 10\% respondió de forma incorrecta.

El mayor porcentaje como se observa en el gráfico han adquirido conocimientos sobre las niguas, y un menor porcentaje desconoce que son las niguas y este problema se da principalmente por: distracción y bajo nivel de educación.

Es satisfactorio los resultados obtenidos, especialmente porque la mayor parte de madres conocen sobre esta zoonosis que es muy común en la comunidad ya que se han presentado variedad de casos de niguas especialmente en los niños que andan descalzos, sin embargo este problema se reducirá cuando se apliquen medidas higiénicas y sanitarias, y cambios de actitudes y comportamiento de la comunidad comprometiéndose a cambiar sus estilo de vida hacia un estilo de vida saludable.

2.- CONOCIMIENTOS SOBRE MECANISMO DE TRANSMISIÓN DE LAS NIGUAS

TABLA No 68

CONOCIMIENTOS SOBRE MECANISMO DE TRANSMISIÓN DE LA TUNGA

PENETRANS (NIGUAS) EN LA COMUNIDAD DE SAN ROQUE, PERTENECIENTE AL CANTÓN SUCRE PARROQUIA CHARAPOTÓ. PROVINCIA DE MANABI.2011. 


\begin{tabular}{ccc}
\hline VARIABLE & $\mathbf{f}$ & $\%$ \\
CORRECTO & 39 & $97 \%$ \\
INCORRECTO & 1 & $3 \%$ \\
TOTAL & 40 & $\mathbf{1 0 0 \%}$ \\
\hline
\end{tabular}

Fuente: Encuesta de Evaluación de las Niguas

GRÁFICO No 68

CONOCIMIENTOS SOBRE MECANISMO DE TRANSMISIÓN DE LA TUNGA PENETRANS (NIGUAS) EN LA COMUNIDAD DE SAN ROQUE, PERTENECIENTE AL CANTÓN SUCRE PARROQUIA CHARAPOTÓ. PROVINCIA DE MANABI.2011. 


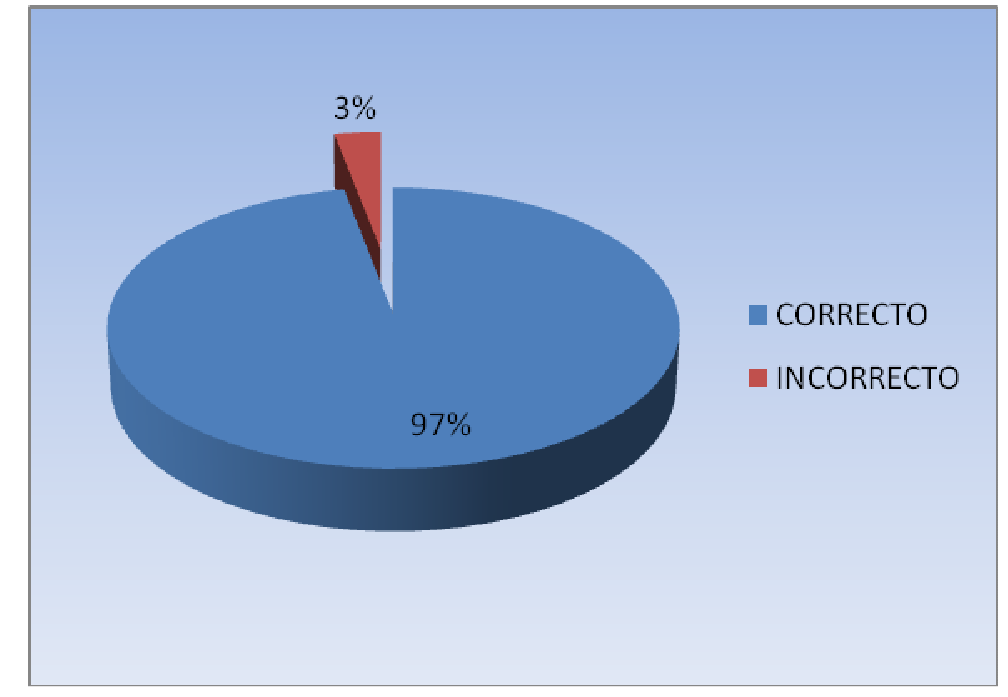

Fuente: Tabla No 68

97\% de madres que asistieron al taller de capacitación contestaron correctamente sobre el mecanismo de transmisión de las niguas, un 3\% contesto de manera incorrecta.

Luego de evaluar los conocimientos se observa en el gráfico que el mayor porcentaje de madres tienen conocimientos sobre el mecanismo de transmisión de las niguas, tan solo un mínimo porcentaje contesto de forma incorrecta y esto puede ser debido a interrupciones, ruido, y analfabetismo.

Es muy importante que las madres tengan conocimientos sobre el mecanismo de transmisión de esta zoonosis; la Tunga Penetrans conocida como Pulga de la arena, y vulgarmente como nigua no requiere ningún huésped intermediario ya que el adulto es directamente el que invade la piel del huésped. Otros animales pueden ser también huéspedes de la Tunga contribuyendo a la perpetuación de la enfermedad, sobre todo animales domésticos (perros, cerdos y gatos), sin embargo el clima y los suelos de la comunidad son 
propicios para que aparezcan estas pulgas que se encuentran generalmente en suelos arenosos y húmedos, y la costa tiene este tipo de suelo por lo que la población es más vulnerable a adquirir esta zoonosis.

Para evitar la transmisión de este parásito se recomienda no andar descalzos dentro ni fuera del hogar, y en lo que respecta a su desarrollo esta pulga se crece en la arena pero para completar su reproducción requiere lugares como la piel y zonas con mayor temperatura que principalmente son los pies.

\section{3.- CONOCIMIENTOS SOBRE LAS MEDIDAS DE PREVENCIÓN DE LA TUNGA PENETRANS (Nigua)}


CONOCIMIENTOS SOBRE MEDIDAS DE PREVENCIÓN DE LA TUNGA PENETRANS (NIGUAS) EN LA COMUNIDAD DE SAN ROQUE, PERTENECIENTE AL CANTÓN SUCRE PARROQUIA CHARAPOTÓ. PROVINCIA DE MANABI.2011.

\begin{tabular}{ccc}
\hline VARIABLE & $\mathbf{f}$ & $\%$ \\
CORRECTO & 37 & $93 \%$ \\
INCORRECTO & 3 & $7 \%$ \\
TOTAL & $\mathbf{4 0}$ & $\mathbf{1 0 0 \%}$
\end{tabular}

Fuente: Encuesta de evaluación de la Nigua

GRÁFICO No 69

CONOCIMIENTOS SOBRE MEDIDAS DE PREVENCIÓN DE LA TUNGA PENETRANS (NIGUAS) EN LA COMUNIDAD DE SAN ROQUE, 


\section{PERTENECIENTE AL CANTÓN SUCRE PARROQUIA CHARAPOTÓ. PROVINCIA DE MANABI.2011.}

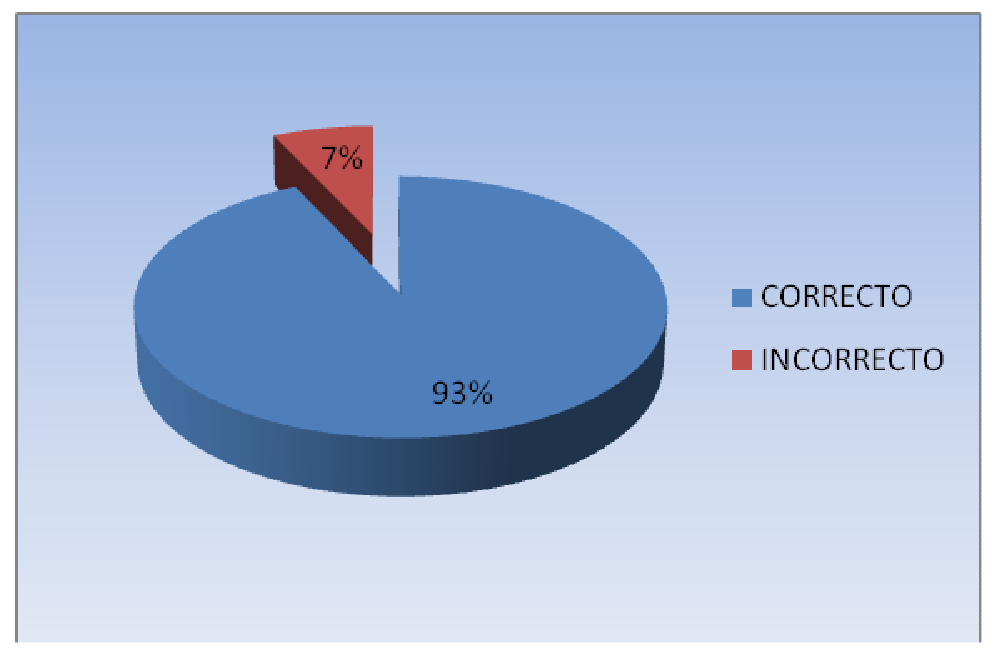

Fuente: Tabla No 69

93\% de las madres respondieron correctamente sobre las medidas para prevenir la Tunga Penetrans (Nigua), mientras un $7 \%$ ha respondido de forma incorrecta.

El mayor porcentaje de madres evaluadas han adquirido conocimientos de cómo prevenir esta zoonosis; un porcentaje menor ha respondido de forma incorrecta y no ha entendido sobre las medidas de prevención debido a problemas de concentración y captación de la información, y a su nivel académico.

La educación es la primera medida de prevención, en los últimos años las definiciones de las Políticas de Salud han pasado a considerar especialmente el valor de las prácticas de Prevención. Estas han sido definidas sobre todo "como aquellas actividades que permiten a las personas tener estilos de vida 
saludables y faculta a las comunidades a crear y consolidar ambientes donde se promueve la salud y se reduce los riesgos de enfermedad. La prevención implica desarrollar acciones anticipatorias. Los esfuerzos realizados para "anticipar" eventos, con el fin de promocionar el bienestar del ser humano y así evitar situaciones indeseables como esta zoonosis.

I) MEDIDAS DE PREVENCIÓN DE LA ZOONOSIS

1.- CONOCIMIENTOS SOBRE LAS MEDIDAS DE PREVENCIÓN DE LA ZOONOSIS

TABLA No 70

CONOCIMIENTOS SOBRE MEDIDAS DE PREVENCIÓN DE ZOONOSIS EN LA COMUNIDAD DE SAN ROQUE, PERTENECIENTE AL CANTÓN SUCRE PARROQUIA CHARAPOTÓ. PROVINCIA DE MANABI.2011.

\begin{tabular}{ccc}
\hline VARIABLE & $\mathbf{f}$ & $\%$ \\
CORRECTO & 38 & $95 \%$ \\
INCORRECTO & 2 & $5 \%$ \\
TOTAL & $\mathbf{4 0}$ & $\mathbf{1 0 0 \%}$ \\
\hline Fuente: Encuesta de evaluación de Prevención de Zoonosis
\end{tabular}

GRÁFICO No 70

CONOCIMIENTOS SOBRE MEDIDAS DE PREVENCIÓN DE ZOONOSIS EN LA COMUNIDAD DE SAN ROQUE, PERTENECIENTE AL CANTÓN SUCRE PARROQUIA CHARAPOTÓ. PROVINCIA DE MANABI.2011. 


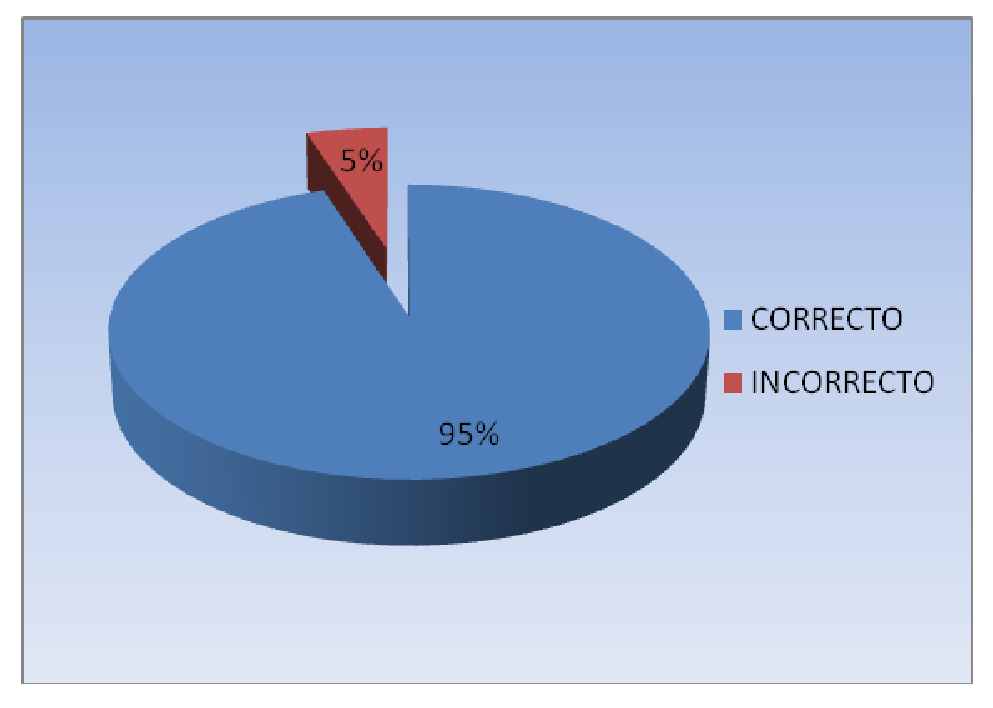

Fuente: Tabla No 70

El $95 \%$ de las madres de familia que asistieron al taller de capacitación respondieron correctamente las medidas de prevención de la zoonosis, tan solo el $5 \%$ de madres respondió de forma incorrecta.

El gráfico nos presenta que el mayor porcentaje de madres que fueron encuestadas tiene conocimientos de cómo prevenir la zoonosis, y un menor porcentaje lo desconoce, y esto se debe a: problemas de atención, hiperactividad y analfabetismo.

La prevención es sobre todo, definida como la protección contra los riesgos, las amenazas del ambiente, lo que significa, inevitablemente la acción mancomunada de las Instituciones de Salud, de las comunidades, y de las personas que más que integrarlas las instituyen.

Según la OMS, uno de los instrumentos de la promoción de la salud y de la acción preventiva es la educación para la salud, que aborda además de la transmisión de la información, el fomento de la motivación, las habilidades 
personales y la autoestima, necesarias para adoptar medidas destinadas a mejorar la salud. La educación para la salud incluye no sólo la información relativa a las condiciones sociales, económicas y ambientales subyacentes que influyen en la salud, sino también la que se refiere a los factores y comportamientos de riesgo, además del uso del sistema de asistencia sanitario.

En conclusión la prevención de salud va relacionada con la promoción y protección de la salud si la comunidad conoce y sabe cómo prevenir lo va hacer.

El trabajo de prevención de zoonosis de esta comunidad se debería coordinar, y planificar, y controlar con instituciones, casas y centros de salud para de esta manera mejorar la salud de las personas, mejorando las condiciones sociales, ambientales, su entorno, reduciendo riesgos para todos y todas.

2.- CONOCIMIENTOS SOBRE EL TRATAMIENTO QUE SE DEBE DAR AL ESTIÍERCOL DE LOS ANIMALES DE GRANJA COMO MEDIDA PREVENTIVA 
TABLA No 71

CONOCIMIENTOS SOBRE MANEJO DE ESTIÉRCOL DE ANIMALES DE GRANJA EN LA COMUNIDAD DE SAN ROQUE, PERTENECIENTE AL CANTÓN SUCRE PARROQUIA CHARAPOTÓ. PROVINCIA DE MANABI.2011.

\begin{tabular}{ccc}
\hline VARIABLE & $f$ & $\%$ \\
CORRECTO & 36 & $90 \%$ \\
INCORRECTO & 4 & $10 \%$ \\
TOTAL & $\mathbf{4 0}$ & $\mathbf{1 0 0 \%}$ \\
\hline
\end{tabular}

Fuente: Encuesta de evaluación de Prevención de la zoonosis

GRÁFICO No 71

CONOCIMIENTOS SOBRE MANEJO DE ESTIÉRCOL DE ANIMALES DE GRANJA EN LA COMUNIDAD DE SAN ROQUE, PERTENECIENTE AL 


\section{CANTÓN SUCRE PARROQUIA CHARAPOTÓ. PROVINCIA DE \\ MANABI.2011.}

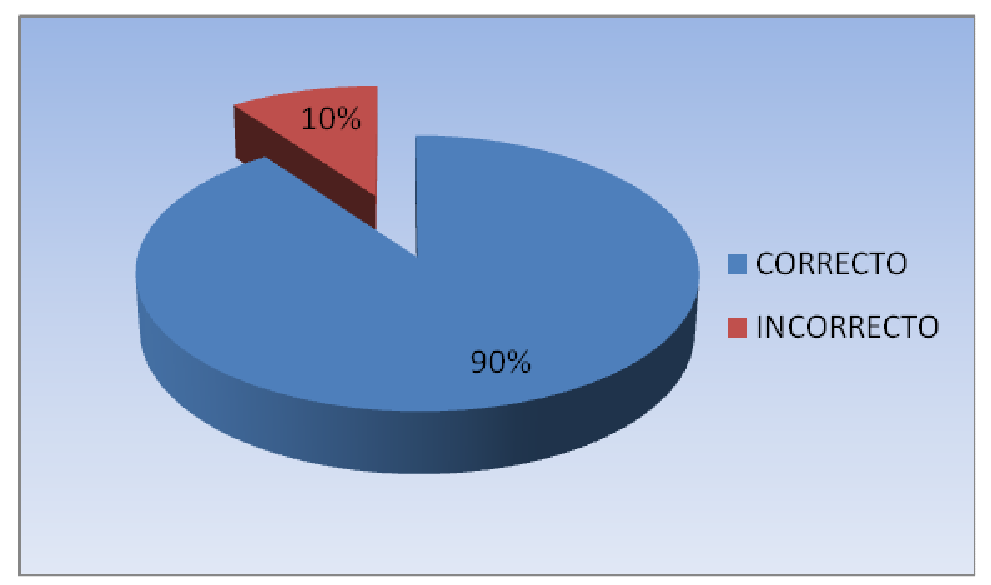

Fuente: Tabla No 71

El $90 \%$ de madres que asistieron al taller tiene conocimientos correctos de cómo debe ser el tratamiento del estiércol de los animales de granja, un 10\% ha respondido de forma incorrecta.

El gráfico nos da a conocer que el mayor porcentaje de las madres tienen conocimientos sobre el tratamiento que se debe dar al estiércol de los animales, pero un menor porcentaje lo desconoce por lo que ha respondido de forma incorrecta y esto se debe a: una actitud negativa, y analfabetismo.

El que las madres tengan conocimientos de cómo debe ser el tratamiento de estiércol lo van a practicar e incluso puede generarles un ingreso económico extra, es decir buscamos la prevención pero a la vez se puede llegar a conseguir beneficios, todo está en la forma en que aplicamos los conocimientos adquiridos y la utilidad que obtenemos. 
El manejo del estiércol animal se define como un proceso de toma de decisiones que apunta a combinar la producción agrícola rentable con pérdidas mínimas de nutrientes del estiércol, tanto en el presente como en el futuro. El buen manejo del estiércol minimizará los efectos negativos en la salud y estimulará los efectos positivos sobre el medio ambiente. La emisión de gases y el lavado de nutrientes, la materia orgánica y los olores tienen efectos indeseables sobre el medio ambiente y sobre las personas. La contribución del estiércol a la nutrición de las plantas y a la acumulación de materia orgánica en el suelo es considerada como efecto positivo. Un efecto positivo indirecto es que el uso del estiércol puede ahorrar recursos no renovables usados en la producción de fertilizantes inorgánicos.

Los aspectos negativos y positivos del estiércol están estrechamente relacionados entre sí porque por una parte ayuda en los cultivos y por otra afecta la salud de las personas, por eso es recomendable darle un debido tratamiento como el almacenaje que se lo debe hacer en una bodega o cuarto, lejos de la vivienda y no tenerlo por mucho tiempo para prevenir malos olores y problemas de zoonosis, sin olvidarnos de la frecuencia de la limpieza y de las medidas profilácticas sanitarias.

\section{PROGRAMA EDUCATIVO}

\section{A. ANTECEDENTES}


Las Zoonosis constituye un serio problema de salud, algunas de ellas con alta prevalencia de infección en el hombre, por lo cual si no son controladas se convierten en una importante causa del incremento de la morbilidad. (1).

El complejo impacto que causan las zoonosis parasitarias demanda con urgencia el reconocimiento de la importancia real en los diferentes países de Latinoamérica y el Caribe y el desarrollo de programas para su control, lo que constituye la base racional para determinar la prioridad en las campañas contra estas enfermedades y su incorporación a las actividades de la Atención Primaria de Salud. (1)

A nivel de Latinoamérica la Zoonosis es la endemia más olvidada. Si bien las prevalencias de las principales zoonosis del mundo no ha cambiado, ellas han aumentado en términos absolutos debido al crecimiento de la población. Es así como hace 51 años se estimaba que en el mundo habían 644 millones de personas (30\%) infectadas con Ascaris lumbricoides, 355 millones con toxoplasmosis (16\%) y 457 millones con ancy-lostomídeos (21\%)y que en 1997 se estimó que habían 1273 millones de personas (24\%) con Áscaris lumbricoides, 902 millones (17\%) con ancy-lostomideos y 1.277 millones (24\%) con toxoplasmosis. O sea, que estas tres parasitosis han mantenido sus prevalencias a pesar de los avances tecnológicos y médicos. (2)

La zoonosis en Chile, se determinó una prevalencia de 61,8\% entre habitantes de comunidades rurales ribereñas del Río Valdivia. En Argentina se han registrado elevadas tasas de zoonosis (entre 43 y $52,6 \%$ ) y otras parasitosis intestinales. En Brasil se encontró un 54\% de infección por zoonosisentre familias de la comunidad rural de Pedreira en el estado de São Paulo. Todos 
estos resultados coinciden con las elevadas prevalencias de parasitosis intestinales y en especial de zoonosis. (3)

De acuerdo a las investigaciones de la Organización Mundial de la Salud (OMS) y la Sociedad Venezolana de Infectología, en Venezuela hay poblaciones donde hasta el $80 \%$ de sus habitantes, tanto adultos como niños, han padecido de zoonosis alguna vez en su vida. Y esto tiene mucha relación con el saneamiento ambiental, contacto con animales portadores de hongos, virus, y bacterias, no tienen la disposición de agua potable para el consumo, excretas de animales causantes de proliferación de moscas, que también son un vehículo para el parásito, y la cantidad de basura.

El problema de la zoonosis en la comunidad de San Roque es muy grave, el $80 \%$ de la población tienen este problema. Penosamente los más afectados son los niños de la comunidad ocupando un $81 \%$, así como embarazadas en un $70 \%$.

Una de las grandes causas para esta problemática es la insalubridad, tanto en niños que están descuidados, muchas veces caminan descalzos entre basura o por el estiércol de vacas, gallinas o chanchos que constituyen una fuente de infección, o en contacto con animales domésticos; como en adultos, que no toman las medidas necesarias de protección y prevención de zoonosis.

Manabí es la tercera provincia con mayor población en el Ecuador la población total es 1.370.734 habitantes. 
Al ser Manabí una provincia con gran cantidad de habitantes se constituye en un lugar con mayores problemas de salud uno de ellos es la zoonosis, debido a que gran parte de la población se encuentra en el sector rural, en donde proliferan las infecciones por presencia de animales domésticos en grandes cantidades, que pueden estar cerca de los alimentos o al estar en contacto con ellos especialmente con perros, gatos, chanchos, gallinas, vacas, caballos, mulas y sus excretas cerca de la vivienda, al no lavar las manos de los niños después de jugar en la tierra, en el suelo o con algún animal, es decir las condiciones de vida, de saneamiento y los servicios básicos en esta comunidad no son adecuados. 


\section{B. OBJETIVOS}

\section{General}

Mejorar los conocimientos sobre medidas higiénico sanitarias de las viviendas de la comunidad San Roque a través de la participación activa de las madres de Familia de la comunidad, para prevenir la zoonosis.

\section{Específicos}

- Identificar conocimientos y prácticas del grupo de estudio.

- Implementar un plan de capacitación dirigido a las familias que ayuden a mejorar los conocimientos y prácticas sobre medidas de prevención de enfermedades zoonóticas.

- Coordinar actividades encaminadas al mejoramiento de las condiciones higiénicas sanitarios de la comunidad. 


\section{METAS}

1. Disminuir en el impacto ambiental, causado por el manejo inadecuado de estiércol de animales domésticos y de granja en un 30\%,mediante la práctica de medidas profilácticas en el cuidado de sus animales (limpieza, vacunación, y desparasitación).

2. Disminuir en un $30 \%$ la proliferación de vectores en las viviendas.

3. Mejorar conocimientos en un $15 \%$ y prácticas higiénicas sanitarias en un $30 \%$ de las familias de la comunidad.

\section{METODOLOGÍA DEL PROYECTO EDUCATIVO}

\section{A. Localización y duración}

La presente investigación se realizó en la Comunidad San Roque del Cantón Sucre Parroquia Charapotó. Provincia de Manabí. La recolección, procesamiento, análisis de la información y desarrollo de la intervención educativa se realizó en un periodo de 6 meses desde abril a octubre 2011.

\section{B. Población San Roque}

Se trabajó con 40 familias de cobertura de Plan Internacional

\section{Población indirecta}

Guardería de la comunidad y los líderes de la comunidad.

\section{Método}

El método aplicado para la ejecución del proyecto fue el activo-participativo. 


\section{Técnicas}

Las técnicas utilizadas para las intervenciones fueron:

- Lluvia de ideas

- Talleres educativos

- Videos educativos

- Reuniones grupales

\section{E. ESTRATEGIAS METODOLÓGICAS}

1.- Se realizará el diagnóstico de salud para identificar los principales problemas de salud higiénica sanitaria y así diseñar el material educativo para el desarrollo de los talleres.

2.- Motivar las madres de familia mediante la aplicación de técnicas activas participativas a través de diferentes actividades, contenidos atractivos, y dinámicas.

3.- Conocer el nivel de conocimientos de las madres y sus experiencias relacionadas con el tema a través de la aplicación de técnicas de diagnóstico como es la lluvia de ideas.

4.- Adaptar los ejemplos y explicaciones de la temática a su nivel y tipo de experiencias anteriores.

5.- Explicar siempre la utilidad de la temática que se va a aprender, tanto para su futuro, como para fundamentar conocimientos y aplicaciones posteriores. 
6.- Dar a conocer los objetivos antes de empezar, esto permite generar expectativas apropiadas de lo que van aprender y forma un criterio sobre que se espera de ellos al termino de la clase.

7.- Realizar trabajos en grupos esto potenciará el trabajo colaborativo y evaluar formativamente el progreso, para que las madres tengan siempre información de qué está haciendo bien y qué debe corregir.

8.- El diseño del material educativo se realizará pensando en la capacidad de concentración y atención que le puede ofrecer con gráficos y animación, y de acuerdo al nivel de escolaridad de la audiencia.

9.- La retroalimentación y las evaluaciones se realizarán después de cada capacitación y actividad.

10.- Para promover la participación comunitaria se entregará refrigerios y se pasará una lista de asistencia que incluirá las firmas y compromisos dados por los asistentes al finalizar el proceso educativo. 


\section{F. PLAN DE ACCIÓN}

\begin{tabular}{|c|c|c|c|c|c|}
\hline ESTRATEGIAS & ACTIVIDADES & FECHAS & RECURSOS & RESPONSABLES & PRODUCTO ESPERADO \\
\hline $\begin{array}{l}\text { Promover } \\
\text { participación } \\
\text { comunitaria }\end{array}$ & $\begin{array}{l}\text { Reuniones con } \\
\text { líderes comunitario, } \\
\text { madres de familia }\end{array}$ & Mayo 20 & $\begin{array}{l}\text { - Transporte } \\
\text { - Guardería } \\
\text { para } \\
\text { reuniones }\end{array}$ & $\begin{array}{l}\text { - FDC } \\
\text { - Educador para la } \\
\text { salud }\end{array}$ & $\begin{array}{l}\text { - Contar con la } \\
\text { asistencia de } 25 \text { a } 40 \\
\text { familias }\end{array}$ \\
\hline $\begin{array}{l}\text { Diagnóstico de la } \\
\text { situación de } \\
\text { salud }\end{array}$ & $\begin{array}{l}\text { - Realizar el } \\
\text { diagnóstico en } \\
\text { salud con la } \\
\text { participación de los } \\
\text { voluntarios }\end{array}$ & $\begin{array}{c}\text { Mayo } 15 \text { a } \\
29 \text { Mayo }\end{array}$ & $\begin{array}{l}\text { - Transporte } \\
\text { - Papelería- } \\
\text { material } \\
\text { - Guardería } \\
\text { para } \\
\text { reuniones }\end{array}$ & $\begin{array}{l}\text { - Educador para la } \\
\text { salud } \\
\text { - Voluntarios de } \\
\text { participación }\end{array}$ & $\begin{array}{l}\text { Documento de } \\
\text { diagnóstico en salud de } \\
\text { problemas, necesidades y } \\
\text { expectativas de la } \\
\text { población en materia de } \\
\text { condiciones y estilos de } \\
\text { vida }\end{array}$ \\
\hline $\begin{array}{l}\text { Desarrollar planes } \\
\text { de clase en base } \\
\text { al diagnóstico }\end{array}$ & $\begin{array}{l}\text { - Revisar los } \\
\text { resultados de la } \\
\text { encuesta } \\
\text { - Priorizar problemas } \\
\text { de salud } \\
\text { - Diseño de planes } \\
\text { de clase } \\
\end{array}$ & $\begin{array}{c}\text { Junio } 2 \text { a } \\
12 \text { Julio }\end{array}$ & - Papelería & $\begin{array}{l}\text { FDC } \\
\text { - Educador para la } \\
\text { salud }\end{array}$ & $\begin{array}{l}\text { Priorizar los principales } \\
\text { factores de riesgo para } \\
\text { que se presenten las } \\
\text { enfermedades zoonóticas }\end{array}$ \\
\hline $\begin{array}{l}\text { Capacitar a las } \\
\text { familias sobre } \\
\text { Zoonosis y } \\
\text { enfermedades } \\
\text { zoonóticas }\end{array}$ & $\begin{array}{l}\text { - Desarrollar } 10 \\
\text { talleres de salud } \\
\text { dirigido a madres de } \\
\text { familia } \\
\text { - Evaluar } \\
\text { conocimientos } \\
\text { mediante un test de } \\
\text { evaluación para } \\
\text { cada taller } \\
\text { - Realizar } \\
\text { compromisos al } \\
\text { finalizar cada taller }\end{array}$ & $\begin{array}{c}\text { Julio } 6 \text { a } 6 \\
\text { Agosto }\end{array}$ & $\begin{array}{l}\text { - Transporte } \\
\text { - Material } \\
\text { didáctico } \\
\text { - Guardería de } \\
\text { la comunidad }\end{array}$ & $\begin{array}{l}\text { - Educador para la } \\
\text { salud } \\
\text { - FDC }\end{array}$ & $\begin{array}{l}\text { Las familias asistan a los } \\
\text { talleres de capacitación y } \\
\text { pongan en práctica lo } \\
\text { aprendido identificando y } \\
\text { analizando los problemas } \\
\text { de zoonosis en su } \\
\text { comunidad planteando } \\
\text { soluciones viables }\end{array}$ \\
\hline
\end{tabular}




\section{PLAN DE CLASE No 1}

TEMA: LA ZOONOSIS UN PROBLEMA DE SALUD

FECHA: 25 de julio del 2011

INSTRUCTORA: Katy Logroño

AUDIENCIA: Madres de familia de la comunidad de San Roque

LUGAR: Guardería de la comunidad de San Roque

OBJETIVO: Mejorar la calidad de vida de los niños, niñas, jóvenes y sus familias, mediante capacitación sobre zoonosis y su importancia para reducir la prevalencia del problema, en la comunidad de San Roque.

METODOLOGÍA: La metodología a utilizar es eminentemente participativa, activa y experencial.

RECURSOS:

HUMANOS

Educadora para la Salud de la Escuela Superior Politécnica de Chimborazo

\section{MATERIALES}

Carteles, afiches, trípticos, papelotes, videos, diapositivas.

ECONÓMICOS: Transporte y refrigerios 
Planificación Operativa del Plan de Clase No 1

\begin{tabular}{|c|c|c|c|}
\hline TIEMPO & $\begin{array}{l}\text { ESQUEMA PARA } \\
\text { LA } \\
\text { INTERVENCIÓN }\end{array}$ & PUNTOS A DESTACAR & $\begin{array}{l}\text { CÓMO } \\
\text { DESTACARLOS }\end{array}$ \\
\hline $10 \mathrm{~min}$ & $\begin{array}{l}\text { 1.- } \\
\text { AMBIENTACIÓN }\end{array}$ & $\begin{array}{l}\text { - Saludo de } \\
\text { bienvenida } \\
\text { - Presentación del } \\
\text { objetivo } \\
\text { - Dinámica } \\
\text { Rompehielos lo que } \\
\text { digo repito y hago }\end{array}$ & - Papelotes \\
\hline $20 \mathrm{~min}$ & $\begin{array}{l}\text { 2.- } \\
\text { PRESENTACIÓN } \\
\text { DEL TEMA }\end{array}$ & $\begin{array}{l}\text { - ¿Qué es la } \\
\text { zoonosis? } \\
\text { - Antropozoonosis } \\
\text { - Zooantroponosis } \\
\text { transmisión directa } \\
\text { y por medio de } \\
\text { vectores }\end{array}$ & $\begin{array}{l}\text { - Ilustraciones } \\
\text { gráficas } \\
\text { - Discusión } \\
\text { - Trabajo en } \\
\text { grupo }\end{array}$ \\
\hline
\end{tabular}




\begin{tabular}{|c|c|c|c|c|}
\hline 20 & $\begin{array}{l}\text { 3.- PLENARIA Y } \\
\text { EVALUACIÓN } \\
\text { DEL TEMA }\end{array}$ & $\bullet$ & $\begin{array}{l}\text { Refuerzo y } \\
\text { evaluación de los } \\
\text { conocimientos. } \\
\text { Preguntas y } \\
\text { respuestas sobre el } \\
\text { tema por parte de } \\
\text { instructoras } \\
\text { oyentes de } \\
\text { Aclaración } \\
\text { inquietudes de las } \\
\text { participantes }\end{array}$ & $\begin{array}{l}\text { - Mediante el } \\
\text { intercambio de } \\
\text { ideas los } \\
\text { conocimientos } \\
\text { de en } \\
\text { participantes en } \\
\text { base } \\
\text { informativos, } \\
\text { trípticos, lluvia } \\
\text { de } \\
\text { cartillas, } \\
\text { juegos, } \\
\text { preguntas. }\end{array}$ \\
\hline 10 minutos & $\begin{array}{l}\text { 4.- } \\
\text { COMPROMISOS } \\
\text { Y CIERRE }\end{array}$ & $\bullet$ & $\begin{array}{l}\text { Cambios de } \\
\text { comportamiento } \\
\text { referente al tema } \\
\text { tratado } \\
\text { Cierre de la sesión } \\
\text { e invitación al } \\
\text { próximo taller }\end{array}$ & $\begin{array}{l}\text { - llustraciones } \\
\text { de Estilos de } \\
\text { vida saludable }\end{array}$ \\
\hline
\end{tabular}




\section{EVALUACIÓN DEL TEMA}

\section{LA ZOONOSIS}

Marque con una x la respuesta que usted crea correcta y, de acuerdo a lo aprendido responda las siguientes preguntas

1.- ¿Qué es la zoonosis?

Enfermedad o infección que se da en los animales y que es transmisible al hombre ( )

Enfermedad de los animales( )

Son una afección y alteración infecciosa en los animales( )

\section{2.- ¿Cuándo se da una zoonosis de transmisión directa?}

Es aquella que se transmite directamente del hombre a los animales

Es la zoonosis ocasionada por insectos directamente al hombre

Cuando la zoonosis se transmite directamente del animal vivo, o a través de los alimentos de él obtenidos o de sus desechos. 


\section{3.- ¿Cuándo se da una zoonosis por medio de vectores?}

Cuando la Zoonosis es transmitida por vectores como insectos y animales que sirven de transporte y mantienen la cadena de transmisión de la enfermedad entre los animales y el hombre

Cuando la zoonosis se transmite directamente del animal vivo, o a través de los alimentos de él obtenidos o de sus desechos. ( ) 


\section{PLAN DE CLASE No 2}

TEMA: PRINCIPALES CAUSAS DE ZOONOSIS

FECHA: 27 de julio del 2011

INSTRUCTORA: Katy Logroño

AUDIENCIA: Madres de familia de la comunidad de San Roque

LUGAR: Guardería de la comunidad de San Roque

OBJETIVO: Identificar las causas para que se dé una zoonosis en las madres de familia de la comunidad de San Roque evitando riesgos para todos y todas.

METODOLOGÍA: La metodología a utilizar es eminentemente participativa, activa y experencial.

RECURSOS:

HUMANOS

Educadora para la Salud de la Escuela Superior Politécnica de Chimborazo

\section{MATERIALES}

Carteles, afiches trípticos, papelotes, videos, diapositivas.

ECONÓMICOS: Transporte y refrigerios. 
Planificación Operativa del Plan de Clase No 2

\begin{tabular}{|c|c|c|c|c|}
\hline TIEMPO & $\begin{array}{l}\text { ESQUEMA PARA } \\
\text { LA } \\
\text { INTERVENCIÓN }\end{array}$ & $\begin{array}{l}\text { PUNTOS } \\
\text { DESTACAR }\end{array}$ & A & $\begin{array}{l}\text { CÓMO } \\
\text { DESTACARLOS }\end{array}$ \\
\hline $10 \mathrm{~min}$ & 1.- AMBIENTACIÓN & $\begin{array}{l}\text { - Saludo } \\
\text { bienvenida } \\
\text { - Presentación } \\
\text { del objetivo } \\
\text { - Dinámica } \\
\text { Rompehielos } \\
\text { cocodrilo }\end{array}$ & de & - Papelotes \\
\hline $20 \mathrm{~min}$ & $\begin{array}{l}\text { 2.- } \\
\text { PRESENTACIÓN } \\
\text { DEL TEMA }\end{array}$ & $\begin{array}{l}\text { Causas de } \\
\text { zoonosis }\end{array}$ & & $\begin{array}{l}\text { - Ilustraciones } \\
\text { gráficas } \\
\text { - Discusión } \\
\text { - Trabajo en } \\
\text { grupo }\end{array}$ \\
\hline 20 & $\begin{array}{l}\text { 3.- PLENARIA Y } \\
\text { EVALUACIÓN DEL } \\
\text { TEMA }\end{array}$ & $\begin{array}{l}\text { - Refuerzo } \\
\text { evaluación c } \\
\text { los } \\
\text { conocimientos } \\
\text { actitudes. }\end{array}$ & & 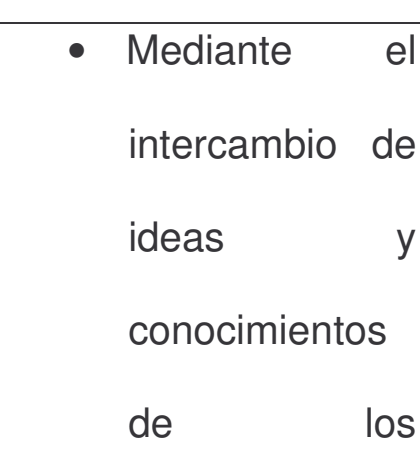 \\
\hline
\end{tabular}




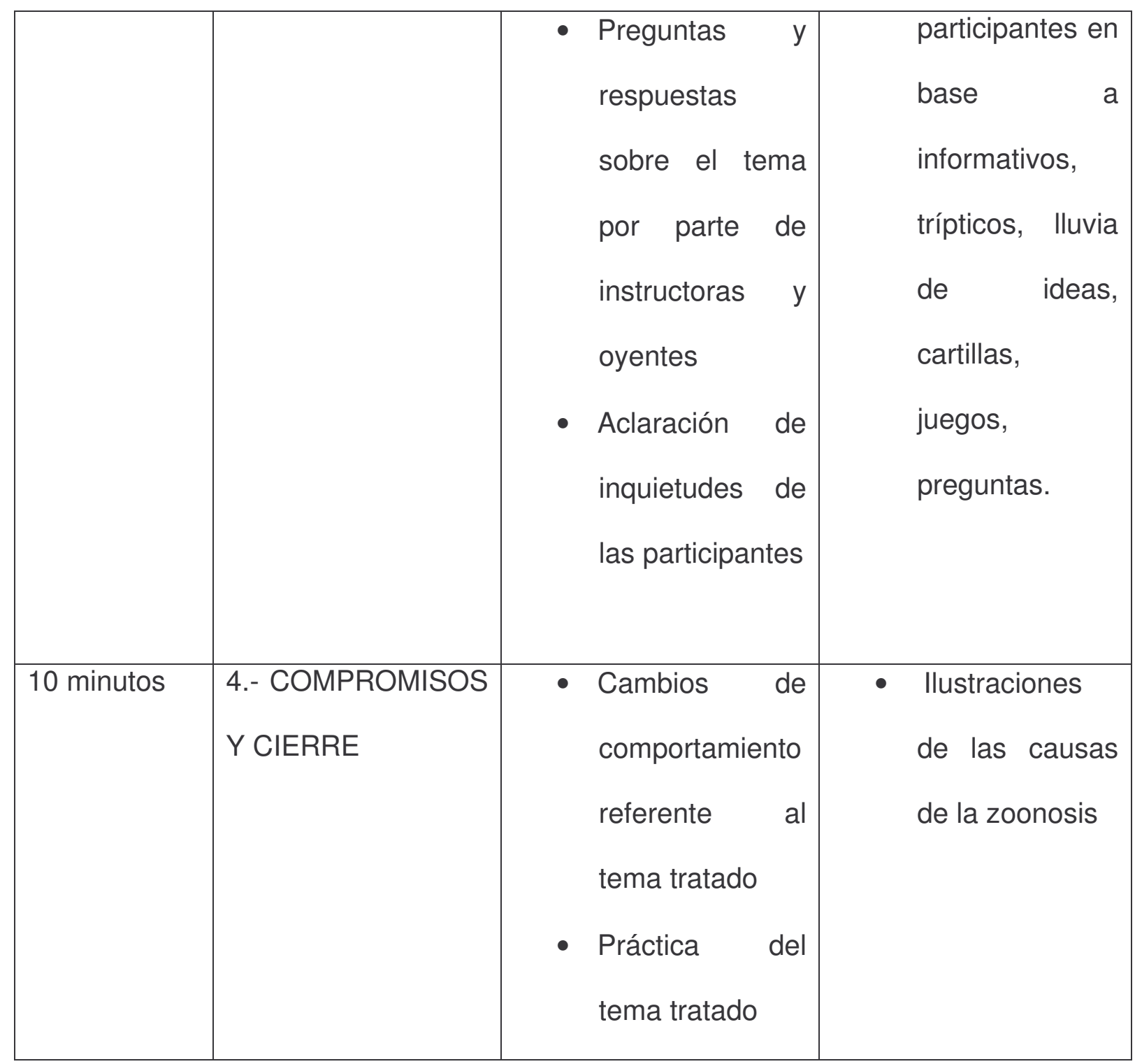




\section{EVALUACIÓN DEL TEMA}

\section{CAUSAS DE LA ZOONOSIS}

\section{De acuerdo a lo aprendido responda las siguientes preguntas}

\section{1.- Señale con una $x$ cuales son las causas para que se dé una zoonosis}

Presencia de estiércol de animales cerca de la vivienda

No se vacuna a los animales

Alimentación adecuada a los animales

No se desparasita a los animales

No se baña a los animales

Cuando no se alimenta adecuadamente a los animales

Limpieza de estiércol de animales

Andar sin zapatos

Andar con zapatos sucios

Almacenamiento de aguas estancadas

Falta de corrales para animales

Basura eliminada al campo abierto, ríos y quebradas

Animales dentro de la vivienda 
Perros callejeros

2.- Responda según su criterio ¿por qué es importante conocer las causas de la zoonosis? 


\section{PLAN DE CLASE No 3}

TEMA: TOXOPLASMOSIS UNA GRAVE ENFERMEDAD ZOONÓTICA

FECHA: 30 de julio del 2011

INSTRUCTORA: Katy Logroño

AUDIENCIA: Madres de familia de la comunidad de San Roque

LUGAR: Guardería de la comunidad de San Roque

OBJETIVO: Sensibilizar sobre la importancia, causas, consecuencias y el efecto en la salud de la toxoplasmosis, para reducir la incidencia y prevalencia de zoonosis en las madres de familia de la comunidad de San Roque.

METODOLOGÍA: La metodología a utilizar es eminentemente participativa, activa y experencial.

RECURSOS:

\section{HUMANOS}

Educadora para la Salud de la Escuela Superior Politécnica de Chimborazo

\section{MATERIALES}

Carteles, afiches trípticos, papelotes, videos, diapositivas.

ECONÓMICOS: Transporte y refrigerios. 
Planificación Operativa del Plan de Clase No 3

\begin{tabular}{|c|c|c|c|}
\hline TIEMPO & $\begin{array}{l}\text { ESQUEMA PARA } \\
\text { LA } \\
\text { INTERVENCIÓN }\end{array}$ & PUNTOS A DESTACAR & $\begin{array}{c}\text { CÓMO } \\
\text { DESTACARLOS }\end{array}$ \\
\hline $10 \mathrm{~min}$ & $\begin{array}{l}\text { 1.-- } \\
\text { AMBIENTACIÓN }\end{array}$ & $\begin{array}{l}\text { - Saludo de } \\
\text { bienvenida } \\
\text { - Presentación del } \\
\text { objetivo } \\
\text { Dinámica } \\
\text { Rompehielos: } \\
\text { En alta mar }\end{array}$ & - Papelotes \\
\hline $30 \mathrm{~min}$ & $\begin{array}{l}\text { 2.- } \\
\text { PRESENTACIÓN } \\
\text { DEL TEMA }\end{array}$ & $\begin{array}{l}\text { - Toxoplasmosis } \\
\text { - Causas, } \\
\text { consecuencias, } \\
\text { signos y síntomas }\end{array}$ & $\begin{array}{l}\text { - Ilustraciones } \\
\text { gráficas } \\
\text { - Discusión } \\
\text { - Trabajo en } \\
\text { grupo }\end{array}$ \\
\hline 20 & $\begin{array}{l}\text { 3.- PLENARIA Y } \\
\text { EVALUACIÓN DEL } \\
\text { TEMA }\end{array}$ & $\begin{array}{l}\text { - Refuerzo y } \\
\text { evaluación de los } \\
\text { conocimientos y } \\
\text { actitudes. } \\
\text { - Preguntas y }\end{array}$ & $\begin{array}{l}\text { - Mediante el } \\
\text { intercambio de } \\
\text { ideas y } \\
\text { de los }\end{array}$ \\
\hline
\end{tabular}




\begin{tabular}{|c|c|c|c|}
\hline & & $\begin{array}{l}\text { respuestas sobre } \\
\text { el tema por parte } \\
\text { de instructoras y } \\
\text { oyentes } \\
\text { - Aclaración de } \\
\text { inquietudes de las } \\
\text { participantes }\end{array}$ & $\begin{array}{l}\text { participantes en } \\
\text { base a } \\
\text { informativos, } \\
\text { trípticos, lluvia } \\
\text { de ideas, } \\
\text { cartillas, } \\
\text { juegos, } \\
\text { preguntas. }\end{array}$ \\
\hline 10 minutos & $\begin{array}{l}\text { 4.- } \\
\text { COMPROMISOS Y } \\
\text { CIERRE }\end{array}$ & $\begin{array}{l}\text { - Cambios de } \\
\text { comportamiento } \\
\text { referente al tema } \\
\text { tratado } \\
\text { - Práctica del tema } \\
\text { tratado }\end{array}$ & $\begin{array}{l}\text { - llustraciones } \\
\text { de las } \\
\text { enfermedades } \\
\text { zoonóticas }\end{array}$ \\
\hline
\end{tabular}


EVALUACIÓN DEL TEMA

LA TOXOPLASMOSIS UNA GRAVE ENFERMEDAD ZOONÓTICA

RESPONDA LO SIGUIENTE DE ACUERDO A LOS CONOCIMIENTOS ADQUIRIDOS EN EL TALLER

Una con líneas la enfermedad con su respectiva definición

\section{1.-La toxoplasmosis es:}

a) Una enfermedad propia de los perros que afecta al hombre( )

b) Una enfermedad generalmente que se da en el gato causado por el virus toxoplasma gandii y que es transmisible al hombre.

c) Es una enfermedad que les da a los gatos y que no es transmisible al hombre $($ )

2.- ¿Cómo se transmite la toxoplasmosis a las personas?

Al comer carne cruda de aves

b) Al acariciar a los gatos

c) Su transmisión se da cuando los gatos eliminan el virus con las heces y estos pasan al ganado o a las personas. 
3.- Señale con líneas las medidas de prevención de la Toxoplasmosis TOXOPLASMOSISMEDIDAS DE PREVENCIÓN

a) Evitando jugar con los gatos, y no se les debe dar la carne cruda.

b) Tapar huecos y agujeros dela vivienda

c) No se debe permitir que los gatos cacen y que ingieran sus presas

d) Se debe dar de comer carne cruda a los gatos

e) Se debe bañar, vacunar y desparasitar a los gatos

f) Se debe limpiar diariamente el cajón donde defeca el gato con agua hirviendo (o usar bolsas de plástico para los cajones) y usar guantes al manipular la arena. 


\section{PLAN DE CLASE No 4}

TEMA: HISTOPLASMOSIS UN PROBLEMA DE SALUD

FECHA: 1 de agosto del 2011

INSTRUCTORA: Katy Logroño

AUDIENCIA: Madres de familia de la comunidad de San Roque

LUGAR: Guardería de la comunidad de San Roque

OBJETIVO: Sensibilizar sobre la importancia, causas, consecuencias y el efecto en la salud de la histoplasmosis, para reducir la incidencia y prevalencia de zoonosis en las madres de familia de la comunidad de San Roque.

METODOLOGÍA: La metodología a utilizar es eminentemente participativa, activa y experiencial.

RECURSOS:

\section{HUMANOS}

Educadora para la Salud de la Escuela Superior Politécnica de Chimborazo

\section{MATERIALES}

Carteles, afiches trípticos, papelotes, videos, diapositivas.

ECONÓMICOS: Transporte y refrigerios. 
Planificación Operativa del Plan de Clase No 4

\begin{tabular}{|c|c|c|c|}
\hline TIEMPO & $\begin{array}{c}\text { ESQUEMA PARA } \\
\text { LA } \\
\text { INTERVENCIÓN }\end{array}$ & PUNTOS A DESTACAR & $\begin{array}{c}\text { CÓMO } \\
\text { DESTACARLOS }\end{array}$ \\
\hline $10 \mathrm{~min}$ & $\begin{array}{l}\text { AMBIENTACIÓN } \\
\text { AMIE }\end{array}$ & $\begin{array}{l}\text { - Saludo de } \\
\text { bienvenida } \\
\text { - Presentación de } \\
\text { objetivo } \\
\text { - Dinámica } \\
\text { Rompehielos: } \\
\text { En alta mar }\end{array}$ & - Papelotes \\
\hline $30 \mathrm{~min}$ & $\begin{array}{l}\text { 2.- } \\
\text { PRESENTACIÓN } \\
\text { DEL TEMA }\end{array}$ & $\begin{array}{l}\text { - Toxoplasmosis } \\
\text { - Causas, } \\
\text { consecuencias } \\
\text { efecto }\end{array}$ & $\begin{array}{l}\text { - Ilustraciones } \\
\text { gráficas } \\
\text { - Discusión } \\
\text { - Trabajo en } \\
\text { grupo }\end{array}$ \\
\hline 20 & $\begin{array}{l}\text { 3.- PLENARIA Y } \\
\text { EVALUACIÓN DEL } \\
\text { TEMA }\end{array}$ & $\begin{array}{l}\text { - Refuerzo y } \\
\text { evaluación de los } \\
\text { conocimientos y } \\
\text { actitudes. } \\
\text { - Preguntas y }\end{array}$ & $\begin{array}{l}\text { - Mediante el } \\
\text { intercambio de } \\
\text { ideas y } \\
\text { de los }\end{array}$ \\
\hline
\end{tabular}




\begin{tabular}{|c|c|c|c|}
\hline & & $\begin{array}{l}\text { respuestas sobre } \\
\text { el tema por parte } \\
\text { de instructoras y } \\
\text { oyentes } \\
\text { - Aclaración de } \\
\text { inquietudes de las } \\
\text { participantes }\end{array}$ & $\begin{array}{l}\text { participantes en } \\
\text { base a } \\
\text { informativos, } \\
\text { trípticos, lluvia } \\
\text { de ideas, } \\
\text { cartillas, } \\
\text { juegos, } \\
\text { preguntas. }\end{array}$ \\
\hline 10 minutos & $\begin{array}{l}\text { 4.- } \\
\text { COMPROMISOS Y } \\
\text { CIERRE }\end{array}$ & $\begin{array}{l}\text { - Cambios de } \\
\text { comportamiento } \\
\text { referente al tema } \\
\text { tratado } \\
\text { - Práctica del tema } \\
\text { tratado }\end{array}$ & $\begin{array}{l}\text { - llustraciones } \\
\text { de las } \\
\text { enfermedades } \\
\text { zoonóticas }\end{array}$ \\
\hline
\end{tabular}


EVALUACIÓN DEL TEMA

\section{LA HISTOPLASMOSIS UN PROBLEMA DE SALUD}

\section{RESPONDA LO SIGUIENTE DE ACUERDO A LOS CONOCIMIENTOS ADQUIRIDOS EN EL TALLER}

Una con líneas la enfermedad con su respectiva definición

\section{1.-La histoplasmosis es:}

a) Es una enfermedad que les da a los gatos y que no es transmisible al hombre $($ )

b) Es una enfermedad de las vacas y que es transmisible a las personas )

c) La histoplasmosis es una infección micótica causada por el hongo Histoplasma .Esta infección ingresa al cuerpo a través de los pulmones. $(\quad)$

2.- ¿Cómo se transmite la toxoplasmosis a las personas?

a) Al comer carne cruda de aves

b) Por la inhalación de partículas transportadas por el aire del suelo contaminado con excrementos de aves. 
b) Su transmisión se da cuando los gatos eliminan el virus con las heces y estos pasan al ganado o a las personas.

\section{3.- Subraye las respuestas correctas ¿Cómo podemos prevenir la histoplasmosis?}

1) Reduciendo la exposición al polvo en galpones para pollos, cuevas de murciélagos y otros lugares de alto riesgo.

2) Limpiando chancheras de animales

3) Utilice máscaras y otros equipos de protección para limpiar los excrementos de los pollos

4) Recogiendo el estiércol de vacas y chanchos

5) Si tiene en los hogares gallinas de campo limpiar diariamente sus excrementos que se encuentran en el suelo utilizando mascarillas

6) No permitir que ingresen los pollos a la vivienda o que duerman dentro de la vivienda. 


\section{PLAN DE CLASE No 5}

TEMA: Mal de Hanta

FECHA: 03 de agosto del 2011

INSTRUCTORA: Katy Logroño

AUDIENCIA: Madres de familia de la comunidad de San Roque

LUGAR: Guardería de la comunidad de San Roque

OBJETIVO: Concienciar sobre la importancia, vía de transmisión y la prevención del mal de hanta en la salud, para reducir la incidencia y prevalencia de zoonosis en las madres de familia de la comunidad de San Roque.

METODOLOGÍA: La metodología a utilizar es eminentemente participativa, activa y experiencial.

RECURSOS:

\section{HUMANOS}

Educadora para la Salud de la Escuela Superior Politécnica de Chimborazo

\section{MATERIALES}

Carteles, afiches trípticos, papelotes, videos, diapositivas.

ECONÓMICOS: Transporte y refrigerios. 
Planificación Operativa del Plan de Clase No 5

\begin{tabular}{|c|c|c|c|}
\hline TIEMPO & $\begin{array}{l}\text { ESQUEMA PARA } \\
\text { LA } \\
\text { INTERVENCIÓN }\end{array}$ & $\begin{array}{l}\text { PUNTOS } \\
\text { DESTACAR }\end{array}$ & $\begin{array}{l}\text { CÓMO } \\
\text { DESTACARLOS }\end{array}$ \\
\hline $10 \mathrm{~min}$ & 1.- AMBIENTACIÓN & $\begin{array}{l}\text { - Saludo d } \\
\text { bienvenida } \\
\text { - Presentación } \\
\text { del objetivo } \\
\text { - Dinámica } \\
\text { Rompehielos: } \\
\text { En alta mar }\end{array}$ & - Papelotes \\
\hline $30 \mathrm{~min}$ & $\begin{array}{l}\text { 2.- } \\
\text { PRESENTACIÓN } \\
\text { DEL TEMA }\end{array}$ & $\begin{array}{l}\text { - Mal de hanta } \\
\text { - Causas, } \\
\text { consecuencias } \\
\text { y efecto }\end{array}$ & $\begin{array}{l}\text { - Ilustraciones } \\
\text { gráficas } \\
\text { - Discusión } \\
\text { - Trabajo en } \\
\text { grupo }\end{array}$ \\
\hline 20 & $\begin{array}{l}\text { 3.- PLENARIA Y } \\
\text { EVALUACIÓN DEL } \\
\text { TEMA }\end{array}$ & $\begin{array}{l}\text { - Refuerzo } \\
\text { evaluación d } \\
\text { los } \\
\text { conocimientos } \\
\text { actitudes. }\end{array}$ & $\begin{array}{l}\text { - Mediante el } \\
\text { intercambio de } \\
\text { ideas y } \\
\text { conocimientos } \\
\text { de los }\end{array}$ \\
\hline
\end{tabular}




\begin{tabular}{|c|c|c|c|}
\hline & & $\begin{array}{l}\text { - Preguntas y } \\
\text { respuestas } \\
\text { sobre el tema } \\
\text { por parte de } \\
\text { instructoras y } \\
\text { oyentes } \\
\text { - Aclaración de } \\
\text { inquietudes de } \\
\text { las participantes }\end{array}$ & $\begin{array}{l}\text { participantes en } \\
\text { base a } \\
\text { informativos, } \\
\text { trípticos, lluvia } \\
\text { de ideas, } \\
\text { cartillas, } \\
\text { juegos, } \\
\text { preguntas. }\end{array}$ \\
\hline 10 minutos & $\begin{array}{l}\text { 4.- COMPROMISOS } \\
\text { Y CIERRE }\end{array}$ & $\begin{array}{l}\text { - Cambios de } \\
\text { comportamiento } \\
\text { referente } \\
\text { - Práctica de } \\
\text { tema tratado }\end{array}$ & $\begin{array}{l}\text { - llustraciones } \\
\text { de las } \\
\text { enfermedades } \\
\text { zoonóticas }\end{array}$ \\
\hline
\end{tabular}




\section{EVALUACIÓN DEL TEMA}

\section{MAL DEL HANTA}

\section{RESPONDA LO SIGUIENTE DE ACUERDO A LOS CONOCIMIENTOS ADQUIRIDOS EN EL TALLER}

\section{1.-El mal de Hanta es:}

a) Es una enfermedad que les da a las aves y que es transmisible al hombre $(\quad)$

b) Es una enfermedad de los cerdos y que es transmisible a las personas $($ )

c) Es un virus que vive en el ratón silvestre y que al transmitirse al hombre produce una enfermedad que puede ser mortal. $($ )

\section{2.- ¿Cómo se transmite el mal de hanta a las personas?}

a) Por la inhalación de partículas transportadas por el aire del suelo contaminado con excrementos de aves.

b) Al respirar aire contaminado por excrementos (deposiciones), orina o saliva del ratón silvestre. 
c) Su transmisión se da cuando las aves gatos eliminan el virus con las heces y estos pasan al ganado o a las personas.( )

3.- De acuerdo a lo aprendido Subraye ¿Cuáles considera usted son las medidas para prevenir el mal de Hanta?
a) Eliminar los ratones de su casa
b) Conservar sus alimentos en envases bien cerrados
c) Mantener la basura en recipientes con tapa
d) No dejar restos de comida sobre muebles, piso, mesas, etc.
e) Tapar agujeros con material firme.
f) Enterrar la basura.
g) Cortar a ras de suelo malezas y pastizales.
h) Alejar bodegas y leñeras de su casa 


\section{PLAN DE CLASE No 6}

TEMA: LA LEPTOSPIROSIS

FECHA: 06 de agosto del 2011

INSTRUCTORA: Katy Logroño

AUDIENCIA: Madres de familia de la comunidad de San Roque

LUGAR: Guardería de la comunidad de San Roque

OBJETIVO: Sensibilizar sobre la importancia, causas, consecuencias y el efecto en la salud de la leptospirosis, para reducir la incidencia y prevalencia de zoonosis en las madres de familia de la comunidad de San Roque.

METODOLOGÍA: La metodología a utilizar es eminentemente participativa, activa y experiencial.

\section{RECURSOS:}

\section{HUMANOS}

Educadora para la Salud de la Escuela Superior Politécnica de Chimborazo

\section{MATERIALES}

Carteles, afiches trípticos, papelotes, videos, diapositivas.

ECONÓMICOS: Transporte y refrigerios. 


\section{Planificación Operativa del Plan de Clase No 6}

\begin{tabular}{|c|c|c|c|}
\hline TIEMPO & $\begin{array}{l}\text { ESQUEMA PARA } \\
\text { LA } \\
\text { INTERVENCIÓN }\end{array}$ & $\begin{array}{l}\text { PUNTOS } \\
\text { DESTACAR }\end{array}$ & $\begin{array}{l}\text { CÓMO } \\
\text { DESTACARLOS }\end{array}$ \\
\hline $10 \mathrm{~min}$ & 1.- AMBIENTACIÓN & $\begin{array}{l}\text { - Saludo d } \\
\text { bienvenida } \\
\text { - Presentación } \\
\text { del objetivo } \\
\text { - Dinámica } \\
\text { Rompehielos: } \\
\text { En alta mar }\end{array}$ & - Papelotes \\
\hline $30 \mathrm{~min}$ & $\begin{array}{l}\text { 2.- } \\
\text { PRESENTACIÓN } \\
\text { DEL TEMA }\end{array}$ & $\begin{array}{l}\text { - Leptospirosis } \\
\text { - Causas, signo } \\
\text { y síntomas }\end{array}$ & $\begin{array}{l}\text { - Ilustraciones } \\
\text { gráficas } \\
\text { - Discusión } \\
\text { - Trabajo en } \\
\text { grupo }\end{array}$ \\
\hline 20 & $\begin{array}{l}\text { 3.- PLENARIA Y } \\
\text { EVALUACIÓN DEL } \\
\text { TEMA }\end{array}$ & $\begin{array}{l}\text { - Refuerzo } \\
\text { evaluación d } \\
\text { los } \\
\text { conocimientos }\end{array}$ & $\begin{array}{l}\text { - Mediante el } \\
\text { intercambio de } \\
\text { ideas y } \\
\text { conocimientos }\end{array}$ \\
\hline
\end{tabular}




\begin{tabular}{|c|c|c|c|c|}
\hline & & $\bullet$ & $\begin{array}{l}\text { actitudes. } \\
\text { Preguntas y } \\
\text { respuestas } \\
\text { sobre el tema } \\
\text { por parte de } \\
\text { instructoras y } \\
\text { oyentes } \\
\text { Aclaración de } \\
\text { inquietudes de } \\
\text { las participantes }\end{array}$ & $\begin{array}{l}\text { de los } \\
\text { participantes en } \\
\text { base } \\
\text { informativos, } \\
\text { trípticos, Iluvia } \\
\text { de ideas, } \\
\text { cartillas, } \\
\text { juegos, } \\
\text { preguntas. }\end{array}$ \\
\hline 10 minutos & $\begin{array}{l}\text { 4.- COMPROMISOS } \\
\text { Y CIERRE }\end{array}$ & $\bullet$ & $\begin{array}{l}\text { Cambios de } \\
\text { comportamiento } \\
\text { referente al } \\
\text { tema tratado } \\
\text { Práctica del } \\
\text { tema tratado }\end{array}$ & $\begin{array}{l}\text { llustraciones } \\
\text { de las } \\
\text { enfermedades } \\
\text { zoonóticas }\end{array}$ \\
\hline
\end{tabular}


EVALUACIÓN DEL TEMA

\section{LEPTOSPIROSIS UNA ENFERMEDAD DEALERTA}

\section{RESPONDA LO SIGUIENTE DE ACUERDO A LOS CONOCIMIENTOS ADQUIRIDOS EN EL TALLER}

Marque con una $\mathrm{x}$ la respuesta correcta en base a lo aprendido

\section{1.-La Leptospirosis es:}

a) Es una enfermedad que les da a las vacas y que es transmisible al hombre

b) Es una enfermedad febril producida por la Leptospira interrogans, una bacteria que afecta a humanos y un amplio rango de animales, incluyendo a mamíferos, aves, anfibios, y reptiles. ( )

c) Es un virus que vive en las aves y que al transmitirse al hombre produce una enfermedad que puede ser mortal. ( )

\section{2.- ¿Cómo se transmite leptospirosis a las personas?}

a) La infección se produce por contacto directo con la orina o los tejidos del animal infectado o por medio del agua o el suelo contaminado

b)La leptospirosis se transmite por las heces de los perros en contacto con las personas( ) 
c) Su transmisión se da cuando las aves eliminan el virus con las heces y estos pasan al ganado o a las personas. ( )

3.- De acuerdo a lo aprendido Subraye ¿Cuáles considera usted son las medidas para prevenir la Leptospirosis?
a) vacunación
b) Aplicar las normas de higiene sanitarias
c) Utilización de los medios de protección al trabajador.
d) Evitar acudir a ríos y lagos contaminados
e) Limpiar dentro y fuera de la vivienda e incluso baldear los alrededores de la vivienda.




\section{PLAN DE CLASE No 7}

TEMA: PONTE ALERTA CONTRA LA RABIA

FECHA: 08 de agosto del 2011

INSTRUCTORA: Katy Logroño

AUDIENCIA: Madres de familia de la comunidad de San Roque

LUGAR: Guardería de la comunidad de San Roque

OBJETIVO: Sensibilizar sobre la importancia, causas, consecuencias y el efecto en la salud de la rabia, para reducir la incidencia y prevalencia de zoonosis en las madres de familia de la comunidad de San Roque.

METODOLOGÍA: La metodología a utilizar es eminentemente participativa, activa y experiencial.

RECURSOS:

\section{HUMANOS}

Educadora para la Salud de la Escuela Superior Politécnica de Chimborazo

\section{MATERIALES}

Carteles, afiches trípticos, papelotes, videos, diapositivas.

ECONÓMICOS: Transporte y refrigerios. 
Planificación Operativa del Plan de Clase No 7

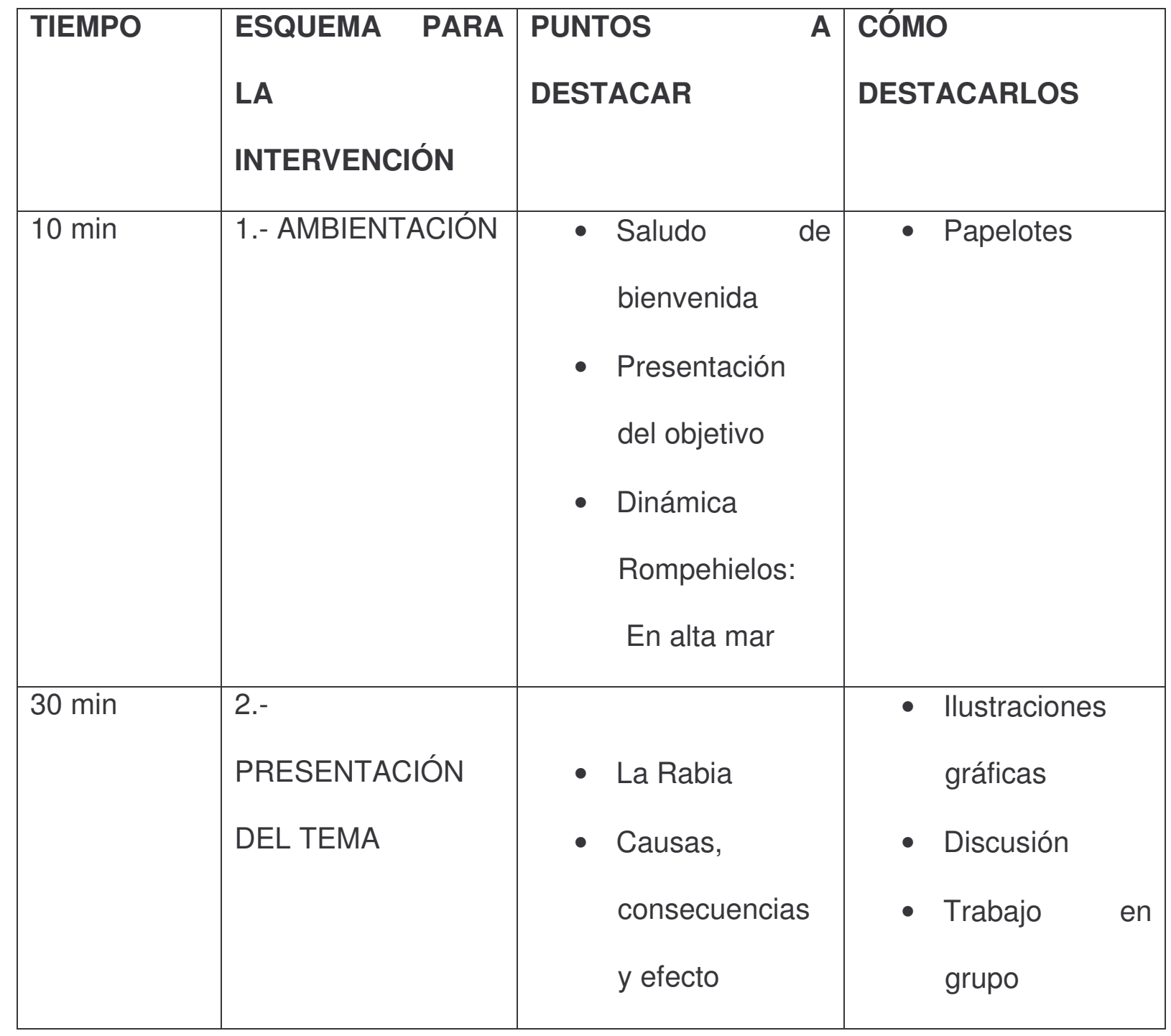




\begin{tabular}{|c|c|c|c|c|}
\hline 20 & $\begin{array}{l}\text { 3.- PLENARIA Y } \\
\text { EVALUACIÓN DEL } \\
\text { TEMA }\end{array}$ & & $\begin{array}{l}\text { Refuerzo y } \\
\text { evaluación de } \\
\text { los } \\
\text { conocimientos y } \\
\text { actitudes. } \\
\text { Preguntas y } \\
\text { respuestas } \\
\text { sobre el tema } \\
\text { por parte de } \\
\text { instructoras y } \\
\text { oyentes de } \\
\text { Aclaración de } \\
\text { inquietudes de } \\
\text { las participantes }\end{array}$ & $\begin{array}{l}\text { - Mediante el } \\
\text { intercambio de } \\
\text { ideas los } \\
\text { conocimientos } \\
\text { de a } \\
\text { participantes en } \\
\text { base } \\
\text { informativos, } \\
\text { trípticos, lluvia } \\
\text { de ideas, } \\
\text { cartillas, } \\
\text { juegos, } \\
\text { preguntas. }\end{array}$ \\
\hline 10 minutos & $\begin{array}{l}\text { 4.- COMPROMISOS } \\
\text { Y CIERRE }\end{array}$ & 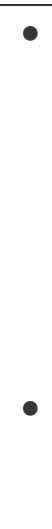 & $\begin{array}{l}\text { Cambios de } \\
\text { comportamiento } \\
\text { referente al } \\
\text { tema tratado } \\
\text { Práctica del } \\
\text { tema tratado }\end{array}$ & $\begin{array}{l}\text { llustraciones } \\
\text { de las } \\
\text { enfermedades } \\
\text { zoonóticas }\end{array}$ \\
\hline
\end{tabular}




\title{
EVALUACIÓN DEL TEMA
}

\author{
EVITEMOS LA RABIA
}

\section{RESPONDA LO SIGUIENTE DE ACUERDO A LOS CONOCIMIENTOS ADQUIRIDOS EN EL TALLER}

Marque con una $\mathrm{x}$ la respuesta correcta en base a lo aprendido

\section{1.-La rabia es:}

a) Es una enfermedad que les da a las vacas y que es transmisible al hombre

b) Es una enfermedad que afecta a los mamíferos domésticos y salvajes incluyendo al hombre, se encuentra en la saliva y en las secreciones de los animales infectados se transmite al hombre cuando éstos lo atacan y provocan en el hombre alguna lesión por mordedura

c) Es un virus que vive en las aves y que al transmitirse al hombre produce una enfermedad que puede ser mortal. ( )

\section{2.- ¿Cómo se transmite la Rabia?}

a) Al acariciar a un perro o gato ( )

b) A través de mordedura o contacto directo de mucosas o heridas con saliva del animal infectado 
c) A través del aire el virus pasa al hombre ( )

3.- De acuerdo a lo aprendido Subraye ¿Cuáles considera usted son las medidas para prevenir la Rabia?

a) Si observa un perro furioso evite pasar cerca de él, aléjese

b) Limpiar dentro y fuera de la vivienda e incluso baldear los alrededores de la vivienda.

c) Si en la comunidad existe un perro que está atacando a la población informe en el Ministerio de Salud al departamento de Sanidad para que se lo elimine.

d) Aplicar las normas de higiene sanitarias

e) Acuda a un centro de salud más cercano en caso de haber sido atacado por un perro rabioso.

f) Vacunar a perros y gatos 


\section{PLAN DE CLASE No 8}

TEMA: COMO ATACAN LAS NIGUAS

FECHA: 10 de agosto del 2011

INSTRUCTORA: Katy Logroño

AUDIENCIA: Madres de familia de la comunidad de San Roque

LUGAR: Guardería de la comunidad de San Roque

OBJETIVO: Sensibilizar sobre la importancia, causas, consecuencias y el efecto en la salud de las Niguas, para reducir la incidencia y prevalencia de zoonosis en las madres de familia de la comunidad de San Roque.

METODOLOGÍA: La metodología a utilizar es eminentemente participativa, activa y experiencial.

\section{RECURSOS:}

\section{HUMANOS}

Educadora para la Salud de la Escuela Superior Politécnica de Chimborazo

\section{MATERIALES}

Carteles, afiches trípticos, papelotes, videos, diapositivas.

ECONÓMICOS: Transporte y refrigerios 
Planificación Operativa del Plan de Clase No 8

\begin{tabular}{|c|c|c|c|}
\hline TIEMPO & $\begin{array}{l}\text { ESQUEMA PARA } \\
\text { LA } \\
\text { INTERVENCIÓN }\end{array}$ & $\begin{array}{l}\text { PUNTOS } \\
\text { DESTACAR }\end{array}$ & $\begin{array}{l}\text { CÓMO } \\
\text { DESTACARLOS }\end{array}$ \\
\hline $10 \min$ & 1.- AMBIENTACIÓN & $\begin{array}{l}\text { - Saludo de } \\
\text { bienvenida } \\
\text { - Presentación } \\
\text { del objetivo } \\
\text { - Dinámica } \\
\text { Rompehielos: } \\
\text { En alta mar }\end{array}$ & - Papelotes \\
\hline $30 \mathrm{~min}$ & $\begin{array}{l}\text { 2.- } \\
\text { PRESENTACIÓN } \\
\text { DEL TEMA }\end{array}$ & $\begin{array}{l}\text { - Las Niguas } \\
\text { - Causas, } \\
\text { consecuencias } \\
\text { y efecto }\end{array}$ & $\begin{array}{l}\text { - llustraciones } \\
\text { gráficas } \\
\text { - Discusión } \\
\text { - Trabajo en } \\
\text { grupo }\end{array}$ \\
\hline 20 & $\begin{array}{l}\text { 3.- PLENARIA Y } \\
\text { EVALUACIÓN DEL } \\
\text { TEMA }\end{array}$ & $\begin{array}{l}\text { - Refuerzo J } \\
\text { evaluación de } \\
\text { los } \\
\text { conocimientos } \\
\text { actitudes. }\end{array}$ & 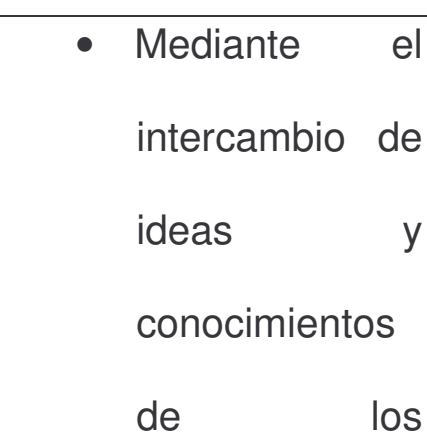 \\
\hline
\end{tabular}




\begin{tabular}{|c|c|c|c|}
\hline & & $\begin{array}{l}\text { - Preguntas y } \\
\text { respuestas } \\
\text { sobre el tema } \\
\text { por parte de } \\
\text { instructoras y } \\
\text { oyentes } \\
\text { - Aclaración de } \\
\text { inquietudes de } \\
\text { las participantes }\end{array}$ & $\begin{array}{l}\text { participantes en } \\
\text { base a } \\
\text { informativos, } \\
\text { trípticos, lluvia } \\
\text { de ideas, } \\
\text { cartillas, } \\
\text { juegos, } \\
\text { preguntas. }\end{array}$ \\
\hline 10 minutos & $\begin{array}{l}\text { 4.- COMPROMISOS } \\
\text { Y CIERRE }\end{array}$ & $\begin{array}{l}\text { - Cambios de } \\
\text { comportamiento } \\
\text { referente } \\
\text { - Práctica de } \\
\text { tema tratado }\end{array}$ & $\begin{array}{l}\text { - llustraciones } \\
\text { de las } \\
\text { enfermedades } \\
\text { zoonóticas }\end{array}$ \\
\hline
\end{tabular}




\section{EVALUACIÓN DEL TEMA}

\section{COMO ATACAN LAS NIGUAS}

\section{RESPONDA LO SIGUIENTE DE ACUERDO A LOS CONOCIMIENTOS ADQUIRIDOS EN EL TALLER}

\section{Marque con una $\mathrm{x}$ la respuesta correcta en base a lo aprendido}

\section{1.-¿Qué son las niguas}

a) Es una enfermedad que les da a las vacas y que es transmisible al hombre

b) Es un virus que vive en las aves y que al transmitirse al hombre produce una enfermedad que puede ser mortal.

c) Es una pulga que ataca la piel, principalmente la piel de los pies; se introduce en ella y produce prurito intenso. ( )

\section{2.- ¿Cómo se transmiten a las personas?}

a) Se suele contraer al pisar suelos mojados y sucios, pero en especial afectan a los cerdos y a las vacas y de estos se transmiten al ser humano estar en contacto con estos especialmente en las zonas rurales y comunidades donde existen cantidad de cerdos y vacas cerca de la vivienda.( )

b) Las niguas se transmiten al comer carne de cerdo 
c) Al acariciar a un perro o gato( )

5.- De acuerdo a lo aprendido Subraye ¿Cuáles considera usted son las medidas para prevenir las Niguas?

a) En zonas donde existan las niguas, es necesario lavarse bien los pies y revisarlos a diario para sacar las niguas antes de que produzcan infecciones.

b) No se debe permitir entrar a los cerdos dentro de la vivienda para prevenir este problema.

c) Otra medida de prevención es caminar con zapatos cerrados. Especialmente si tienen cerdos o vacas y al limpiar las heces de estos animales es recomendable hacerlo en los corrales utilizando botas.

d) No se debe caminar sin zapatos dentro ni fuera de los hogares ni los niños, ni las personas adultas.

e) Cortar los pastizales altos cerca de la vivienda donde se reproduce esta pulga 


\section{PLAN DE CLASE No 9}

TEMA: ENFERMEDADES ZOONÓTICAS PARASITARIAS

FECHA: 13 de Agosto del 2011

INSTRUCTORA: Katy Logroño

AUDIENCIA: Madres de familia de la comunidad de San Roque

LUGAR: Guardería de la comunidad de San Roque

OBJETIVO: Sensibilizar sobre la importancia, causas, consecuencias y el efecto en la salud de las enfermedades parasitarias a las madres de familia de la comunidad de san Roque para reducir la incidencia y prevalencia de zoonosis.

METODOLOGÍA: La metodología a utilizar es eminentemente participativa, activa y experencial.

RECURSOS:

HUMANOS

Educadora para la Salud de la Escuela Superior Politécnica de Chimborazo

MATERIALES

Carteles, afiches trípticos, papelotes, videos, diapositivas.

ECONÓMICOS: Transporte y refrigerios. 
Planificación Operativa del Plan de Clase No 9

\begin{tabular}{|c|c|c|c|}
\hline TIEMPO & $\begin{array}{l}\text { ESQUEMA PARA } \\
\text { LA } \\
\text { INTERVENCIÓN }\end{array}$ & $\begin{array}{ll}\text { PUNTOS } & \text { A } \\
\text { DESTACAR } & \end{array}$ & $\begin{array}{l}\text { CÓMO } \\
\text { DESTACARLOS }\end{array}$ \\
\hline $10 \mathrm{~min}$ & 1.- AMBIENTACIÓN & $\begin{array}{l}\text { - Saludo de } \\
\text { bienvenida } \\
\text { - Presentación } \\
\text { del objetivo } \\
\text { - Dinámica } \\
\text { Rompehielos: } \\
\text { Mi vecina }\end{array}$ & - Papelotes \\
\hline $30 \mathrm{~min}$ & $\begin{array}{l}\text { 2.- } \\
\text { PRESENTACIÓN } \\
\text { DEL TEMA }\end{array}$ & $\begin{array}{l}\text { Enfermedades } \\
\text { Zoonóticas } \\
\text { Parasitarias } \\
\text { - Parasitosis } \\
\text { intestinales } \\
\text { (tenia, } \\
\text { cisticercosis) }\end{array}$ & $\begin{array}{l}\text { - llustraciones } \\
\text { gráficas del } \\
\text { ciclo de vida } \\
\text { - Discusión } \\
\text { - Trabajo en } \\
\text { grupo }\end{array}$ \\
\hline
\end{tabular}




\begin{tabular}{|c|c|c|c|c|}
\hline 20 & $\begin{array}{l}\text { 3.- PLENARIA Y } \\
\text { EVALUACIÓN DEL } \\
\text { TEMA }\end{array}$ & $\bullet$ & $\begin{array}{l}\text { Refuerzo y } \\
\text { evaluación de } \\
\text { los } \\
\text { conocimientos y } \\
\text { actitudes. } \\
\text { Preguntas y } \\
\text { respuestas } \\
\text { sobre el tema } \\
\text { por parte de } \\
\text { instructoras. } \\
\text { Aclaración de } \\
\text { inquietudes de } \\
\text { las participantes }\end{array}$ & $\begin{array}{l}\text { - Mediante el } \\
\text { intercambio de } \\
\text { ideas los } \\
\text { de anocimientos } \\
\text { participantes en } \\
\text { base } \\
\text { informativos, } \\
\text { trípticos, lluvia } \\
\text { de ideas, } \\
\text { preguntas. }\end{array}$ \\
\hline 10 minutos & $\begin{array}{l}\text { 4.- COMPROMISOS } \\
\text { Y CIERRE }\end{array}$ & $\bullet$ & $\begin{array}{l}\text { Cambios de } \\
\text { comportamiento } \\
\text { referente al } \\
\text { tema tratado } \\
\text { Práctica del } \\
\text { tema tratado }\end{array}$ & $\begin{array}{l}\text { llustraciones } \\
\text { de las } \\
\text { enfermedades } \\
\text { zoonóticas }\end{array}$ \\
\hline
\end{tabular}




\section{EVALUACIÓN DEL TEMA}

\section{LA CISTICERCOSIS}

\section{RESPONDA LO SIGUIENTE DE ACUERDO A LOS CONOCIMIENTOS ADQUIRIDOS EN EL TALLER}

1.- Marque con una x la respuesta correcta ¿Qué es la cisticercosis?

a) La cisticercosis es una infección producida por un parásito llamado cisticerco )

b) Es una parasitosis ocasionada por estar en contacto con los cerdos( )

c) Es un parasito que se aloja en la piel de los cerdos ( )

\section{2.- ¿Cómo se transmite la cisticercosis a las personas?}

a) El cerdo a su vez adquiere la enfermedad al consumir y estar en contacto con heces fecales humanas, es decir, que los seres humanos contagiamos a los cerdos y estos nos retransmiten el parásito a través de la ingestión de su carne.( )

a) El hombre se infecta al andar descalzos en medio del estiércol de cerdos $(\quad)$

b) Esta parasitosis se transmite al hombre al estar en contacto con los cerdos $(\quad)$ 
3.- Subraye ¿Cuáles de las siguientes medidas nos ayudan a prevenir la cisticercosis?

a) Evitar que los cerdos entren en contacto con heces fecales teniéndoles en corrales y chancheras

b) Comiendo esta exquisita carne bien cocida

d) Tomando agua purifica o hervida

e) Lavándose las manos luego de ir al baño.

f) Dándoles de comer comida sana y limpia a los cerdos. 


\section{PLAN DE CLASE No 10}

TEMA: PREVENCIÓN DE ZOONOSIS

FECHA: 15 de agosto del 2011

INSTRUCTORA: Katy Logroño

AUDIENCIA: Madres de familia de la comunidad de San Roque

LUGAR: Guardería de la comunidad de San Roque

OBJETIVO: Incentivar a las madres de la comunidad de san Roque a aplicar medidas de prevención de zoonosis para disminuir el riesgo de contraerlas.

METODOLOGÍA: La metodología a utilizar es eminentemente participativa, activa y experiencial.

\section{RECURSOS:}

\section{HUMANOS}

Educadora para la Salud de la Escuela Superior Politécnica de Chimborazo

\section{MATERIALES}

Carteles, afiches trípticos, papelotes, videos, diapositivas.

\section{ECONÓMICOS}

Transporte y refrigerios. 
Planificación Operativa del Plan de Clase No 10

\begin{tabular}{|c|c|c|c|c|}
\hline TIEMPO & $\begin{array}{l}\text { ESQUEMA PARA } \\
\text { LA } \\
\text { INTERVENCIÓN }\end{array}$ & $\begin{array}{l}\text { PUNTOS } \\
\text { DESTACAR }\end{array}$ & & $\begin{array}{l}\text { CÓMO } \\
\text { DESTACARLOS }\end{array}$ \\
\hline $10 \mathrm{~min}$ & 1.- AMBIENTACIÓN & $\begin{array}{l}\text { - Saludo } \\
\text { bienvenida } \\
\text { - Presentación } \\
\text { del objetivo } \\
\text { Dinámica } \\
\text { El vendedor }\end{array}$ & & - Papelotes \\
\hline $20 \mathrm{~min}$ & $\begin{array}{l}\text { 2.- } \\
\text { PRESENTACIÓN } \\
\text { DEL TEMA }\end{array}$ & $\begin{array}{l}\text { - Prevención } \\
\text { zoonosis }\end{array}$ & & $\begin{array}{l}\text { - Ilustraciones } \\
\text { gráficas del } \\
\text { ciclo de vida } \\
\text { - Discusión } \\
\text { - Trabajo en } \\
\text { grupo }\end{array}$ \\
\hline 20 & $\begin{array}{l}\text { 3.- PLENARIA Y } \\
\text { EVALUACIÓN DEL } \\
\text { TEMA }\end{array}$ & $\begin{array}{l}\text { Refuerzo } \\
\text { evaluación } \\
\text { los } \\
\text { conocimientos }\end{array}$ & & $\begin{array}{l}\text { - Mediante el } \\
\text { intercambio de } \\
\text { ideas y } \\
\text { conocimientos }\end{array}$ \\
\hline
\end{tabular}




\begin{tabular}{|c|c|c|c|c|}
\hline & & $\bullet$ & $\begin{array}{l}\text { actitudes. } \\
\text { Preguntas y } \\
\text { respuestas } \\
\text { sobre el tema } \\
\text { por parte de } \\
\text { instructora. } \\
\text { Aclaración de } \\
\text { inquietudes de } \\
\text { las participantes }\end{array}$ & $\begin{array}{l}\text { de los } \\
\text { participantes en } \\
\text { base a } \\
\text { informativos, } \\
\text { trípticos, lluvia } \\
\text { de ideas, } \\
\text { preguntas. }\end{array}$ \\
\hline 10 minutos & $\begin{array}{l}\text { 4.- COMPROMISOS } \\
\text { Y CIERRE }\end{array}$ & $\bullet$ & $\begin{array}{l}\text { Cambios en sus } \\
\text { estilos de vida } \\
\text { Práctica de } \\
\text { medidas de } \\
\text { prevención } \\
\text { higiénico } \\
\text { sanitarias en las } \\
\text { madres de la } \\
\text { comunidad. }\end{array}$ & $\begin{array}{l}\text { - llustraciones } \\
\text { de medidas de } \\
\text { prevención de } \\
\text { la zoonosis en } \\
\text { la comunidad. }\end{array}$ \\
\hline
\end{tabular}


EVALUACIÓN DEL TEMA

PREVENCIÓN DE ZOONOSIS

RESPONDA LO SIGUIENTE DE ACUERDO A LOS CONOCIMIENTOS ADQUIRIDOS EN EL TALLER

\section{MARQUE CON UNA X LA RESPUESTA CORRECTA}

1.- ¿Cuáles de las siguientes medidas higiénico sanitarias son importantes para prevenir la zoonosis?

Bañar a los animales domésticos ( ) Limpiar heces de animales domésticos ( )

Limpiar la vivienda ( ) Limpiar y desinfectar el baño y cocina ( )

Limpieza de estiércol de animales de granja. ( )

Vacunar, desparasitar, y curar a los animales domésticos y de granja ( )

Lavarse las manos luego de manipular animales domésticos y de granja ( )

Dar de beber agua de ríos o pozos a los animales de granja( ）

Realizar corrales, establos chancheras y galpones para animales de granja ( )

Bañar a los animales en ríos y pozos

Andar sin zapatos

Almacenar el estiércol de animales de granja cerca de la vivienda 
Andar siempre con zapatos

Evitar el contacto de niños con animales, especialmente si estos están enfermos

Dar de comer carne cruda y ratones a los gatos ( )

Que los niños estén en contacto con animales domésticos

2.- ¿Cuál es el tratamiento que se debe dar al estiércol de los animales de granja?

Almacenarlo cerca de la vivienda para venderlo ( )

Crear una bodega o cuarto de almacenamiento en caso de que se lo venda

Utilizarlo como abono orgánico en el campo lejos de la vivienda( ）

Limpiar cada 15 días el estiércol con agua( ）

Evitar períodos de almacenamiento en bodegas de más de tres meses para evitar malos olores( )

Limpiar el estiércol diariamente con agua y a presión o raspándolos( ）

Mantener el estiércol bien tapado en las bodegas o cuarto de almacenaje

La localización del cuarto de almacenaje de estiércol debe ser lejos de las fuentes de agua y fuera de las vías naturales de drenaje ( ) 
3.-¿Qué es lo que aprendió del taller y cuál es su compromiso? 


\section{EVALUACIÓN}

A.- nivel de conocimientos

TABLA No 72

NIVEL DE CONOCIMIENTOS ANTES Y DESPUES DE LAS INTERVENCIONES EDUCATIVAS EN LA COMUNIDAD DE SAN ROQUE PERTENECIENTE AL CANTÓN SUCRE PARROQUIA CHARAPOTÓ. PROVINCIA DE MANABÍ.2011

\begin{tabular}{|c|c|c|}
\hline ZOONOSIS & $\begin{array}{c}\text { Porcentaje de } \\
\text { conocimientos antes de } \\
\text { las intervenciones } \\
\text { educativas }\end{array}$ & $\begin{array}{c}\text { Porcentaje de } \\
\text { conocimientos } \\
\text { después de las } \\
\text { intervenciones } \\
\text { educativas }\end{array}$ \\
\hline ZOONOSIS & $5 \%$ & $93 \%$ \\
\hline RABIA & $80 \%$ & $97 \%$ \\
\hline TOXOPLASMOSIS & $0 \%$ & $98 \%$ \\
\hline NIGUAS & $72 \%$ & $90 \%$ \\
\hline HISTOPLASMOSIS & $18 \%$ & $88 \%$ \\
\hline MAL DE HANTA & $0 \%$ & $93 \%$ \\
\hline LEPTOSPIROSIS & $5 \%$ & $97 \%$ \\
\hline TOTAL & $26 \%$ & $94 \%$ \\
\hline
\end{tabular}


Gráfico No 72

NIVEL DE CONOCIMIENTOS ANTES Y DESPUES DE LAS INTERVENCIONES

EDUCATIVAS EN LA COMUNIDAD DE SAN ROQUE PERTENECIENTE AL

CANTÓN SUCRE PARROQUIA CHARAPOTÓ. PROVINCIA DE MANABÍ.2011

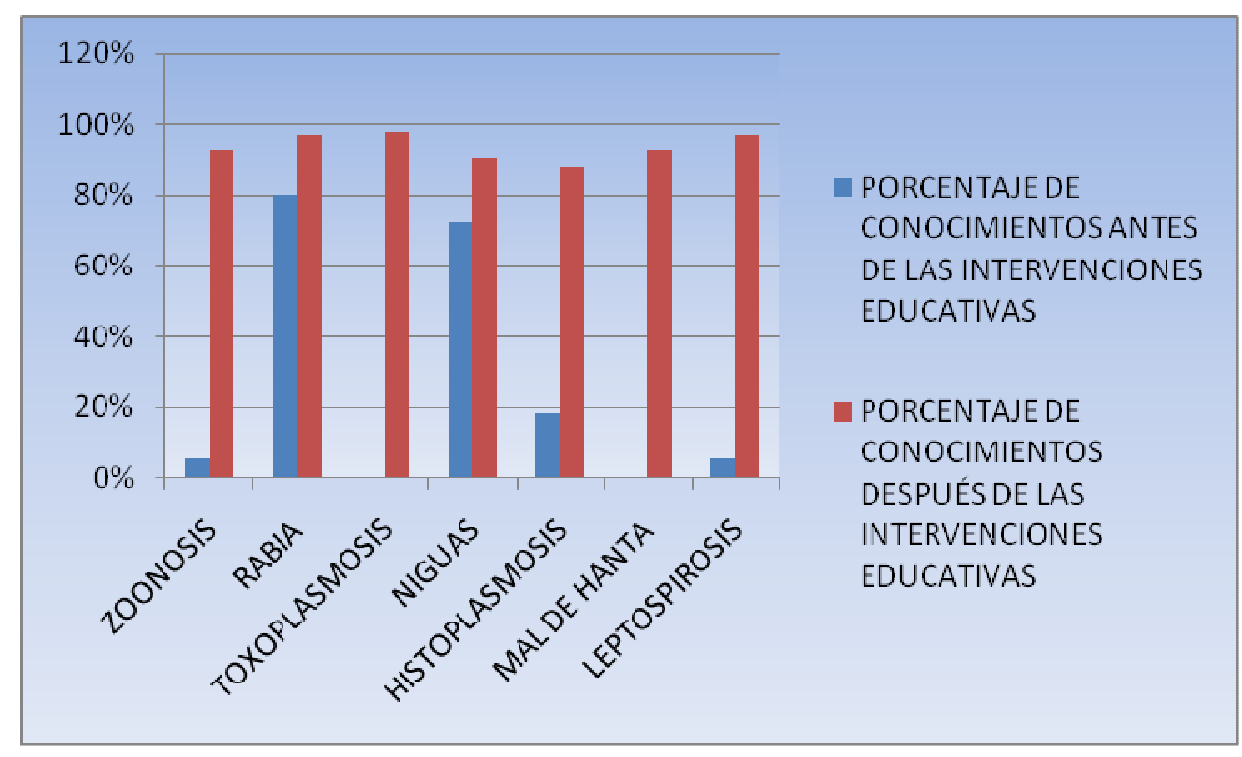

Fuente: Tabla No 72

el porcentaje promedio antes de realizar las intervenciones educativas corresponde al $26 \%$, luego de que se aplicó el programa educativo el nivel de conocimientos se elevó al 94\% obteniendo un resultado satisfactorio.

El programa fue efectivo y eficaz porque la gente ahora conoce la gravedad del problema y lo va a prevenir en base al temor de contraer alguna zoonosis. 


\section{CONCLUSIONES}

- Del grupo de estudio se identificó un $33 \%$ de madres analfabetas que se encuentran en proceso de alfabetización, con organismos del estado ecuatoriano.

- Se observó un impacto positivo en las madres principalmente en los temas relacionados a las vías de transmisión de enfermedades zoonóticas y en el conocimiento sobre el uso de medidas profilácticas como desinfección, vacunación y desparasitación a los animales domésticos y de granja; así como medidas de prevención las mismas que las pondrán en práctica, luego de conocer la gravedad del problema y por el temor a adquirirlas.

- Las enfermedades zoonóticas son las más predominantes, debido a bajo nivel de escolaridad, insalubridad, gran porcentaje de animales domésticos y de granja en la comunidad y en contacto con la familia.

- Los animales domésticos junto a la vivienda genera la presencia de vectores que ocasionan la proliferación de microorganismos dañinos para la salud.

- Conocer el tipo, características de la vivienda, y forma de tenencia de la misma, así como la disponibilidad de agua, servicio higiénico, servicio eléctrico, servicio telefónico, formas de eliminación de la basura, eliminación de excretas de animales, manejo de animales domésticos y otros servicios, nos permitió determinar las condiciones sociales, económicas y de salud en las que vive la población. 


\section{RECOMENDACIONES}

- Educar a la población para una tenencia responsable de mascotas. Se debe promover el control de los animales domésticos y de granja con médico veterinario y su vacunación para disfrutar de los beneficios de tener mascotas, minimizando los riesgos especialmente en la población vulnerable a adquirir estos problemas.

- Inspección y control de establecimientos como el Ministerio de Salud pública, Sub centros de Salud, y entidades responsables de velar por la salud de la comunidad; aplicando la Detección precoz de zoonosis especialmente en zonas consideradas de riesgo.

- Realizar intervenciones educativas, capacitaciones y brindar asesoría técnica por parte de Instituciones como el Ministerios de Salud y Agricultura; con el fin de hacer conocer y concientizar a la población del peligro de las enfermedades zoonóticas.

- Se recomienda aplicar la atención y prevención primaria de salud es decir asistencia sanitaria esencial basada en métodos y tecnologías práctica, científicamente fundada y socialmente aceptable, y una serie de acciones de Salud Pública sean de diagnóstico, prevención, curación y rehabilitación, que deben realizarse desde un nivel primario y local en beneficio de la comunidad.

- Dar seguimiento a este tipo de estudios y fortalecer las herramientas de apoyo que puede utilizar el educador en el campo profesional. 


\section{REFERENCIAS BIBLIOGRÁFICAS}

(1) FAUSI, A. S. y otros.Principios de Medicina Interna. Harrison 16ª . ed. México: McGraw-Hill. Interamericana 2003. 3111p.

\section{(2) ZOONOSIS (REALIDAD MUNDIAL)}

www.infodoctor.org

2011-04-25

(3) BOTERO, D.Enfermedades parasitarias en Latinoamérica.Persistencia de Zoonosis y parasitosis intestinales endémicas en América Latina.

Bol Ofic Sanit Panam (Panamá) 1990

www.yasalud.com/

2011-04-25

\section{(4)PREVALENCIA DE ZOONOSIS}

www.guiaverde.info/articulos/salud-ge..

2011-04-25

(5)ORGANIZACIÓN MUNDIAL DE LA SALUD (OMS)Infecciones

Intestinales por protozoos y helmintos.

www.mex.ops-oms.org

2011-04-27 
(6) INFECCIONES PARASITOLÓGICAS Y FRECUENCIA DE

\section{ENFERMEDADES PARASITARIAS.}

www.diccionario.babylon.com/zoonosis/

2011-04-27

(7)OPS ORGANIZACIÓN MUNDIAL DE LA SALUD. EL PROBLEMA DE LA ZOONOSIS EN EL ECUADOR

www.paho.org/spanish

2011-04-27

(8)ENDEMAIN.2004. Epidemiología 2004 Problemas de Salud parasitosis y Zoonosis en el Ecuador, y en Manabí.

www.cepar.org.ec/endemain_04/.../inicio.htm

2011-04-27

(9)DEFINICIÓN DE ENFERMEDAD.

www.elalmanaque.co

2011-04-27

(10)PARASITISMO

http://es.wikipedia.org

2011-04-27 
(11)LAS ENFERMEDADES ZOONÓTICAS

www.uprm.edu/biology

2011-04-27

(12)EPIDEMIOLOGÍA CADENA EPIDEMIOLÓGICA, CONCEPTOS EPIDEMIOLÓGICOS

www.epi.minsal.cl/epi/ht

2011-04-27

(13)ENFERMO CLÍNICO

www.epi.minsal.cl/epi/html/elvigia/vigia19/VIGIA1939.pdf

2011-04-28

(14)ENFERMO SUBCLÍNICO

www.monografias.com.ec

2011-04-28

(15)PORTADORES EPIDEMIOLÓGICOS

www.medicinainterna.com/concepto. epi.

2011-04-28

(16)MECANISMOS DE TRANSMISIÓN

www.manual epidemiológico.com

2011-04 


\section{(17)DEFINICIÓN DE PARÁSITO}

www.tusalud.com.mx/site/...

2011-04-28

(18)PARASITOSIS Y SALUD PÚBLICA

www.enciclopedia microbiologia.com.mx/site/...

2011-04-28

(19)

VIRULENCIA

www.es.wikipedia.org/wiki/Virulencia

2011-04-28

(20) PODER ANTÍGENO

www.monografias.com

2011-04-28 
(21)INMUNIDAD

www.monografias.com

2011-07-12

(22) SUCEPTIBILIDAD.

www.microbiology/epi.com

2011-04-28

(23) PERIODO DE TRANSMISIBILIDAD

www.microbiology/epi.com

2011-04-28

(24)DEFINICIÓN DE ANIMALES DOMÉSTICOS

www.conciencia-animal.cl/paginas/.../temas.php?d

2011-04-28

(25) TOXOPLASMOSIS Y AGENTE CAUSAL

www.microbiology/epi.com

2011-04-28 


\section{(26)TOXOPLASMOSIS.}

www. world wide web.educ.ec

2011-04-28

\section{(27)ENFERMEDADES ZOONOTICAS}

www.definicionesmedicas.com/concepto-de-lyme.html

2011-04-28

(28)EPIDEMIOLOGIA DE LA HISTOPLASMOSIS HISTOPLASMOSIS.

www.epi/edu.histoplasmosis.ec

2011-04-28

(29)EPIDEMIOLOGIA DE LA ENFERMEDAD DEL TUNGA PENETRANS

(NIGUA)

www.epi/edu.com

2011-04-29

(30)PREVENCIÓN LA RABIA

www.salud.com/enfermedades.asp

2011-04-29

\section{1)PATOLOGÍA DE LA RABIA}

www.rabia-canina.com

2011-04-29 


\section{$X$ ANEXOS}

Anexo $\mathbf{N}$ 1.- Encuesta para las familias de la comunidad

\section{ESCUELA SUPERIOR POLITÉCNICA DE CHIMBORAZO}

FACULTAD DE SALUD PÚBLICA

\section{ESCUELA DE PROMOCIÓN Y CUIDADOS DE LA SALUD}

\section{ENCUESTA A LAS MADRES DE FAMILIA DE LA COMUNIDAD}

Objetivo: Identificar características sociodemográficas del grupo de estudio, determinar los factores de Riesgo y nivel de conocimientos que tienen las familias sobre Zoonosis (Enfermedades ocasionadas por Animales Domésticos al Hombre) en la Comunidad de San Roque del Cantón Sucre Parroquia Charapotó. Provincia de Manabí.2011.

Instructivo: El siguiente cuestionario recoge toda la información que usted nos puede brindar sobre el tema, cuyo contenido será completamente anónimo y confidencial. Para que los resultados de nuestra investigación sean satisfactorios necesitamos que no deje preguntas en blanco y la mayor sinceridad posible en sus respuestas.

Marque con una $\mathrm{x}$ en la respuesta. 


\section{CARACTERÍSTICAS SOCIO-DEMOGRÁFICAS}

PROVINCIA............... CANTÓN

NOMBRE DE LA COMUNIDAD.

Edad:

Termino sus estudios en:

Escuela ( ) Colegio Universitario ( ) Ninguno ( )

Mujeres embarazadas en el hogar:

$\operatorname{Si}() \quad$ No ( )

\section{DATOS HIGIÉNICOS SANITARIOS}

1.- Marque con una $x$ que animal doméstico tiene en su casa

Perros ( ) Gatos ( ) Otros ( ) ¿Cuál?

2.-. ¿Para qué tiene Usted animales domésticos (perros, gatos) en la vivienda?

Cuidar la casa( ) Cazar ratones ( ) Mascota ( ) Otros( )

3.- ¿Cuáles son las personas de la familia que mantienen contacto directo con los perros en su vivienda?

Niños ( ) Adultos ( ) 
4.-¿Cuáles son las personas de la familia que mantienen contacto directo con los gatos en su vivienda?

Niños ( ) Adultos ( )

5.- ¿Usted Limpia y desinfecta el lugar donde come el perro y el gato?

Si ( ) No ( ) Nunca( )

6.-¿Usted Limpia y desinfecta el lugar donde defeca el perro?

Si ( ) No( ) Nunca( )

7.- ¿Usted Limpia y desinfecta el lugar donde defeca el gato?

Si ( ) No( ) Nunca( )

8.- ¿Usted le baña al perro?

Si ( ) No ( ) Nunca ( )

9.- ¿Usted le baña al gato?

Si ( ) No ( ) Nunca ( )

10.- ¿Usted lleva a vacunar a los perros contra la rabia? 
Si ( ) No ( ) Nunca( )

11.- ¿Usted lleva a vacunar a los gatos contra la rabia?

Si ( ) No ( ) Nunca( )

12.- ¿Les ha dado algún remedio para los parásitos a los perros?

Si ( ) No( ) Nunca( )

13.-¿Les ha dado algún remedio para los parásitos a los gatos?

Si ( ) No( ) Nunca( )

14.- ¿ Tienen alguno de los siguientes animales de granja (vacas, puercos, gallinas, patos, ganzos, caballos, mulas)?

Si ( ) No ( )

15.- Señale ¿Qué tipo de animal de granja tiene?

Vacas ( ) Cerdos ( ) Gallinas ( ) Patos ( ) Gansos ( ) Caballos ( )

Mulas ( )

16.- ¿Para qué sirven los animales de granja que tiene?

Sirven paraConsumo ( ) Ayuda económica ( ) Para trabajo en agricultura ( ) otra actividad ( ) cual? 
17.- ¿Cuál es el miembro de familia que se encarga del cuidado de los animales de granja?

Padre( ) Madre( ) Hijos( ) Otra persona( ) cuál?

18.- ¿Tiene Corrales para las vacas?

Si ( ) No ( ) Porque?

19.- ¿Tiene chancheras para los cerdos?

Si ( ) No ( ) Porque?

20.- ¿Tiene galpones o corrales para las gallinas?

Si ( ) No ( ) Porque?

21.- ¿Limpia el estiércol de las vacas?

Si ( ) No ( )

22.- ¿Con qué frecuencia realizan la limpieza de estiércol de las vacas?

A diario ( ) Una vez por semana ( ) Cada 15 días ( ) Mensualmente ( ) A veces ( )Nunca ( )

23.- ¿Limpia el estiércol de los chanchos?

Si ( ) No ( ) 
24.- ¿Con qué frecuencia realizan la limpieza de estiércol de los chanchos?

A diario ( ) Una vez por semana ( ) Cada 15 días ( ) Mensualmente ( ) A veces ( )Nunca ( )

25.- ¿Limpia el estiércol de las gallinas?

Si ( ) No ( )

26.- Con qué frecuencia realizan la limpieza de estiércol de las gallinas?

A diario ( ) Una vez por semana ( ) Cada 15 días ( ) Mensualmente ( ) A veces ( )Nunca ( )

27.- ¿Limpia el estiércol de caballos y mulas?

$\mathrm{Si}(\mathrm{)}$ No ( )

28.- ¿Les pone las vacunas correspondientes a las vacas?

Si ( ) No ( ) Nunca ( )

29.- ¿Les pone las vacunas correspondientes a los chanchos?

Si ( ) No ( ) Nunca ( )

30.- ¿Les ha dado algún medicamento para desparasitar a las vacas?

Si ( ) No( ) Nunca( ) 
31.- ¿Les ha dado algún medicamento para desparasitar a los chanchos?

Si ( ) No( ) Nunca( )

32.- El agua que consumen es:

Potable ( ) Entubada ( ) Otro ( ) cuál?

33.- ¿Qué hace con la basura que genera la familia?

Quema ( ) Recicla ( ) Bota en campo abierto ( ) Bota en ríos y quebradas ( )

Manda en el carro recolector ( ) otra ( ) cuál?

34.- ¿Existe agujeros y huecos en el piso y paredes de la vivienda?

$\mathrm{Si}(\mathrm{)}$ No( )

35.- En su familia los niños andan sin zapatos

Si ( ) No ( ) Nunca ( )

36.-En la familia los adultos andan sin zapatos:

Si ( ) No ( ) Nunca ( )

37.- Existe la Presencia de roedores (ratas) en la vivienda

Si ( ) No ( ) Tal vez ( ) 


\section{CONOCIMIENTOS}

38.- Señale con una $x$ ¿qué es la zoonosis?

Ciencia que estudia los animales

Es una enfermedad que puede transmitirse de animales a seres humanos ( )

Ciencia que estudia Enfermedades de los animales

39.- ¿Qué es la rabia?

Enfermedad de las aves

Enfermedad viral mortal que afecta al sistema nervioso ocasionada principalmente por el perro

Enfermedad que se produce al estar en contacto con los perros vacunados

40.- Señale con una x ¿Qué es La toxoplasmosis?

Una enfermedad propia del ser humano

Enfermedad infecciosa ocasionada por un protozoo parásito llamado Toxoplasma cuyo hospedador principal es el gato

Una infección de las vías respiratorias ( ) 
41.- Marque con una $x$ ¿Qué son las niguas?

Son Irritaciones de la piel ( )

Es una pulga que ataca la piel de los pies( )

Son erupciones cutáneas en la cara de la persona

42.-Marque con una x ¿Qué es para usted la Histoplasmosis?

Infecciones del riñón

Es un hongo que crece en el suelo y la infección resulta de la inhalación de partículas transportadas por el aire del suelo contaminado con excrementos de aves.

Es una inflamación de la garganta

43.- Marque con una $x$ ¿Qué es para usted el Mal de Hanta?

Es un mal ocasionada por la orina, excrementos y saliva de ratas

Es un mal ocasionado por orina de perros y gatos

Es un mal ocasionado por el estiércol de caballos y mulas( )

44.- Marque con una $\times$ ¿Qué es para usted la Leptospirosis?

Enfermedad ocasionada por la orina de perros enfermos 
Enfermedad ocasionada por los gatos

Enfermedad ocasionada por una bacteria de los chanchos( ) 


\section{ANEXO No 2}

\section{FOTOS}

Foto No 1 Taller de enfermedades zoonóticas

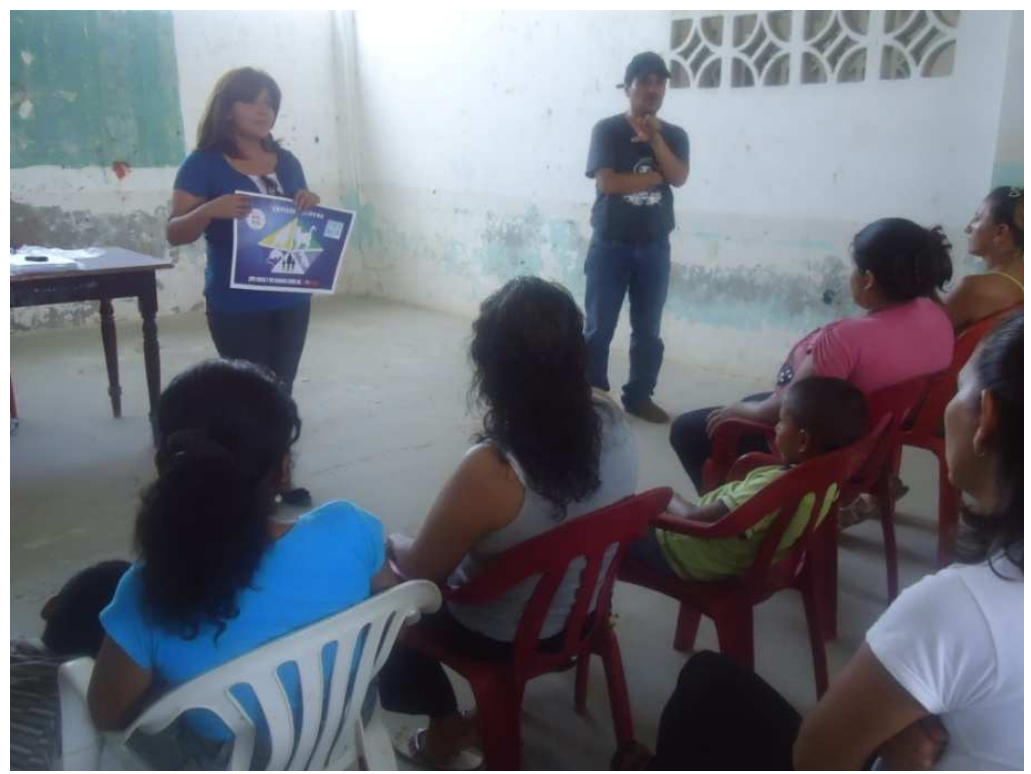

FOTO No 2 Taller de Toxoplasmosis con ayuda de un FDC de Plan Internacional

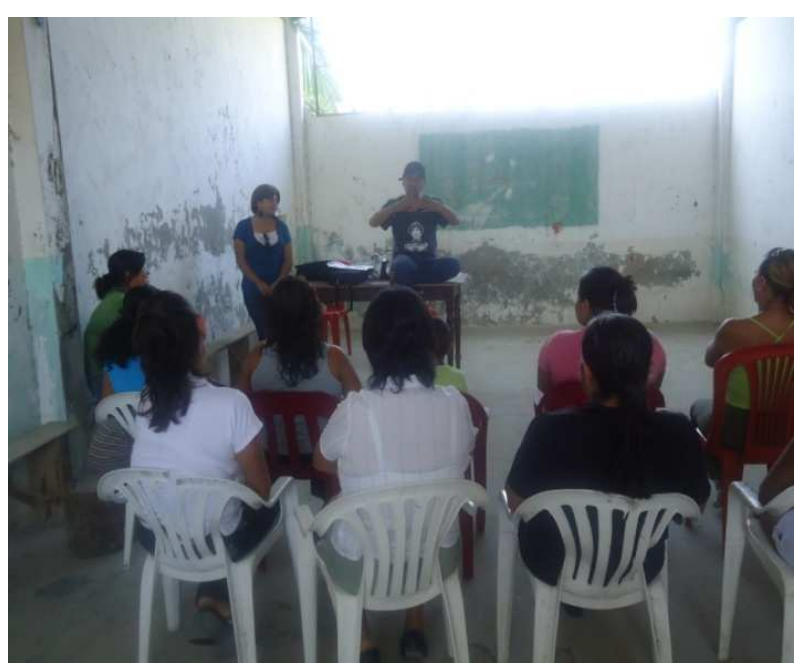


Foto No 3 Población expuesta a adquirir zoonosis en la Comunidad de San Roque

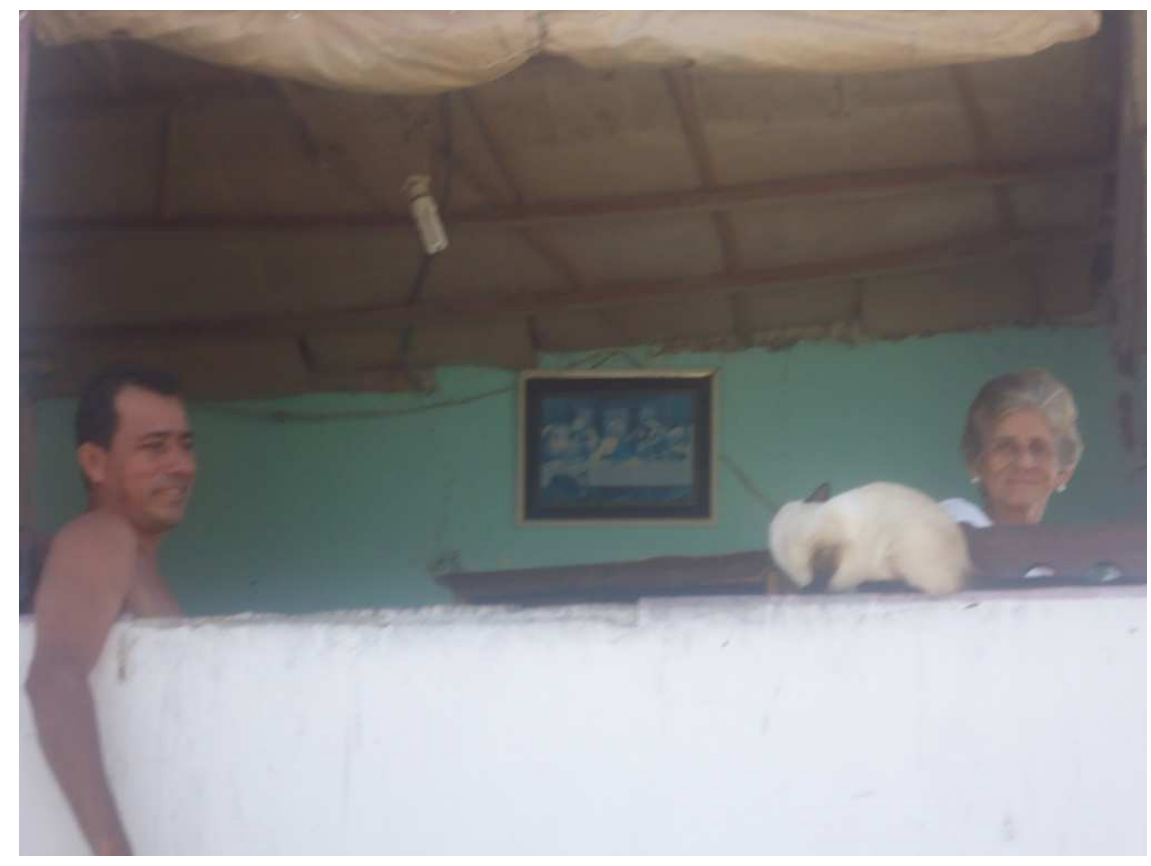

Foto No 4 gran cantidad de perros callejeros en la comunidad de San Roque

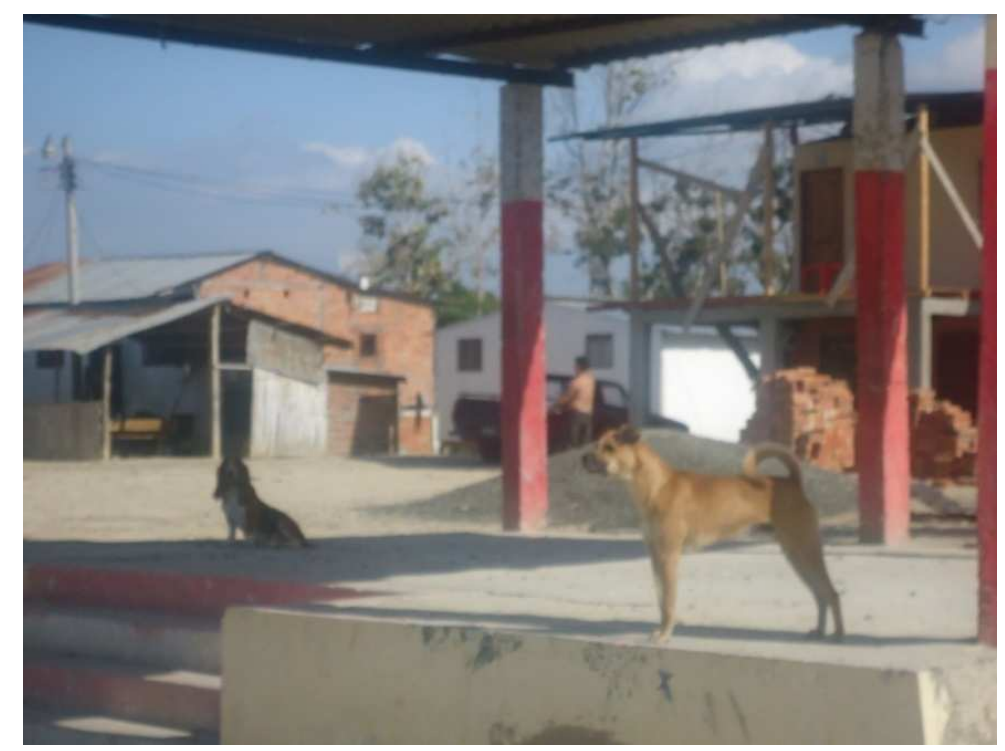


Foto No 5 Intervención Educativa sobre Histoplasmosis con videos de casos de personas con zoonosis

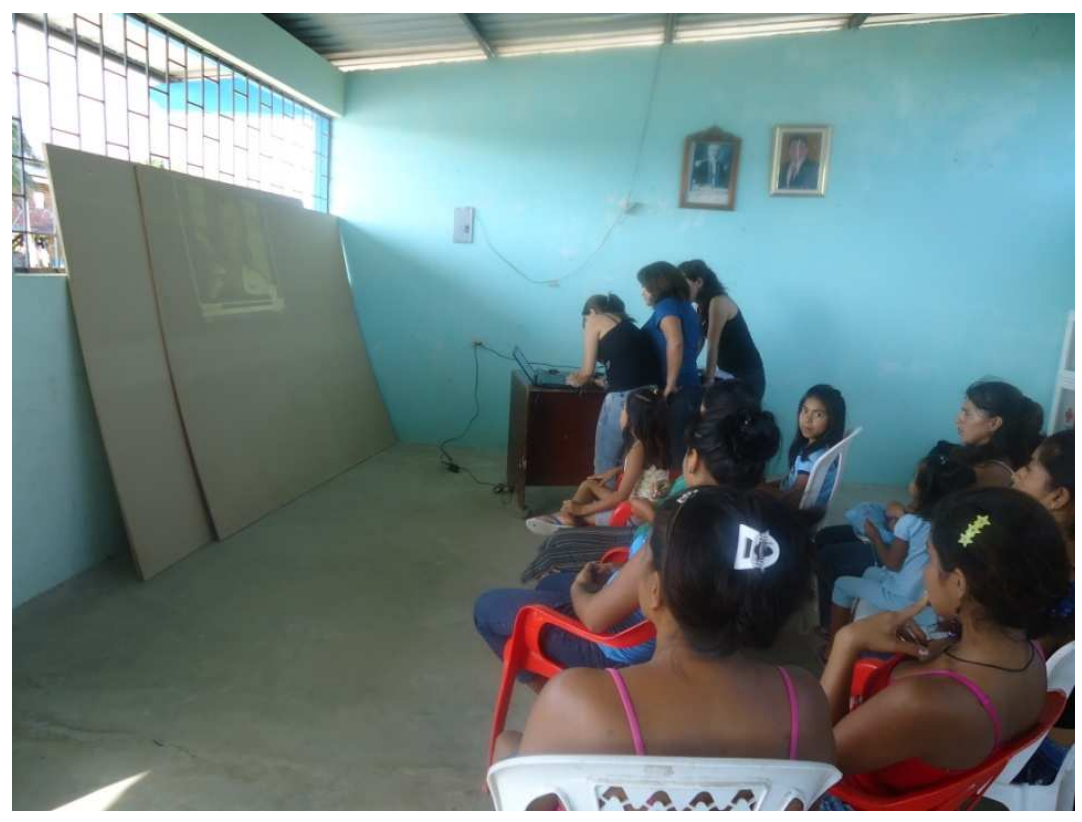

Foto No 6 Video foro de la Histoplasmosis

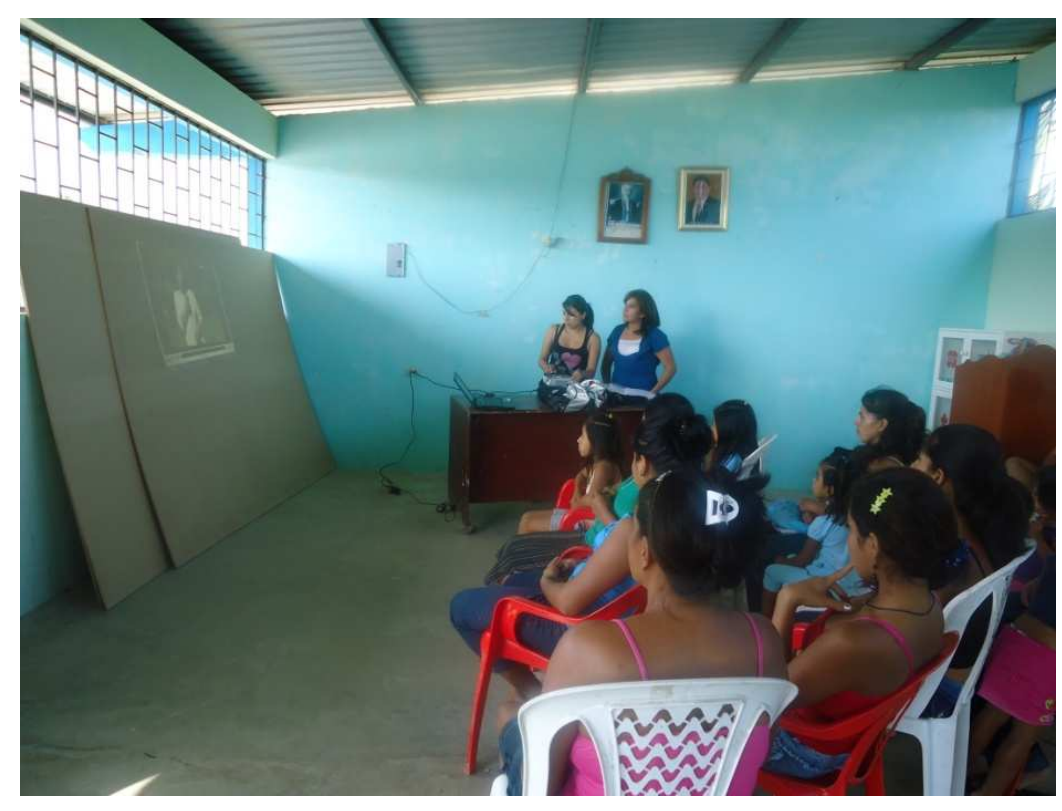


Foto No 7 Porcinos deambulando por la comunidad de San Roque

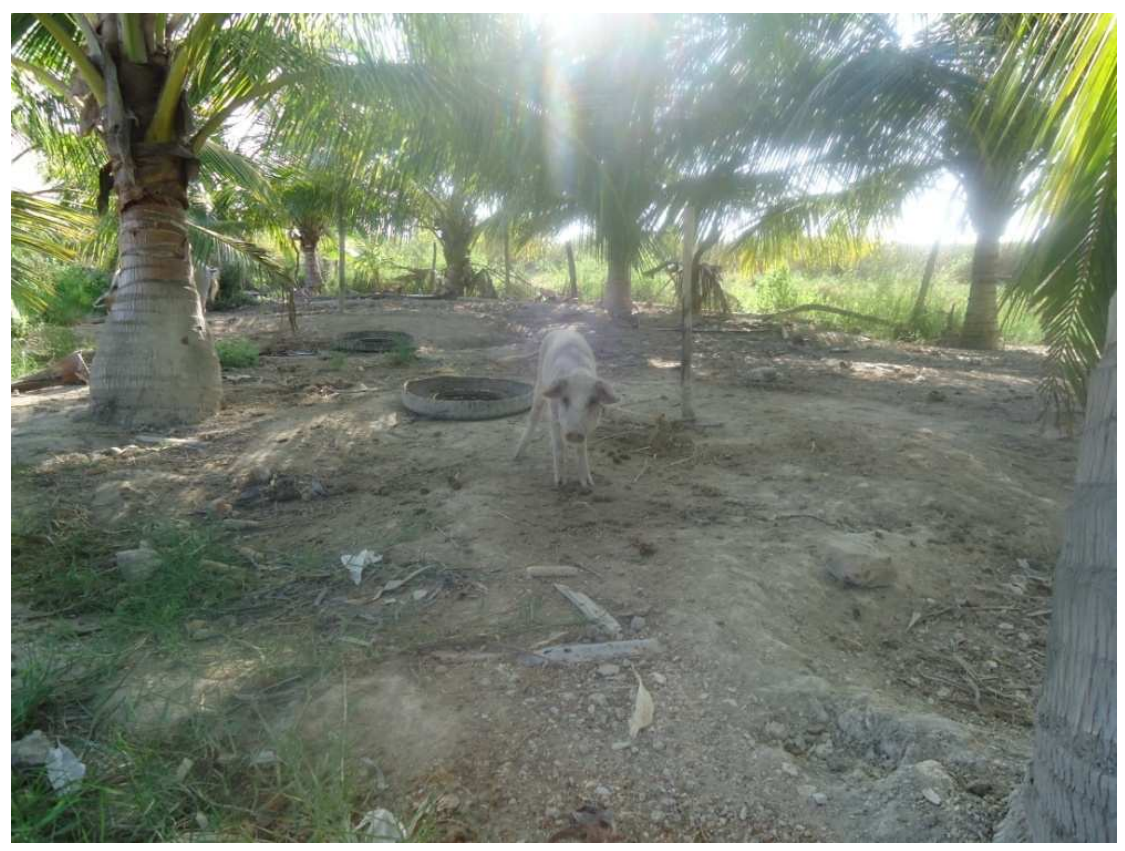

Foto No 8 aplicación de Test de Evaluación de la intervención educativa de zoonosis

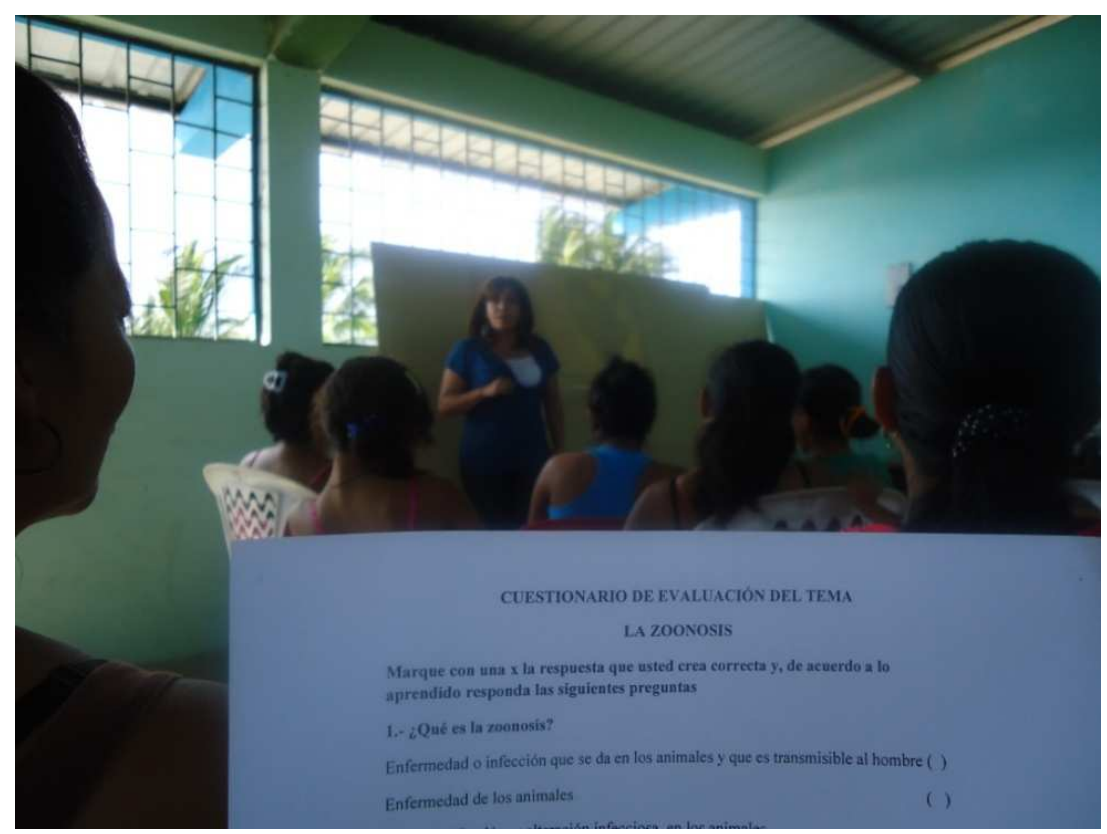


Foto No 10 Insalubridad en la comunidad, porcinos sueltos ingiriendo estiércol de bovinos.

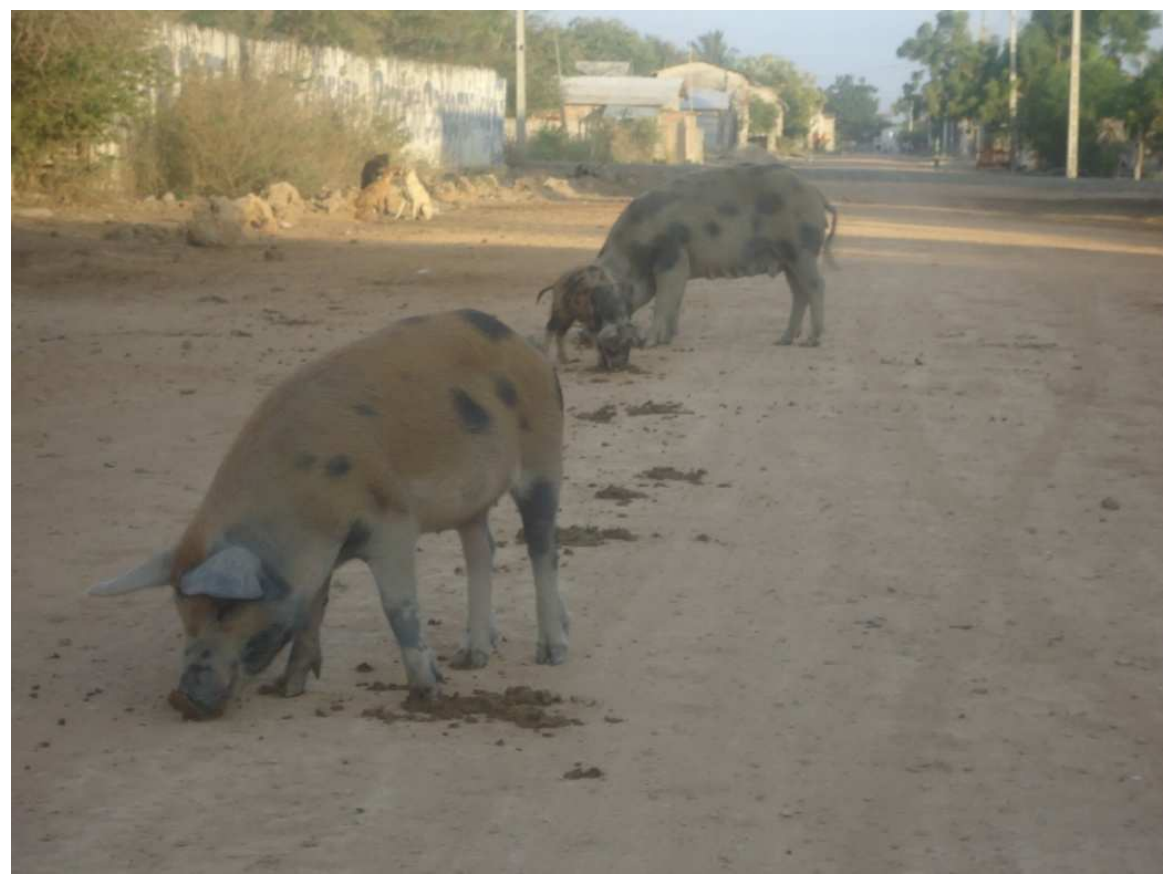

Foto No 11 animales sueltos por la comunidad de San Roque

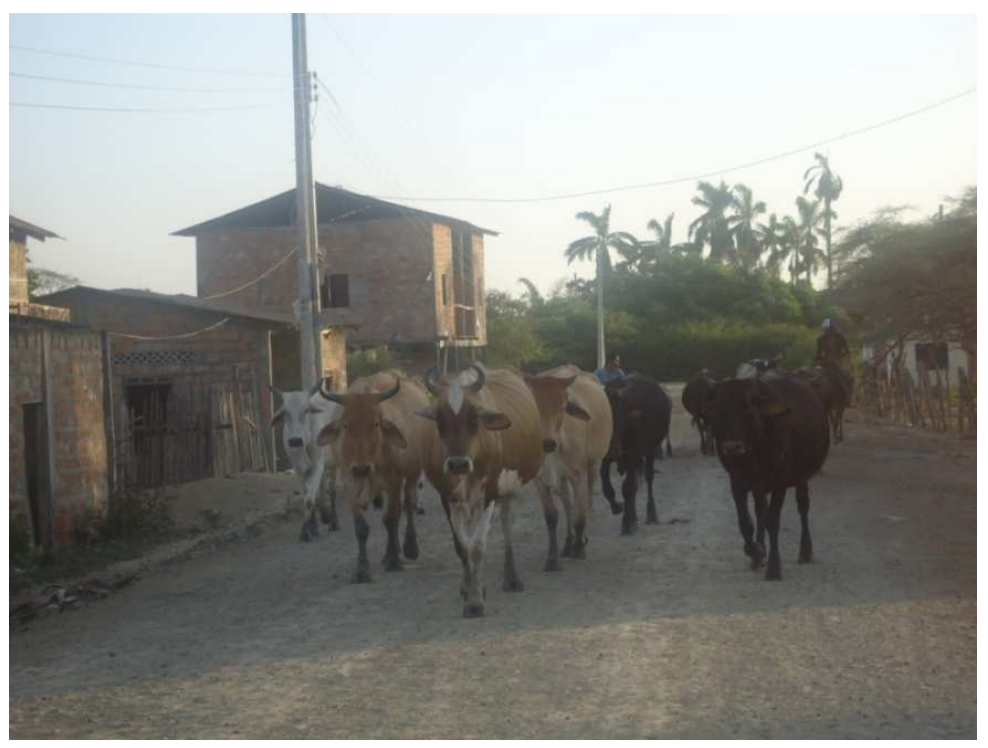


Foto No 12 Dinámicas antes de empezar el taller educativo en la comunidad de San Roque

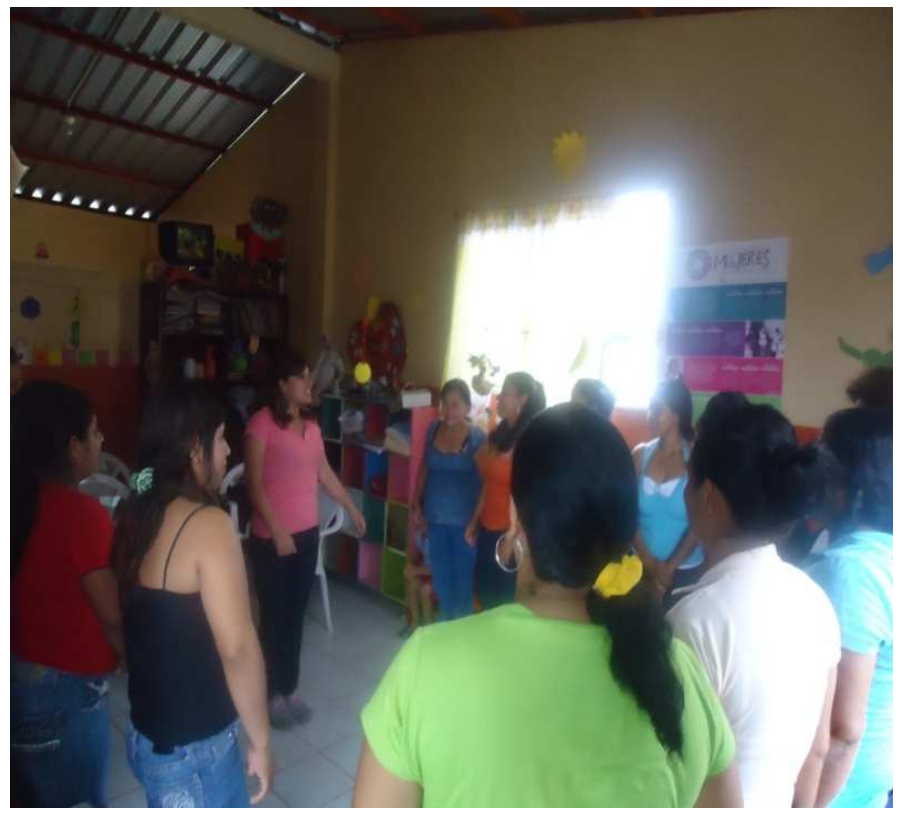

Foto No 13 Evaluación de conocimientos sobre el tema a tratar en la comunidad de San Roque

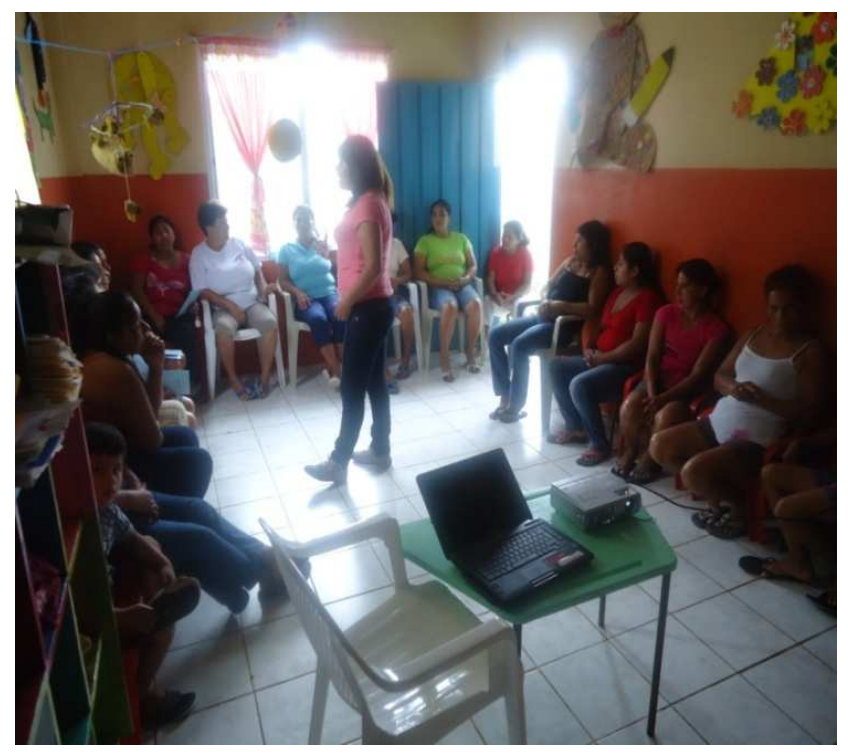


Foto No 14 Niños que andan descalzos por el estiércol de animales en la comunidad de San Roque
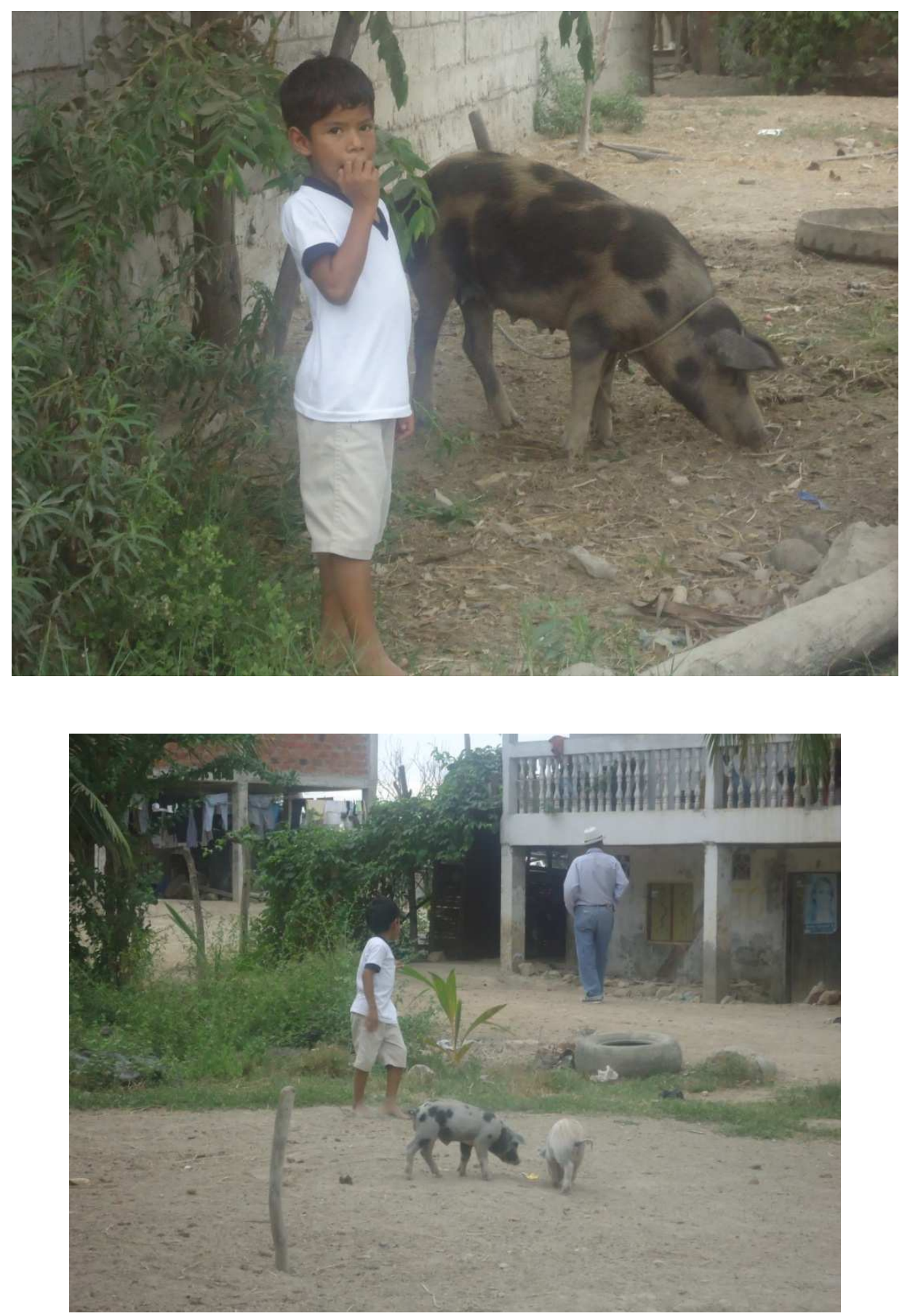